\section{Pacific Northwest}

National Laboratory

Operated by Battelle for the

U.S. Department of Energy

\title{
Pacific Northwest National Laboratory Institutional Plan FY 2001-2005
}

D. Fisher

E. Pearson

December 2000

Prepared for the U.S. Department of Energy

under Contract DE-AC06-76RL01830 


\title{
DISCLAIMER
}

This report was prepared as an account of work sponsored by an agency of the United States Government. Neither the United States Government nor any agency thereof, nor Battelle Memorial Institute, nor any of their employees, makes any warranty, express or implied, or assumes any legal liability or responsibility for the accuracy, completeness, or usefulness of any information, apparatus, product, or process disclosed, or represents that its use would not infringe privately owned rights. Reference herein to any specific commercial product, process, or service by trade name, trademark, manufacturer, or otherwise does not necessarily constitute or imply its endorsement, recommendation, or favoring by the United States Government or any agency thereof, or Battelle Memorial Institute. The views and opinions of authors expressed herein do not necessarily state or reflect those of the United States Government or any agency thereof.

\author{
PACIFIC NORTHWEST NATIONAL LABORATORY \\ operated by \\ BATTELLE \\ for the \\ UNITED STATES DEPARTMENT OF ENERGY \\ under Contract DE-AC06-76RL01830
}

Printed in the United States of America

Available to DOE and DOE contractors from the

Office of Scientific and Technical Information, P.O. Box 62, Oak Ridge, TN 37831; prices available from (615) 576-8401.

Available to the public from the National Technical Information Service, U.S. Department of Commerce, 5285 Port Royal Rd., Springfield, VA 22161

PNNL-13098-1

This document was printed on recycled paper.

$(9 / 97)$ 


\section{Pacific Northwest National Laboratory Institutional Plan FY 2001-2005}

December 2000

Prepared for the

U.S. Department of Energy

under Contract

DE-AC06-76RL01830

Pacific Northwest National Laboratory

Richland, Washington 99352 


\section{Contents}

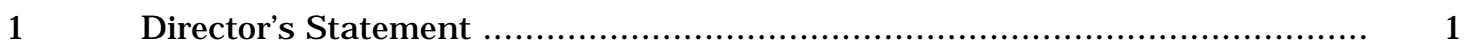

2 Laboratory Mission, Roles, and Technical Capabilities .............................. 5

Mission Statement n.................................................................. 5

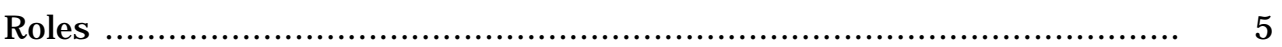

Technical Capabilities .............................................................. 6

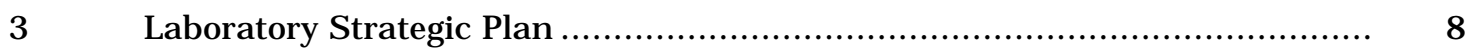

Key Planning Assumptions .................................................................. 10

The Laboratory Agenda …......................................................... 12

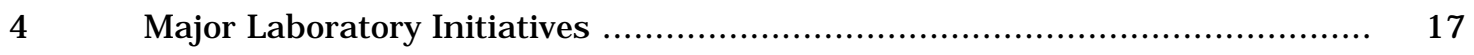

Biological Sciences .......................................................................... 18

Computational Sciences and Engineering ...................................... 22

Carbon Management .............................................................. 26

Fuel Cell Technology ................................................................ 28

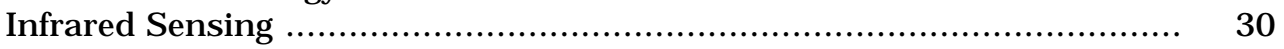

Emerging Initiatives ................................................................ 33

Nanoscience and Technology ....................................................... 33

Imaging Science and Technology ............................................. 34

Transitioning Initiatives ........................................................ 36

Cyber Security ....................................................................... 36

Microsystems Science and Engineering ..................................... 37

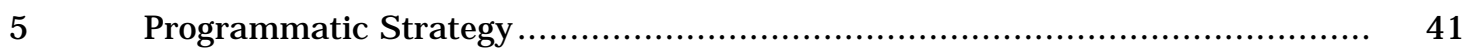

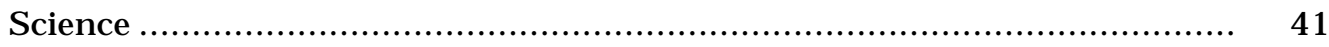

Strategic Intent .................................................................. 41

Our Role in Supporting the Themes and Challenges of DOE Science ...... 43

Research Thrusts ............................................................................. 5

Environmental Quality .............................................................. 61

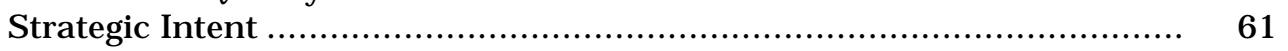

Our Role in the Environmental Quality Research and

Development Portfolio ........................................................ 62

Major Research and Development Thrusts .................................. 66

Capability Development: Role of Laboratory Initiatives ..................... 68

Energy Resources ........................................................................ 70

Strategic Intent ................................................................. 70

Our Role in the Energy Resources Research and Development Portfolio... 71

Major Research and Development Thrusts ...................................... 73

Capability Development: Role of Laboratory Initiatives ....................... 74

National Security ................................................................. 76

Strategic Intent ................................................................. 76

Our Role in the National Security Research and Development Portfolio ... 77

Major Research and Development Thrusts .................................... 85

Capability Development: Role of Laboratory Initiatives ...................... 86 


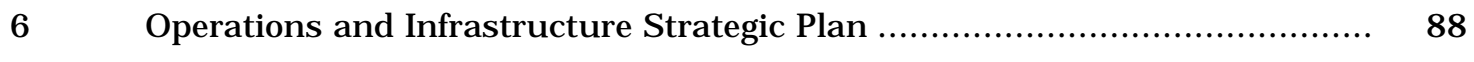

Human Resources ....................................................................... 88

Environment, Safety, and Health Management ................................. 91

Safeguards and Security ......................................................... 94

Site and Facilities Management ................................................. 99

Information Resources .......................................................... 108

Management Practices and Standards ....................................... 111

Communications and Trust ................................................ 113

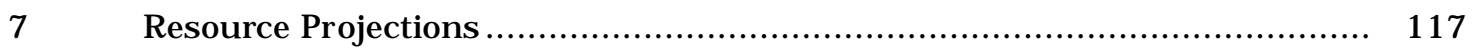

Subcontracting and Procurement .............................................. 126

Small and Disadvantaged Business Procurement ............................ 126

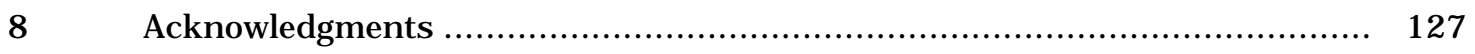

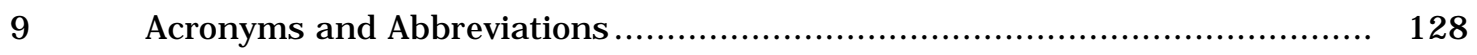

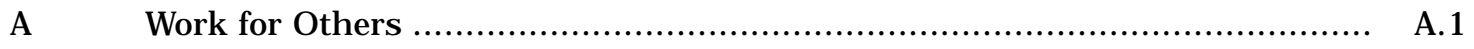

B University Partnerships and Collaborations ..................................... B. 1 


\section{1}

\section{Director's Statement}

I am honored to be the new Director of the Pacific Northwest National Laboratory. After a longtime career managing federal programs designed to develop exciting science and technology and move it into application, I am pleased to be leading a national laboratory that has made extraordinary contributions to the U.S. Department of Energy's missions and is now well positioned to provide the next generation of science and technology solutions.

I was initially attracted to this position because of the Laboratory's cutting-edge research and development, but now that I'm here I'm also impressed by its approach to simultaneous excellence in science and technology, operations, and community development. While our core purpose is providing science and technology in support of DOE's missions, we also recognize that excellence in operations is necessary to enabling cost-effective research and protecting our employees, the public, and the environment. Excellence in community development ensures open communication and trust with stakeholders, and helps us attract and retain high caliber staff.

Our journey to becoming a premier science and technology institution is well started, but far from finished. As we head into the next century,

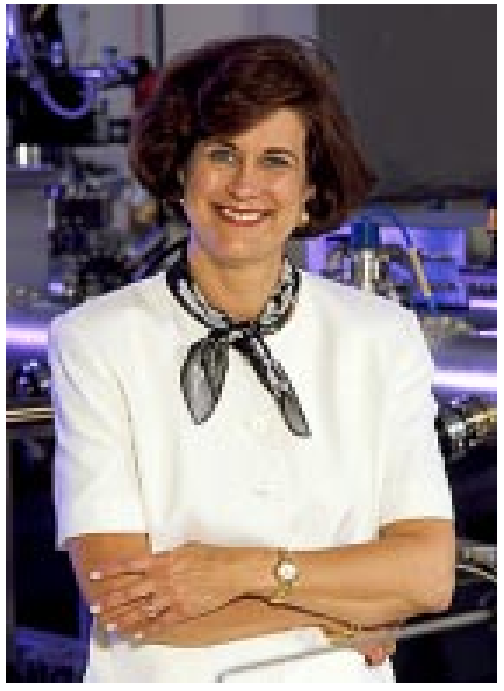

Dr. Lura Powell, Director of Pacific Northwest National Laboratory we face many challenges that will change the way we work. Because of the interdisciplinary nature of advanced research and development, we must form partnerships with universities, industries, and other government laboratories. Equally important to our success will be our ability to rapidly translate the discoveries of science into new products and processes. We want to infuse Laboratory-based technologies in to the marketplace, demonstrating to the public and Congress that DOE's science and technology programs are good investments of taxpayer dollars. Based on our record of accomplishment over the past three and a half decades, I am confident the Laboratory stands ready for a bright future.

\section{Strengthening Fundamental Science}

Strengthening our fundamental science program will place us at the intersection of the physical, biological, and information sciences, where much of the scientific history of the $21^{\text {st }}$ century will be written and where solutions to DOE's most pressing problems will be found. In this Institutional Plan, we outline three major science thrusts that will strengthen our fundamental science program and move us closer to the goal of being recognized as a national scientific resource.

We are undertaking a major effort in biosciences, including instrumentation and model development work aimed at critical problems in both mammalian and microbial biology. Now that the sequencing of the human genome is essentially complete, we are seeking to better understand the roles and functions of genes and proteins in humans and other biological systems. Researchers at the William R. Wiley Environmental Molecular Sciences Laboratory already have made extraordinary progress in using mass spectrometry to catalogue and characterize proteins on a large scale, and have demonstrated the ability to precisely monitor how cells respond to environmental impacts. We anticipate that this work may serve as the foundation for a second user facility that would house instrumentation for the growing needs of the biological sciences community. EMSL researchers also completed testing of first-generation 
instrumentation that combines an optical microscope and magnetic resonance microscopy. The combined microscope is expected to help researchers gain insight into how cells react and recover from induced damage.

A second major thrust involves strengthening our capabilities in computational science and engineering. We are developing advanced scientific simulation software that will exploit the potential of next-generation supercomputers. The Molecular Science Software Suite developed at the Laboratory is the first general-purpose software that enables researchers to solve complex environmental problems quickly and cost-effectively. This award-winning software also will be used in the search for new pharmaceuticals, for ways to improve agricultural productivity, and for insights into how organisms function at the molecular level.

In the third major thrust area, we plan to bring expertise in materials synthesis and characterization to bear on the opportunities in nanoscience and technology. By precisely manipulating atoms and molecules - the very building blocks of nature-our research could yield safe, just-in-time sources of hydrogen for a wide range of energy applications, new instruments to observe chemical processes in living cells, and miniaturized sensors to detect pathogens in foods and the environment.

Through these key initiatives and a strengthened fundamental science program, I intend to make sure that the Laboratory is at the leading edge of new discoveries and that we will help DOE play a proactive role in setting the scientific agenda for the nation.

\section{Enhancing Mission Contributions}

A strengthened science foundation, coupled with growing technological expertise, positions the Laboratory for substantial contributions to DOE's most demanding challenges. As we develop new instrumentation, build computational capabilities, and enhance strategic partnerships, we can bring higher value to DOE's science and technology investments, and foster more science-based decisions for cleanup. Such is the approach for the Groundwater/Vadose Zone Integration Project, which is evaluating future and accumulative impacts from contaminant movement through the Hanford Site's subsurface and ultimately into the Columbia River.

Over the past five years, we made great strides in helping DOE with cleanup problems throughout the complex. Through new processes, partnerships, and science-based approaches, we are assisting with plutonium cleanup activities that take advantage of existing equipment, streamlines work processes, and saves millions of dollars while also reducing the work schedule. We also developed the award-winning In Situ Redox Manipulation technology, a passive permeable barrier being deployed full-scale at Hanford to prevent chromium plumes from reaching the Columbia River. In collaboration with the University of Cincinnati, we developed and successfully tested a sensor 1000 times more sensitive than current instruments that measure ferrocyanide in Hanford tanks. We are continuing to develop the sensor for other waste applications.

We also are applying science-based methods to issues of significant concern to the Pacific Northwest region. We are supporting DOE, the Bonneville Power Administration, and the U.S. Army Corps of Engineers by conducting multiple research projects to assess impacts of energy development and water uses, with emphasis on fish survivability. Our researchers developed a sensor fish-a plastic model filled with sensors that provide important data on what it is like for salmon to pass through hydropower dams on the Columbia River. The research is expected to advance the development of fish-friendly power turbines.

In DOE's national security mission, we are developing technologies for monitoring nuclear treaties and agreements, arms control, nonproliferation, and infrastructure protection. For example, we have developed an instrument to detect chemicals used in 
weapons of mass destruction that can be applied in treaty verification and battlefields. Our state-of-the-art Critical Infrastructure Protection Analysis Laboratory is used to assess computer systems, networks, and software in a secured environment. We also have developed technology that enables tritium to be safely produced in a commercial light water reactor. Another exciting development in the national security arena is the multiple applications for our radio frequency tagging technology. These tiny tags are being used by the U.S. military to track inventory; and to store, record, and transmit medical information about soldiers' medical conditions.

To help DOE's efforts to sustain clean, affordable energy resources, we strengthened longstanding programs in building science and technology and energy conservation, and established a significant program in lightweight materials and emissions reduction for vehicles. Our researchers, in partnership with the National Energy Technology Laboratory, are developing advanced solid-oxide fuel cell technology - a core element in DOE's vision for reliable, efficient energy sources of the future. The Laboratory's leadership in multidisciplinary climate research continues to play a key role in DOE's energy mission. In collaboration with several other national laboratories, we are exploring technology options for carbon management and a new terrestrial carbon sequestration center.

\section{Partnering for Success}

Strengthening our science base and enhancing our mission contributions will depend on our ability to build strong partnerships. These partnerships have been key to our successes in the Atmospheric Radiation Measurement program, where researchers from national laboratories and universities collaborate across a global network; and the Environmental Management Science Program, where many of our most promising projects are based on principal investigator collaborations with university researchers. We also continue our leadership of the Northwest Alliance for Transportation Technologies, a multiyear partnership with DOE, industry, and academia, which has resulted in a number of technologies that will enable a more fuel-efficient and environmentally friendly vehicle of the future.

We are, however, committed to building even stronger partnerships that will complement and expand our research programs, enhance access to research facilities, and provide new opportunities for students. In fact, we established the Joint Institute for Nanoscience and Technology with the University of Washington to explore the understanding and use of nanostructures, and launched a new program with Washington State University to help students interested in obtaining a degree in chemistry.

We want to improve access to our research facilities, particularly to EMSL. We have broken ground on a User Housing Facility, a dorm-like building on the Laboratory's campus that will provide low-cost housing for students and faculty who participate in our education programs, and for visiting researchers who come to use EMSL. We also are deploying collaboratory technology that will allow researchers to remotely access facilities and equipment.

\section{Setting New Standards for Excellence}

Over the past several years, the Laboratory has revamped and analyzed every aspect of its operation and management, making significant progress in reducing costs, increasing productivity, and instituting standards-based management systems that govern all the work we do. Our goal in the next five years is to take a fresh look at our management systems and processes to ensure they truly support and enable research while still protecting the safety and health of our workers, the public, and the environment. This effort, called second generation management systems, will keep the Laboratory as the recognized benchmark for laboratory operations. 
Institutional Plan FY 2001-2005

The Laboratory also has set the standard for good community relations, with historically strong programs in local economic development, science education, and staff volunteerism. As we look to the future, we want to expand beyond our reputation as a good neighbor and take our community development activities to a broader geographic area, bringing value not just to the local community but also to the entire Pacific Northwest.

As always, our strategies to strengthen fundamental science, enhance value to DOE's missions, develop partnerships, and broaden community outreach depend on first-rate scientists, engineers, and support staff. Thanks to their efforts, the Laboratory has delivered world-class science and technology solutions for more than 35 years. We now stand ready to deliver on the promise of our past -to become a national scientific resource for the $21^{\text {st }}$ century.

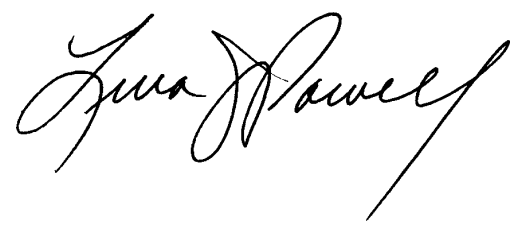

4 


\section{2 \\ Laboratory Mission, Roles, and Technical Capabilities}

\section{Mission Statement}

Pacific Northwest National Laboratory's vision is to be numbered among the world's leading research laboratories, distinguished for scientific excellence, and recognized for our ability to solve the U.S. Department of Energy's most critical and challenging technical problems. We strive for operational excellence and to be respected by the community and region in which we operate. In line with this vision, we have established the following mission statement:

"Pacific Northwest National Laboratory's core mission is to deliver environmental science and technology in the service of the nation and humanity. Through basic research, we create fundamental knowledge of natural, engineered, and social systems that is the basis for both effective environmental technology and sound public policy. We solve legacy environmental problems by delivering technologies that remedy existing hazards. We address today's environmental needs with technologies that prevent pollution and minimize waste, and we lay the technical foundation for tomorrow's inherently clean energy and industrial processes. We apply our capabilities to meet selected national security, energy, and human health needs, to strengthen the U.S. economy and to support the education of future scientists and engineers."

\section{Roles}

As a Department of Energy national laboratory, our roles and responsibilities are aligned with the priorities identified in DOE's strategic plan and in its research and development portfolio for science, environmental quality, energy resources, and national security.

In the science mission, we operate the William R. Wiley Environmental Molecular Sciences Laboratory (EMSL), a user facility providing a broad range of advanced experimental and computational facilities to the environmental, life, chemical, and materials science communities. We play a leadership role in DOE's Biological and Environmental Research programs, including atmospheric science, climate research, subsurface science, microbial genomics, life science, and molecular science. We also conduct significant research programs in chemical physics, materials science, geoscience, and computer and information sciences.

In the environmental quality mission, we provide science and technology support to DOE's waste characterization, waste disposal, cleanup, and land restoration programs, both nationally and at the Hanford Site. Areas of emphasis include leadership of the Tanks Focus Area, a nationwide program to help solve tank waste problems at DOE sites, vitrification and processing technologies for waste treatment and immobilization, and groundwater cleanup.

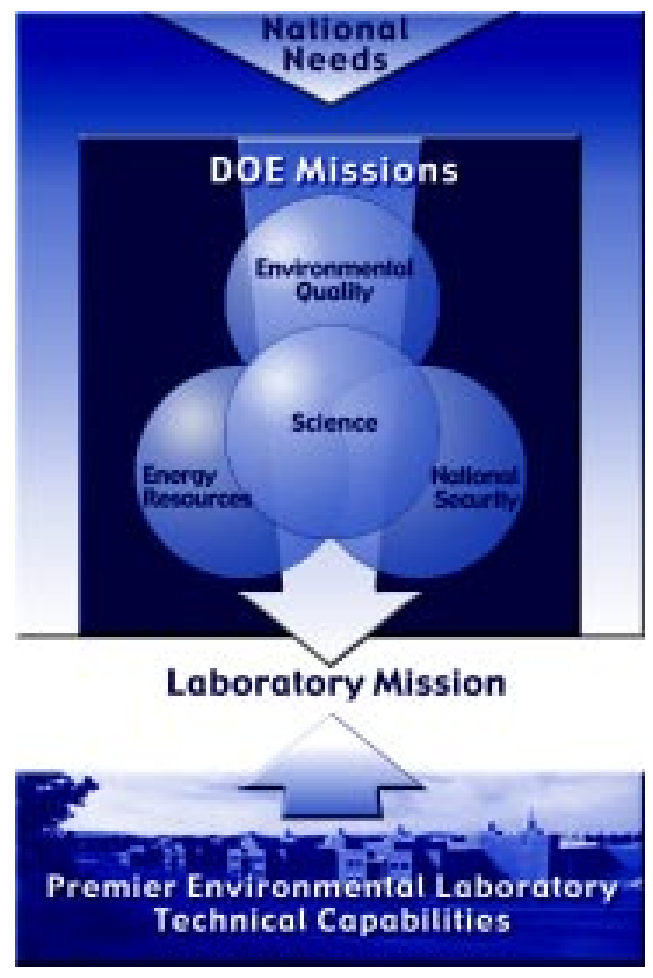

Pacific Northwest National Laboratory's mission and roles are determined by the match between DOE's mission needs and the Laboratory's technical capabilities. 


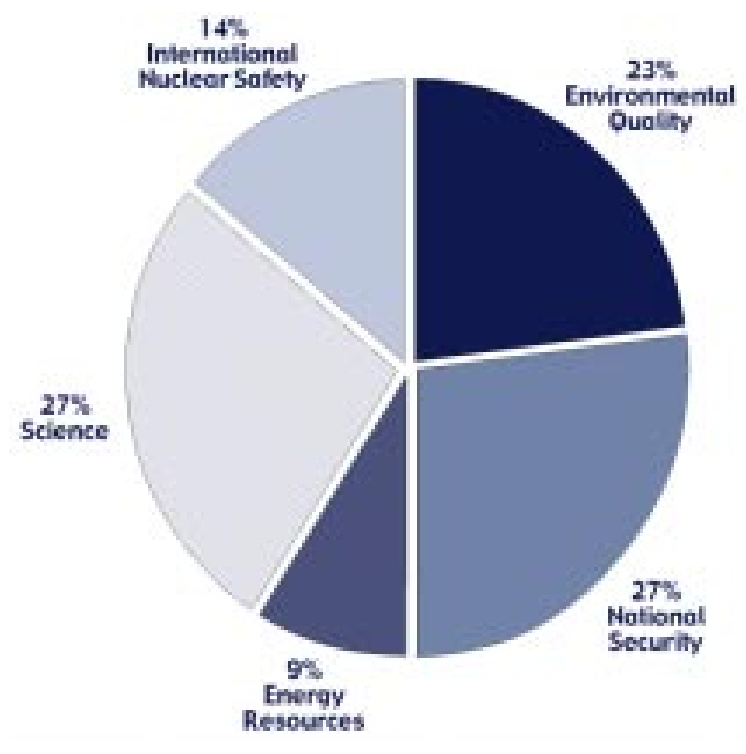

The distribution of DOE research and development at Pacific Northwest National Laboratory for fiscal year 2000. The International Nuclear Safety Program is included for emphasis as a special category.
In the energy resources mission, we provide science and engineering for developing clean, efficient technologies for transportation, energy generation, buildings, and industrial processing. Particular areas of emphasis include lightweight materials for light and heavy vehicles, advanced fuel cell technology, and technologies to improve building performance.

In the national security mission, our primary role is support to DOE efforts in arms control and nonproliferation and to DOE's role in the intelligence and counterintelligence community. We focus on providing science, technology, and engineered systems that support monitoring of nuclear treaties and agreements, preventing the proliferation of weapons of mass destruction, and countering weapons terrorism. We provide leadership and technical expertise for the United States' efforts to improve the safety of nuclear power generation and the management and disposal of nuclear materials in the former Soviet Union. We also provide support to maintaining the nuclear deterrent by developing designs and production processes for producing tritium in commercial light-water reactors.

Pacific Northwest National Laboratory's distribution of effort by DOE mission area is shown in the figure. Detailed information about the specific roles and strategies of the science, environmental quality, energy resources, and national security programs at the Laboratory, in the context of DOE's research and development portfolios, is given in Section 5 of this plan.

\section{Technical Capabilities}

Our ability to fill our mission roles is based on the strength and vitality of our technical capabilities. Pacific Northwest National Laboratory employs a diverse array of professional staff with a broad array of capabilities throughout many different organizations. To enhance the connectivity of staff and to align their capabilities for optimum response to programmatic requirements, the Laboratory has established a set of technical networks. These technical networks are groups of professional staff members across different organizational boundaries with shared scientific and technical capabilities within certain focus areas. Research staff participate in one or more of these networks. Senior scientists provide leadership for these networks. The technical network leaders make up a Technical Council. This Technical Council provides science and technology advice to management. The Technical Council also organizes and leads technical peer reviews of Laboratory Directed Research and Development proposals. These technical networks increase our ability to fulfill DOE mission needs and to apply the full strength of staff capabilities to research priorities. The technical networks at Pacific Northwest National Laboratory are

- Analytical and Physical Chemistry

- Biosciences and Biotechnology

- Computational Science and Engineering

- Computer Science and Information Technology 
- Design and Manufacturing Engineering

- Earth Systems Science

- Energy Technology and Management

- Human Health and Safety

- Materials Science and Technology

- Molecular and Cellular Biology

- Nuclear Science and Engineering

- Policy and Management Sciences

- Sensors and Electronics

- Separations and Conversion

- Statistics.

These capabilities underpin our research programs and provide the science and technology competencies that are needed to solve the most complex environmental challenges and meet critical national needs.

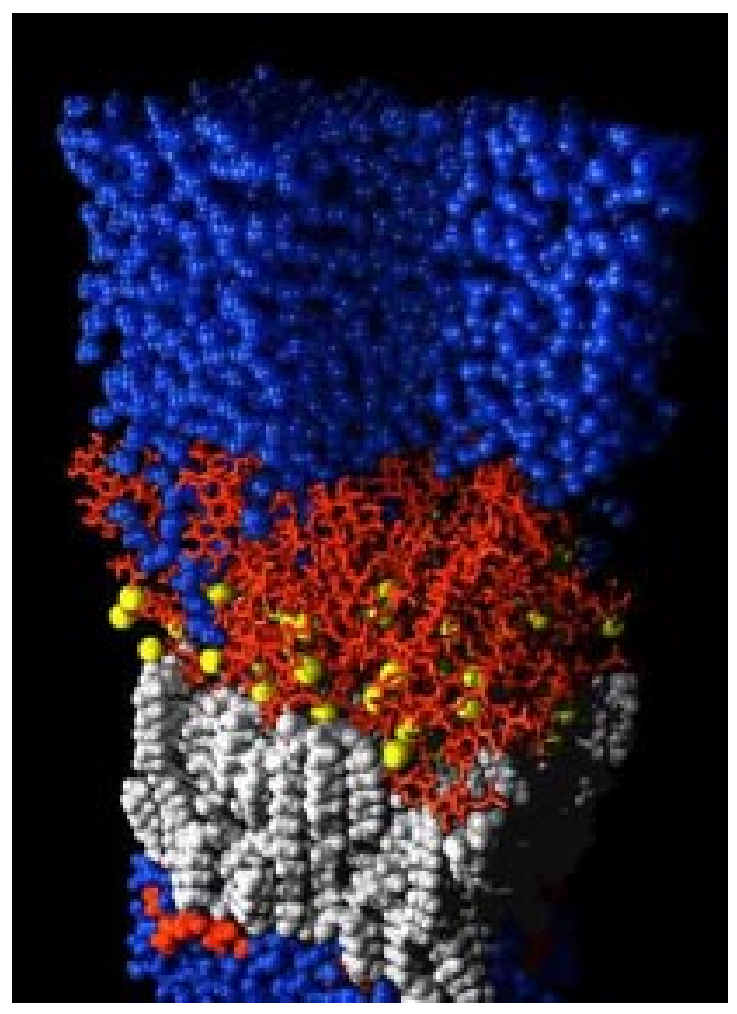

A computational modeling capability is being developed for the study of geochemical reactions at the outer bacterial envelope of gram-negative bacteria. This modeling capability is applied to study the molecular processes that govern microbial metal binding, microbial adsorption to mineral surfaces, and microbe mediated oxidation or reduction reactions at the bacterial exterior surface. Understanding these mechanisms is crucial for developing successful bioremediation strategies. Lipopolysaccharides form the major constituent of the outer membrane of gram-negative bacteria and are believed to be a key factor in these processes. 


\section{3}

\section{Laboratory Strategic Plan}

We are living in a time that offers both extraordinary opportunity and daunting challenges to the research community. Scientific discovery and technological progress are occurring at unprecedented rates. The fast rate of advance is continuing as new science leads to new technologies and these new technologies, in turn, provide powerful new tools for discovery. Our growing abilities to observe and understand fundamental biological processes, to manipulate matter on the molecular scale, and to create computational models that embody genuinely realistic representations of the natural world promise independently to revolutionize multiple scientific fields and provide tremendous technological opportunities. Taken together, the impact of scientific advances over the next few decades may well exceed even our boldest imaginings.

\begin{tabular}{|c|c|c|}
\hline \multirow[b]{2}{*}{ Date } & \multicolumn{2}{|c|}{$\begin{array}{l}\text { Major Change Initiatives at Pacific Northwest National Laboratory, } \\
\text { 1985-Present }\end{array}$} \\
\hline & Situation & Pacific Northwest National Laboratory Response \\
\hline $\begin{array}{l}\text { Mid-late } \\
1980 \text { s }\end{array}$ & $\begin{array}{l}\text { As an Office of Energy Research Laboratory, } \\
\text { Pacific Northwest National Laboratory } \\
\text { needed to significantly strengthen basic } \\
\text { science capabilities and participate in } \\
\text { DOE-ER's user facility mission. }\end{array}$ & $\begin{array}{l}\text { Launched a major initiative in molecular science, } \\
\text { carried out a recruiting program, and conceived and } \\
\text { developed instrumentation and facility concepts } \\
\text { leading to the Environmental Molecular Sciences } \\
\text { Laboratory. }\end{array}$ \\
\hline \multirow[t]{4}{*}{$1994-1996$} & $\begin{array}{l}\text { A clear need for increased productivity } \\
\text { and reduced cost was identified by the } \\
\text { Galvin Report, other reviews, and budget } \\
\text { pressures. }\end{array}$ & $\begin{array}{l}\text { - Increased productivity and reduced costs, leading } \\
\text { to more effective work processes and redesigned } \\
\text { management systems to better support mission } \\
\text { accomplishment. }\end{array}$ \\
\hline & $\begin{array}{l}\text { A clear requirement for improved } \\
\text { operations was identified as a result of } \\
\text { performance reviews and the unacceptable }\end{array}$ & $\begin{array}{l}\text { - Established an objective to become the best- } \\
\text { managed laboratory. }\end{array}$ \\
\hline & frequency of operational problems. & $\begin{array}{l}\text { - Designed and implemented a broad operational } \\
\text { improvement program in cooperation with DOE. }\end{array}$ \\
\hline & $\begin{array}{l}\text { The local communities' concern was } \\
\text { economic development. }\end{array}$ & $\begin{array}{l}\text { Created the Economic Development Office and } \\
\text { associated small business assistance, entrepreneurial } \\
\text { leave, and other economic development programs. }\end{array}$ \\
\hline 1995-1996 & $\begin{array}{l}\text { In response to the Galvin Report and DOE } \\
\text { direction, a need was identified for clearer } \\
\text { technical focus at Pacific Northwest } \\
\text { National Laboratory. }\end{array}$ & $\begin{array}{l}\text { - Focused concept of "Premier Environmental } \\
\text { Laboratory," with strong environmental science } \\
\text { and technology core applied to well-defined roles } \\
\text { in each of DOE's missions. }\end{array}$ \\
\hline $\begin{array}{l}\text { 1996- } \\
\text { present }\end{array}$ & $\begin{array}{l}\text { Many laboratory facilities are aging; DOE } \\
\text { plans revitalization of Hanford Site } \\
\text { facilities. }\end{array}$ & $\begin{array}{l}\text { - Focused on facility consolidation and revitalization } \\
\text { to eliminate, replace, or refurbish legacy facilities; } \\
\text { participated in DOE comprehensive site planning. }\end{array}$ \\
\hline $\begin{array}{l}\text { 1998- } \\
\text { present }\end{array}$ & $\begin{array}{l}\text { Increasing DOE and national need for } \\
\text { improved understanding of the health } \\
\text { consequences of environmental } \\
\text { contamination for worker protection, } \\
\text { cleanup decisions, and environmental } \\
\text { regulation. }\end{array}$ & $\begin{array}{l}\text { - Established a new initiative in biological sciences } \\
\text { to strengthened capabilities in life science and } \\
\text { environmental health. }\end{array}$ \\
\hline
\end{tabular}


As we seek to grasp the scale of the opportunities afforded by these advances, we are faced with almost unlimited societal demands on science and technology. Over the next few decades, we will be challenged to provide several-fold increases in the average standard of living for a growing world population while reducing the impact of energy use, food production, and other economic activity on our global environment. Environmental cleanup across the DOE complex remains a demanding task. Perhaps even greater demands are created by the need to restore and to protect other environmental resources, both in the United States and worldwide. As advances in science and technology create opportunities for great benefit, they also create new kinds of challenges to our national security, from chemical and biological weapons to threats to crucial computer and communications networks and other infrastructure, to which we must respond. Each of the Department of Energy's core missions responds to challenges over the coming years that go well beyond what can be accomplished with current technology.

Pacific Northwest National Laboratory is better prepared today than at any time in its history to contribute broadly to meeting these challenges. The last 15 years have been a time of change for the national laboratory system in general, and Pacific Northwest National Laboratory in particular. In response to both external forces and our vision of a stronger and more effective research institution, and in partnership with DOE leadership, we thoroughly revamped every major element of Laboratory operations through a series of major change initiatives. We took our first major scientific user facility from concept to reality, quickly establishing its reputation as a premier research facility serving a broad and productive user

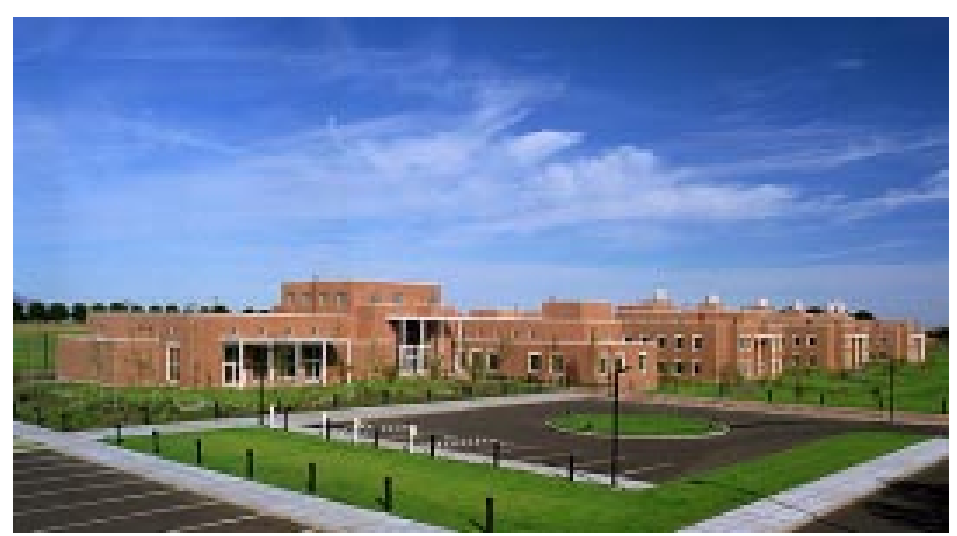

The William R. Wiley Environmental Molecular Sciences Laboratory, DOE's newest user facility located at Pacific Northwest National Laboratory. community. We sharpened our focus as DOE's premier environmental laboratory; established well-defined, consistent roles in each of DOE's missions; and built new research capabilities in line with these roles. We revitalized much of our physical plant through a combination of new construction and facility rehabilitation and consolidation. We completely rebuilt our management systems to increase productivity, reduce cost, and improve operational performance. We expanded our partnerships with other research institutions and increased our visibility and impact in our community.

These changes have positioned this Laboratory to contribute substantially to DOE's most critical needs over the coming decades. We intend to help establish the scientific basis for understanding the health impacts of environmental contaminants, continually enhance the quality and impact of our scientific research, deliver extraordinary research tools for the scientific community, help reduce the danger of weapons of mass destruction through DOE's arms control and nonproliferation programs, respond to national and international needs for clean energy and increased energy efficiency, and provide science and technology to speed and reduce the cost of cleaning up the DOE complex. We intend to enhance our operations and management systems to more effectively support research while protecting DOE's assets, the environment, and the health and safety of our staff and the public. We intend to further increase our role in and contributions to the community and region, from education to economic development.

To realize these aspirations, we must meet a variety of challenges that we have recognized and many more that we may not yet anticipate. Pacific Northwest National Laboratory's Institutional Plan for fiscal years 2001 through 2005 presents our strategy for responding to these challenges, enhancing our contributions to DOE's missions, and strengthening 


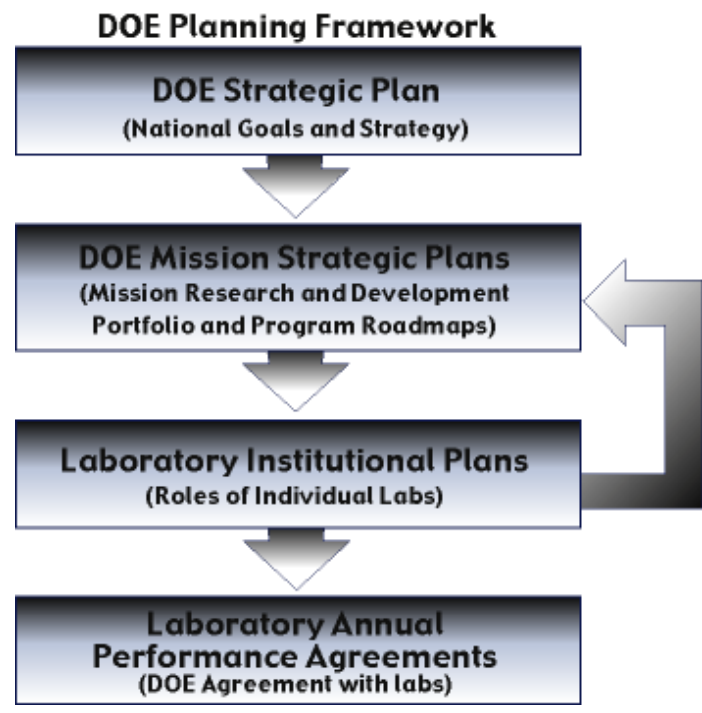

Pacific Northwest National Laboratory's Institutional Plan is part of the DOE planning framework. Laboratory Institutional Plans describe laboratory roles in meeting DOE's objectives as laid out in DOE's strategic plan and mission-specific plans and the research and development programs defined in the mission research and development portfolios. The Institutional Plans also serve to propose new initiatives for inclusion in DOE's planning. the Laboratory. In the following paragraphs we present our planning assumptions and strategy. Our major research initiatives are described in Section 4. Section 5 provides detailed descriptions of our role in and strategy for supporting each of DOE's core missions. Section 6 summarizes our strategy for strengthening Laboratory operations, supporting our staff, and further enhancing our research facilities to enable the work of our scientists and engineers. This plan describes our roles and opportunities for responding to DOE research and development priorities, and provides our vision for ensuring that Pacific Northwest National Laboratory becomes an even more vigorous and productive research institution in the years to come.

\section{Key Planning Assumptions}

The Laboratory's strategic plan arises from four key planning assumptions and drivers, as follows and shown in the figure:

- roles that Pacific Northwest National Laboratory plays in each of DOE's missions, as determined by the match between the objectives laid out in DOE's Strategic Plan and Laboratory capabilities (described in this plan)

- a set of planning assumptions that captures our understanding of the issues and drivers underlying national needs and DOE research and development mission priorities, the science and technology opportunities that will allow us to address those needs, and the policy and budget climate in which we will operate

- an overall management philosophy that requires simultaneous excellence in science and technology, Laboratory operations, and community relations, and that emphasizes both effective performance on current programs and long-term institutional stewardship

- results of our ongoing selfassessment and DOE's annual appraisal of our performance.

Our planning is strongly influenced by a set of assumptions regarding national needs, trends in science and technology, science policy and budgets, and DOE management expectations for its national laboratory system. These assumptions and their implications are presented in the following table. 


\section{Planning Assumptions and Implications}

National Needs and DOE Missions

The impact of economic development and human needs on human health and the global and local environment will continue to be a primary driver for long-term science and technology investments. Societal response will be based on perceived impacts on human health and well-being.

Preventing the proliferation of weapons of mass destruction into the hands of rogue states and terrorist groups will be a significant driver for national security for the foreseeable future. Counterterrorism at home and abroad will continue to grow in importance. Addressing international nuclear safety, fuel disposition, and related matters will remain a high priority.
Improvement in the understanding of natural systems and our ability to forecast the impact of human activities on those systems will be required, as will be a better understanding of the consequent impacts on human health. Technologies that allow economic growth while maintaining our environment will remain critical.

High sensitivity instrumentation and related capabilities required to detect nuclear, chemical, and biological weapons activity are required. Nuclear science and technology capabilities will find significant application in dealing with international reactor safety and materials protection and disposition issues.

\section{Science and Technology}

Advances in information technology will continue at a rapid rate. Modeling and simulation will become increasingly important in many scientific fields. The ability to embed "intelligence" will transform everything from consumer products to sophisticated scientific instrumentation.

Understanding biological systems at the molecular level will be a dominant science and technology focus. Advances will have dramatic effects, not only on medicine and human health but on industrial process technology and on our understanding and management of the environment.

The ability to manipulate matter on the molecular and even atomic scales also will be a major scientific theme of the coming years. Transforming effects are likely on everything from human health to industrial production technology.
Continuing investments in the information technology knowledge, expertise of staff, research equipment, and in information technology infrastructure are required. Pacific Northwest National Laboratory must continue to enhance computational science capabilities.

Pacific Northwest National Laboratory must strengthen life sciences capabilities both internally and through partnerships.

Significant opportunities will emerge to develop energy-efficient, low-pollution scalable technology for a variety of applications. Engineering of microscale and nanoscale devices, design of chemically active surfaces, and systems engineering will be significant growth areas for the Laboratory.

\section{Science Policy and Budgets}

Investment in government-funded research will be at least stable and perhaps show modest growth, with most funding going toward research areas linked closely to a specific societal need. DOE resources will be limited.

Accountability for delivery of tangible results from public investment will continue to grow in importance.

Industrial research and development will continue to be characterized by a focus on product development issues with limited investment in longer-term basic research.
DOE and its laboratories must demonstrate a clear link between research programs and potential societal benefits. Multiagency partnerships will be important.

DOE and its laboratories must deliver significant outcomes that impact DOE's mission objectives from its research programs and collaborations.

Industry will continue to look toward government spending in basic research to provide the new knowledge from which breakthrough commercial technologies can arise. Strong industrial partnerships will be required to ensure the greatest public return from the nation's research and development investment.

\section{DOE and the Laboratory System}

DOE and its national laboratories will remain under pressure to improve management practices and to increase productivity. The pressure for excellence in operations will be intense. Research facilities that are perceived as posing hazards to nearby populations will be difficult to justify and operate.

Substantial pressure will be made to improve performance on security, particularly in regard to electronic data and network infrastructure.

DOE will continue to expect the national laboratories to operate more closely as a system when carrying out major programs.

The United States high technology economy will remain vigorous, and there will be fierce competition for highly capable staff in information technology, molecular biology, and other rapidly advancing areas.
Laboratories must continue to improve performance through using best commercial practices, developing outcome-oriented performance measures, and eliminating low-value-added activities.

We must demonstrate reliably outstanding performance on security to ensure that Pacific Northwest National Laboratory can be trusted with sensitive work while maintaining our role in DOE's international programs.

Laboratories must give increasing emphasis to building capability through partnerships with other national laboratories and universities.

Laboratories must provide a high-quality work environment, including outstanding facilities and equipment, intellectual freedom, and the opportunity to contribute to significant outcomes. 


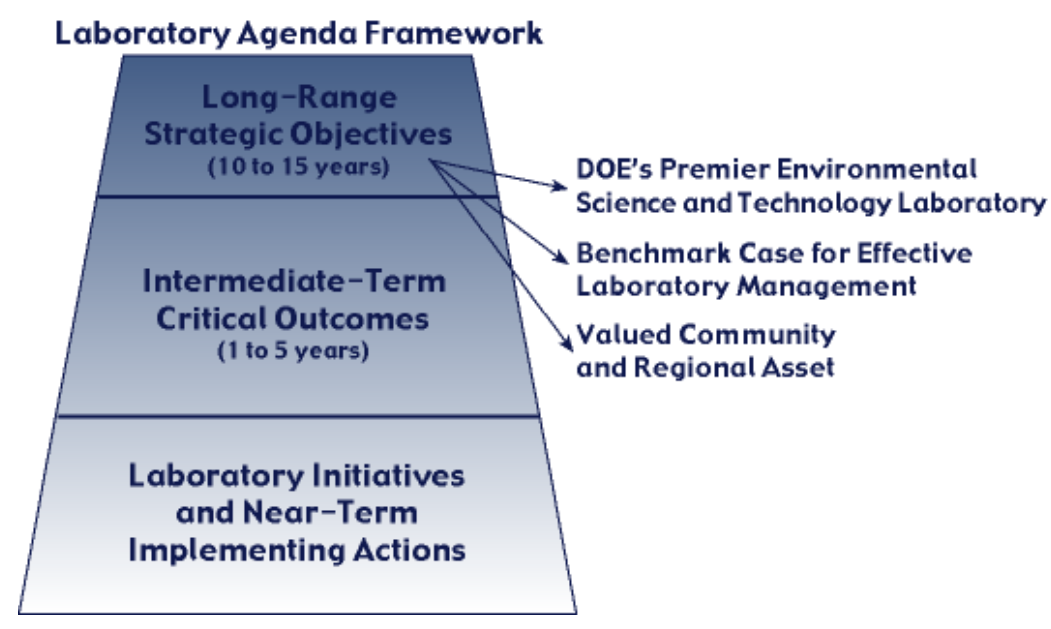

Major elements of Pacific Northwest National Laboratory's Agenda consist of long-range strategic objectives, intermediate-term critical outcomes, and short-term Laboratory initiatives.

\section{The Laboratory Agenda}

The major elements of Pacific Northwest National Laboratory's strategy are captured in our Laboratory Agenda. The Laboratory Agenda provides a structured framework for Pacific Northwest National Laboratory's long-term strategic objectives, intermediateterm critical outcomes, and the initiatives and actions needed to achieve those outcomes. This structure, represented in the figure, is updated using information developed through our annual planning process. The Agenda includes clear statements of the primary results that Pacific Northwest National Laboratory will deliver to DOE over the next few years, and the major science and technology, operational improvement, and community relations initiatives that we are undertaking to deliver those results.

The structure and selected key elements of our Agenda for fiscal year 2001 are shown in the figure below. These elements are further described in the following paragraphs.

\section{Strategic Objective 1-Pacific Northwest National Laboratory Serves as DOE's Premier Environmental Science and Technology Laboratory}

Pacific Northwest National Laboratory will be DOE's premier environmental science and technology laboratory, as demonstrated by the significant contributions we make toward solving the nation's and world's most critical environmental challenges. We will conduct research in well-defined areas that support each of the DOE's missions. Pacific Northwest

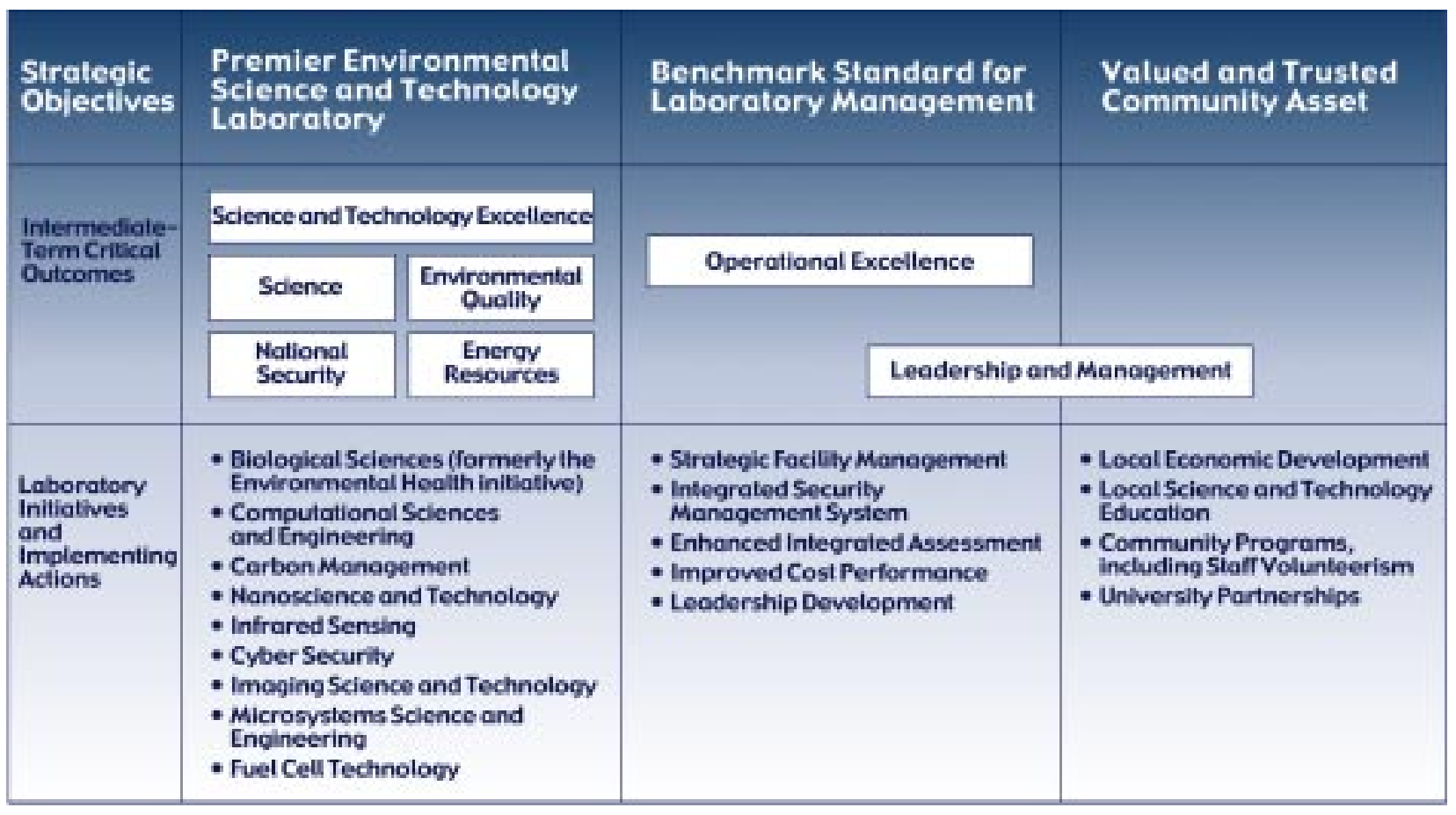

The major elements of Pacific Northwest National Laboratory's strategy are captured in our Laboratory Agenda. 
National Laboratory will earn recognition for scientific excellence and innovative solutions to major problems. We will operate singular research facilities that represent essential elements in the nation's science and technology infrastructure. Over the next several years, we will deliver a number of major actions in line with this objective.

Science. Pacific Northwest National Laboratory will conduct basic research that develops new knowledge and understanding which underpins the missions of the Department of Energy. In particular, Pacific Northwest National Laboratory will

- operate the William R. Wiley Environmental Molecular Sciences Laboratory with distinction as a national scientific user facility that contributes substantially to DOE's environmental and science missions

- develop strong capabilities in advanced biological sciences research, supported by exposure-to-dose modeling, biomarker measurement, cell-signaling analysis, and protein screening as indicators of cellular damage

- establish enhanced capabilities in computational science and modeling by development of robust, high-performance software suites, and by delivery of significant new science to support DOE programs in energy, environment, and national security

- contribute to global environmental science by successfully operating DOE's Atmospheric Radiation Measurement program, by research that improves our models of the effects of energy production and use on the environment, and by developing the tools needed to mitigate the social, economic, and environmental impacts of global change.

Environmental Quality. Pacific Northwest National Laboratory will deliver fundamental improvements in science and technology that provide for a healthy global environment and sustainable world development. In particular, Pacific Northwest National Laboratory will

- deliver science and technology critical to productivity improvements that enable DOE to accelerate cleanup and closure schedules and lower the overall life-cycle cleanup costs at Hanford and across the DOE complex

- contribute to the development of the basis for long-term management at Hanford and other DOE sites

- develop and apply innovative solutions that enable sustainable world development while addressing DOE activities to ensure a cleaner environment and manage our national resources.

Energy Resources. Pacific Northwest National Laboratory will demonstrate leadership and technical quality in energy-efficiency programs and carbon management. In particular, Pacific Northwest National Laboratory will

- deliver science and technology critical to clean, lightweight, and efficient vehicles

- develop leadership, direction, and technical program support for the developing advanced power systems

- provide sustaining leadership for programs in building codes and standards and intelligent building systems and controls.

National Security. Pacific Northwest National Laboratory will enhance national and international security by developing and applying new science and technology and delivering creative and innovative solutions to arms control and nonproliferation, infrastructure protection and counterterrorism, and other major national security needs. In particular, Pacific Northwest National Laboratory will

- anticipate emerging threats by developing technologies to protect critical infrastructures and information and communications systems 
- develop, apply, and deploy the science, technology, and human resources for policy development and effective operation of the International Nuclear Safety Program

- develop and deploy innovative solutions to respond to national security needs, including new infrared sensing technologies for detecting effluents from nuclear, chemical, and biological weapons; materials protection, control, and accountability upgrades at selected sites; and science leadership roles for existing and future treaties and agreements.

Science and Technology-Implementing Actions. In support of these objectives and in line with our planning assumptions, the Laboratory is undertaking a number of implementing actions, including strategic science and technology initiatives. Major implementing actions are described below.

- Our biological sciences initiative (formerly called the Environmental Health initiative) will build the scientific foundation for improved understanding of the health impacts of environmental contaminants, will strengthen our experimental and computational capabilities in molecular biology, and create novel research instrumentation that may serve as the basis for new user facility concepts.

- The Computational Sciences and Engineering initiative will build integrated capabilities in computer science, applied mathematics, molecular science, regional climate prediction, subsurface and atmospheric reactive transport, and engineering modeling and simulation.

- The Carbon Management initiative will provide DOE with an integrated approach to the problems of climate change and carbon management, encompassing global and regional-scale prediction and technology options for energy efficiency, non-fossil energy sources, and carbon sequestration.

- Work in Microsystems Science and Engineering will develop a fundamental understanding of and devise engineering capabilities for microscale heat and mass transfer, device fabrication, and surface modification with applications to DOE's energy, environmental quality, and national security missions.

- The Cyber Security initiative will build forefront capabilities in cyber security and critical infrastructure protection.

- The Infrared Sensing initiative will provide new means to detect and identify chemicals in the atmosphere and on surfaces that are associated with the proliferation of nuclear, chemical, and biological weapons.

- The Fuel Cell Technology initiative will provide leadership to support DOE's solid oxide fuel cell program, as well as new fuel cell materials, fabrication techniques, and systems integration approaches for cost-effective manufacturing.

- The Nanoscience and Technology initiative will provide new separation technologies, surface coatings and films, and applications in surface chemistry catalysis, sensing, energy storage, and microelectronics.

- The Imaging Science and Technology initiative will provide new image processing theories, analytical methods, and algorithms for improved image collection, fusion, interpretation, and analysis.

- We will continue our efforts to enhance the Environmental Molecular Sciences Laboratory as a premier scientific user facility, adding new and renewing existing information and strengthening support to the user community.

Details of each of the initiatives are provided in Section 4. 


\section{Strategic Objective 2-Pacific Northwest National Laboratory Exemplifies the Benchmark Case for Effective Laboratory Management}

Our second strategic objective is that Pacific Northwest National Laboratory will be the benchmark case for laboratory management, enabling high-quality, relevant science and technology at the lowest possible cost, operating our facilities and programs with distinction, and protecting the environment and the health and safety of our staff and the public.

Operational Excellence. Pacific Northwest National Laboratory will conduct work and operate laboratory facilities with distinction, fully supportive of our science and technology mission, and fully protective of workers, the public, and the environment. In particular, Pacific Northwest National Laboratory will

- manage the physical plant to provide a set of facilities and the supporting infrastructure that are aligned with future mission needs

- sustain and enhance Pacific Northwest National Laboratory's integrated processes and training for ensuring excellence in safety, health, and environmental protection.

Leadership and Management. Pacific Northwest National Laboratory will provide the leadership that ensures science and technology excellence and maintains the infrastructure necessary to accomplish DOE's missions. We will operate the Laboratory as a good neighbor in the community. This outcome is also part of the third strategic objective of being a valued community and regional asset. In particular, Pacific Northwest National Laboratory will

- provide leaders and staff necessary to ensure the achievement of simultaneous excellence in science and technology, operations, and community relations

- ensure that Pacific Northwest National Laboratory has a clear identity separate from Hanford by effectively communicating the results of leading-edge scientific research and its societal benefits, by continuing to be a good corporate citizen by contributing expertise to key community and regional issues, and by enhancing the science and mathematics education efforts in our area

- drive continuous improvement through comprehensive self-assessment.

Benchmark Case Implementing Actions. Major implementing actions for this strategic objective include the following:

- developing a comprehensive security management system designed to strengthen our security systems, increase staff awareness of security issues, and ensure the reliable protection of classified and other sensitive information

- enhancing our integrated safety management system by implementing a rigorous self-assessment and by broadening its deployment

- developing a strategic facilities management plan to ensure that our physical plant is revitalized to meet expected mission requirements in the years to come, to support the Hanford Site and the private sector, and to ensure that operations are cost-effective and commensurate with mission requirements

- conducting a comprehensive evaluation of the internal and external factors affecting laboratory costs to identify opportunities for near- and long-term cost reductions

- implementing a comprehensive leadership development program to provide training and support for staff entering leadership positions and to broaden and diversify our leadership pool

- continuing the development of our integrated assessment management system to provide early and reliable detection of operational and other issues and to support continuous improvement in management and support functions. 


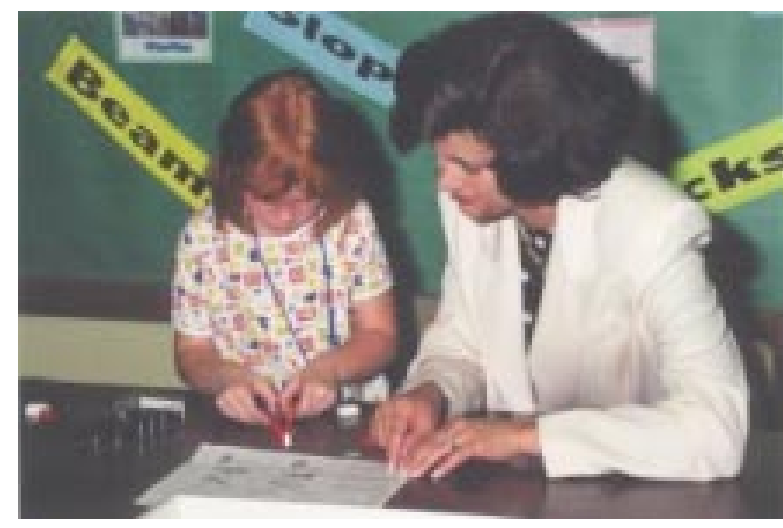

During the grand opening of the Battelle Academy of Engineering, Leah Glesener demonstrated to Director Lura Powell how she is using LEGOs® to learn about simple machines and levers. The program uses LEGOs to introduce children to basic mechanical engineering concepts through interesting, fun, hands-on activities.

As a framework for many of these implementing actions, we are initiating a "second generation management systems" program. This effort will build on the experience that we have gained in redesigning our management and operational systems over the last five years. Our overall goal is to ensure that our management systems and operational practice enable our researchers as effectively as possible, while enhancing stewardship of DOE assets and further improving worker health and safety and our protection of the environment.

\section{Strategic Objective 3-Pacific Northwest National Laboratory Is a Valued Community and Regional Asset}

In line with our philosophy of simultaneous excellence in science and technology, Laboratory operation, and community relations, our third strategic objective is that Pacific Northwest National Laboratory will be a valued community and regional asset. The Laboratory will make significant contributions to local economic development, science education, and other major community interests. We also will play an integral role in the national and regional science and technology infrastructure and will make significant contributions to regional environmental and other issues. Primary implementing actions include

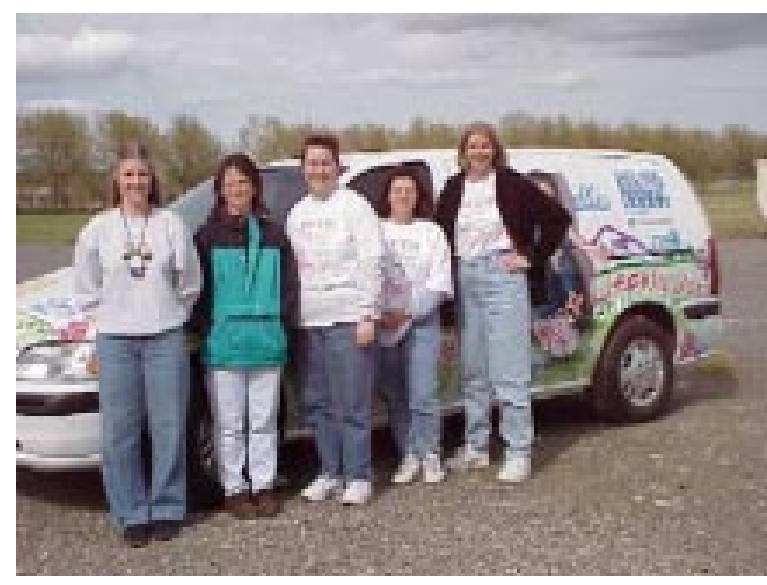

Volunteers teamed with the Benton Franklin Health District to provide car seat safety checks for parents and grandparents at the Battelle Staff Association picnic grounds.
- enhancing the performance of Pacific Northwest National Laboratory's Economic Development Office, supporting the formation of new companies, providing support to local and regional economic development agencies, providing access to our capabilities for small businesses, and strengthening the technology transfer function and increasing its effectiveness and value

- strengthening Pacific Northwest National Laboratory's successful science and technology education programs to improve the overall quality of science and technology education in the local community, and strengthening scientific collaborations with regional research universities

- enhancing our participation in community programs, with increased emphasis on minority outreach and "Team Battelle" volunteer activities

- supporting DOE's Richland Operations Office in planning for the future of the Hanford Site and ensuring positive benefits to the community and region through the completion of the cleanup program. 


\section{4}

\section{Major Laboratory Initiatives}

Laboratory science and technology research initiatives ${ }^{(a)}$ strengthen our ability to respond to current and anticipated DOE mission needs. These initiatives ensure that Pacific Northwest National Laboratory remains well positioned to provide a high level of science capability and responsiveness to DOE's research and development portfolio. Over time, successful initiatives transform into significant new DOE research programs, with new

\section{Relevance of Initiatives at Pacific Northwest National Laboratory to Elements of the DOE Research and Development Portfolio}

\begin{tabular}{|c|c|c|c|c|}
\hline Initiative & Science & $\begin{array}{c}\text { Environmental } \\
\text { Quality }\end{array}$ & $\begin{array}{c}\text { Energy } \\
\text { Resources }\end{array}$ & $\begin{array}{l}\text { National } \\
\text { Security }\end{array}$ \\
\hline $\begin{array}{l}\text { Biological } \\
\text { Sciences }^{(a)}\end{array}$ & $\begin{array}{l}\text { Impacts of People } \\
\text { and the Environment; } \\
\text { Prevention and } \\
\text { Protection }\end{array}$ & $\begin{array}{l}\text { Environmental } \\
\text { Remediation; } \\
\text { Deactivation and } \\
\text { Decommissioning }\end{array}$ & & \\
\hline $\begin{array}{l}\text { Computational } \\
\text { Sciences and } \\
\text { Engineering }\end{array}$ & $\begin{array}{l}\text { Scientific Simulation; } \\
\text { Instrumentation for the } \\
\text { Frontiers of Science }\end{array}$ & $\begin{array}{l}\text { Enhance Future Land } \\
\text { Use; Environmental } \\
\text { Remediation }\end{array}$ & $\begin{array}{l}\text { Efficient and } \\
\text { Productive Energy Use; } \\
\text { Clean and Efficient } \\
\text { Vehicles; Enhancing } \\
\text { Utility Infrastructure }\end{array}$ & $\begin{array}{l}\text { Monitoring Nuclear } \\
\text { Treaties and } \\
\text { Agreements }\end{array}$ \\
\hline $\begin{array}{l}\text { Carbon } \\
\text { Management }\end{array}$ & $\begin{array}{l}\text { Sources and Fate of } \\
\text { Energy Byproducts; } \\
\text { Climate Change } \\
\text { Research; Clean and } \\
\text { Affordable Power }\end{array}$ & $\begin{array}{l}\text { Enhance Future Land } \\
\text { Use }\end{array}$ & $\begin{array}{l}\text { Reliable and Diverse } \\
\text { Energy Supply; Clean } \\
\text { and Affordable Power }\end{array}$ & \\
\hline $\begin{array}{l}\text { Nanoscience and } \\
\text { Technology }\end{array}$ & $\begin{array}{l}\text { Extraordinary Tools; } \\
\text { Instrumentation for the } \\
\text { Frontiers of Science; } \\
\text { Components of Matter }\end{array}$ & $\begin{array}{l}\text { Environmental } \\
\text { Remediation }\end{array}$ & $\begin{array}{l}\text { Clean and Affordable } \\
\text { Power; Efficient and } \\
\text { Productive Energy Use }\end{array}$ & $\begin{array}{l}\text { Verification } \\
\text { Technologies; } \\
\text { Chemical Detection }\end{array}$ \\
\hline Infrared Sensing & $\begin{array}{l}\text { Sources and Fate of } \\
\text { Energy Byproducts }\end{array}$ & $\begin{array}{l}\text { Management of Waste } \\
\text { Material }\end{array}$ & & Effluent Detection \\
\hline Cyber Security & & & $\begin{array}{l}\text { Enhancing Utility } \\
\text { Infrastructure }\end{array}$ & Physical Detection \\
\hline $\begin{array}{l}\text { Microsystems } \\
\text { Science and } \\
\text { Engineering }\end{array}$ & $\begin{array}{l}\text { Clean and Affordable } \\
\text { Power; Efficient Energy } \\
\text { Use; New Fuels }\end{array}$ & $\begin{array}{l}\text { Management of High- } \\
\text { Level and Mixed Low- } \\
\text { Level Waste }\end{array}$ & $\begin{array}{l}\text { Producing Clean Fuels; } \\
\text { Clean and Efficient } \\
\text { Vehicles; Efficient } \\
\text { Buildings }\end{array}$ & \\
\hline $\begin{array}{l}\text { Fuel Cell } \\
\text { Technology }\end{array}$ & $\begin{array}{l}\text { New Fuels; Clean and } \\
\text { Affordable Power }\end{array}$ & & $\begin{array}{l}\text { Advanced Power } \\
\text { Systems }\end{array}$ & \\
\hline $\begin{array}{l}\text { Imaging Science } \\
\text { and Technology }\end{array}$ & $\begin{array}{l}\text { Instrumentation for the } \\
\text { Frontiers of Science }\end{array}$ & $\begin{array}{l}\text { Enhance Future Land } \\
\text { Use }\end{array}$ & $\begin{array}{l}\text { Enhancing Domestic } \\
\text { Supply }\end{array}$ & $\begin{array}{l}\text { Monitoring Nuclear } \\
\text { Treaties and } \\
\text { Agreements }\end{array}$ \\
\hline
\end{tabular}

(a) Initiatives are provided for consideration by the Department of Energy. Inclusion in this Plan does not imply DOE approval of or intent to implement an initiative. 
capabilities that also may benefit other existing programs. The knowledge, tools, and scientific competencies that emerge from successful initiatives often lead to new scientific or technical opportunities.

Our portfolio of initiatives supports the Laboratory's roles in each of DOE's four primary missions. Initiatives create new knowledge in areas that affect one or more of DOE's missions or major programs. For example, our Microsystems Science and Engineering initiative will provide the underlying scientific understanding and technology for application of microtechnology-based devices in DOE's environmental quality, energy resources, and national security missions.

The research themes used by the Office of Science to provide a framework for DOE's science programs provide an alternative look at our initiatives. In line with the "Extraordinary Tools for Extraordinary Science" theme, the Computational Sciences and Engineering and biological sciences initiatives will develop significant new tools for multidisciplinary research. Our biological sciences initiative (formerly called the Environmental Health initiative) will provide fundamental insight into cell-signaling processes by proteins that we believe can significantly impact our understanding of the effect of environmental impacts on human health and the ecosystem. The initiative on Carbon Management will engage our scientists in technologies that can positively contribute to atmospheric stabilization of carbon dioxide levels. In keeping with our environmental mission, these initiatives are aligned with the theme "Protecting Our Living Planet."

Other initiatives are directed toward supplying the science and technology base needed for specific mission requirements. For example, our Cyber Security initiative builds the technical foundations that DOE needs to protect critical information systems and networks from foreign and domestic threats. The Infrared Sensing initiative will develop sensors to detect and identify chemicals associated with threats from chemical, biological, and nuclear terrorism, as well as other applications in environmental research.

In line with the Office of Science's "Fueling the Future" theme, our Fuel Cell Technology initiative supports DOE's efforts to ensure abundant and clean energy. This initiative will integrate new materials and designs into high-density configurations that can be

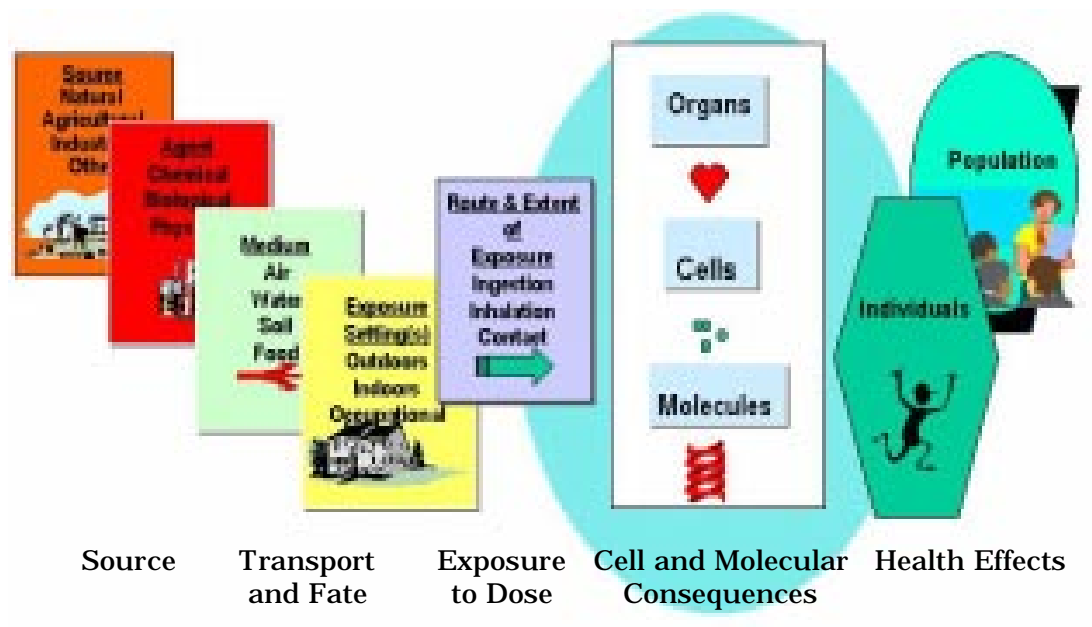

The goals of our biological sciences initiative are to 1) understand, predict, and mitigate the adverse health effects of environmental agents derived from human activity; 2) integrate emerging science and technology in the physical, biological, and information sciences; 3) develop state-of-the-art science tools and instruments to study the effects of contaminants on living cells; and 4) apply frameworks and predictive models to capture and extend our healtheffects knowledge. manufactured cost-effectively as energy sources for both stationary and mobile applications.

\section{Biological Sciences(a)}

Pacific Northwest National Laboratory has been investing for the past few years in a collaborative research program that integrates emerging science and technology in molecular biology, biochemistry, physics, and computation to advance our understanding of important biological problems in the postgenomic era. The intent of this initiative is to provide a framework and set of tools for tackling complex problems in biological systems that can be solved only by work at the interface among disciplines.

(a) Formerly the Environmental Health initiative. 
The completion of the sequencing of the genome presents new challenges and opportunities in the biological sciences. Understanding how cells process information is one of the important problems we must now address. All living cells respond to signals from their environment, whether they are free-living in the soil or part of a tissue. The ability of cells to perceive and correctly respond to their microenvironment is the basis of development and tissue repair. Cell communication is necessary for the existence of multicellular organisms. Errors in cellular information processing also are responsible for many human diseases, including cancer, autoimmunity, and diabetes. We are using the one-of-a-kind facilities in the Environmental Molecular Sciences Laboratory to identify the proteins involved in cellular communication. We are developing new optical instruments to visualize these processes and creating sophisticated computer models to help us understand how information is both encoded and decoded by cells. Our work will significantly advance our basic understanding of cellular dynamics and will allow us to better use genomics data to address complex biological problems.

\section{Research Strategy}

The research strategy for moving our biological sciences program forward is a multidisciplinary approach that integrates computational modeling, imaging, proteomics, and experimental work, and is driven by and drives the latest advances in technology and research tools. The scientific foundation of our biological sciences initiative is the study of the complex cell-signaling networks responsible for biological function with a focus on cellular information processing - understanding the networks through which information passes and the dynamics of how it is processed by cells. In the postgenomic era, understanding these networks and mechanisms is key to translating genetic information into relevant knowledge about integrated biological functions in living organisms. This translation requires an understanding of spatial and temporal dynamics, receptor activity, and signaling pathways. Key to this work will be an understanding of protein-protein interactions, molecular biology, computational modeling, imaging, and a systems perspective of the whole cell. Success requires the simultaneous application of these capabilities by multidisciplinary teams capable of advancing each of these capabilities well beyond the current state of the art.

A coordinated, multipronged research strategy is required to understand the dynamics of cellular information systems and the responses of those systems to environmental influences. Studies of single-cell microbial organisms as well as simpler, multicellular organisms will lend insight to parallel studies of more complex mammalian model systems. We have identified three critical research directions: 1) analyze and understand cellular components involved in cell signaling, 2) study cell signaling in vivo, and 3) synthesize acquired knowledge into an integrated cellular context using computation and modeling. These research areas will require the development and acquisition of science and technology capabilities currently unavailable to the scientific community. A senior science director was hired to lead the intellectual development of this initiative and to refine the Laboratory's scientific directions. A vigorous recruiting effort is under way to acquire additional scientific and leadership talent for key elements of this initiative.

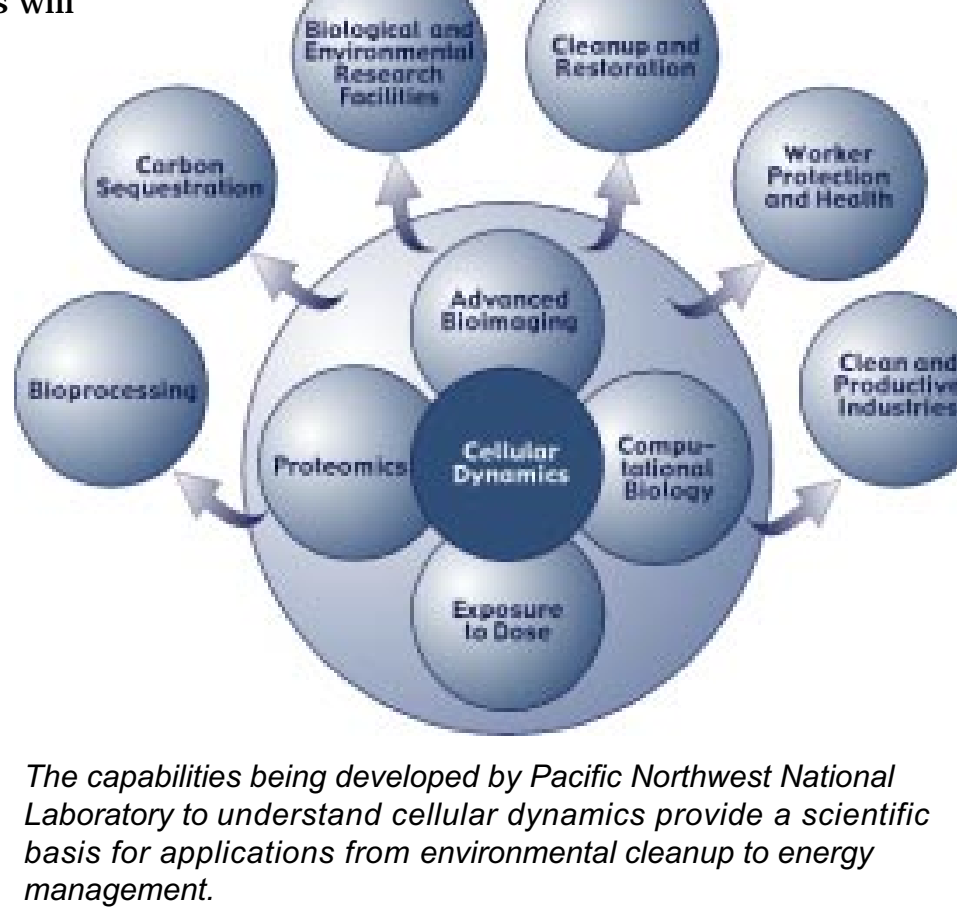




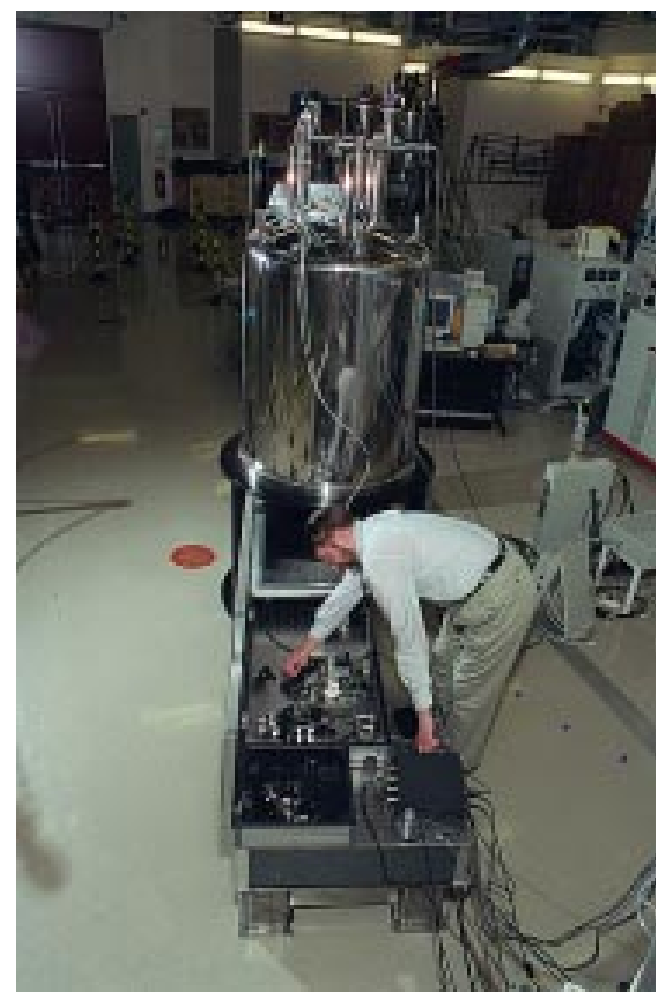

Researchers have obtained the world's first simultaneous images of biological cells using a prototype of a combined microscope that allows fluorescent optical microscopes and magnetic resonance to focus on the same samples at the same time.
Cell-signaling research requires the development of new measurement technologies that allow the observation of complex biological systems in vivo. We are building a program that will 1) enable cell-signaling research, 2) effectively capitalize on information available in the post-genome era, and 3) serve the scientific community. Through this initiative, we have already developed an initial state-of-the-art compound microscope that combines high-resolution nuclear magnetic resonance with optical methods. We believe that this program may require a new facility to accommodate the instrumentation, supporting research capabilities, and collaborative environment required to perform the envisioned research. This initiative will provide DOE and the scientific community with capabilities that significantly extend current DOE plans for functional genomics and provide a science and technology base that broadly supports DOE missions.

This initiative builds on the Laboratory's extraordinary combination of skills and the capabilities of the Environmental Molecular Sciences Laboratory. Key resources at EMSL (magnetic resonance, mass spectrometry, optical spectroscopy, computational chemistry) are being linked with university centers of excellence and other DOE national user facilities. Advances in computing and communication technologies now make it possible to share instrumentation, data, and data analyses, and EMSL staff continued to pioneer development of a "virtual laboratory."

Research is being coordinated conceptually through specific programs that integrate research in single-cell microbiology, molecular and cellular biology, computational biology, and proteomics, and support essential collaborations with other centers of excellence. Our research programs include four key enabling components.

Cellular Observatory. Biological function cannot be fully understood outside of the living cell. Biological processes occur on and around organized intracellular structures, are modulated by participation of associated processes, and are controlled by intact signaling pathways organized and integrated into interactive signaling networks. All biological information obtained to date is interpreted in the form of conceptual and/or mathematical models. None of these models can fully and accurately predict the function of a living system. Obtaining in vivo and in vitro dynamic measurements in real time provides biologically relevant information for constructing and testing advances in conceptual and predictive models. To this end, we are building a program and experimental capability to deploy new measurement techniques for biological research in live cells. Our approach to date is to develop multifunctional instrumentation that provides simultaneous information on several cellular functions at several scales, from the molecular to the multicellular. Five multifunctional instruments are in development in the cellular observatory, none of which have existing successful counterparts. EMSL's combination of optical spectroscopy, magnetic resonance, x-ray spectroscopy, mass spectrometry, and computation-modeling capabilities provides the genesis of the cellular observatory. The x-ray imaging capabilities at the Advanced Light Source and Advanced Photon Source synchrotron light sources also will be valuable to this effort. Partnerships with other national laboratories (Brookhaven, Argonne, and others) are being established in support of this research. 
Computational Biology. The development of computational models that couple theory to experiment are important in leading to predictive understanding of how cellsignaling pathways and networks work. A key element of this research is the need to cross many temporal and spatial scales in order to connect diverse data and obtain biological consequences at a systems level. At the smallest spatial scale, our program is investigating how small-to-medium molecules interact with proteins and lead to signaling events. At the next higher level, we are studying the role of protein-protein interactions in controlling cell-signaling pathways. At the cellular level, we are developing and employing a range of mathematical tools and models to predict the behavior of cell-signaling pathways, with a particular focus on microbial systems. We also are developing models that can be used to model organs with a focus on the respiratory system and the lung. The respiratory system represents an important target organ that responds to a broad range of environmental agents (vapors, metals, radionuclides, and combustion products) resulting in an expansive array of human disease states. We have developed a detailed branching model of the lung air space based on fractals and are in the process of applying new mathematical grid methods to the model.

Proteomics. As we approach the post-genome era, the next grand challenge in biology will be to decipher the proteome (the dynamics of protein arrays that are expressed by the genome). Current capabilities for characterizing the proteome use two-dimensional gels. Because of extensive limitations of two-dimensional gels approaches, we have developed and tested 1) advanced separation-sciences techniques involving protein arrays and chromatography techniques that provide high resolution, and 2) mass spectrometry that provides the mass accuracy, sensitivity, and dynamic range for identifying these proteins. Together, these two technologies can show how proteins are organized into pathways and networks, and how proteins interact to form functional complexes. Advanced mass spectrometry is a tool for mass screening of the entire proteome of organisms. These technologies are being used to examine the proteomes of simple organisms such as bacteria and yeast. Further analytical methods are being implemented to address the additional complexity introduced in mammalian samples.

Exposure to Dose. The exposure-to-dose research component is the crucial link for bringing the results of our science to "understand and protect our living planet from adverse impacts from energy supply and use" to the other important mission areas of DOE. Understanding the link between the presence of agents in the environment or workplace and the amount of that agent or a metabolite delivered to a sensitive tissue within the human body will support worker protection and cleaner energy technology development efforts across the DOE complex. The path from contact to dose begins with assimilation at biological boundaries and is determined by biochemical interactions. The focus of the exposure-to-dose research agenda is the identification and use of biological markers (biomarkers) to provide quantitative assessment of environmental agents delivered to target tissues and cellular systems and as identifiers of early warning signals of biological effects. Biomarkers constitute observable properties of an organism that can be used to estimate exposure to an environmental toxicant. Biomarkers also can be used as surrogate quantities for the prediction of human health risks. Technical approaches to determine if a tissue or cell receives a delivered dose, and if so how much, represent a critical link in the chain from exposure to cellular response and health effects. Knowledge that target cells actually received and responded adversely to a delivered dose would greatly reduce uncertainty in health risk assessments. Biomarker research provides an excellent bridge between the DOE fundamental science and technology elements of the initiative and the applied programs in exposure assessment and health effects research. 


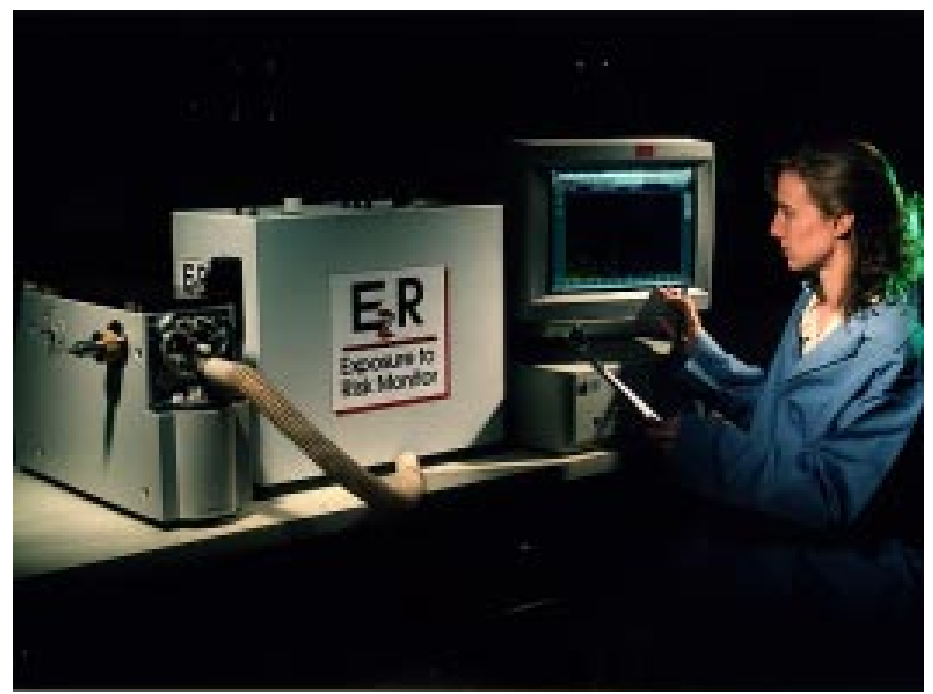

The Exposure-to-Risk Monitoring System provides immediate measurement of chemicals that workers may have ingested, absorbed, or inhaled. A worker breathes into a tube for one to two minutes, the system identifies chemicals in the breath sample, and a computer model translates the levels of different chemicals into dosages.

\section{Link to DOE Research Agenda}

Our biological sciences program responds to the DOE science mission to better understand biological mechanisms relevant to microorganisms and the human health effects of low-dose exposures, in addition to furthering discoveries in advanced technologies and computational models for use in the biological sciences. Powerful new observational instruments and advanced computation and modeling will be required to attack fundamental questions of biological mechanisms and effects at the molecular and cellular levels. We specifically address two major themes of DOE's science portfolio: Protecting Our Living Planet and Extraordinary Tools for Extraordinary Science. The initiative also is well aligned with the environmental quality mission and its attention to worker and public health risk assessment and to environmental restoration. It addresses the national security mission need to understand the consequences of chemical and biological weapons, and the energy resources mission needs for clean and affordable power and efficient and productive energy use.

\section{Computational Sciences and Engineering}

Advanced capabilities in computer modeling and simulation have been the hallmark of the national laboratories since they were founded to develop nuclear weapons for the nation's defense. The need for high-performance computer systems for national defense applications has historically driven the development of supercomputers, first the large machines from Control Data Corporation and Cray, and now massively parallel processor computer architectures. At Pacific Northwest National Laboratory, we employ advanced computation systems and powerful new algorithms implemented in high-performance software to advance our fundamental understanding of science and technology. It is becoming possible to solve the complex equations that describe natural phenomena, such as the Schroedinger equation for electronic motion in molecules and the NavierStokes equations for fluid flow at accuracies that are comparable to, and in some cases, better than those available from experimental measurements. Together with theory and experimentation, computational science has developed into the third branch of science and is a vital element of the DOE science mission. Today, computational science at Pacific Northwest National Laboratory is being applied to major issues in DOE's science mission, and also provides the modeling and engineering capabilities for DOE's energy resources and environmental quality missions, but we must also build for the future role of this third leg of the scientific triangle. For Pacific Northwest National Laboratory to maintain its core science programs, meet the mission needs of the Laboratory, and to build for its future role, we must and will be among the world's premier computational science institutions, helping to lead the journey to effective application of petaflop computing. We envision a future in which the Laboratory delivers substantial contributions to the theory and practice of computational science and engineering, and in which computation is an integral part of essentially every element of the Laboratory's research. Thus, we have embarked on an ambitious effort to enhance our core computational science and engineering capabilities. 


\section{Research Strategy}

The goal of our internal investments in computational sciences and engineering is to address mission needs through the use of high-performance computing by intimately coupling hardware, software with advanced algorithms, and methods to address complex problems. This initiative focuses on

- developing high-performance, portable, and scalable algorithms and software for massively parallel computer systems

- developing the associated computational infrastructure, especially high-performance parallel computing tools and frameworks, advances in the use of operating systems for massively parallel processor computers, and collaborative problem-solving environments

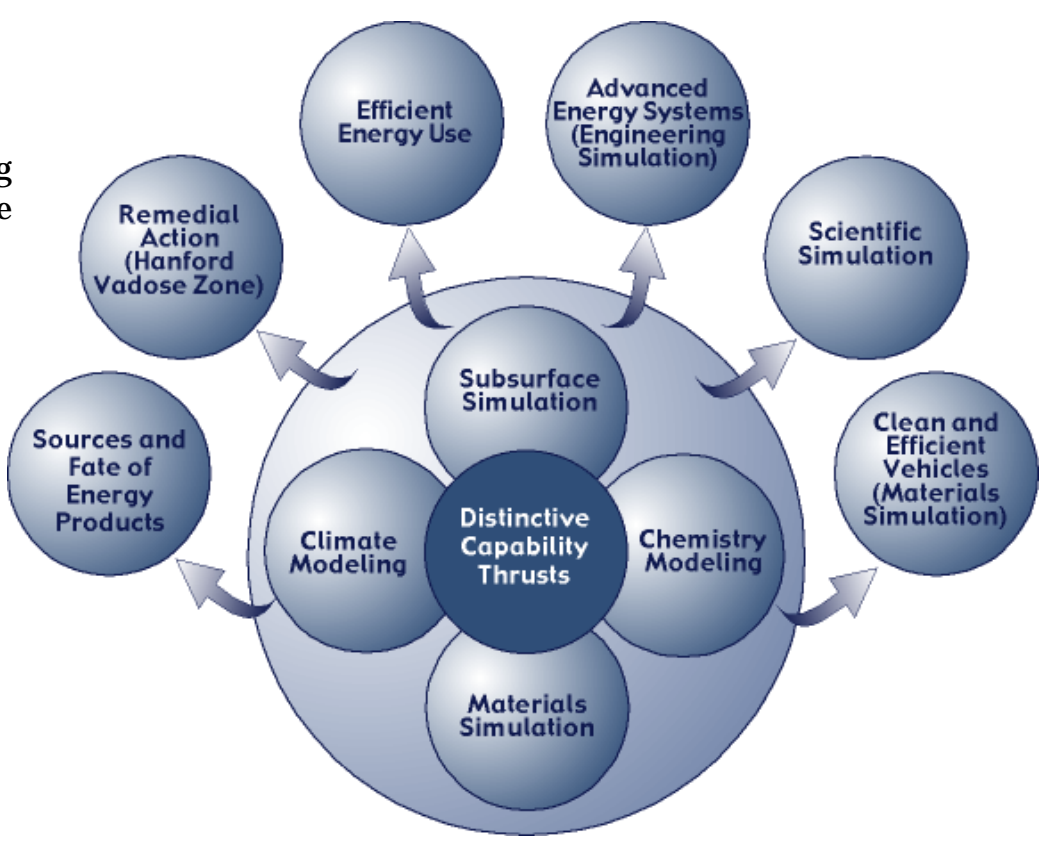

The capabilities being developed in the Computational Sciences and Engineering initiative tie to many of DOE's missions research and development portfolio elements.

- developing an applied mathematics infrastructure coupled to the computer science effort to support the computational science effort

- applying computational sciences to selected Laboratory missions, focusing primarily on complex basic science, environmental, and engineering issues.

This investment will position Pacific Northwest National Laboratory to support major DOE computational science initiatives, including DOE's participation in the national Scientific Discovery through Advanced Computing (SciDAC) initiative now before Congress. A key component to our vision is the development of topical computer facilities as noted in DOE's SciDAC plan. This involves the codevelopment of hardware and software in a single facility tuned to the needs of a specific scientific or engineering domain so that the highest possible performance is achieved. Our goal is to be home to major topical computing facilities in specific domain areas appropriate to the Laboratory's mission. The Molecular Sciences Computing Facility is the prototype for a SciDAC topical computing facility with its integrated combination of high-end massively parallel hardware, high-end software (Molecular Science Software Suite or MS ${ }^{3}$ ), graphics and visualization laboratory, and large-scale data archive and scientific data management system. The Laboratory's investments are designed to provide enduring value by strengthening our capabilities in areas of computational modeling and simulation that are critical to our long-term goals.

To meet the goals of the initiative, investments are being made in the following areas of strategic Laboratory interest (environment, chemistry, and engineering), and in the base underlying technologies (computer science and applied mathematics):

- Subsurface Sciences. The emphasis is on developing high-fidelity reactive transport codes applicable to a wide range of environmental problems, including the vadose zone at the Hanford Site. Significant success has been achieved in developing new methods implemented in high-performance software for massively parallel architectures that are being used to address reactive transport in the Hanford vadose zone.

- Atmospheric Sciences. The emphasis is on developing a prototype regional climate center, one of the key features of DOE's proposed Accelerated Climate Prediction 


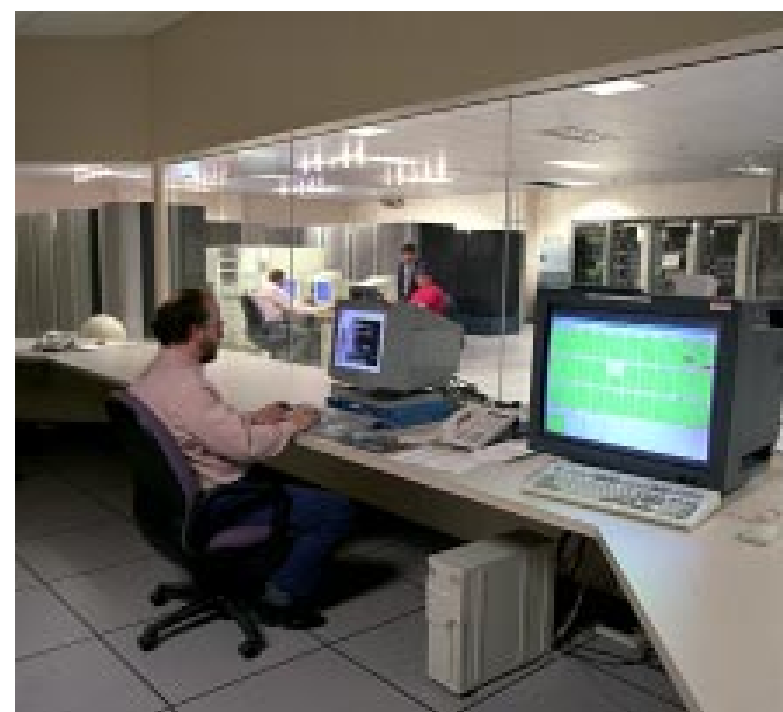

Laboratory goals in Computational Sciences are to become a premier computational science institution in support of DOE science missions, effectively integrate computation and experimentation to deliver outstanding science and new technology, develop petaflop computing capabilities, and develop integrated software to support science and solve important problems. initiative, and on developing other modules, such as aerosol chemistry for inclusion in global climate models. For example, we have developed new software (Pegasus) with advanced capabilities for atmospheric chemistry modeling that runs at high performance on massively parallel architectures-allowing us to model stratospheric ozone intrusions.

- Chemical Sciences. The emphasis is on improving the performance and capabilities of the NWChem code for the types of thermochemical, chemical kinetics, and spectroscopic calculations broadly needed for addressing DOE's scientific missions. Significant advances have been made in developing new coupled cluster methods (including open shells) and implementing these methods in NWChem. This progress will allow us to investigate the reactions of the much larger molecules that are of key interest to a broad range of DOE mission areas.

- Materials Engineering. The emphasis is on developing material models capable of accurately predicting the behavior of materials for energyefficient automotive and aerospace applications. Significant advances have been made in integrating commercial software tools into an engineering design environment and then using these tools to address complex engineering problems-such as hydroforming of metals, a key technology needed for the design of new lightweight transportation systems.

- Computer Science. The emphasis is on developing the base infrastructure for the construction and maintenance of discipline-specific collaborative problem-solving environments for regional climate modeling, computational chemistry, and atmospheric chemistry and engineering simulations, as well as providing the computer science basis for high-performance scalable and portable computer codes for present and future massively parallel computing systems. We have made key hires in the area of high-performance computing and in problem-solving environments. Significant developments in new security and web-based database technologies for collaborative problem-solving environments have been made, and a prototype for regional climate modeling has been developed. Work has been initiated to develop new database tools for computational chemistry to allow for a better description of chemical reactions through a more efficient use of computational data.

- Applied Mathematics. The emphasis is on various application areas and highperformance parallel computing. Significant progress in building up this area has been made through new key hires. A focus on grid technologies and the underlying mathematics was established to provide the best description of the physics for the most realistic geometry of the system. The new codes, NWGrid (grid generation) and NWPhys (physical equation solvers), are being developed for massively parallel computer systems.

Planning for multi-teraflops scale topical computing facilities requires a focus on the next generation of massively parallel computers and the associated software development needed to drive new applications, as well as for the gigabit networks and infrastructure to support such computers and applications for a national user base. The science drivers for the new hardware include computational molecular science with a focus 
on basic science including reaction energetics and kinetics, atmospheric chemistry, environmental science and interfacial science, catalysis, subsurface reactive transport with a focus on the DOE-wide vadose zone issues, regional climate modeling and atmospheric chemistry, and engineering simulations with a focus on energy efficiency. High-bandwidth, low-latency networking that supports differentiated services will be a critical component for any teraflops computing site and a critical capability to support major computational activity. Therefore, planning will be carried out to determine the network and infrastructure required to support the next generation of simulation and computing activities at Pacific Northwest National Laboratory. In addition to supporting this initiative, high-performance networking will benefit other initiatives and will position the Laboratory to be competitive for other work requiring high-performance electronic communications capability.

Computational science and engineering is a key to many of the advances that will occur in science during the $21^{\text {st }}$ century. As such, it plays a key role in many of the Laboratories initiatives, including the biological sciences and the Nanoscience and Technology initiatives. The efforts in the Computational Sciences and Engineering initiative provide much of the base technology for the computational aspects of the advanced biology and nanoscience research. We have established a significant degree of commonality in the leadership teams of the various initiatives and in the management of the staff to fully integrate all aspects of the computational science that is being carried out at the Laboratory.

\section{Link to DOE Research Agenda}

Scientific simulation makes defining contributions to almost every area of science and engineering. The efforts of this initiative are strongly tied to many missions of DOE and the Office of Science. Among the direct relationships to the following parts of the Office of Science portfolio are

- Fueling the Future-Efforts are being made to develop capabilities 1) to improve our ability to model combustion processes beginning at the molecular level and going to the macroscopic level; 2) to improve modeling of metals, ceramics, and advanced materials; and 3) to improve our ability to design catalysts from first principles with a focus on energy production from fossil fuels.

- Protecting Our Living Planet-Our efforts are focused on helping to clean up the environment by providing tools to understand the fate and transport of contaminants in the subsurface and in the atmosphere from a variety of anthropogenic sources. We also are developing new tools to aid in minimizing pollution and energy use in chemical production processes, as well as for the design of new materials for environmental cleanup and restoration.

- Exploring Energy and Matter-The software being developed under this initiative is relevant to modeling simple and complex molecular systems, including activities and biomolecular systems relevant to environmental health, restoration, and protection. In addition, these tools will let us explore larger molecules in significantly more detail than previously possible, and will make accurate computational thermochemistry, kinetics, and spectroscopy a reality. A significant effort is under way to investigate the fundamental relationships involved in the behavior of systems at different scales that underlie the behavior of complex systems.

- Extraordinary Tools for Extraordinary Science-Efforts are focused on providing groundbreaking applications based on advances in software, computer science tools, libraries, and infrastructure to solve complex problems on the world's fastest computers.

We have developed a new paradigm for software development based on teams. Our team approach to software development is based on our successful development of the award-winning Molecular Science Software Suite (MS') for computational chemistry, initially funded under the Office of Biological and Environmental Research and the 
Office of Computational and Technology Research "Computational Grand Challenge" program in high-performance computing. A crucial component of this successful effort was the teaming of computer scientists, applied mathematicians, application developers, theoreticians, and users (domain scientists) in designing and implementing the software. This approach results in synergy that enables development of the highestperformance software with the best algorithms that is scalable, portable, and has the longest in-use lifetime. Such teams also help to minimize long-term development costs by producing software that is, to the maximum extent possible, portable and readily maintained and updated. These factors are especially important when tackling the many grand challenge computational problems faced by DOE. Our approach to software development is a key capability that we bring to DOE as it advances its agenda in computational science.

\section{Carbon Management}

Carbon management is the science, technology, and policy required for the world to stabilize the atmospheric concentration of greenhouse gases at a level that minimizes adverse impacts. Historically, the Laboratory's major efforts in climate change have revolved around developing an increased understanding of factors that influence global warming, the atmospheric chemistry associated with global warming, and the likely impacts of climate change on natural and human systems. While Pacific Northwest National Laboratory will continue significant efforts to broaden our understanding of the climate change problem through ongoing programs, the new Carbon Management initiative will sharpen our focus on climate change solutions.

This initiative will

- further our basic understanding of the science, technology, and policy required to stabilize atmospheric carbon in ways that will enable the Laboratory to be instrumental in shaping DOE's efforts to develop carbon management solutions. To accomplish this, we will need to expand our understanding of the economic, environmental, and social dimensions of technological and natural systems with particular emphasis on energy systems and their relationship to the earth's natural systems.

- conduct basic research on specific carbon management technologies (such as lowcarbon fuels, bioenergy, and carbon sequestration technologies) that are novel and that are identified as critical to solving the climate change problem.

\section{Research Strategy}

Most United States and international efforts to identify climate change solutions focus on the near-term actions that are needed to reduce carbon emissions. While various nearterm actions are necessary, climate change is a global, century-scale problem. We believe that it must be solved with a global, century-scale carbon management approach.

While the future is uncertain, we can analyze a range of global futures and construct plausible profiles of future carbon emissions. Over a diverse set of futures, a considerable gap remains between anticipated future emissions that would stabilize levels of atmospheric carbon. Carbon management includes three key elements that must be addressed for the United States and for the rest of the world to best understand the magnitude and timing of this gap, and then fill this gap with solutions.

The three key elements are

- An integrated scientific understanding of the natural carbon cycle that would enable substantially better projections of future atmospheric concentrations of carbon and the anticipated changes in concentrations which would be attributable to alternative carbon management approaches. The carbon cycle is dominated by highly complex interactions between the oceans, atmosphere, and terrestrial ecosystems. Therefore, developing this increased scientific understanding will require 
integration of significant capabilities in ocean chemistry, ocean circulation, atmospheric chemistry, and terrestrial systems. We also will need to consider interactions with the other prominent, non-carbon dioxide greenhouse gases. Given the complexity of the individual components of the carbon cycle and the complexity of the integration effort, progress in this area will depend on supercomputing resources at Pacific Northwest National Laboratory and other national laboratories.

- An increased understanding of the economic, ecological, and social

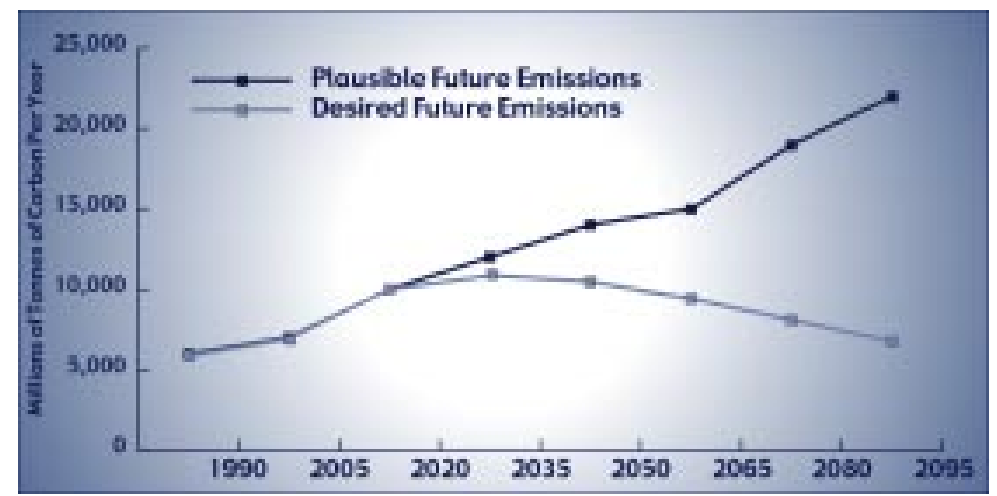

Graph showing projected carbon dioxide emissions compared to desired levels. This "emissions gap" must be managed by new technologies to reduce emissions and increase carbon sequestration. consequences of alternative atmospheric stabilization targets and the timing for achieving the targets. While the ultimate decision to stabilize atmospheric carbon at $550 \mathrm{ppm}$ or some other similar level is ultimately a policy decision, it is a decision that policymakers should make based on solid scientific information. Alternative levels and the time to achieve these levels will require various technology portfolios. Understanding the consequences of alternative targets will draw heavily upon the Laboratory's capabilities in evaluating climate change impacts. This understanding also will require expanded capabilities in environmental and social sciences, because many of the technologies that would be implemented as part of stabilizing atmospheric carbon are largely uncharacterized with respect to their environmental, economical, and social impacts. Examples of unexplored issues include the environmental impacts associated with carbon dioxide disposal in deep ocean environments or deep geologic formations, the economic impacts of largescale land-use changes that are designed to increase terrestrial carbon uptake, and the value of various research and development technologies and the appropriate timing of their deployment to address climate change.

- Novel technology that will replace and complement our existing energy system. Managing carbon will ultimately require a diverse set of novel technologies, such as

- low-carbon-fuel technology (hydrogen technology or novel low-carbon molecules)

- technologies that capture carbon from fuels processing, biomass processing, and power generation

- novel biomass conversion technologies (microorganisms for converting biomass and catalytic upgrading processes)

- technologies and science to support ocean and geologic carbon sequestration

- science and technology that would allow us to sequester carbon in terrestrial ecosystems.

Because these three elements are broad in scope, our strategy will be to focus on several efforts within these three elements. We will build our capabilities to take the second of these elements to the next level of scientific understanding, and we will play a supporting role in the third element, particularly in the area of carbon sequestration. We will strive to build relationships with other national laboratories, industry, and others to help ensure that collectively we are addressing the overall scope of carbon management and creating the necessary scientific and technological breakthroughs.

Areas of research where the Laboratory will focus the efforts of this initiative include

- Integrated Assessment. We will provide intellectual leadership across the DOE complex with respect to an integrated carbon management approach. This activity 
will be a logical extension of our current work and will be an area where the Laboratory is viewed by DOE, industry, and the scientific community as working at the leading edge of science. Specific near-term efforts will focus on advanced computational approaches for modeling technological, economic, agricultural, and earth systems in an integrated fashion to develop a higher level of understanding between the components of earth and natural systems. We also will explore approaches for extending to global scales the analysis of climate-change impacts on managed ecosystems through use of simulation models, geographic information systems, and global datasets.

- Low-Carbon Fuels and Biomass-Based Products. We will focus on production of novel fuels and chemicals from bio-based and fossil-based feedstocks using nontraditional processing approaches (continuous rather than batch fermentations, fungal fermentations, microscale processing, and microscale carbon capture). These efforts will draw from our capabilities in aqueous phase catalysis and our emerging capabilities in nanotechnology and microtechnology, and will create new capabilities in separations and fungal-based processing. We expect that our focus in fiscal year 2001 will emphasize biomass-based products. Our focus in the following years will emphasize fossil-based fuels. We also may evolve this technological thrust into an independent, but aligned initiative in fiscal year 2002.

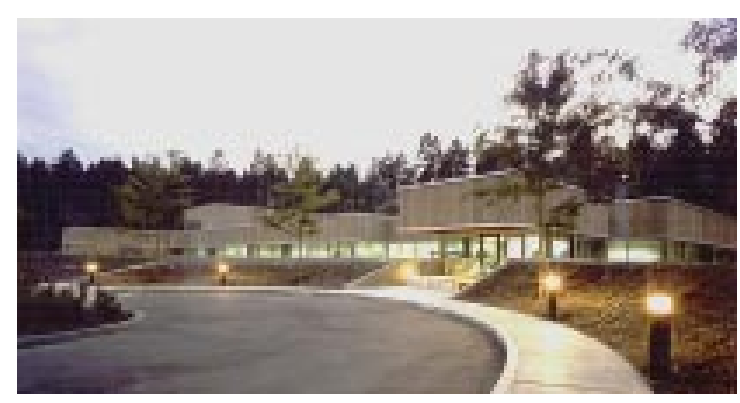

The Marine Sciences Laboratory in Sequim, Washington, is the only major ocean-side laboratory in the DOE national laboratory system. The capabilities of this laboratory will play a prominent role in scientific explorations related to the carbon cycle, ocean sequestration, terrestrial wetlands sequestration, and fungal fermentations.
- Carbon Sequestration. Our research on carbon sequestration will address three areas: terrestrial sequestration in degraded lands and wetlands, resource assessment and the geochemistry aspects of geologic sequestration, and selected aspects of ocean chemistry. Early efforts will emphasize terrestrial sequestration, and in particular, dynamic simulation of organic matter transformation in managed soils, the relation of erosional processes to the fate of carbon, and scaling procedures to project carbon changes in managed ecosystems in time and space.

\section{Link to DOE Research Agenda}

The Carbon Management initiative is directly aligned with two DOE missions: science and energy resources. The Office of Science recognizes that the Integrated Assessment, Understanding of the Carbon Cycle, Terrestrial Sequestration, and Ocean Sequestration programs are increasingly important components of their missions. The Office of Fossil Energy has primary mission responsibility for geologic sequestration. The Office of Fossil Energy and the Office of Energy Efficiency both have existing and emerging components of their mission related to bio-based products, low-carbon fuels, and other stationary and mobile energy technologies that will be part of a future energy infrastructure.

\section{Fuel Cell Technology}

Solid-state fuel cell technology has distinct advantages over conventional combustionbased power generation technology because it offers extremely high thermal to electrical conversion efficiency (up to 80 percent) in staged or hybrid systems configurations. Fuel cell technology also offers fuel flexibility in terms of fuel types (gasoline, diesel, natural gas). Advanced solid-state fuel cell designs are capable of producing the high-power densities needed to meet the demanding size and weight requirements of auxiliary and primary propulsion systems.

The Fuel Cell Technology initiative will extend Pacific Northwest National Laboratory's capabilities in solid-oxide fuel cell system research and development beyond our 
basic foundation in materials chemistry and ceramic processing. Our goal is to develop and build a solid-oxide fuel cell stack "observatory" to advance the underlying chemical, electrical, and electrochemical mechanisms. We will improve the design and reduce mass-production costs for modular solid-state fuel cell power generation systems. These designs will be adapted to transportation and stationary power applications. Advanced fuel cell designs will extend the life cycle for these systems and will make them more cost-competitive than the less-efficient fuel cell technologies that are presently in use.

Our recent technical achievements include development of anode supported cell structures, thin electrolyte membrane fabrication processes, micro-channel fuel processing technology, improvements in power electronics at the device level, and integration of semiconductor manufacturing techniques. Advanced modeling activities have led to an understanding of thermal and chemical processes during normal and transient operations of such fuel cells. With the added capability of the solid-oxide fuel cell stack observatory, the Laboratory will conduct and deliver advanced system-level research. The stack observatory will provide a collaborative environment for scientists and engineers from industry, national laboratories, and universities for the DOE Advanced Research and Technology Development Program.

\section{Research Strategy}

Pacific Northwest National Laboratory is developing a broad scientific base and engineering capability in fuel cell technology. The objective of our research strategy is to improve the chemical, thermal, mechanical, and electro-chemical processes and thereby improve the performance and cost metrics of advanced solid-oxide fuel cell systems. Through this understanding and hardware development capability, we plan to develop and demonstrate highly efficient prototypical fuel cell devices that can serve as a common building block for stationary and mobile systems. This investment will provide the Laboratory with capabilities in systems engineering, diagnostics and prognostics, advanced sensing, component fabrication, and
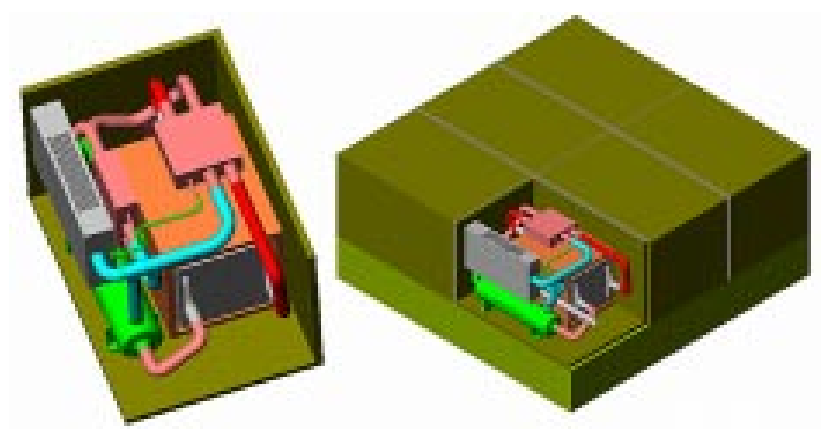

A proposed five-kilowatt solid-oxide fuel cell module (above left) will be used to meet smaller energy needs or be combined with other identical modules (above right) to handle larger power requirements. performance characterization that complement our materials and ceramics processing strengths. Our goal is to develop solid-oxide fuel cell designs and components that can be mass-produced at low cost for a variety of power-generation applications.

Laboratory research will optimize the electrical performance and long-term operational reliability of power generation systems. Better understanding of electrodics will enhance system reliability by reducing operating temperatures from the nominal $800^{\circ} \mathrm{C}$ to $1000^{\circ} \mathrm{C}$ range to the $600^{\circ} \mathrm{C}$ to $750^{\circ} \mathrm{C}$ range. At lower temperatures, metal components may be substituted for ceramic components of the electrical interconnect structure. This substitution will provide longer cell lifetimes, simpler fabrication methods, and more favorable tolerance for thermal gradients.

Optimized designs will minimize the thermo-mechanical stress within the various ceramic components of the fuel cell stack. We will integrate simple, practical gasoline and diesel reformers and improved ceramic processing methods in the fuel cell system. These improvements will contribute to lower cost, higher efficiency, and more practical fuel cell systems. Our current estimate for the initial cost of a $5 \mathrm{~kW}$ to $10 \mathrm{~kW}$ solidoxide fuel cell system is about $\$ 2000 / \mathrm{kW}$, and our goal is to eventually reduce this cost to less than $\$ 400 / \mathrm{kW}$. 
Solid-Oxide Fuel Cell Stack Observatory. The observatory will evaluate parameters that influence the cell and stack performance, reliability, degradation modes, and the physical, chemical, mechanical, and electrical interactions during the nominal and transient operations of solid-oxide fuel cell stacks. The observatory will monitor electrodic processes in reformed fuels under internal oxidation and direct oxidation conditions. Thermal outcome also will be monitored during stack operation. Mechanical stresses generated during thermal cycling will be observed and computed to develop an operating model for development of robust stack configurations.

Component Fabrication and Assembly for High-Power-Density Solid-Oxide Fuel Cells. Key ceramic components fabrication capability will be enhanced for a high-powerdensity solid-oxide fuel cell through better understanding of stack operational mechanisms. Our goals are to 1) fabricate thin, anode-supported electrolytes; 2) fabricate ceramic and metal interconnect plates; and 3) assemble these components into operable solid-oxide fuel cell stacks. This research will help us better understand options for various designs and approaches for fuel cell stack components that can be readily adapted for high-volume manufacturing techniques. We successfully produced thin anode-supported electrolyte structures using tape casting, a high-volume manufacturing technique. A tape-casting method was developed to produce 4-inchsquare components, with 10-micron yttria-stabilized zirconia electrolyte supported on 400-micron-thick nickel-alumina-yttria-stabilized-zirconia anodes. These components produced flat, leak-free structures that could be manufactured in high volume. Cells configured in this manner could yield $0.5 \mathrm{~W} / \mathrm{cm}^{2}$ power density at $800^{\circ} \mathrm{C}$.

In-Stack Reforming for Solid-Oxide Fuel Cells. We are developing, fabricating, and testing a thick, porous anode that is compatible with other solid-oxide fuel cell components. The porous anode also will be coke-resistant, will have excellent electrochemical properties, and will have catalytic activity for internal reforming of methane.

Advanced Simulation and Modeling of Electrochemistry and Performance Assessment. The stack observatory will help us design and optimize the performance of solidoxide fuel cell components and stacks. We made substantial progress in modeling heat transfer in solid-oxide fuel cell stacks during rapid heat-up, a critical issue for mobile applications of solid-oxide fuel cells. Computational fluid dynamics modeling shows how to transfer enough heat into a stack to bring it to operational temperature within five minutes. Thermo-mechanical modeling shows whether the stack will fracture during rapid heat-up and helps us to develop strategies to modify stack designs to minimize stress concentration.

\section{Link to DOE Research Agenda}

Pacific Northwest National Laboratory's Fuel Cell Technology initiative responds to DOE Fossil Energy and DOE Office of Energy Efficiency and Renewable Energy mission needs for development and deployment of highly efficient and environmentally friendly solid-oxide fuel cell power generation systems and the zero emission goals of "Vision 21." The Laboratory's advanced capabilities in materials research and synthesis and system modeling have already proven highly effective in setting long-term program objectives. The solid-oxide fuel cell stack observatory will help us to establish a leadership role in advanced fuel cell research, system development capabilities, and large-scale testing. This laboratory will be a national user facility under the DOE Advanced Research and Technology Development Program.

\section{Infrared Sensing}

Pacific Northwest National Laboratory has established an initiative to advance the science and technology of detecting and identifying chemicals in the air and on surfaces. This initiative addresses key DOE missions, such as detecting and countering the proliferation of nuclear, biological, and chemical weapons; counterterrorism; support to law enforcement; environmental cleanup; and science research. Other national 
security needs are intelligence collection and targeting; battlefield defense against nuclear, biological, and chemical weapons use; and battle or collateral damage assessment. Key civil applications include atmospheric science, transportation issues, and industrial or agricultural process control. The national importance of improved national security capabilities is underscored by growth of federal funding for all remote chemical detection research from about $\$ 10$ million in 1992 to approximately $\$ 400$ million in fiscal year 2000 .

The Infrared Sensing initiative focuses on infrared optical sensing techniques, because remote chemical detection is needed for the most critical applications. Most of the molecular spectral features with sufficient differences for identification and enough strength for remote detection are found in the infrared part of the light spectrum. Infrared sensing research involves multiple science and engineering disciplines in three major areas of effort:

- Signatures identification determines the measurement requirements for a given application. It involves 1) analyzing the manufacturing or usage processes to determine the chemical identities, concentrations, forms, phases, and other parameters of initial chemical release; 2) quantifying the fate and transport of materials to determine applicable chemical reactions, hydrolysis products, photolysis products, aerosol formation and deposition, atmospheric transport, and other factors that determine the presence of certain target chemicals, the concentrations of targets, and optimal measurement locations; and 3) measuring the spectroscopic features to identify optical characteristics of target chemicals that may be exploited for detection and identification.

- Sensor development includes formulation of instrument and measurement platform concepts; concept performance evaluation; component technology development; system design, construction, and testing; and comparison of predictions with experimental results on scales from laboratory experiments using operational prototypes.

- Data exploitation involves extracting useful information from raw sensor data that may contain target and interfering ambient chemical information, artifacts of the sensor system and collection conditions, and other environmental factors. These data and associated data analysis algorithms are assembled as information extraction toolkits for operational use.

Significant advances in chemical detection capabilities are usually the product of careful integration of these activities in cohesive programs because the necessary prioritization of effort and appropriate technical choices in any particular area requires thorough understanding of the other two. Appropriate choices of optical wavelengths, laser and other technology, and sensing techniques, for example, require detailed knowledge of the signature chemicals and their spectroscopy, as well as the effectiveness of algorithms for reducing the noise in practical measurements of different types. Integration of these efforts into a Laboratory-wide initiative is, therefore, essential to realizing the synergy of Pacific Northwest National Laboratory's broad capabilities.

\section{Research Strategy}

Chemical sensing research and development is made up of three major branches of technical effort. Signatures identification consists of identifying the chemicals associated with the process of interest, understanding their evolution and distribution in the environment, and identifying appropriate optical or other properties to exploit for detection and identification. Sensor development addresses the science, technology, and engineering of sensing mechanisms and devices. Data exploitation involves extracting 
useful information from collected data, and establishing the minimum detectable concentrations, or certainties of detection, for a given device in a given scenario.

Signatures Identification. In terrorism or warfare scenarios, chemical weapons, biological weapons, and other pollutants may be present as condensates on surfaces or as suspended aerosols, because many of the substances involved have low vapor pressures. The infrared spectra of condensed materials are usually smeared beyond recognition by intermolecular forces. This smearing of spectral lines makes the chemicals difficult to detect and to identify using traditional infrared spectroscopy. However, polarization effects in reflected and scattered light from condensed materials on surfaces and in aerosols offer potential for improved sensing capabilities.

Sensor Development. Pacific Northwest National Laboratory staff recognized the limitations of conventional differential absorption techniques early in the development of remote chemical sensing technology, and focused research efforts on thorough understanding of spectroscopy and novel sensing methods. Many chemicals of interest have sharp spectral peaks associated with the $Q$ branches of molecular rotations and vibrations. The slopes of typical $\mathrm{Q}$ branches are sufficiently narrow and steep to eliminate spectral interference from other molecules or condensed matter in the background. In laboratory experiments, frequency-modulation spectroscopy techniques were found to provide excellent chemical detection sensitivity with less of the speckle and clutter that are associated with conventional differential absorption techniques. Practical chemical detection systems require highly stable lasers capable of producing substantial power at the precise wavelengths of relevant $\mathrm{Q}$ branch features, however, and such lasers were unavailable prior to recent developments by Lucent Technologies. We identified optimum lasers for remote sensing applications and established a partnership with Lucent.

We plan to develop additional capabilities in sensor concepts, system performance evaluation, and proof-of-principle demonstration. Our modeling and system performance capabilities will be strengthened for developing short-to-intermediate range airborne chemical sensors for proliferation detection, wartime intelligence collection, and other missions. We are focusing on heterodyne detection techniques while exploring the potential of chemical detection at short infrared wavelengths.

Data Exploitation. Few chemicals provide stand-alone proof of proliferation. Our ability to correlate chemical information with other types of intelligence is therefore critical, and we are working on techniques for facilitating and exploiting such correlations. The STARLIGHT data correlation and visualization software developed

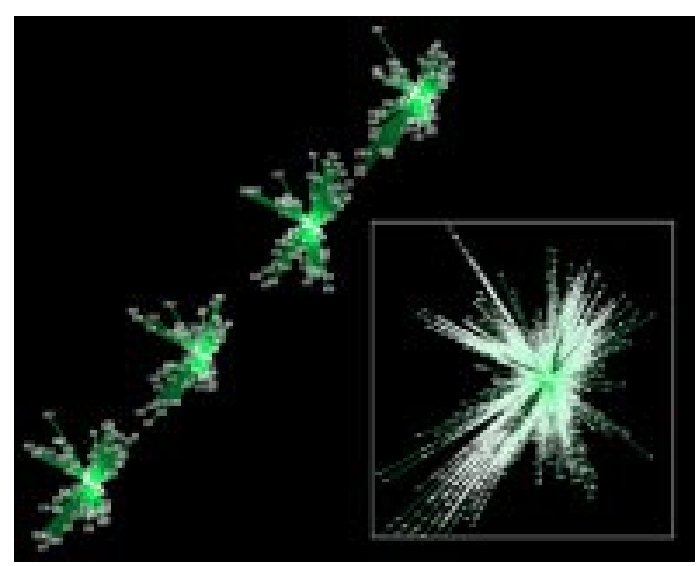

STARLIGHT is a powerful information visualization tool that clusters "like" information together. at Pacific Northwest National Laboratory is a useful platform for conducting this work. We are working on methods of automating imagery analysis and using overhead imagery to build three-dimensional computeraided design files of ground sites. If sufficient images of a given facility have been taken over long enough periods of time, a temporal axis can be added to provide time sequences of events that are likely to contain information about facility characteristics and use.

Skilled, multidisciplinary teams will be needed to extract chemical information from intelligence data. We will participate in DOE field measurement experiments using a new imaging spectrometer. Pacific Northwest National Laboratory has recently developed new capabilities in ground truth data analysis, and these could be applied using spectral libraries. 


\section{Link to DOE Research Agenda}

The central mission of the DOE Office of Nonproliferation Research and Engineering is developing technology for detecting and countering nuclear, biological, and chemical weapons proliferation, minimizing the consequences of their use, countering terrorism, and supporting law enforcement. Most nuclear, biological, and chemical weapons production activities, many narcotics production processes, and use of chemical weapons produce chemical effluents. The ability to detect and identify chemicals in the air and on surfaces is essential to detecting the production activities and minimizing the consequences of chemical weapons use, but current technology is lacking in sensitivity and range for many important applications. Our development of advanced chemical detection science, technology, and research and development capabilities is therefore directly linked to a critically important element of the DOE research agenda.

\section{Emerging Initiatives}

\section{Nanoscience and Technology}

Many areas of science and technology will be revolutionized by new opportunities to model, observe, understand, and manipulate material structures that have dimensions on the order of the size of molecules and molecular clusters. Nanoscience is an exciting new interdisciplinary area of research for studying materials, chemical processes, electronics, and the molecular components of living cells. It offers the ability to visualize, synthesize, and manipulate structures for a wide variety of technology applications.

Many distinctive and potentially useful phenomena and properties emerge as feature sizes approach the nanoscale level. These include the transport properties (momentum, energy, and mass) that extend from a continuum description to a molecular description. Similarly, the optical, electrical, magnetic, and chemical properties extend from a classical to a quantum description. By manipulating matter on a nanometer scale and by taking advantage of changes in these physical properties, it will be possible to develop nanoscale devices and materials that provide new capabilities, tools, and technologies. A major federal initiative in nanoscience and nanotechnology is under way to take advantage of and influence the development of this rapidly growing field.

Pacific Northwest National Laboratory is actively pursuing opportunities in nanoscience research in the areas of synthesis and fabrication of singular materials and materials systems, in the use of interface control to optimize properties of nanomaterials, and for exploitation of biology systems at the nanoscale. Under the Nanoscience and Technology initiative, we propose to strengthen the Laboratory's capabilities and form strategic alliances with other national laboratories and regional universities to enable scientists to make fundamental scientific contributions in synthesis and characterization-as well as theory, modeling, and simulation of nanoscale materials and processes. This initiative will actively support an expanded research and development agenda in DOE core mission areas. We anticipate that this initiative also will draw from Laboratory capabilities in material sciences and molecular biology. This initiative will help us to understand and exploit the nature of nanoscale systems and processes for

- developing improved chemical separations using nanoporous materials

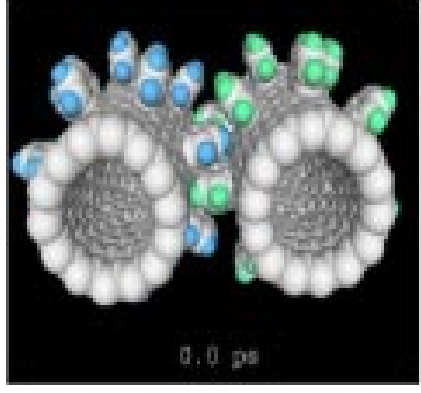

microdevices

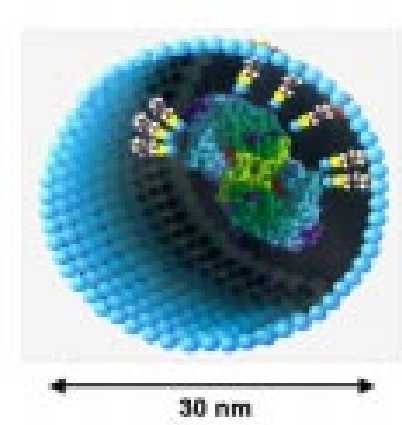

chemical sensors
The goals for the Nanoscience and Technology initiative are to build on technical strengths in synthesis, materials characterization, nanobiology, computations, and modeling; and develop exciting new applications for chemical synthesis, separations, sensors, photocatalysis, detecting biological warfare agents, energy production and storage, separations, microelectronic devices, and new materials. 
- combining engineered and self-assembled components into useful devices ranging from sensors to photocatalysts for water splitting

- accessing the properties of nanobiological systems such as enzymes, other proteins, and biochemical processes for better understanding of fundamental life processes and for developing new and useful products from these technologies.

Nanoscale Fabrication. The Laboratory is studying the formation and properties of engineered and self-assembled nanomaterials. Materials with dimensions on the scale of nanometers are strongly influenced by the high density of surfaces and interfaces. The distinctive Laboratory capabilities to control the interface structure of oxide and other films are being used to engineer the interfaces of materials to control both the materials' properties and physical structures. We are growing films of metal oxides and doped metal oxides with record porosity using ballistic deposition techniques. This capability comes from our chemical physics program and allows for the growth of new materials such as catalysts and support systems with tightly controlled dispersion. This capability also allows for the in situ study of transport phenomena in small (nanoscale) channels.

Nanobiology. We are interested in attaching recombinant enzymes to nanoporous materials as long-lifetime biological reactors for a variety of applications. We are analyzing the structure of individual biomolecules using a variety of single-molecule spectroscopies to better understand their properties and function in living cells. Our characterization capabilities are being expanded by integrating scanning probe techniques with optical spectroscopy (vibrational, second harmonic generation, and fluorescence) to allow high spatial resolution as well as chemical-state detection of nanoscale features.

Theory, Modeling, and Simulation. Advances in theory, modeling, and simulation at the nanoscale level are being pursued using high-performance computers, software, and algorithms to guide the design, synthesis, monitoring, and testing of nanoscale systems. Computational modeling will be used to simulate the quantum chemical reactions and molecular dynamics of materials and processes. These simulations provide insights into the phenomena that underlie the properties and reactivities of materials, and will aid in the design and optimization of new nanoscale materials. Our modeling and simulation effort is designed to directly support the experimental programs that are funded in the initiative.

\section{Imaging Science and Technology}

Image collection and analysis play an increasingly important role in scientific investigation, since digital imaging is a prime method for representing data and extracting key information for decision making. Continued scientific advancements in many fields depend on instruments that generate large, multidimensional images at various scales. Whether one is investigating environmental changes on the earth via satellites, the microstructure of advanced materials, or the function of human cells-the image analysis and information extraction challenges are similar. The search for greater information and insight has created new technical challenges that cannot be met using conventional imaging processing theories and visualization technologies. Although imaging science has made rapid progress in the past decade, the standard approaches used today to image and analyze digital information are still inadequate to handle the complicated tasks of fusing together and interpreting complex data that result from multiple sensors having differing spatial scales (pixel sizes), numerous spectral bands, and dynamic, time-dependent features.

A comprehensive response to these technical challenges requires research into new mathematical approaches for co-registering disparate images, fusing the relevant data, analyzing the combined features, and extracting the most pertinent information. These methods must be coupled with new computational approaches, information management tools, and visualization technologies to maximize our ability to gain insight from these 
complex information sources. Therefore, the purpose of the initiative is to establish Pacific Northwest National Laboratory as a national leader in imaging science and technology.

The Laboratory will develop new, fundamental image-processing theories, analytical methods, and algorithms that provide a solid, yet innovative scientific foundation for complex image collection, fusion, interpretation, and analysis. We will then develop software tools that process complex image data, identify key features and uncertainties, and enable analysts and decision makers to construct more accurate, rapid, and meaningful decisions.

New imaging technology will have many applications. It will support DOE's new Multispectral Thermal Imager satellite, which carries a sophisticated satellite that collects day and night images of earth in 15 spectral bands ranging from the visible to long-wave infrared. It also will be applied to the new cellular imaging system in the EMSL that combines optical microscopy with highresolution nuclear magnetic resonance spectrometry.

\section{Research Strategy}

The Imaging Science and Technology initiative will support the Laboratory's strategic objectives by

- advancing our ability to accurately fuse, co-register, and calibrate images from multiple imaging sensors in a way that preserves the underlying physics of sensing mechanisms and illuminates the characteristic of the image target

- developing tools that automatically extract and classify features from multisensor imagery

- developing decision-support technologies that enable analysts and decision makers to interact with three-dimensional visualizations of imagery data, visualize the uncertainty associated with image features, and explore the time-change history and scientific pedigree of image data.

These objectives will be met by conducting research and technology development in five areas that are common to virtually all imaging applications: 1) fundamental mathematical theories of imaging science; 2) phenomenology - the interaction of real-world properties and sensor physics; 3) image-to-image geometric registration and calibration; 4) automatic feature extraction, such as earth imagery of roads, rivers, structures, and land cover; and 5) data fusion, visualization, and information extraction.

This initiative builds on and strengthens our current capabilities in remote sensing, information technology, visualization, and statistics. We pioneered "Comparative Information Theory," an approach to image science and processing that is ideally suited to multisensor image analysis and the requirements of future image-analysis systems. We will expand these capabilities by implementing the method of "random computing using software agents and transaction control," a new approach to parallel computing that is flexible, robust, and effective on dynamic and poorly defined imaging problems. These innovations will be integrated with our pioneering work in image visualization and statistical analysis to create a new generation of analysis and visualization capabilities. 


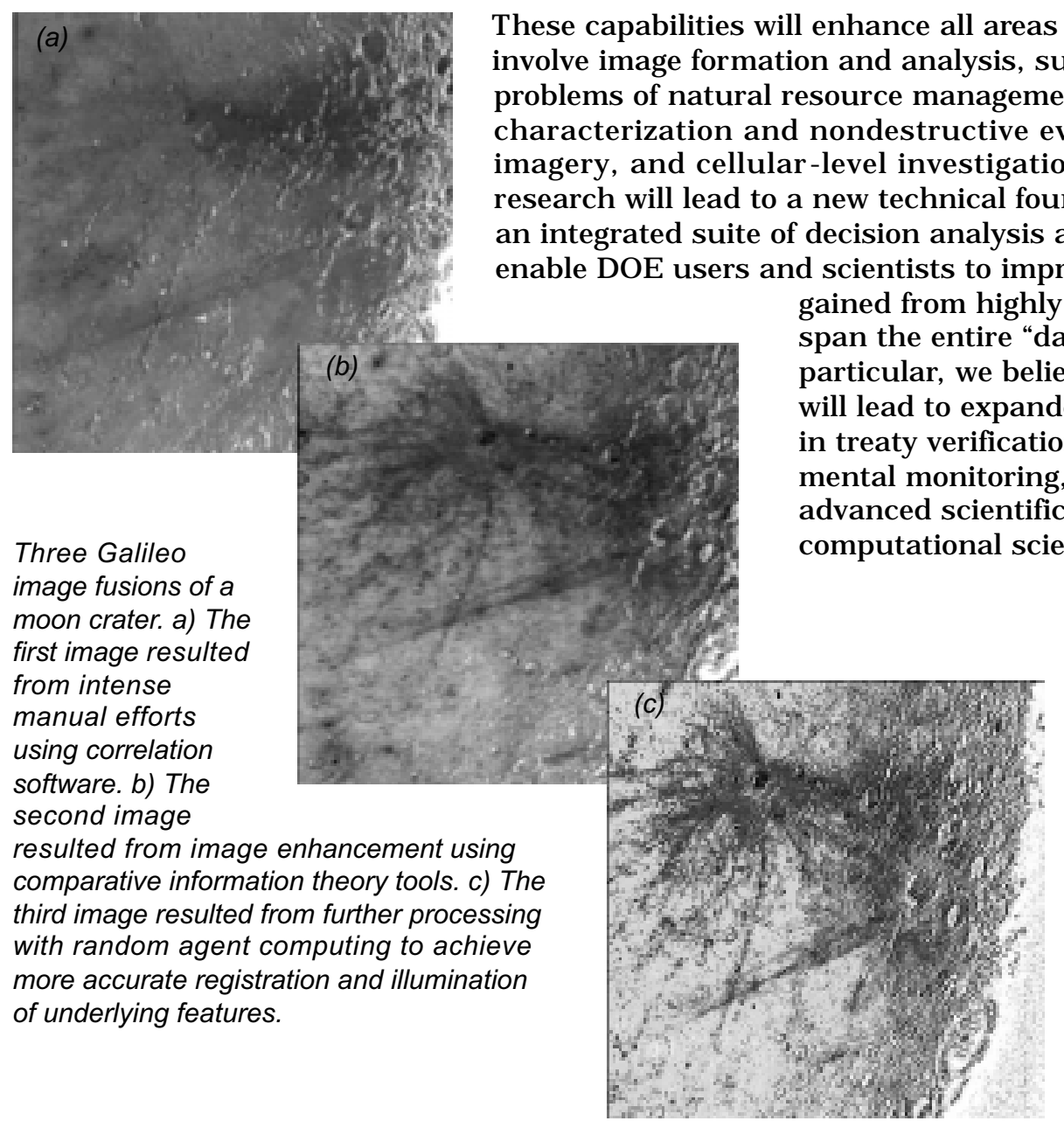

These capabilities will enhance all areas of Laboratory research that involve image formation and analysis, such as the complex practical problems of natural resource management, global change, materials an integrated suite of decision analysis and support tools that will mprove scientific understanding gained from highly complex imagery and to span the entire "data-to-decision" process. In dvanced scientific instrumentation, and engineering.

\section{Transitioning Initiatives}

\section{Cyber Security}

The Administration recognizes that combating terrorism is one of its highest policy and budgetary priorities. A recent Presidential Directive $^{(a)}$ calls for a national effort to ensure the security of increasingly vulnerable and interconnected critical infrastructures. Another Directive ${ }^{(b)}$ reinforces the missions of the United States federal agencies (including DOE) with roles related to defeating terrorism-including increasing infrastructure security, enhancing response capabilities, and protecting the computer-based systems that lie at the heart of America's economy.

Critical infrastructures are the physical and cyber-based systems that are essential to the operations of the economy and government. They include, but are not limited to, telecommunications, energy, banking and finance, transportation, water systems, and emergency services, both governmental and private. Historically, many of the nation's critical infrastructures have been physically and logically separate systems with little interdependence. As a result of advances in information technology and the necessity of improved efficiency, these infrastructures have become increasingly automated and linked. The massive interconnection of computerized communications and information networks across the public and private sectors has increased the vulnerability of the entire system and has provided existing and potential adversaries with a means for attacking United States interests.

The objective of the Cyber Security initiative is to enhance Pacific Northwest National Laboratory's capabilities in information assurance and infrastructure protection, automation of cyber attack-and-defend tools, and cyber forensics. Technologies and

(a) The White House, Presidential Decision Directive 63 "Protecting America's Critical Infrastructures," 22 May 1998.

(b) The White House, Presidential Decision Directive 62, "Combating Terrorism," 22 May 1998. 
techniques have been developed to 1) safeguard key elements of critical infrastructures from exploitation, degradation, and denial of services; 2) support command and control functions; and 3) protect friendly information assets and infrastructure from adversaries. Research and development activities have focused on intrusion analysis tools to fully characterize intruders and countermeasures and mitigating strategies for technology vulnerabilities. Our activities also have focused on the establishment of a flexible, modular, and interoperable command and control workspace environment to successfully detect, defend against, and mitigate or neutralize attacks on an organization's information and infrastructure functions and systems.

Under this initiative, an information security research facility was established at Pacific Northwest National Laboratory. This research facility has an isolated computer network with a broad range of

(

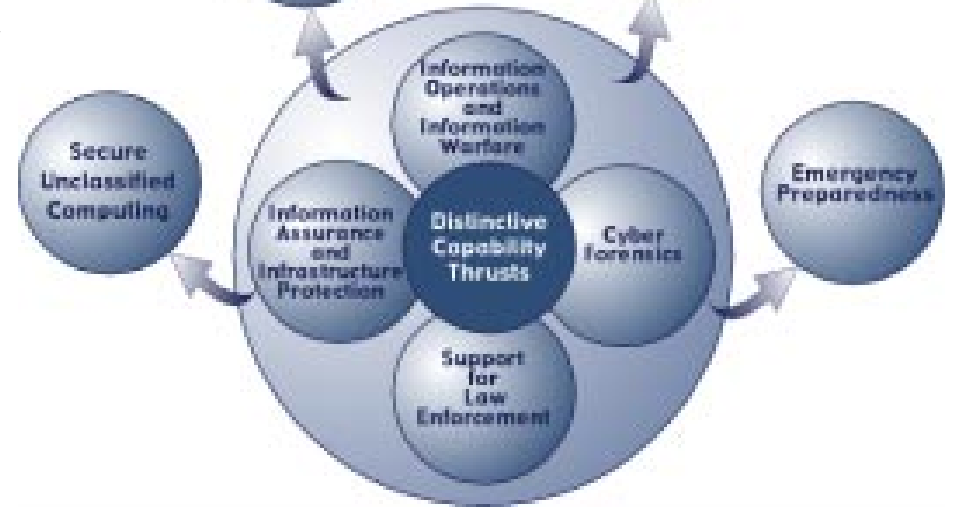

Capabilities developed under the Cyber Security initiative enhance our strengths in information and computer sciences, and support primarily our national security research.

computer platforms and systems so that vulnerability testing and research can be performed without the constraints imposed on an open network. This facility enables the unimpeded vulnerability testing of new software agents and tools, and "carbon copies" of clients' computer systems and networks. Our technical approach allows for testing a full attack on target systems within the facility-permitting an extreme level of stress testing.

These core technical capabilities form the foundation for Pacific Northwest National Laboratory's continued growth and increased visibility in the cyber security arena, and provide DOE with the means for protecting the nation's critical infrastructures from a variety of cyber-related threats.

\section{Microsystems Science and Engineering}

Pacific Northwest National Laboratory will continue the development and utilization of capabilities to design, fabricate, and test compact energy conversion and chemical processing systems based on incorporated, engineered microstructures.

\section{Strategic Intent}

The strategic intent of the Microsystems Science and Engineering initiative is to strengthen capabilities for developing miniature energy and chemical systems. This initiative supports DOE missions related to

- energy production (miniature hydrogen production systems for fuel cells)

- heating and cooling (miniature heat pumps for buildings and automobiles)

- carbon management (compact natural gas processing and carbon dioxide collection systems)

- energy-efficient chemical processing (compact reactors, heat exchangers, and separations systems)

- environmental cleanup (miniature chemical separations systems).

Thermal and chemical systems may be miniaturized by capitalizing on high rates of heat and mass transfer available in certain microstructures. Examples include 


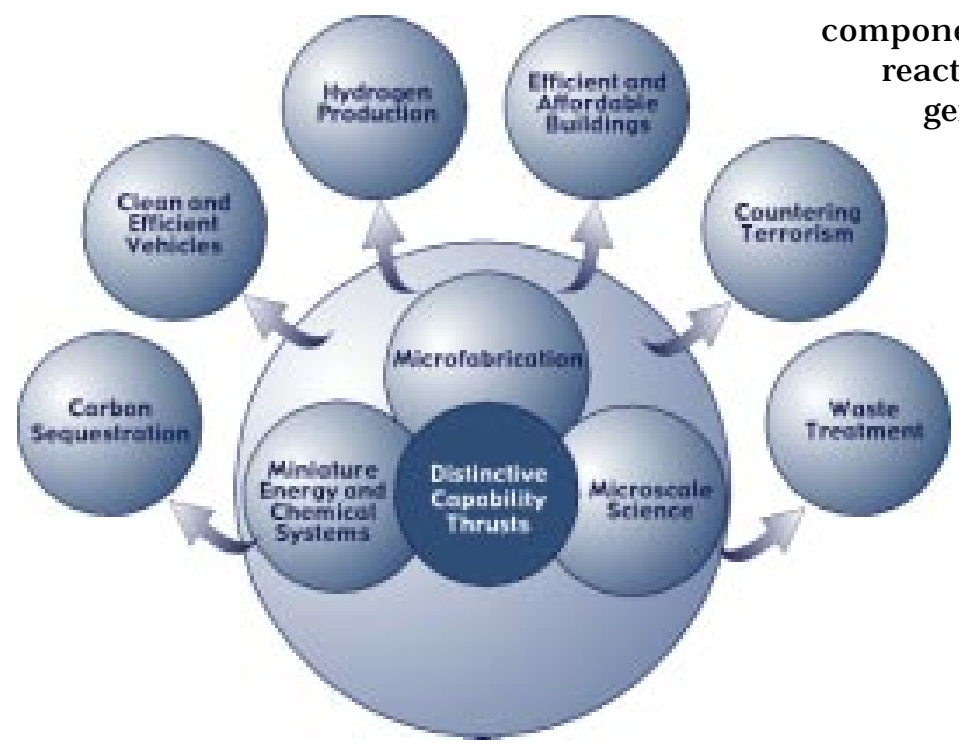

Capabilities developed in Microsystems Science and Engineering support all of DOE's mission areas with particular emphasis on the energy research and development portfolio. mponents such as heat exchangers, chemical reactors, separation devices, gas absorbers, gas generators, and combustors. These components may be incorporated into miniature combustion systems, absorption heat pumps, engines, fuel processors for hydrogen production, chemical separators, and carbon dioxide absorbers.

\section{Expected Outcomes}

This transitioning initiative provided the foundation for several new projects at the Laboratory. Microsystem technologies provide opportunities to realize economies of mass production. Rapid heat and mass transport enabled improvements in energy conversion, chemical processing, and distributed processing for energy-efficient technologies that reduce reliance on fossil fuels and associated emissions.

\section{Scientific and Technical Challenges}

Although miniaturized systems for rapid heat and mass transport have attractive applications, many technical obstacles have yet to be overcome. The preferred materials for microchemical and thermal systems are not well suited for micromachining and fabrication. Fluid mechanics at the microscale scale is not very well understood, and substantial scientific and modeling expertise is needed to design reliable chemical and thermal systems. An interdisciplinary approach was taken to address these challenges.

\section{Major Accomplishments}

This initiative established the capability to develop microchemical and thermal systems. The Laboratory achieved international recognition and took a leading role in conferences on microtechnology. Projects were funded by DOE and the Army on microchannel fuel processing components for fuel cells, by the National Aeronautics and Space Administration for compact propellant and oxygen production on Mars, and by the Defense Advanced Research Projects Agency for microchannel combustors, fuel processors, and heat pumps. Six U.S. patents were granted, and others are pending. Proof-of-principle demonstrations were conducted for microchannel heat exchangers, reactors, and separations units. Microchannel steam reforming in extremely compact units was proven to be feasible, opening up the possibility for distributed, low-cost hydrogen production. Preliminary studies showed that low-temperature enzyme catalysts and self-assembling coatings could be manufactured. Two R\&D 100 Awards were received recognizing advances in microchemical and thermal systems. A series of annual, international conferences on microreaction technology was established by the American Institute of Chemical Engineers and its German equivalent. One of the chairmen of the conference is a Laboratory staff member. 


\begin{tabular}{|c|c|c|c|c|c|c|c|}
\hline \multicolumn{8}{|c|}{$\begin{array}{l}\text { Pacific Northwest National Laboratory Initiatives }{ }^{(a)} \\
\text { (Budget Authorization Dollar Amount in Millions) }\end{array}$} \\
\hline Initiative & \multicolumn{7}{|c|}{ Fiscal Year } \\
\hline \multicolumn{8}{|l|}{ Biological Sciences } \\
\hline Office of Science & 0.5 & 3.5 & 5.8 & 6.7 & 7.9 & 9.0 & 10.0 \\
\hline Office of Environmental Management & 0.0 & 0.0 & 0.5 & 1.0 & 2.0 & 2.5 & 3.0 \\
\hline Office of Environmental Safety \& Health & 0.0 & 0.0 & 0.3 & 0.5 & 0.7 & 0.8 & 1.0 \\
\hline Nonproliferation and National Security & 0.0 & 0.0 & 0.3 & 0.7 & 1.0 & 1.0 & 1.2 \\
\hline Other Federal Agencies & 0.0 & 3.1 & 3.8 & 4.4 & 7.0 & 8.9 & 10.0 \\
\hline Capital & 0.0 & 0.0 & 1.5 & 1.2 & 2.0 & 3.0 & 4.0 \\
\hline Total Environmental Health & 0.5 & 6.6 & 12.2 & 14.5 & 20.6 & 25.2 & 29.2 \\
\hline \multicolumn{8}{|l|}{ Computational Sciences and Engineering } \\
\hline Office of Environmental Management & 1.0 & 2.1 & 2.2 & 2.2 & 2.2 & 2.2 & 2.2 \\
\hline Office of Science & 0.4 & 1.8 & 6.0 & 11.0 & 12.0 & 17.3 & 17.3 \\
\hline Energy Efficiency and Fossil Energy & 0.0 & 1.1 & 3.4 & 10.4 & 10.4 & 10.0 & 10.0 \\
\hline Nonproliferation and National Security & 0.1 & 0.0 & 0.3 & 0.3 & 0.3 & 0.0 & 0.0 \\
\hline Department of Defense & 0.2 & 0.0 & 0.2 & 0.0 & 0.0 & 0.0 & 0.0 \\
\hline Other Federal Agencies & 0.0 & 0.4 & 0.0 & 0.0 & 0.0 & 0.0 & 0.0 \\
\hline Office of Science Capital & 0.0 & 0.0 & 4.2 & 5.0 & 8.0 & 18.0 & 18.0 \\
\hline $\begin{array}{l}\text { Total Computational Sciences } \\
\text { and Engineering }\end{array}$ & 1.7 & 5.4 & 16.3 & 28.9 & 32.9 & 47.5 & 47.5 \\
\hline \multicolumn{8}{|l|}{ Carbon Management } \\
\hline Energy Efficiency and Renewable Energy & 0.0 & 0.0 & 0.3 & 0.5 & 1.0 & 1.5 & 1.5 \\
\hline Office of Science & 0.0 & 0.5 & 1.0 & 1.5 & 2.5 & 3.0 & 3.0 \\
\hline Fossil Energy & 0.0 & 0.3 & 0.3 & 0.5 & 1.0 & 1.5 & 1.5 \\
\hline Total Carbon Management & 0.0 & 0.8 & 1.6 & 2.5 & 4.5 & 6.0 & 6.0 \\
\hline \multicolumn{8}{|l|}{ Fuel Cell Technology } \\
\hline Fossil Energy & 1.0 & 2.6 & 3.6 & 4.1 & 4.3 & 4.3 & 4.3 \\
\hline Energy Efficiency and Renewable Energy & 0.0 & 0.0 & 0.1 & 0.2 & 0.2 & 0.2 & 0.2 \\
\hline Department of Defense & 0.0 & 0.0 & 0.2 & 0.3 & 0.3 & 0.3 & 0.3 \\
\hline Total Fuel Cell Technology & 1.0 & 2.6 & 3.9 & 4.6 & 4.8 & 4.8 & 4.8 \\
\hline \multicolumn{8}{|l|}{ Infrared Sensing } \\
\hline Nonproliferation and National Security & 2.7 & 4.6 & 5.0 & 5.5 & 6.0 & 6.5 & 7.0 \\
\hline Defense Advanced Research Project Agency & 0.0 & 1.8 & 2.5 & 3.0 & 4.0 & 4.5 & 5.0 \\
\hline National Reconnaissance Office & 0.0 & 0.5 & 0.5 & 0.5 & 0.5 & 0.5 & 0.5 \\
\hline U.S. Geological Survey & 0.0 & 0.3 & 0.3 & 0.5 & 0.8 & 1.0 & 1.2 \\
\hline Total Infrared Chemical Sensing & 2.7 & 7.2 & 8.3 & 9.5 & 11.3 & 12.5 & 13.7 \\
\hline \multicolumn{8}{|l|}{ Nanoscience and Technology } \\
\hline Office of Science & 0.0 & 0.0 & 1.5 & 2.0 & 3.0 & 3.0 & 3.0 \\
\hline Nonproliferation and National Security & 0.0 & 0.0 & 0.5 & 0.5 & 0.9 & 0.9 & 0.9 \\
\hline Department of Defense & 0.0 & 0.0 & 2.5 & 4.0 & 4.1 & 4.1 & 4.1 \\
\hline National Aeronautics and Space Administration & 0.0 & 0.0 & 0.5 & 1.0 & 1.5 & 1.5 & 1.5 \\
\hline Department of Commerce & 0.0 & 0.0 & 0.0 & 0.5 & 0.5 & 0.5 & 0.5 \\
\hline Total Nanoscience and Technology & 0.0 & 0.0 & 5.0 & 8.0 & 10.0 & 10.0 & 10.0 \\
\hline
\end{tabular}




\begin{tabular}{|c|c|c|c|c|c|c|c|}
\hline \multicolumn{8}{|c|}{$\begin{array}{l}\text { Pacific Northwest National Laboratory Initiatives } \\
\text { (B) } \\
\text { (Budget Authorization Dollar Amount in Millions) }\end{array}$} \\
\hline \multirow[b]{2}{*}{ Initiative } & \multicolumn{7}{|c|}{ Fiscal Year } \\
\hline & 1999 & 2000 & 2001 & 2002 & 2003 & 2004 & 2005 \\
\hline \multicolumn{8}{|l|}{ Imaging Science and Technology } \\
\hline Nonproliferational and National Security & 0.0 & 0.0 & 0.1 & 0.2 & 0.6 & 1.5 & 2.0 \\
\hline Office of Intelligence (IN) & 0.0 & 0.0 & 0.0 & 0.1 & 0.2 & 0.3 & 0.4 \\
\hline Fossil Energy & 0.0 & 0.0 & 0.2 & 0.2 & 0.3 & 0.4 & 0.5 \\
\hline Office of Science & 0.0 & 0.0 & 0.0 & 0.0 & 0.3 & 0.5 & 0.5 \\
\hline Science and Technology Programs & 0.0 & 0.0 & 0.0 & 0.1 & 0.1 & 0.2 & 0.3 \\
\hline $\begin{array}{l}\text { National Reconnaissance/Imaging } \\
\text { and Mapping }\end{array}$ & 0.0 & 0.0 & 0.2 & 0.2 & 0.8 & 1.5 & 2.1 \\
\hline Department of Defense & 0.0 & 0.0 & 0.0 & 0.1 & 0.4 & 0.8 & 1.5 \\
\hline National Aeronautics and Space Administration & 0.0 & 0.0 & 0.0 & 0.1 & 0.3 & 0.5 & 0.5 \\
\hline Other Federal Agencies & 0.0 & 0.0 & 0.0 & 0.0 & 0.1 & 0.3 & 1.0 \\
\hline Total Imaging Science and Technology & 0.0 & 0.0 & 0.5 & 1.0 & 3.1 & 6.0 & 8.8 \\
\hline \multicolumn{8}{|l|}{ Cyber Security } \\
\hline Office of Security Affairs (SO) & 2.9 & 4.0 & 5.0 & 4.2 & 5.0 & 4.5 & 5.0 \\
\hline Office of Intelligence (IN) & 0.5 & 0.6 & 0.4 & 0.5 & 0.5 & 0.5 & 0.5 \\
\hline Office of Counterintelligence (CN) & 1.7 & 5.0 & 3.0 & 4.5 & 5.0 & 5.5 & 5.0 \\
\hline Department of Defense & 4.4 & 0.6 & 0.5 & 0.5 & 0.5 & 0.5 & 0.5 \\
\hline Federal Bureau of Investigation & 2.1 & 0.0 & 0.1 & 0.3 & 0.5 & 0.5 & 0.5 \\
\hline Total Cyber Security & 11.6 & 10.2 & 9.0 & 10.0 & 11.5 & 11.5 & 11.5 \\
\hline \multicolumn{8}{|l|}{ Microsystems Science and Engineering } \\
\hline Energy Efficiency and Renewable Energy & 1.2 & 1.2 & 1.8 & 2.2 & 3.0 & 4.0 & 5.0 \\
\hline Office of Science & 0.4 & 0.4 & 0.4 & 0.6 & 0.6 & 0.6 & 0.6 \\
\hline Fossil Energy & 0.0 & 0.0 & 0.3 & 0.5 & 0.8 & 1.3 & 1.5 \\
\hline Office of Environmental Management & 0.0 & 0.0 & 0.2 & 0.4 & 0.8 & 1.2 & 2.0 \\
\hline Laboratory Technology Transfer & 0.1 & 0.2 & 0.2 & 0.3 & 0.3 & 0.4 & 0.4 \\
\hline National Aeronautics and Space Administration & 0.2 & 0.6 & 1.0 & 1.5 & 2.0 & 3.0 & 3.5 \\
\hline Department of Defense & 3.0 & 4.0 & 4.5 & 5.0 & 5.0 & 5.0 & 5.0 \\
\hline Total Microsystems Science and Engineering & 4.9 & 6.4 & 8.4 & 10.5 & 12.5 & 15.5 & 18.0 \\
\hline $\begin{array}{l}\text { Total Pacific Northwest National } \\
\text { Laboratory Initiatives }\end{array}$ & 22.4 & 39.2 & 65.2 & 89.5 & 111.2 & 139.0 & 149.5 \\
\hline
\end{tabular}




\section{5 \\ Programmatic Strategy}

\section{Science}

\section{Strategic Intent}

In keeping with Pacific Northwest National Laboratory's continuing commitment to strengthen its fundamental science base, we focus our scientific enterprise to provide leadership, advance knowledge, and operate user facilities for national, high-impact initiatives in the environmental, energy, national security, and environmental health mission areas. Since increasing our emphasis on fundamental science in the mid1980 s, we have established preeminent capabilities within the Laboratory and for the Department of Energy in environmental molecular science and global change research. The Laboratory's first major DOE scientific user facility, the William R. Wiley Environmental Molecular Sciences Laboratory (EMSL), is serving a growing and scientifically productive user community. Pacific Northwest National Laboratory's scientific programs have grown in stature and impact with significant benefit to its intellectual vitality and demonstrated impact on our performance in all of DOE's missions. We intend to increase both the quality and impact of our programs, including significant investments to increase our capabilities in cellular and molecular biology, computational science, and nanoscience.

Over the next five years, we will support this strategic intent by

- enhancing our capabilities in the EMSL,

delivering forefront science and service to its growing user community interested in molecular and nanoscale science, and making EMSL a widely recognized facility in the DOE system

- revitalizing our life science capabilities, by focusing on the molecular processes involved in cell signaling, an important element of the science required to understand the impacts of environmental contaminants on living organisms

- strengthening our capabilities in computational science, with emphasis on molecular science, regional-scale climate prediction, subsurface contaminant transport and fate, computer science, applied mathematics, atmospheric chemistry and transport, modeling of living systems, and manufacturing simulation

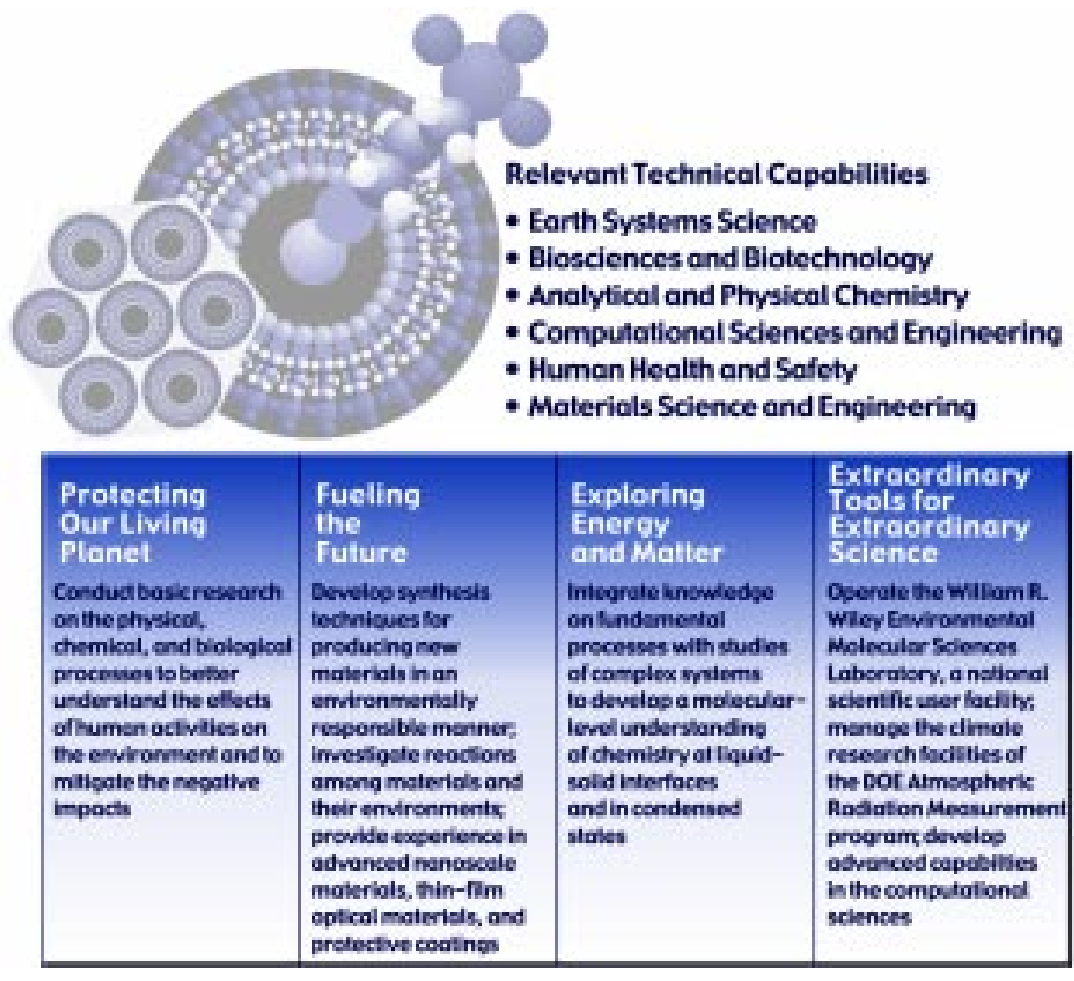

Science mission strategy. 

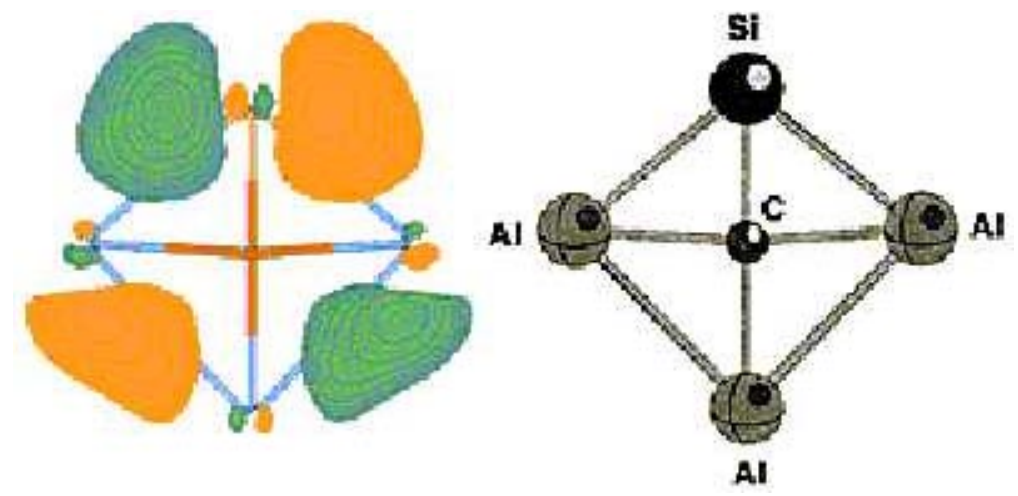

Thirty years ago theorists suggested the possibility of tetracoordinate carbon existing in a flat configuration, rather than the lower energy tetrahedral structure usually assumed by carbon in such molecules. Researchers at Pacific Northwest National Laboratory in collaboration with Washington State University, Utah State University, and University of Utah, have synthesized a series of simple molecules with a flat tetracoordinate carbon. These molecules have only five atoms, the fewest number possible. Such molecules have been considered intractable, because of bond strain. This simple planar molecule has carbon at its center and four aluminum ligands. The molecular orbital diagram of carbon surrounded by three aluminum and one silicon ligand shows the highest occupied molecular orbital formed by ligandligand interactions, which is crucial for stabilizing the planar structure.
- providing the greatest possible impact on climate and subsurface science, broadly construed, from basic understanding of physiochemical reactions and fundamental biogeochemical cycles to the complex, collective processes that impact global climate change and carbon sequestration

- developing new measurement capabilities that can serve as a focus for new facilities, particularly in cellular-molecular biology, enhancing the capabilities in the EMSL and Atmospheric Radiation Measurement facilities, and developing cross-institutional distributed facilities for ecological research in carbon sequestration.

With these efforts, we expect to continue to impact DOE's science and technology agenda with our research accomplishments and support critical efforts within the other DOE missions.

Our experience is proving that microtechnology and nanoscience research facilities such as the EMSL can play a valuable role in the nation's science and technology infrastructure. Over this planning period, we intend to explore and, if promising, develop the concept for a new research facility to provide novel high-resolution imaging and other equipment for fundamental life sciences research.

The DOE science mission comprises both basic and applied components. This section addresses Pacific Northwest National Laboratory's basic research supported by the Office of Science. To accomplish this research, we will employ a programmatic strategy with five central elements.

- We will use our strong culture of peer review and commitment to excellence to deliver top-quality science with significant impact on DOE mission needs.

- We will strengthen our involvement in the nation's basic research enterprise through effective operation of the EMSL and Atmospheric Radiation Measurement facilities, through strong partnerships with our colleagues at research universities and other national laboratories, and by participating in the training and educating of the next generation of scientists.

- We will take a "grand challenge" approach, building broad, interdisciplinary programs that target central and scientifically demanding problems-factors that control climate change and impact the carbon cycle; the interaction of molecules in complex, dynamic systems; the interaction of environmental contaminants with the genome; and the need to develop efficient, environmentally sound energy systems.

- We will help to demonstrate and communicate the value of DOE research programs to the public. In this spirit, basic science presented in this section will convey the impact of the accomplishments within the DOE research missions.

- We will ensure our continued ability to operate complex scientific laboratory facilities by conducting our research in a safe and environmentally responsible manner. 


\section{Our Role in Supporting the Themes and Challenges of DOE Science}

Research at Pacific Northwest National Laboratory is well aligned with the research themes and challenges of the Office of Science: Protecting Our Living Planet, Extraordinary Tools for Extraordinary Science, Exploring Matter and Energy, and Fueling the Future.

\section{Protecting Our Living Planet}

This theme has been, is currently, and will continue to be central to the research programs at Pacific Northwest National Laboratory. We already have significant accomplishments in environmental molecular science, global change, atmospheric chemistry, and subsurface science. We intend to expand our accomplishments through the application of physical chemistry tools and capabilities and knowledge garnered from the Human Genome project to address and to understand the molecular and cellular basis of the interaction of living organisms with their environment.

Simulating complex biogeochemical processes in natural systems from first principles (molecular dynamics) is both a fundamental theme and scientific challenge in our subsurface science research. We expect to increase emphasis on research to significantly improve our ability to predict and assess the effects of increasing atmospheric concentrations of greenhouse gases on the earth's climate and on the life support systems that depend on it. We also expect to increase research to build the necessary knowledge base for managing natural environmental processes that optimize the sequestration of atmospheric carbon and on using biological systems to reduce society's dependency on fossil fuels.

Our broad-based capabilities will support three challenges identified by the Office of Science: the sources and fate of energy products, impacts on people and the environment, and prevention and protection. These challenges are described in the next paragraphs.

\section{Sources and Fate of Energy Products}

We will provide accurate physical descriptions of the processes and the life cycles of materials involved in the production and use of energy as well as the activities of the Department of Energy. We will continue to conduct research on fundamental geological, atmospheric, and biological processes to better understand how energy-derived byproducts are transported, concentrated, and localized in subsurface, atmospheric, ocean, and terrestrial environments. Using state-of-the-art tools and facilities, we are studying subsurface science and bioremediation, waste processing and chemistry, climate change, air pollution chemistry and transport, and the transport and transformation of toxic substances in the biosphere.

Research in carbon sequestration establishes the scientific basis for enhancing carbon capture and long-term storage in terrestrial ecosystems and wetlands. Work is under way to identify and characterize links between critical molecular, eco-physiological, and ecosystem processes to better assess and manage sequestration potential and its ecological and socioeconomic impacts.

Research in the area of subsurface science is developing a molecular-level understanding of the surface chemistry and reactivity of environmentally important mineral phases and is coupling that research with advanced transport models. These investments have made Pacific Northwest National Laboratory an international leader in subsurface science and continued its leadership in the Natural and Accelerated Bioremediation Research program. As a result, our scientists provide national technical leadership for the Hanford Vadose Zone project, a major DOE site cleanup issue, where we are translating this knowledge into predictive models that yield usable results for decision makers. 
Our researchers also play a major role in the Environmental Management Science Program. Much of our success is attributed to multidisciplinary research teamsscientists who explore the natural interfaces and interactions of chemistry, biology, geology, and physics. A strong computational emphasis is central to exploring these complex systems.

An example of this multidisciplinary approach is our research directed at understanding the fundamental mechanisms of microbial attachment to mineral surfaces. This research involves geochemistry and microbiology to describe the basic interfacial interactions between the microbial membrane and the mineral surface, atomic force microscopy to measure the force potential between the microorganism and mineral surface, and computational science to upscale measurements of the force potential to kinetic-based parameters that can be applied to groundwater models. This multidisciplinary approach has accelerated advances in environmental sciences and has led to the Laboratory's strong role in DOE's environmental sciences research.

In geosciences research, we are developing a molecular-level understanding of the surface chemistry and reactivity of environmentally important mineral phases, particularly the surface chemistry of carbonate minerals. The incorporation of contaminants such as heavy metals and radionuclides into mineral crystals is an important process affecting contaminant movement through soils and groundwater, and is controlled by the structure and availability of surface sites on the mineral. On a mineral face, crystal growth may reduce surface symmetry and generate multiple, structurally distinct incorporation sites having different preferences for contaminants. Incorporation systematics of highly mobile uranyl complexes on a specific face of calcite were studied using advanced instrumentation in EMSL. This work showed multiple coordination environments and differential incorporation of uranyl carbonate. Our understanding

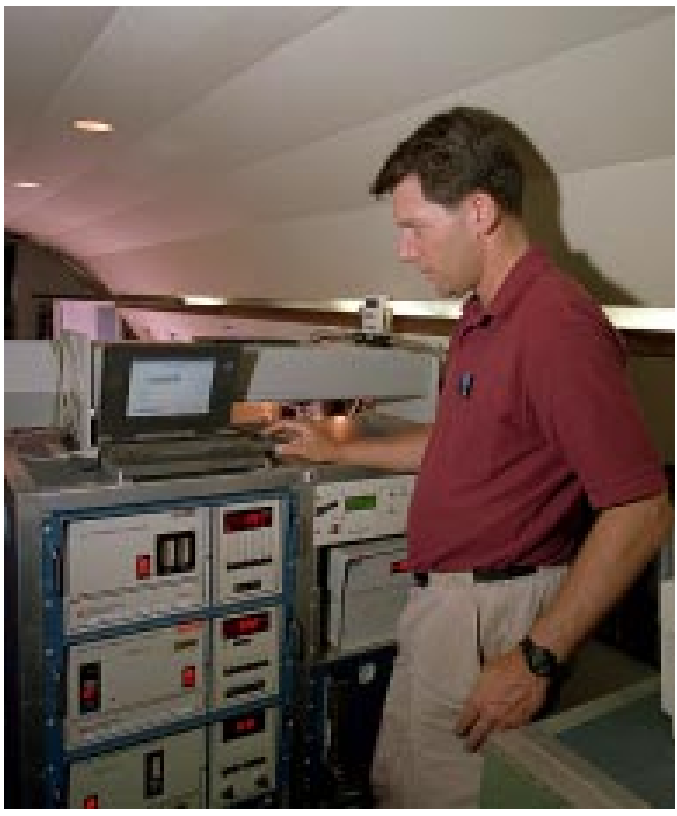

Sophisticated analytical equipment for measuring atmospheric phenomena and other conditions is located inside the Grumman Gulfstream 1 aircraft operated by the Laboratory as a DOE research aircraft. of differential incorporation of uranyl complexes by a common mineral such as calcite is important for modeling the transport of such contaminants in the environment.

In the computational area of our geosciences research, emphasis has been placed on the transfer of information from the molecular scale to the macroscopic or thermodynamic level. The upscaling of information across such time and length scales is one of the most challenging problems facing researchers. We are applying molecular level information to in-the-field environmental problems. This work requires close integration of experimental and computational approaches.

In the atmospheric sciences, the research frontiers are the interactions between meteorology and atmospheric chemistry and in the transformation of pollutants into particles that affect visibility, climate processes, and human health. Over the planning period, we expect to contribute to the Environmental Meteorology program and the emerging focus on tropospheric aerosols. In these areas, we will bring to bear our capabilities in field research, including our Gulfstream 1 aircraft, computational modeling of both meteorology and chemical processes, and the distinctive analytic capabilities of the EMSL. 
Programmatic Strategy

\section{Impacts on People and the Environment}

The effects of energy-derived products range from the direct effects of radiation and pollutants on living organisms to the more indirect effects that are manifest as climate is altered by the increasing concentrations of greenhouse gases. Pacific Northwest National Laboratory programs address many of the most difficult of these problems.

Understanding the physics of climate change as it is driven by increasing greenhouse gas concentrations requires a detailed understanding of the multiple feedback processes initiated by the seemingly small changes in the atmospheric energy balance caused by carbon dioxide increases. The most important of these feedbacks involves the impact on the hydrologic cycle, most notably the increase in water vapor concentration in a warmer atmosphere and, most uncertain, the distribution and properties of clouds in this wetter and warmer atmosphere. The Atmospheric Radiation Measurement program, a multilaboratory effort with considerable involvement of universities and other agencies, is enlarging our understanding of clouds and their impact on atmospheric radiation. We currently provide leadership for this program in both the scientific and operational components and will continue in that role.

In the next few years we expect to play a much larger role in the scientific investigations related to climate change. We will continue research on improving remote sensing of atmosphere and cloud properties, parameterizing cloud processes, and elucidating the role of surface properties in the formation of clouds. In addition, we are developing a state-of-the-art mobile remote sensing facility that includes dual-wavelength millimeter radar, dual-wavelength lidar, and passive radiometry. This facility can be used locally or deployed nationally and internationally to carry out research on the hydrologic cycle. We also will perform a range of atmospheric research on the regional and global consequences of climate change. Regional and global general circulation models support investigations into how clouds, trace gases, and aerosols affect global climate and how changes in the global climate are expressed at the regional scale. The regional models provide essential coupling between the greenhouse gas drivers and the effect on human systems, such as agriculture.

On the human effects side of the equation, our research in molecular toxicology examines mechanisms by which hazardous physical and chemical agents affect living systems. The emphasis of this research is on determining the molecular basis of receptor-mediated processes at the cellular level. We will employ a multilevel approach to investigating the human health impacts and risks associated with the environment, incorporating studies from the molecular to the whole-animal level. Using dosimetric, molecular, cellular, and intact animal analytical techniques, we are gaining a quantitative understanding of mechanisms underlying the health effects of chemical and physical agents.

To expand our capabilities, our biological sciences initiative integrates biology in the post-genome era of discoveries with new developments in measurement, computational, and modeling science. The genome produces a wealth of information, but this information cannot be fully utilized until we understand the role and function of the proteins coded by these genes. Our scientific emphasis is to identify and describe the proteins involved in cell signaling. This initiative will lead to the ability to observe molecular processes inside of living cells, to model complex living organisms at the level of cellular control, and to evaluate the expression of genetic control, as manifest in the proteome, in response to environmental changes.

Our initial work in proteomics focuses on microbial systems-identifying proteins in the cell and understanding the protein's structure and function. We are particularly interested in the cell's ability to repair DNA damaged by low-dose exposure to radiation and environmental pollutants. This research relies on the advanced protein characterization capabilities in EMSL and integration with new computational capabilities that will allow us to track the interdependent and overlapping reaction pathways in the cell. 
These capabilities may serve as the basis for a new research facility at some time in the future, but will most certainly allow the exploitation of the results from the human genome and contribute substantially to the DOE network of life science investigators. An important manifestation of this contribution will be to allow Pacific Northwest National Laboratory researchers to explain the effects of low-dose exposures to contaminants. Such exposures may be occupational exposures or those received through the environment and may either be the result of ionizing radiation or chemical exposure.

\section{Prevention and Protection}

We will provide innovative approaches for preventing the deleterious effects of energy use, mitigating its injurious outcomes, and protecting our environment, both current and in the future. The Laboratory's strengths in environmental biotechnology include well-integrated capabilities in microbial and plant sciences, enzymology, and genomics. These capabilities are applied to environmental restoration, pollution minimization, and waste processing research.

To environmental biosciences, we bring strong capabilities in radiation measurement and radiochemistry, mass spectrometry (organic and inorganic), magnetic resonance spectrometry, laser spectroscopy, surface instrumentation, and distinctive computational capabilities. These multiple strengths combine scientific and technical support for research programs in carbon management and form the basis of our leadership in the Oak Ridge-Argonne-Pacific Northwest National Laboratory collaboration in the study of the sequestration of carbon in terrestrial ecosystems.

Our groundbreaking work in the development of integrated assessment of climate change will continue to be useful in understanding the policy options available for minimizing and mitigating climate change. This capability will help us better understand the role of technology in stabilizing of greenhouse gas concentrations at internationally acceptable levels.

Prevention and protection also motivate Pacific Northwest National Laboratory's role as a major provider of science and technology for cleanup of DOE weapons production sites. The Laboratory performs research in all aspects of the cleanup, including designing novel separations agents for waste processing, understanding radiation effects in ceramic waste forms, understanding tank waste chemistry, and researching and improving passive cleanup strategies such as bioremediation and reactive barriers. In addition, our environmental statistics research provides the foundation for comprehensive environmental cleanup plans used by DOE, the Army, and the Environmental Protection Agency. By implementing statistically based decision tools, policymakers may construct scientifically defensible cleanup plans, arrive at statistically sound estimates of uncertainty, streamline regulatory agency acceptance of cleanup plans, and provide a basis for balancing decision uncertainty with available resources. These actions will help reduce cleanup costs.

\section{Extraordinary Tools for Extraordinary Science}

Pacific Northwest National Laboratory's next important contribution to the Office of Science themes is its support of Extraordinary Tools for Extraordinary Science. We are leading efforts to define the next generation of user facilities to support environmental and health sciences, in line with DOE's traditional facility and capability stewardship in the physical sciences. We successfully operate EMSL, a national scientific user facility that is essential to achieving DOE's environmental quality, science, and technology objectives. The EMSL is recognized as a vital user facility with a broad range of capabilities in environmental molecular science. In addition, the Laboratory is a key participant in managing and operating the climate research facilities of DOE's Atmospheric Radiation Measurement program. We also have undertaken, through the Pacific Northwest Consortium-Collaborative Access Team, the development of two beam lines at the Advanced Photon Source at Argonne National Laboratory. 
Over the past two decades, computational modeling and simulation have emerged as the third leg of a triangle, together with two other legs (experiment and analytical theory), that represent the modern scientific endeavor. DOE has led the way with its investments in computational facilities and in high-performance software and tools. The Laboratory has created a strong focus on the development of advanced computational tools for modern high-performance computer architectures. Areas of research include computational chemistry, subsurface reactive transport, atmospheric chemistry and climate modeling, mathematical tools (including new types of grid technologies), tools to support program generation on and optimal use of massively parallel computers, and novel data analysis and visualization techniques. This research facilitates, for example, remote collaborations in computational biology and advanced manufacturing methods using new "collaboratory" tools.

To design scalable, portable, and high-performance software for massively parallel computers, a new software development paradigm was developed. This paradigm employs groups of users, domain software, theory specialists, computer scientists, and applied mathematicians to develop software that meets the Laboratory's research needs.

\section{Instrumentation for the Frontiers of Science}

Two notable areas of Pacific Northwest National Laboratory's advanced instrumentation are found in the EMSL and the Atmospheric Radiation Measurement program.

The EMSL campus offers-at one location-a comprehensive array of leading-edge resources for research in the environmental and molecular sciences. Users may define combinations of equipment and capabilities from eight facilities that best meet their own special needs. Resident scientists and engineers provide a network for collaboration with users. Over 1200 scientists from universities, other national laboratories, and industry made use of the EMSL during its third year of operation.

Resources available to users and resident staff include these research facilities:

- Gas- and Liquid-Phase Monitoring and Detection Facility for monitoring and detecting trace species in complex matrices

- High-Field Magnetic Resonance Facility for investigating molecular structure, function, and response

- High-Field Mass Spectrometry Facility for detecting and measuring biomolecules and their environmental stimuli

\begin{tabular}{|c|c|c|c|}
\hline \multicolumn{4}{|c|}{ Experimenters at Designated User Facilities - 2000} \\
\hline & $\begin{array}{c}\text { Number of } \\
\text { Experimenters }\end{array}$ & $\begin{array}{c}\text { Number of } \\
\text { Organizations }\end{array}$ & $\begin{array}{c}\text { Percentage } \\
\text { of Use }\end{array}$ \\
\hline \multicolumn{4}{|c|}{ William R. Wiley Environmental Molecular Sciences Laboratory } \\
\hline Laboratory & 248 & & 20 \\
\hline Other Federal Laboratories & 121 & 23 & 10 \\
\hline University (U.S.) & 708 & 103 & 57 \\
\hline Industry (U.S.) & 154 & 17 & 13 \\
\hline Total & 1231 & 143 & \\
\hline Remote Users & 640 & & 48 \\
\hline Visiting Users & 591 & & 52 \\
\hline Total & 1231 & & \\
\hline
\end{tabular}


- Interfacial Structures and Compositions Facility for characterizing interfaces at the molecular level

- Molecular Science Computing Facility for computational simulation of complex phenomena

- Nanoscience and Technology Facility for fabricating and characterizing materials and systems with dimensions on the nanometer length scale

- Optical Imaging and Spectroscopy Facility for developing and using advanced optical techniques to characterize complex systems

- Reactions at Interfaces Facility for studying interfacial chemical reactions and processes.

Additionally, the EMSL Collaboratory facilitates remote collaboration, and the Instrument Development Laboratory works with scientists to develop custom electronics and software to meet specific research needs.

The Atmospheric Radiation Measurement program represents a new direction for atmospheric research and may best be understood as the creation of an atmospheric observatory for developing, deploying, and promoting state-of-the-art atmospheric instrumentation and remote sensing techniques. The major facilities of this program include the three field measurement sites (in Oklahoma, the Tropical Western Pacific, and Alaska), the data archive (operated by other DOE laboratories), and the Data Management facility at Pacific Northwest National Laboratory. Field sites provide the
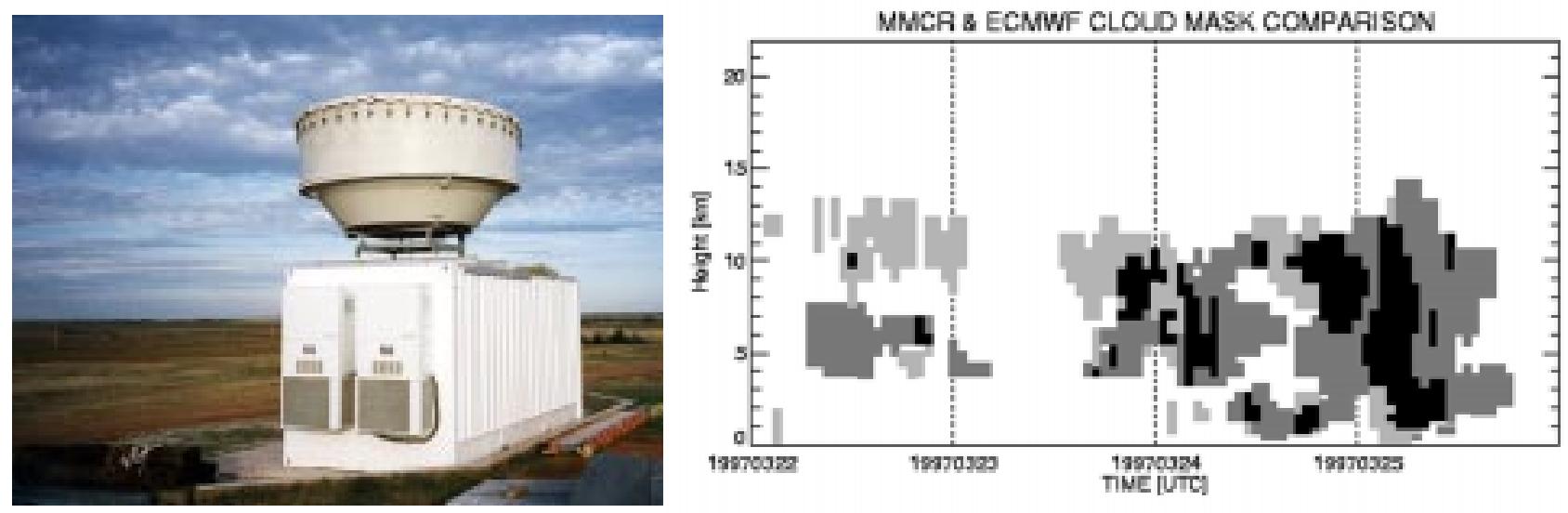

Observations from the Atmospheric Radiation Measurement millimeter cloud radar (above) at the Southern Great Plains site are used to test model predictions of cloud occurrence for a four-day period, March 22-25, 1997. The upper panel (right) compares millimeter cloud radar observations with output from the forecast model of the European Center for Medium-Range Weather Forecasting, while the bottom panel compares observations with output from the ETA model run by the National Centers for Environmental Prediction in the United States. White indicates areas where both model and observations agree on no clouds, and black indicates areas where both show clouds. The light gray indicates areas

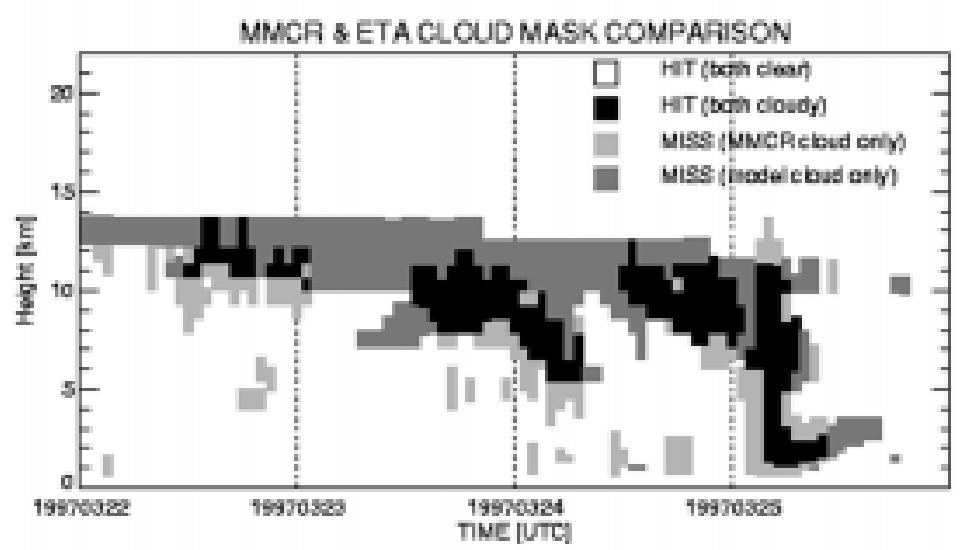
where the radar detected cloud but the model failed to predict cloud; dark gray indicates areas where the model predicted cloud but no cloud was detected by the radar. These results can be used to diagnose meteorological situations in which the models perform well or poorly and, thus, target areas for study and model improvement. 
research community with broad capabilities for studying radiative transport and cloud physics issues of importance to climate. These sites provide a suite of instruments, including millimeter-wavelength radar and Raman lidar, that are operated continuously and with high accuracy to sample atmospheric properties. They also provide a singular environment for enhanced study periods using aircraft and unmanned aerospace vehicles. The Data Management facility oversees the data collection process and develops new computation algorithms to retrieve more complex information from the various data streams. The program office coordinates the multilaboratory research and ensures that the Atmospheric Radiation Measurement facilities are available to and used by a broad spectrum of scientists in the climate change, atmospheric research, and satellite remote sensing communities. Pacific Northwest National Laboratory also operates a Gulfstream 1 research aircraft, for studying atmospheric processing and contaminants.

In our biological sciences initiative, we are developing new methods for biological sciences research. These methods will allow us to observe molecular processes in living cells and will provide insight into phenomena such as cell signaling that are not otherwise possible with existing tools and techniques. A combined microscope was recently developed at the Laboratory that allows scientists to observe processes in living cells in real time. This microscope represents the union of an optical microscope with magnetic resonance spectroscopy, which is similar to magnetic resonance imaging used at hospitals to create visual images of the human body. With this combined microscope, scientists can directly observe the physiological changes that occur when cells are exposed to environmental stresses. In addition, we are developing novel mathematical computational biology techniques spanning the range from the molecular level to the cellular level to the organ in the Virtual Biology Center in order to address the complex issues arising in environmental health.

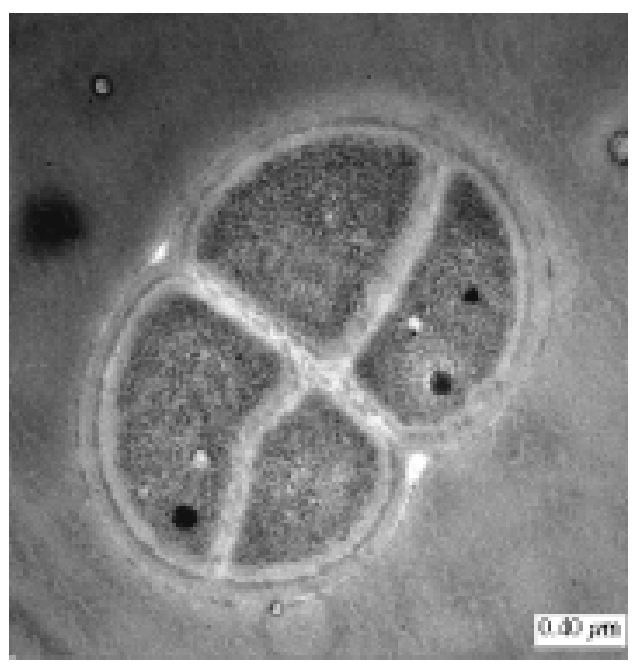

Deinococcus radiodurans is one of the most radiation-resistant microorganisms known, due to its ability to survive radiation absorbed doses at levels approaching 20 kilogray. Because of its high resistance to ionizing radiation and its enhanced ability to survive harsh environmental conditions, D. radiodurans is a candidate for bioremediation of sites contaminated with metals and radionuclides. Researchers at Pacific Northwest National Laboratory and the Uniformed Services University of the Health Sciences in Bethesda, Maryland, provided the first evidence that $\mathrm{D}$. radiodurans can naturally reduce chromium, uranium, and technetium, in the absence of air, to relatively insoluble and immobile forms, when provided with a simple carbon and energy source (such as lactate).

We also are developing techniques for the rapid and sensitive characterization of the changes in the proteome in response to environmental changes. The Fourier transform ion cyclotron resonance mass spectrometer is being modified for high-throughput identification of proteomes. This technique is being applied first to study microbial systems, such as the radioactive-resistant bacteria, Deinococcus radiodurans. Identifying the proteins that allow this microorganism to repair its DNA and live in high radiation environments has implications both to radiation exposure and environmental health, as well as cleanup of mixed hazardous waste. These methods will be an important complement to the major sequencing capability present at the Human Genome Institute and will put those results in an important context for human and environmental health.

\section{Scientific Simulation}

Computer-based simulations provide the means for solving the complex mathematical equations that are used to describe natural phenomena and allow scientists and engineers to quantitatively predict the behavior of complex, and often interrelated systems. When integrated with experimentation and analytical theory, scientific simulation provides the third leg of the triangle needed to rapidly advance a scientific domain. For example, the information gained from many complex experimental systems 


\section{FLC Award Winner}

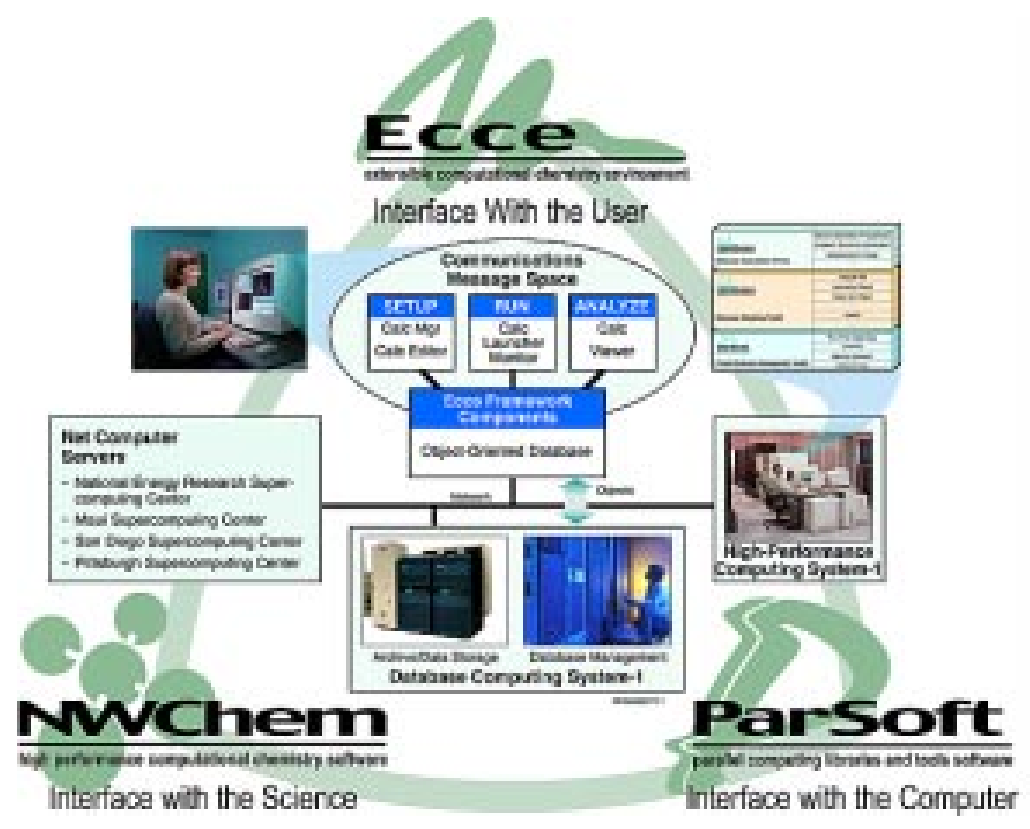

Molecular Science Software Suite $\left(M S^{3}\right)$ is the first general-purpose software that allows a broad range of chemists to easily use highperformance, massively parallel computers for a wide range of applications. It is a comprehensive, integrated suite of software that enables computational chemists to focus advanced techniques on finding solutions to complex issues involving chemical systems. The system allows scientists to easily combine advanced computational chemistry techniques like simulation and modeling with the power of massively parallel computing systems. They even can access these computing systems from their desktop workstations. The software system allows chemists to predict characteristics of chemical systems with a level of accuracy equal to that of the most sophisticated experimental approaches. often does not lead to one identifiable collection of processes. Simulations can quickly evaluate multiprocess systems and eliminate processes, modify processes, and develop new processes that were initially overlooked. In addition, simulations can be used to expand limited experimental results into new domains of parameter space and to uncover new phenomena that can be experimentally tested. DOE's Office of Science recognizes the importance of simulations, and has designed its Scientific Discovery through Advanced Computing (SciDAC) initiative to bring such capabilities to the scientific community.

New relativistic quantum chemical capabilities have been added to NWChem under the sponsorship of the Office of Science Advanced Computing program in "Computational Science Grand Challenges.” This software is being used to predict the properties of the actinides and lanthanides encountered in DOE's environmental management mission. The goal of this work is to simulate the behavior of compounds of these elements to reduce the number of

hazardous and expensive experiments that need to be performed. These capabilities will also be applicable to a broad range of other chemical problems involving heavy atoms. Other new features added to NWChem include advanced electron correlation treatments, molecular dynamics, and density functional theory. These capabilities help us address a number of problems, such as the interactions of complex biomolecules on the surface of bacterial membranes with mineral surfaces and the effect of this interaction on environmental cleanup processes. The software is also being used to design new chemical separation systems. The discovery of the active structure in Argonne National Laboratory's strontium extraction process for the selective removal of divalent strontium from acidic nuclear waste is an example of this application. The software is also enabling scientists to calculate reliably the thermodynamic quantities of molecules for a wide range of needs including "green" chemical process development and combustion modeling without the need to perform expensive and difficult experiments.

A sophisticated, coupled, multiphase flow and reactive transport simulation capability has been developed and is directly applicable to engineering needs at DOE cleanup 
sites. Highly resolved depictions of the effects of physical and chemical heterogeneities on subsurface flow, transport, and reactions have been used to simulate the behavior of leaks from the high-level waste tank, SX-109, at Hanford including mineral dissolution and precipitation as well as to model biogeochemical reactive transport.

We have developed new capabilities for atmospheric chemistry and regional climate modeling. The Eulerian air chemistry model MMART was developed for massively parallel computers. The new code has been used to evaluate the influence of stratospheric intrusions of air upon surface ozone concentrations in urban environments. The much higher resolution of this code allows improved chemistry models to be included and comparisons made to observational data. Our regional climate code based on subgrid models is being run on massively parallel computers. It has been used to study the effects of global warming on precipitation in the Pacific Northwest region and has shown how water management strategies will need to be changed.

We are presently developing two new software suites for solving complex reactive transport and physics problems. The first is NWGrid which is capitalizing on our expertise in new grid methods that correctly capture the underlying geometries and physical symmetries of the objects being modeled. This code will enable the user to use a wide range of grid methods, from structured to unstructured to hybrid grids, to solve complex physical problems. NWGrid is tightly coupled to the simulation program NWSolve, which provides the solutions to various types of computational physics problems. In the short time that this software has been available, it has been used to study the Hanford vadose zone, inhalation and exhalation in a model of human lung airways, global climate change, and design of new mass spectrometers.

Additional efforts are being made to develop new mathematical models and software for data analysis from proteomic and array measurements and for modeling cell-signaling processes, including the use of petri nets.

Another software development effort builds on the ParSoft set of paradigms for managing the complex memory hierarchy in massively parallel computers. Our approach combines the strengths of a shared-memory-programming model with the scalability and performance of the distributed-memory model, from which the highly successful Global Arrays model has emerged. Current applications for which this software serves as the underlying base technology for massively parallel computers include computational chemistry, graphics rendering, and security value forecasting.

By providing advanced computing and collaboration technologies, our research under the DOE2000 Collaboration Management Project will enhance DOE's ability to accomplish its missions. In this program, Pacific Northwest National Laboratory researchers, in collaboration with scientists from other DOE laboratories, are developing the Advanced Computational Testing and Simulation Toolkit that will provide scalable parallel libraries and tools suited to a wide variety of DOE simulation applications. For example, our work on the Aggregated Remote Memory Copy Interface library has developed general purpose, one-sided communication capabilities for many high-performance computers and numerical tools. Under the DOE2000 Collaboration Management Project, we are creating a set of collaboration technologies. One of these, the CORE2000 (COllaborative Research Environment) integrates a suite of real-time collaboration technologies in an easy-to-use package. Extending the Habanero tool from National Center for Supercomputing Applications, CORE2000 adds public domain Internet video tools and screen sharing, and provides an advanced shared white board and remote camera control. The Electronic Laboratory Notebook addresses many of the new requirements of recording and sharing the process of scientific research and creates information in many forms. Pacific Northwest, Argonne, Lawrence Berkeley, and Sandia national laboratories are designing a Collaboratory Interoperability Framework, a 


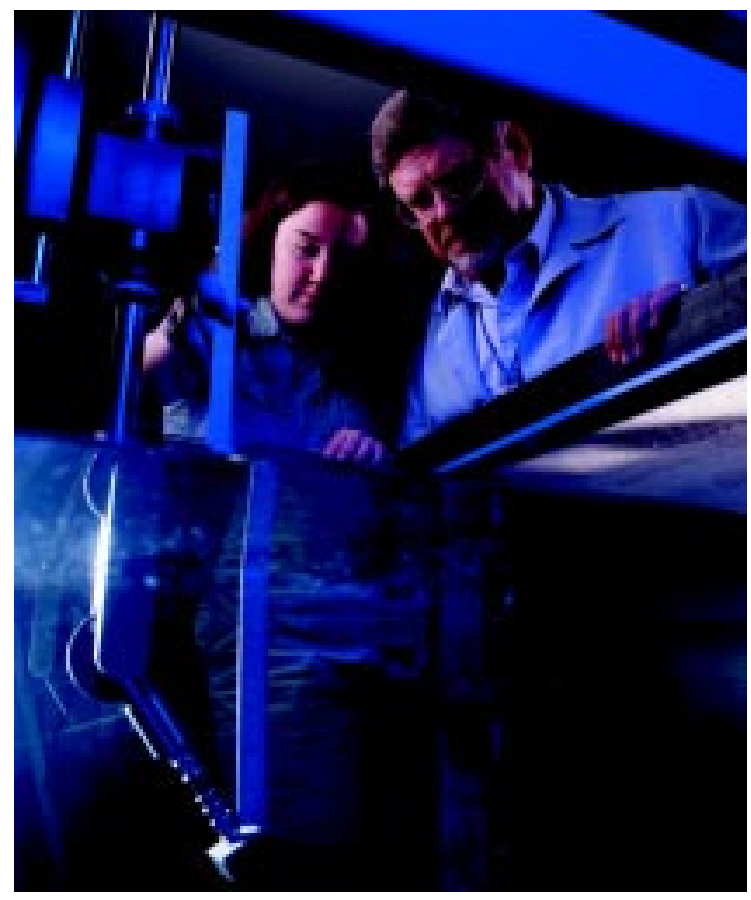

The Student Research Intern Program is a researchbased experience for senior-level high school students interested in preparing for careers in science, technology, and engineering. common software infrastructure for communications among national laboratories' computer resources, enhancing data transport, resource location, and security. Altogether, these collaboratory projects provide major pieces of the architecture of the DOE2000 Collaboration Management Project.

\section{Institutional Capabilities}

The DOE Laboratory Technology Research program funds partnership projects between the Office of Science laboratories and private-sector companies. These partnerships benefit the participating companies and help achieve DOE mission responsibilities. Projects are funded in areas where the laboratories have stateof-the-art scientific capabilities, such as materials sciences, biotechnology, analytical chemistry, and advanced computing. The program also has been a key source of assistance to small and regional businesses. Proposals are being advanced to obtain additional resources to enhance program efforts to develop and deploy the computational capabilities of the Office of Science laboratories in partnerships with industry. We will continue to extend Laboratory resources via frequent and fruitful partnerships with the private sector and universities, as well as with other national laboratories.

Pacific Northwest National Laboratory's University and Science Education programs combine our science, engineering, and technology capabilities with that of our educational partners to create a broad range of environmental science education projects. This program involves students and teachers from elementary school to university graduate school. Last year, approximately 132 students and faculty were funded through DOE's education programs. An additional 570 students and faculty were funded directly by individual research projects at the Laboratory. The Office of Science-supported research at the Laboratory has a significant impact on student training and education.

Our relationship with universities is evolving to strengthen and enhance our basic science capabilities. Over the past decade, our interactions with universities have changed from a subcontracting to a joint proposal mode. The success of these collaborative university and laboratory research proposals has enhanced staff opportunities in training students and new scientists. Significant interest has developed in the "joint institute" concept. Joint institutes are partnerships with regional universities that focus on a specific science capability, such as computational sciences, proteomics, or nanosciences. Under the joint institute concept, a research facility would be staffed by both Laboratory and university scientists and the capabilities of both institutions would be focused on a common research problem. This type of partnership will result in more direct involvement of Laboratory staff in graduate education. 


\section{University and Science Education}

\begin{tabular}{|c|c|c|c|c|c|c|}
\hline & Total & $\begin{array}{l}\text { FY } 1999 \\
\text { Minorities }\end{array}$ & Women & Total & $\begin{array}{l}\text { FY } 2000 \\
\text { Minorities }\end{array}$ & Women \\
\hline \multicolumn{7}{|l|}{$\begin{array}{l}\text { Pre-College Programs } \\
\text { Student Proarams }\end{array}$} \\
\hline Student Research Apprenticeship Programs & 18 & 13 & 14 & 12 & 12 & 9 \\
\hline Scientist, Student, Teacher Enhancement Project & 18 & 0 & 3 & 42 & 2 & 6 \\
\hline Student Research Internship Program & 27 & 2 & 7 & 17 & 1 & 3 \\
\hline DOE Science Bowl Competition ${ }^{(a, b)}$ & & & & 320 & & \\
\hline DOE Science Bowl Workshop ${ }^{(b)}$ & & & & 5 & & 1 \\
\hline \multicolumn{7}{|l|}{ Teacher Programs } \\
\hline Teacher Research Participation Program & 11 & 1 & 3 & 11 & 1 & 8 \\
\hline Partnership for Arid Lands Stewardship & 26 & 1 & 21 & 25 & 1 & 18 \\
\hline Scientist, Student, Teacher Enhancement Project & 14 & 0 & 2 & 15 & 0 & 2 \\
\hline $\begin{array}{l}\text { Washington State Leadership and Assistance for } \\
\text { Science Education Reform Events }\end{array}$ & 421 & & & 437 & & \\
\hline $\begin{array}{l}\text { National Teacher Enhancement Project/Lewis and } \\
\text { Clark Re-Discovery Project }\end{array}$ & 5 & 0 & 4 & 4 & & 4 \\
\hline DOE Science Bowl Competition ${ }^{(a, b)}$ & & & & 150 & & \\
\hline DOE Science Bowl Workshop ${ }^{(\mathrm{b})}$ & & & & 40 & 2 & 25 \\
\hline Materials Science and Technology Workshop ${ }^{(b)}$ & 0 & 0 & 0 & 33 & 4 & 10 \\
\hline \multicolumn{7}{|l|}{ Undergraduate Programs } \\
\hline $\begin{array}{l}\text { Office of Science Undergraduate Laboratory } \\
\text { Fellowship (ERULF) }\end{array}$ & 85 & 25 & 42 & 83 & 21 & 43 \\
\hline Laboratory Co-Operative Program & 217 & 34 & 75 & 221 & 35 & 75 \\
\hline Community College Initiative & 27 & 5 & 8 & 19 & 7 & 9 \\
\hline Pre-Service Teacher Program(c) & & & & 7 & & 5 \\
\hline \multicolumn{7}{|l|}{ Graduate Programs } \\
\hline Laboratory Co-Operative Program & 50 & 17 & 17 & 91 & 22 & 34 \\
\hline \multicolumn{7}{|l|}{ Postgraduate Programs } \\
\hline Post-Baccalaureate Program & 40 & 8 & 24 & 14 & 4 & 7 \\
\hline Post-Masters Program & 29 & 2 & 9 & 21 & 5 & 10 \\
\hline Postdoctoral Program & 130 & 40 & 35 & 101 & 38 & 20 \\
\hline Faculty Fellowships & 58 & 18 & 11 & 54 & 15 & 9 \\
\hline Faculty Travel Grants & 9 & 1 & 1 & 2 & 0 & 0 \\
\hline Faculty Sabbatical & 1 & 0 & 1 & 4 & 0 & 1 \\
\hline Visiting Scientists & 18 & 4 & 1 & 37 & 10 & 7 \\
\hline \multicolumn{7}{|l|}{ Other Programs } \\
\hline Sharing Science with Schools ${ }^{(a)}$ & 1707 & & & 3025 & & \\
\hline Shadowing Program & 46 & (a) & 14 & 70 & & 28 \\
\hline Family Math Programs ${ }^{(a)}$ & & & & 1028 & & \\
\hline Bridges Program(c) & & & & 3 & 2 & 1 \\
\hline \multicolumn{7}{|c|}{$\begin{array}{l}\text { (a) Data on minorities and women are not tracked for these programs. } \\
\text { (b) Not previously reported. }\end{array}$} \\
\hline
\end{tabular}

\section{Exploring Matter and Energy}

Pacific Northwest National Laboratory supports the theme of Exploring Matter and Energy with its continued experimental and theoretical studies of fundamental natural materials and processes at a molecular level and in their combinations in complex systems.

\section{Components of Matter}

The essential contribution of research at the Laboratory is to increase understanding of molecular processes in the condensed phases that are characteristic of natural and contaminated environments. Using sophisticated tools, this research program integrates 
experimental studies of fundamental molecular processes with the modeling of complex molecular systems found in the environment. Internationally known work in electron microscopy and spectrometry is conducted at the Laboratory that examines the fundamental properties of individual molecules and their assemblages, as well as experiments that look at molecules and atoms at surfaces and interfaces. The chemistry and physics at interfaces provide the fundamental knowledge necessary to make advances in the application of catalysis to industrial processes as well as understanding the complex processes that control the transport of contaminants in the subsurface and biological processes in living organisms.

For example, scientists have observed molecules with negative electron binding energies. Guadruply charged anions of copper phthalocyanine tetrasulfonate exhibit a stepwise tuning of the electronic energy levels as the orbital energies are systematically raised by the negative charges carried by the sulfonate groups. Remarkably, the electrons in the highest occupied molecular orbitals possess a negative electron binding energy. These electrons are trapped within a repulsive Coulomb potential barrier created by the excess negative charges, much like the alpha particles in a radioactive nucleus. These molecules store pure electrostatic energy and can be viewed as molecular capacitors.

\section{Complex Systems}

Pacific Northwest National Laboratory will play a special role in understanding complex systems focused on developing a molecular-level understanding of chemistry at liquid/ solid interfaces and in condensed phases. Researchers in chemical structure and dynamics are exploring reactions at a wide variety of solid/liquid interfaces, the dynamics of biological systems, and development of new analytical methods. One application of this research is in unraveling environmental conundrums at contaminated waste sites, in the atmosphere, and in outer space.

Our molecular theory and modeling programs are producing sophisticated and useful methods of studying groundwater chemistry, chemistry at aqueous and mineral interfaces, separations chemistry, and nuclear waste forms. The ability to apply advanced theory and experimental approaches to the same complex problem is a key strength of our program.

Our molecular-level approaches to the study of complex systems have led to fundamental understandings of liquid/liquid interfaces and the transfer of molecules between phases. Much interest has been shown in understanding the crystallization mechanism of amorphous solid water in astrophysical environments. Researchers have found that amorphous solid water crystallizes much faster on a substrate of crystalline ice than on a laboratory substrate such as platinum. The rates were different because the actual mechanism of crystallization varied with the two substrates. These observations have implications for laboratory studies that use vapor-deposited amorphous solid water films as analogs for astrophysical icy bodies, such as comets. Specifically, by understanding the crystallization mechanism, we can help refine models for the evolution of comets and gas retention.

Theory and computational research is studying the interaction of water with carbon nanoreactors. We are interested in the properties of carbon nanotubes and in their abilities to function as small chemical reaction chambers or "nanoreactors." Carbon nanotubes are elongated analogues of the spherical carbon molecules known as fullerenes or "buckyballs." In the future, nanoreactors may play a role in industrial chemical synthesis, such as pharmaceuticals. Green chemical synthesis approaches will make water the preferred solvent for such nanoreactors, yet we do not fully understand how water molecules assemble on the carbon surfaces. Scientists at Pacific Northwest National Laboratory, in collaboration with the University of Pittsburgh, have performed highly accurate electronic structure calculations on water interacting with various size models of single-layer graphite. Contrary to the current belief that water would not bind to graphite, the calculations predict the water to bind to the 
graphite with an energy of about $5.4 \mathrm{kcal} / \mathrm{mol}$, comparable to the binding energy of the water dimer. This finding provides fundamental information for creating a framework to simulate water-based chemical reactions in a nanoreactor.

\section{Fueling the Future}

Pacific Northwest National Laboratory actively anticipates the nation's needs for information about and approaches to the sources and management of energy use and mitigation of unwanted impacts. Research that supports the DOE theme of Fueling the Future is described in this section. Examples include microbiology and plant physiology, fundamental research in geologic sciences, surface and interfacial chemistry and physics, and nuclear magnetic resonance imaging.

The Laboratory's research programs in molecular processes also are focusing on energyintensive chemical conversions. We conduct fundamental studies of reactions in supercritical fluids, free radical chemistry at high temperatures, laser spectroscopy, and theoretical and experimental studies of heterogeneous catalysts. Our research on rhodium catalysts has established a more quantitative relationship between surface structure and catalytic activity for the reduction of nitrogen oxide. This knowledge is being directed toward developing better automobile catalytic converters to control exhaust emissions.

\section{Clean and Affordable Power}

A long-term goal of our research focused on developing advanced structural materials for the high neutron flux regions of fusion power systems. In the near term, our efforts concentrate on developing materials that meet safety, economic, and environmental performance criteria. A principal aim is to assemble fundamental knowledge on the effects of fusion and of variations in material composition and microstructure on engineering properties. We are experimentally determining the response of materials to neutron irradiation and developing new materials with useful properties, such as reduced activation. In addition, computer models are being developed to predict the effects of neutron irradiation on materials.

One of the critical pollution reactions occurring in automobile catalytic converters is the reduction of nitric oxide to the desirable (nitrogen) or undesirable (nitrous oxide, a "greenhouse" gas) products. Researchers are studying model rhodium automobile exhaust catalysts and have identified the important surface structural features that steer the nitric oxide reduction reaction to one or the other of the products, nitrogen or nitrous oxide. In particular, rougher, higher energy surfaces that would be prevalent in smaller rhodium particles are more selective for the desired product, nitrogen. These studies were enabled by a coupled high-pressure microcatalytic reactor ultrahigh vacuum surface analysis system that can measure reaction rates on well-characterized, single-crystal model catalysts. The new insights gained from this work will help catalytic converter manufacturers prepare materials that are optimized for the desired nitrogen product, reducing greenhouse gases in the atmosphere.

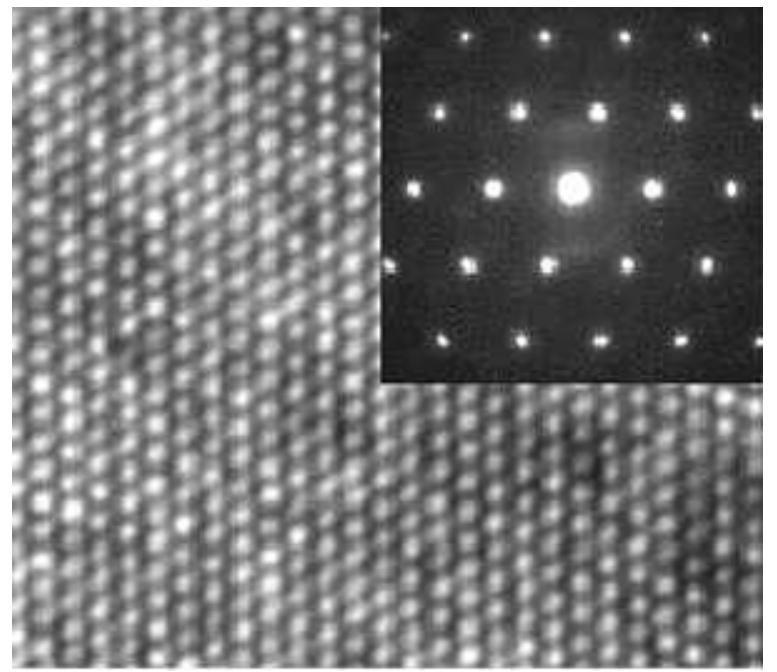

Worldwide, nuclear energy production and defense programs have created 1350 metric tons of plutonium that increases by 70 metric tons annually. Because plutonium has a long radioactive half-life (24,500 years), future generations must be protected from this highly radiotoxic material. An environmentally sound strategy is to immobilize plutonium in materials that are extremely resistant to radiation damage for millennia. Using heavy-ion irradiation, advanced characterization techniques, and computer simulation methods, researchers have discovered that highly durable gadolinium zirconate can lock plutonium into its structure while remaining extremely resistant to radiation damage. 
Pacific Northwest National Laboratory's research in nanomaterials yielded self-assembled monolayers on mesoporous supports, which is a new class of materials that can remove metals and radionuclides from aqueous and organic liquids and gaseous streams. Selfassembled monolayers have fixed porosities and have potential applications in soil and water cleanup at sites where mercury contamination is prevalent, as well as industrial wastewater treatment and metal recovery. A major improvement of the self-assembled monolayers is a new class of innovative synthetic material that contains tunable porosity on the nanoscale (pore diameters of less than $1 \mathrm{~nm}$ ) in ordered nanoporous channels (pore diameter of about $10 \mathrm{~nm}$ ). The accessibility of molecules to these channels is regulated by bound self-assembled molecules that are painted on the interior pore surfaces of the monolayers. The pores can be reversibly opened and closed in response to the nature and $\mathrm{pH}$ of a carrier solvent, just like the micropore channels in biomembranes. This capability allows researchers to selectively capture and separate pollutants from waste streams.

Researchers at the Laboratory and the University of Michigan have demonstrated that gadolinium zirconate is a highly durable storage material for the immobilization of plutonium and other actinides. Unlike the currently proposed phases of gadolinium titanates for immobilization and long-term storage of radioactive waste, gadolinium zirconate and its family members undergo only a minor change in crystal structure and are inherently radiation resistant. Gadolinium zirconates can be easily fabricated using existing technology. A shift from the titanates to a zirconium-rich system could significantly reduce the effects of radiation and improve the safety of plutonium immobilization during long-term storage.

\section{Efficient Energy Use}

We will continue studying energy-efficient materials and techniques to improve the nation's energy efficiency, emphasizing particular synthesis techniques for producing new or improved materials in an environmentally conscious manner, and investigating the reaction of materials with their environments. These activities underpin many technological issues relevant to DOE. We are examining

\section{R\&D 100 Award Winner}

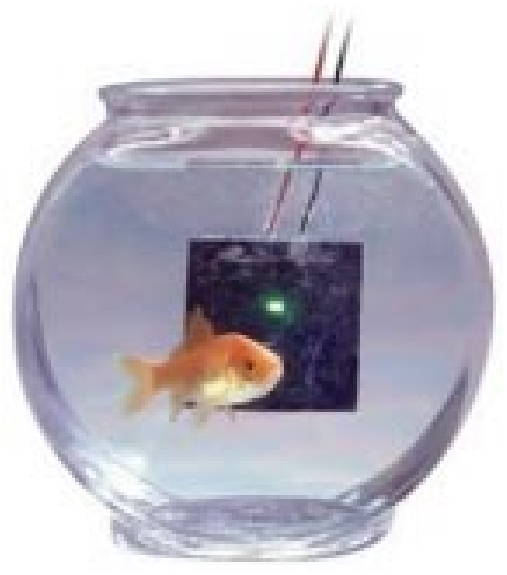

Pacific Northwest National Laboratory's Ultra Barrier Coatings protect this Organic Light Emitting Device (OLED) test unit from moisture. Without the coating, just the moisture in the air would cause this extremly sensitive device to fail in a matter of days. This coated test unit has survived eight months of exposure to air and continues to function while being completely submerged in water. energy-enhancing materials in three areas: thin-film optical materials and protective coatings; synthesis and characterization of advanced nanoscale composites, ceramics, and intermetallics; and mixed conductors for low-temperature gas separation. Research that may affect the length of life of materials includes work on ceramic stability and stress corrosion and corrosion fatigue of metals and ceramics.

Increasing interest is being paid to nature's mineralization strategies, particularly by scientists looking for bio-inspired methods to engineer special ceramic coatings or composites for use in magnetic, optical, and biomedical applications. While nature's biomineralization processes are a complex blend of nucleation and growth events that are not well understood, it is known that acidic proteins may direct this process. Researchers at Pacific Northwest National Laboratory have employed advanced instrumentation to elucidate the molecular recognition mechanisms at the protein/crystal interface. Through our understanding of these structural relationships, we are developing design principles for controlling mineralization processes. This research has resulted in the development of new biomimetic coatings produced from aqueous solution, which can save energy and money. 
In research programs studying superplastic behavior, we are studying fundamental interfacial structure and composition to understand the underlying mechanisms of grain boundary sliding and precipitation effects on crystallization. We have shown that surfactant-directed dispersion of carbon nanotubes in polymer composite materials markedly improves mechanical strength and thermal stability of the composite, allowing use under conditions where the material would normally fail. This improved materials strength contributes to a weight reduction that would promote vehicle efficiency and render such materials suitable for aircraft applications. Other programs are developing alloys suitable for downstream industrial use.

The Advanced Energy Projects program funds innovative research directed at exploring new approaches to energy-related problems. The Laboratory is also exploring metal-ionpromoted and semiconductor-catalyzed selective oxidation of alkanes to assess the technical advantages and limitations of a potentially energy-efficient reaction sequence for selectively oxidizing hydrocarbons.

\section{Research Thrusts}

Pacific Northwest National Laboratory invests discretionary resources to maintain its fundamental sciences programs at the forefront and to develop new leading-edge capabilities for its programs. New multidisciplinary capabilities are being developed in all of the areas mentioned above. The Laboratory has made significant investments in the following areas.

Advanced Biology. Laboratory researchers have developed an Environmental Cell Signaling laboratory that integrates research in molecular cell biology, microbial biology, mathematical and computational biology,

and environmental proteomics to examine biochemical interactions at the cellular level, where the ultimate potential for health effects is determined. Highly specialized instruments and facilities help us to better understand the impact of the environment and contaminants in the environment on human life and health. Noninvasive magnetic resonance, in combination with optical microscopy, has enabled a cellular observatory for scientists to monitor how live cells respond as they are exposed to changes in their environment. High sensitivity mass spectroscopy will yield insight into proteomic responses to the environment. The Virtual Biology Center is developing mathematical and computational tools to integrate the wide range of biological data that is becoming available over a range of temporal and spatial scales from the molecular to the cellular to the organ to the organism to address complex biological problems.

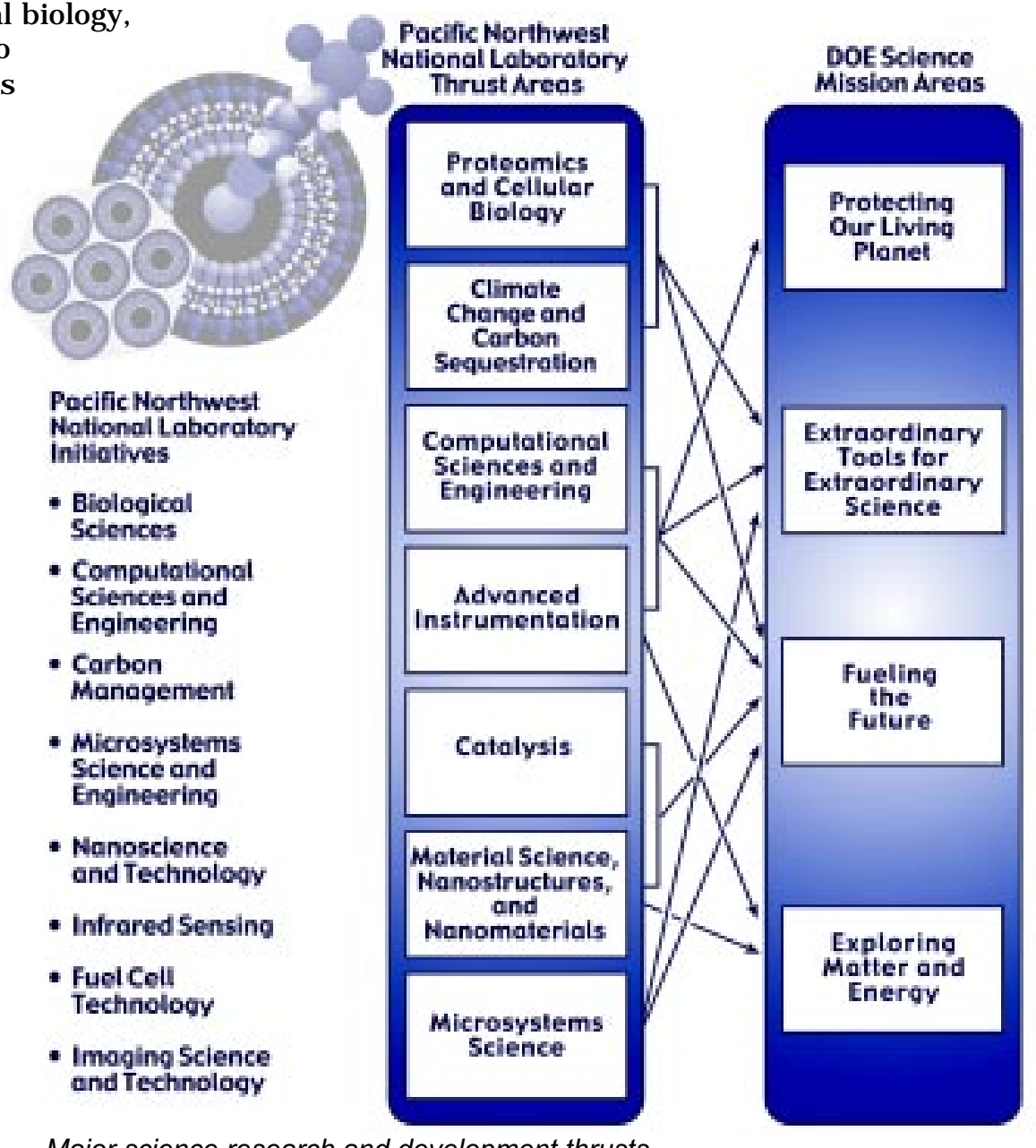

Major science research and development thrusts. 
Climate Change. The Laboratory plays a major role in the Atmospheric Radiation Measurement program, developing and operating state-of-the-art instruments and techniques. We have an end-to-end view of the climate change problem, ranging from atmospheric physics to societal implications and adaptation, and have invested significant resources at several crucial nodes along that continuum. The program office at Pacific Northwest National Laboratory coordinates the field measurement sites and data management and special field campaigns at those sites; this effort spans activities at several DOE laboratories and associated contractors. The Laboratory also coordinates the scientific investigations. This effort engages scientists at academic institutions, the National Aeronautics and Space Administration, National Oceanic and Atmospheric Administration laboratories, and other DOE national laboratories, and has links to international partners. Laboratory science staff members are engaged in research activities linked to the data analysis and modeling. A second crucial node is the use of regional climate models to understand the implications of climate change on the local scene. The Laboratory has developed a nested regional model that is being used to evaluate the impacts of potential changes in the hydrologic cycle on local water availability. A third crucial node is understanding the economic implications of energy policy decisions related to climate change. Because energy is a global commodity, national policy decisions must be evaluated in a framework of international economic interactions. Pacific Northwest National Laboratory is a world leader in this developing arena. Adaptation and mitigation strategies must be evaluated, particularly in societies where conservation and alternative energy are viable strategies. The Laboratory strategy is to supply the nation and its policymakers with a complete picture of the possible physical effects of climate change, the associated social implications, and possible strategies to address those developing issues.

Computational Science. Our investments will build on two significant past accomplishments: the development of the Molecular Science Computing Facility in the EMSL and the collaboratory. The Molecular Science Computing Facility developed an advanced simulation environment with its concurrent development of software, hardware, and problem-solving environments. We will use our software development paradigm and our experience in operating collaboratories and running a highperformance massively parallel computing facility for users to address computationally many of the complex problems faced by DOE. These include climate, combustion, energy-efficient manufacturing in the chemical and energy production industries, new

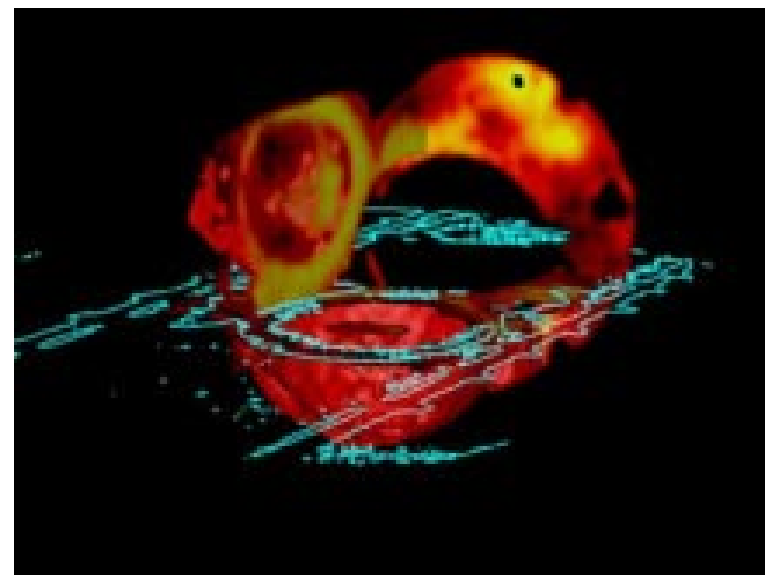

Physicists, molecular biologists, physical chemists, and optical experts from Pacific Northwest National Laboratory and the Massachusetts Institute of Technology jointly developed a new type of microscope termed the magnetic resonance optical microscope. With this new microscope it is possible, for the first time, to simultaneously image "live" cellular systems by confocal fluorescence optical microscopy and magnetic resonance microscopy. manufacturing technologies for lightweight vehicles, cellular processes for environmental health and bioremediation, national security, environmental cleanup of DOE nuclear production sites, and other areas of basic science.

Advanced Instrumentation. Pacific Northwest National Laboratory offers a comprehensive array of state-of-the-art equipment for research in the environmental molecular sciences. These capabilities can be integrated as needed by multidisciplinary teams of scientists to address complex problems.

Environmental Catalysis. Pacific Northwest National Laboratory is conducting theoretical and experimental studies of heterogeneous catalysts. Our research on rhodium catalysts has established a more quantitative relationship between surface structure and catalytic activity for the reduction of nitrogen oxide. This knowledge is being directed toward developing better automobile catalytic converters to control exhaust emissions. Combined theoretical and experimental work on zeolites has led to new understanding on the behavior of these replacements of a range of solid acids used in the energy production industry. 
Materials Science, Nanostructures, and Nanomaterials. Internationally recognized scientists at Pacific Northwest National Laboratory have made major contributions to a fundamental understanding of a wide range of materials science topics, including nanostructure materials, biomimetric processes, the chemistry and physics of ceramic surfaces, irradiation effects in solids, phase transformations, defect processes in ceramics, optical films, stress corrosion, and deformation processes. Our recent research spans fundamental studies of the extraordinary properties of molecular clusters to the creation of new types of self-assembled monolayers on mesoporous supports for removing contaminants from the environment. Innovative, well-defined oxide surfaces are being used to gain new information about environmental and biological interactions at surfaces. Microfabrication capabilities are being used to develop new microanalytical capabilities with nuclear waste and biological applications. New methods for surfactant-directed dispersion of carbon nanotubes in polymer composite materials have improved material strength while reducing weight. These materials have potential application in automobiles and aircraft, saving energy and money. Other advanced characterization methods can be applied to studies as varied as exploring environmental damage to fruit and examining the stability of a nuclear waste form.

Microsystems Science. The objective of the Microsystems Science and Engineering initiative is to establish the capabilities necessary to develop miniature systems that rely on microscale structures to radically reduce the size of energy and chemical systems. By taking advantage of the high rates of heat and mass transfer available in microstructures, a wide range of thermal and chemical systems and components can be miniaturized, resulting in high production rates in compact hardware volumes. Examples include components such as heat exchangers, chemical reactors, separation devices, gas absorbers, gas generators, and combustors. Examples of potential miniaturized systems include compact combustion systems, miniature absorption heat pumps, miniature heat engines, compact fuel processors for hydrogen production, compact chemical separation systems, compact carbon dioxide absorption units, and microscale techniques for improving heat transfer to gases.

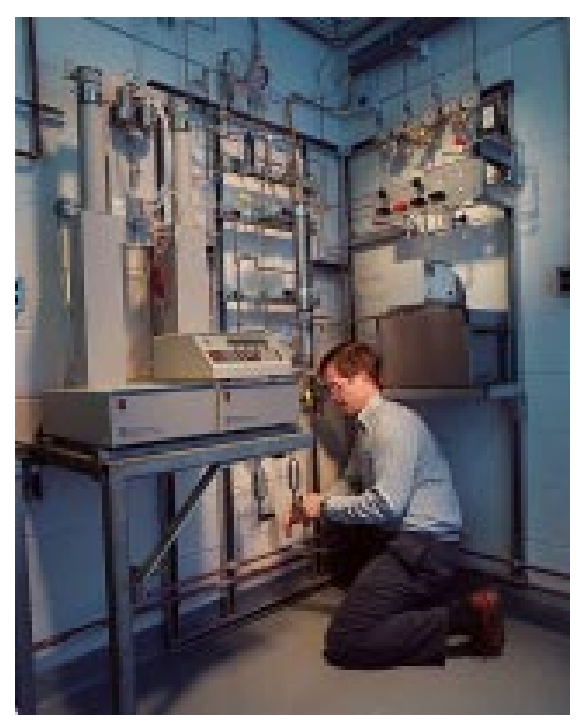

This chemical reactor system was created by Pacific Northwest National Laboratory for developing and optimizing processes to make value-added chemical products from basic chemicals derived from renewable feedstocks.

\section{Science Program Roles}

DOE Office

\author{
Pacific Northwest National Laboratory Role
}

\section{Biological and Environmental Research}

Life Sciences

Division (SC-72)

Medical Sciences Division (SC-73)
Pacific Northwest National Laboratory employs a multilevel approach to incorporating studies from the molecular level to the whole animal level. Emphasis is placed on understanding effects at low-dose exposures to radiation received occupationally or through the environment. We seek a quantitative understanding of mechanisms that underlie the health effects of physical and chemical agents using dosimetric, molecular, cellular, and intact animal analytical techniques. Within the biological sciences initiative our scientific emphasis is on cell signaling.

Pacific Northwest National Laboratory builds on its past contributions in radiation physics, dosimetry, and biophysics. Current research provides methodologies for medical applications, including novel uses of magnetic resonance imaging coupled with high-performance Fourier transform ion cyclotron resonance mass spectrometry. We are continuing efforts in efficient radiochemical separation methods and improved generator designs to make radium-223, actinium-225, and bismuth-213 available to clinical researchers. 


\section{Science Program Roles}

DOE Office

Environmental Sciences

Division (SC-74)

\section{Basic Energy Sciences}

Materials Sciences

Division (SC-13)

Chemical Sciences

Division (SC-14)

Engineering and Geosciences Division (SC-15)

\section{Office of Fusion Energy Sciences}

Science Division

(SC-55)

\section{Pacific Northwest National Laboratory Role}

Pacific Northwest National Laboratory supports Biological and Environmental Research programs in environmental processes and environmental cleanup, including fundamental and applied research in atmospheric science, global climate change, ecological research, subsurface science, microbial genomics, and molecular science. Component programs to which Pacific Northwest National Laboratory makes important contributions are the Atmospheric Radiation Measurement program, the Climate Prediction Program, and the Atmospheric Science and Integrated Assessment programs. We are a key contributor to the Environmental Science Management Program and the Natural and Accelerated Bioremediation Research Program, and we provide national leadership in operating the Environmental Molecular Sciences Laboratory, a national scientific user facility.

Pacific Northwest National Laboratory primarily focuses on 1) the development of synthesis techniques for producing new or improved materials in an environmentally responsible manner and 2) investigating the reactions between materials and their environment.

Pacific Northwest National Laboratory focuses on chemical physics and molecular processes. Our research in chemical physics primarily focuses on developing a molecular-level understanding of chemistry at liquid/solid interfaces and condensed phases important to problems at DOE contaminated waste sites. Our molecular theory and modeling programs develop new theoretical and modeling methods and apply these methods to the study of groundwater chemistry, chemistry at aqueous/mineral interfaces, separations chemistry, and nuclear waste forms. Our chemical, structure, and dynamics programs explore 1) reactions at a wide variety of solid/liquid interfaces, 2 ) the dynamics of biological systems, and 3) development of new analytical methods.

Pacific Northwest National Laboratory is developing a molecular-level understanding of the surface chemistry and reactivity of environmentally important mineral phases. In the computational area, the emphasis is on the transfer of information from the molecular scale to the macroscopic or thermodynamic level. The experimental program focuses on the surface chemistry of carbonate minerals and is well integrated with the theoretical program.

Work at Pacific Northwest National Laboratory focuses on determining the response of candidate materials to neutron irradiation, developing new materials with improved properties, reduced activation materials, and theory and modeling to predict the effect of neutron irradiation on materials. The predictive capability resulting from this research is needed to account for differences between the neutron spectrum of fission reactors where these experiments are performed, and that of fusion power systems.

\section{Advanced Scientific Computing Research}

Mathematical, Information, and Computational Sciences Division (SC-31)
Pacific Northwest National Laboratory focuses on advancing the state of the art in computational modeling and simulation, facilitating remote collaborations through development of collaboratory tools, and linking developments from our basic research activities with industrial needs to foster revolutionary technology spin-offs. We have two major efforts that are advancing the state of the art in computational modeling and simulation. First, we are developing a new generation of software for modeling molecular species containing heavy elements. Second, we are building upon a set of powerful and proven paradigms for managing the complex memory hierarchy in massively parallel computers, and fully integrating that functionality into key areas of the Action and Commitment Tracking System toolkit. We also make key contributions to the DOE 2000 Initiative in which we are collaborating with Argonne, Lawrence Berkeley, Sandia, and Oak Ridge national laboratories on various projects that will provide major pieces of the architecture for the DOE 2000 Collaboratory Environment. 


\section{Environmental Quality}

Pacific Northwest National Laboratory capabilities play a key role in supporting DOE's critical mission of cleaning up the legacy of nuclear weapons production. The science and technology requirements needed to address this challenge are substantial. The Department of Energy is responsible for sites that contain about 3 million cubic meters of solid radioactive and hazardous waste buried in the subsurface, with an estimated 75 million cubic meters of contaminated soil and about 475 billion gallons of contaminated groundwater. In addition, millions of gallons of high-activity radioactive waste are stored in large underground tanks, some of which have exceeded their design lifetimes and have deteriorated and leaked. The science and technology strength provided by the Laboratory, in partnership with others, will be essential in meeting the environmental restoration challenge.

\section{Strategic Intent}

Pacific Northwest National Laboratory will strengthen its science and technology capabilities and contribute substantially to the national research agenda by addressing several critical elements of DOE's environmental quality research portfolio.

- In the high-level waste disposal mission, Laboratory researchers will play a greater role in supporting the Hanford Site's Office of River Protection responsibilities for Hanford high-level tank waste; and at the national level, staff will continue to effectively manage and contribute to the Tanks Focus Area.

- In the disposal and disposition of nuclear materials mission and in the disposal of transuranic and mixed low-level waste, we plan to expand our science and technology support role to be more helpful in addressing the most difficult waste issues, both at Hanford and throughout the DOE complex.

- In the mission to enhance future land use, we will provide the technical basis for site cleanup decisions and will conduct the science research and technology assessments that will be needed for site cleanup actions.

On the national front, we will deliver new technologies that increase the timeliness and effectiveness of cleanup projects. We will continue to manage the Tanks Focus Area and will participate in all focus areas where we offer optimum technology concepts and research capabilities. We will continue to support the Office of Science and Technology in its strategic planning and help develop both the five-year research agenda and its multiyear research and development program roadmaps. Pacific Northwest National Laboratory also will support the Department of Energy planning efforts to provide enhanced

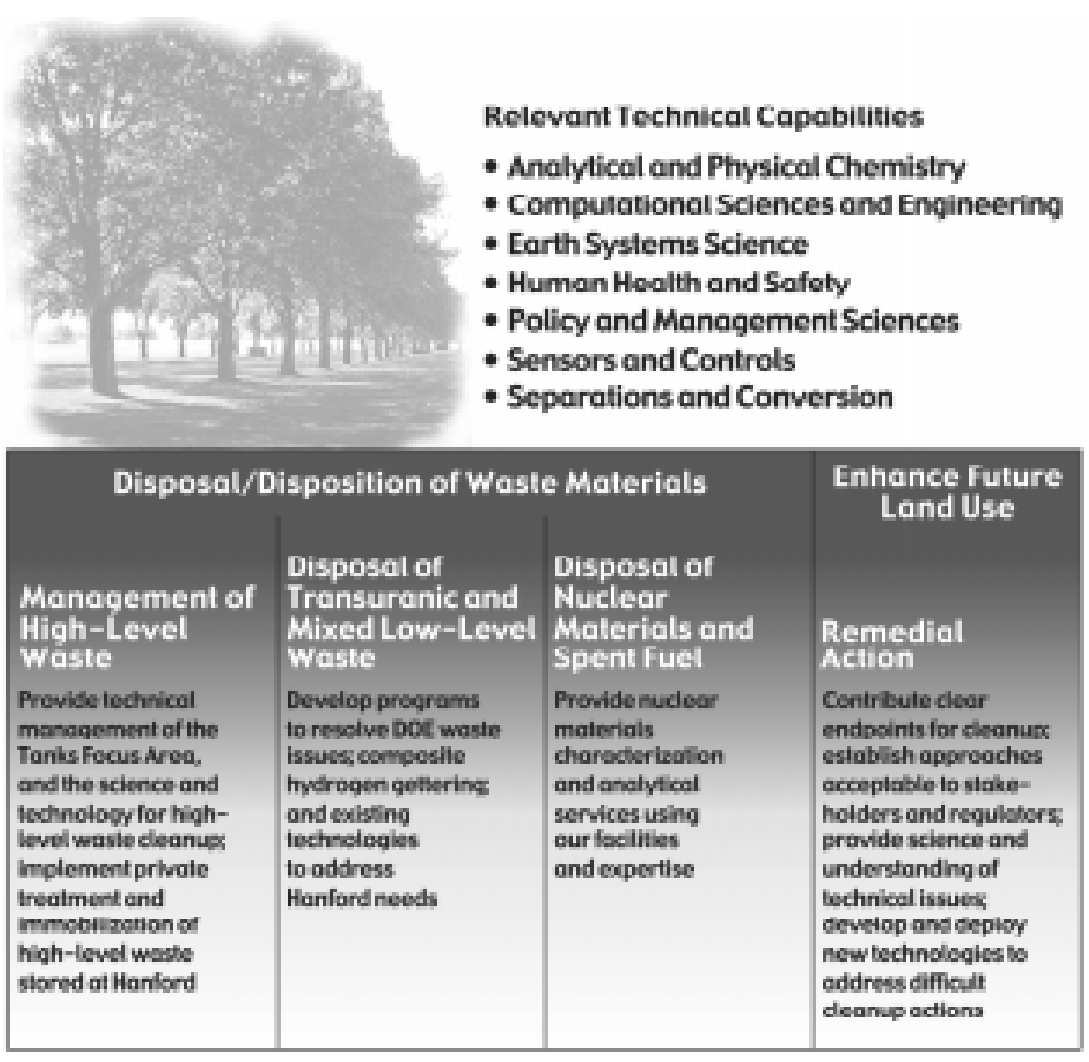

Environmental quality mission strategy. 
synergy between DOE's science and energy missions and those of other federal agencies-where common objectives could lead to better focus and higher-impact environmental research programs at a lower total cost.

At the Hanford Site, we will focus on identifying and resolving technical and programmatic risks within the cleanup projects where we can have significant impact on achieving large cost reductions and enhancing safety. Our specific goals are to

- deliver science and technology to the selected Hanford cleanup projects that represent the largest challenges to site closure (including tank waste cleanup, groundwater and vadose zone restoration, and selected projects for the handling and disposal of special nuclear materials)

- provide DOE with the tools and methods to identify and mitigate technical and programmatic risks using our strengths in systems assessment and environmental science and technology

- establish a technical basis for end-state requirements (the foundation for a longterm management mission at Hanford and future negotiations between DOE and regulatory agencies)

- maintain the critical technical capability base necessary for long-term management of the cleanup site and position Pacific Northwest National Laboratory for stewardship roles at the Hanford Site and elsewhere.

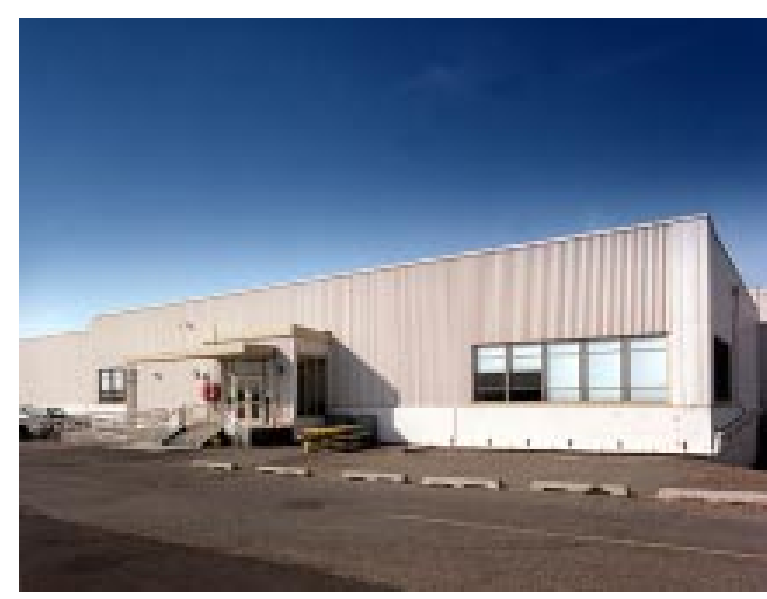

At the Radiochemical Processing Laboratory, researchers create and implement innovative processes for environmental cleanup and the beneficial use of radioactive materials.
The key to delivering science- and technology-based solutions to the most difficult environmental challenges will be strong, science-based programs, such as the Environmental Management Science Program and the advanced research conducted at our strategic facilities (the Environmental Molecular Sciences Laboratory and the Radiochemical Processing Laboratory). The success of our research will depend on the availability of specialized instruments in these laboratories and a trained and experienced scientific staff. Some of the projects most applicable to the environmental quality mission are described later in this section.

\section{Our Role in the Environmental Quality Research and Development Portfolio}

Pacific Northwest National Laboratory will continue working on DOE's highest-priority environmental cleanup needs. Priorities include nuclear and chemical waste management, minimizing future waste generation, and safe disposal of high-level radioactive waste. Our highest priority will be to conduct these research activities safely and effectively.

\section{High-Level Waste Management}

Pacific Northwest National Laboratory will continue to provide leadership and technical management in the Tanks Focus Area, a nationwide program responsible for development and complex-wide delivery of technical solutions to the priority tank waste problems at five DOE sites. Key to this program is the timely, cost-effective application of technology solutions to treat and retrieve tank waste at multiple sites, thus maximizing the investment in technology development. Our goal is to provide the highest quality science and technology necessary to reduce technical and programmatic risks associated with tank cleanup. 
The science base for defining cleanup requirements and developing and deploying technologies to effectively accomplish cleanup is one of the highest priorities at our Laboratory. We have been instrumental in helping to understand and solve the radioactive waste problem for more than 30 years. Our capabilities include waste retrieval, pretreatment, robust primary treatment technologies, and secondary treatment technologies. We are also developing next-generation chemical processes, including micro-chemical systems, for treating high-level waste. For example, we

- provided technical expertise in waste tank chemistry strategies to solve an unexplained crust growth in Tank SY-101 at the Hanford Site

- deployed remote characterization technologies to obtain heel samples from tanks at the Idaho National Engineering and Environmental Laboratory

- delivered an integrated waste pretreatment system to manage waste volumes and prevent equipment fouling at the Oak Ridge Reservation.

Pacific Northwest National Laboratory will continue to partner with industry, universities, stakeholders, and collaborators at other national laboratories to collectively leverage our skills and resources to address the complex issues and requirements involved with high-level tank wastes. High-level tank waste represents DOE's largest and most complex environmental cleanup project (representing 60 percent by volume of the total radioactive waste in the United States from nuclear weapons development). We will continue to provide the essential science and technology leadership to support the efforts to retrieve, treat, and dispose of Hanford tank waste. Our research efforts will seek ways to reduce the cost and uncertainty of tank waste cleanup.

We are continuing to assist the Office of River Protection in developing and executing contracts for designing, constructing, and operating a multibillion dollar tank-waste treatment facility at Hanford. We provide the Office of River Protection the expertise to conduct technical reviews of the products from these contracts. We also support DOE in strategic planning for the complete project life cycle by identifying ways to reduce cost, identifying schedule or uncertainties in the current baseline plans, and providing alternative technical approaches and investments in better science and technology.

We will continue in fiscal year 2001 to contribute to DOE's Environmental Management Science Program by conducting projects on high-level waste, subsurface contamination, and characterization and monitoring. This program, established by Congress, provides an effective teaming of national laboratories and universities on the most critical and urgent research questions. This program will enable our team to deliver technology solutions and support critical cleanup efforts at the Hanford Site and at other highpriority DOE sites.

\section{Disposal of Transuranic and Mixed Low-Level Waste}

Effective and innovative approaches to cleanup of transuranic and mixed waste throughout the DOE complex is another important area where Pacific Northwest National Laboratory is delivering environmental solutions. Our capabilities in remote handling technologies, radiochemistry expertise, and understanding of radioactive waste behaviors are valuable resources for DOE's Office of Science and Technology and its Richland Operations Office.

Full-scale application of cleanup technologies will, in most cases, be performed through partnerships, wherein we will merge the capabilities of our science expertise, research tools, and analytical facilities with our knowledge of our industrial partners to conduct cleanup activities for our client. 


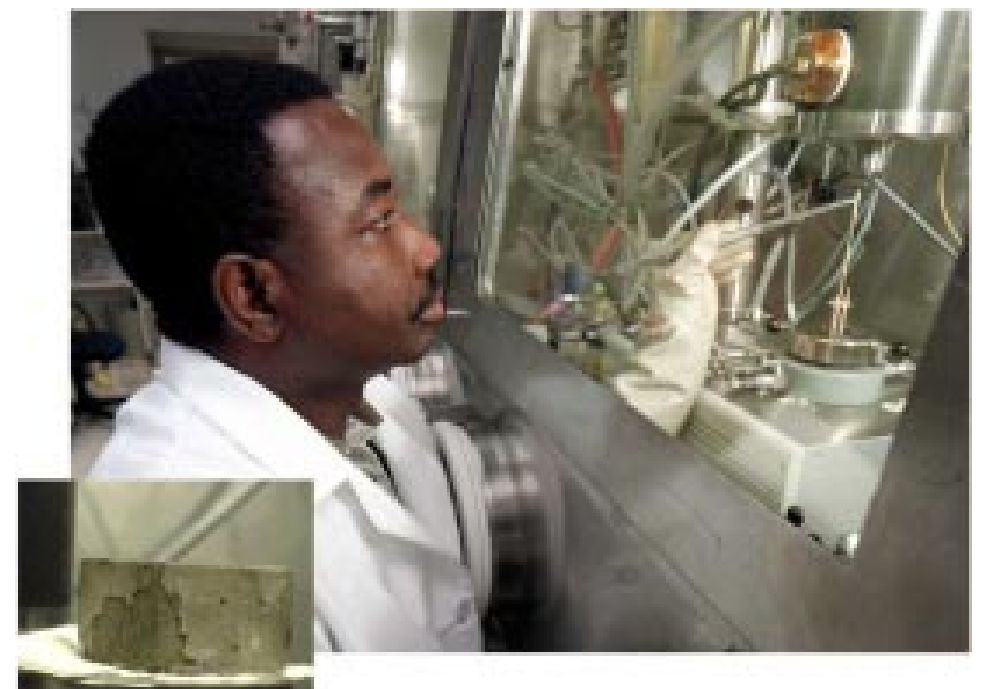

Pacific Northwest National Laboratory's expertise in nuclear materials is resulting in new methods for Hanford cleanup, particularly in preparing waste forms for safe interim, long-term, and permanent disposal. One treatment approach for stabilizing polycubes using existing muffle furnaces, developed together with scientists at Fluor Hanford, will result in substantial savings in cost and time.
An area of growing involvement for the Laboratory has been in our technical support role for cleanup of the Plutonium Finishing Plant in the Hanford 200 Area. The Department of Energy, together with the managing contractor for the Plutonium Finishing Plant (Fluor Hanford) accepted our recommended approach for stabilizing 1600 polycubes-two-inch cubes of plutonium that were fabricated in polystyrene in the 1960s for criticality testing-as well as other hazardous materials, which will result in significant cost and schedule savings. The deteriorating polycubes are creating potential environmental health risks and storage challenges. The treatment process will avoid a costly interim step by stabilizing the polycubes in a muffle furnace. The estimated savings are about \$5 million, as well as reducing three years from the work schedule.

Our success with plutonium polycube stabilization led to an expanded role in support of other plutonium stabilization activities. We are managing the technical scope associated with the magnesium hydroxide precipitation process for plutonium-bearing solutions. We are working on other process improvements at the Plutonium Finishing Plant. One strategy and conceptual design for continuous furnace operations reduced cycle times by nearly 50 percent and resulted in substantial cost savings (perhaps $\$ 50$ million) and may make it possible to close the plant one year ahead of schedule.

\section{Nuclear Material Disposition}

Pacific Northwest National Laboratory contributes to the DOE Materials Disposition Program by applying our plutonium expertise and hot cell facilities to support pit conversion and plutonium waste vitrification. We are developing methods for safe handling of plutonium and other radioactive materials, and we are providing methods for safeguarding plutonium materials during moves from a highly secured laboratory environment to an industrial setting. The Laboratory is involved in facilitating relations with the former Soviet Union to address their material disposition issues and is conducting waste form testing.

Pacific Northwest National Laboratory provides technical support for safe storage of our nation's inventory of depleted uranium. Approximately 700,000 metric tons of uranium hexafluoride gas are stored in more than 46,000 cylinders at Portsmouth (Ohio), Paducah (Kentucky), and Oak Ridge (Tennessee).

\section{Remedial Action}

Pacific Northwest National Laboratory is working to ensure that science and technology investments are focused on priority needs at Hanford and at other sites throughout the DOE complex. We are providing the Richland Operations Office and the Project Hanford Management Company with guidance and technical bases for Site cleanup decisions. This guidance is also applicable to cleanup decisions at other sites with similar waste 
challenges. We are providing new technologies, scientific studies, and other technical services to major programs and a number of direct-support services to the Hanford Site, including integrated groundwater monitoring, radiation protection, analytical services, analyses supporting privatization, and environmental assessments.

A key contribution to environmental restoration activities is our effort to develop systems assessment tools for prioritizing the cleanup activities based on analysis of the health risks to people and ecological impacts. We are developing new and more effective cleanup technologies that provide increased safety for workers.

The Groundwater/Vadose Zone Integration Project was established in late 1997 by DOE to provide an innovative and new approach for protecting the Columbia River, which is paramount to the comprehensive Hanford Site cleanup effort. Pacific Northwest National Laboratory is involved in all activities of the Integration Project, which evaluates future impacts from contaminant movement through Hanford's subsurface-and ultimately into the Columbia River. Our Laboratory leads two of the six primary Integration Project endeavors, including Science and Technology, and development and application of the Systems Assessment Capability. Our leadership within the multilaboratory science and technology role is essential, because many uncertainties and data gaps limit our knowledge of the inventory, distribution, and movement of contaminants in the vadose zone and groundwater beneath the Hanford Site. We need to better understand how contaminants move through soils and groundwater, and we are working to identify effective and appropriate methods to limit this migration. The Systems Assessment Capability is being designed to provide an overall assessment of the impacts and risks associated with Hanford Site contaminants, and will enable the determination of the cumulative long-term impacts of Hanford-derived contaminants on the Columbia River and the Northwest. The Systems Assessment Capability involves an expanded evaluation and methodology to communicate "risk" from Hanford's contaminants, which includes human, ecological, sociocultural, and economic health factors. Pacific Northwest National Laboratory also provides site-wide monitoring and modeling of the Hanford groundwater and river systems. Signatures of the Integration 


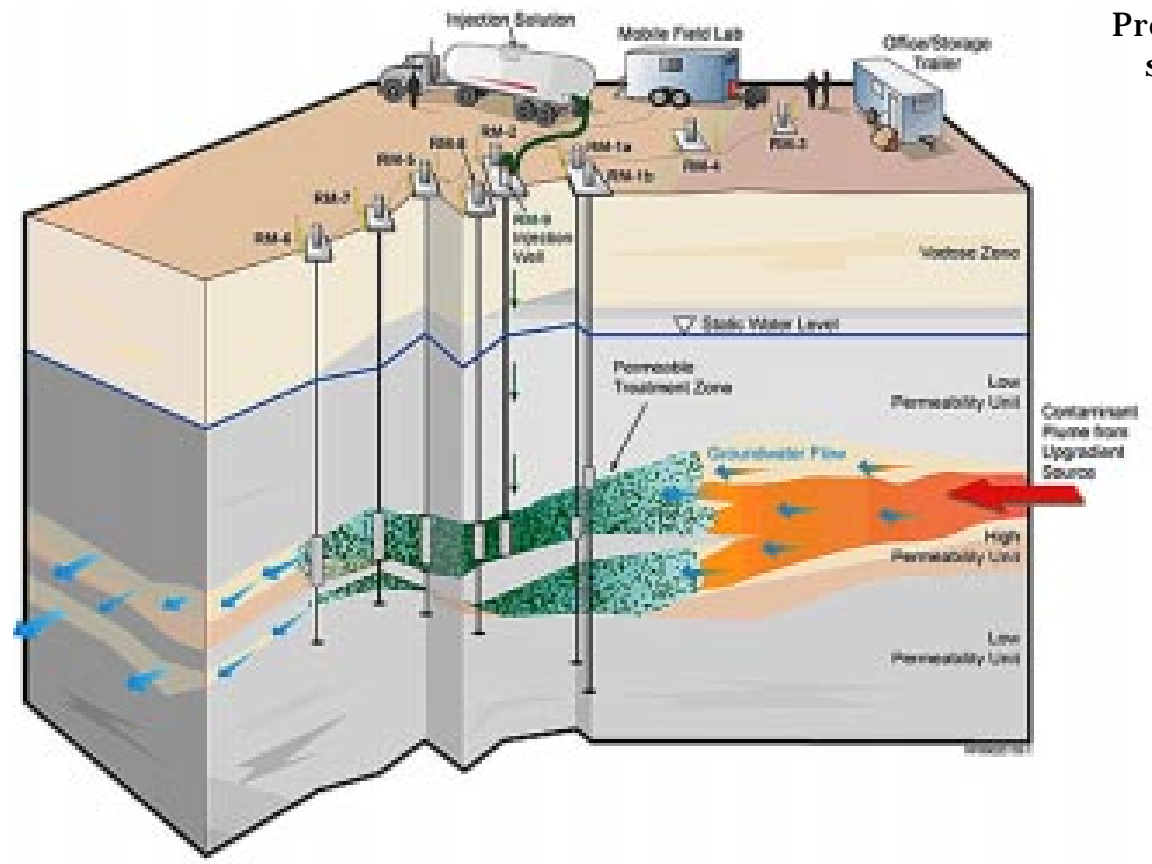

The field tests on In Situ Redox Manipulation show that treatment can remove toxic chromate from the groundwater to levels below drinking water standards and water quality standards for aquatic life.
Project are that the project is science based; includes strong participation from DOE's national laboratories; incorporates rigorous technical reviews, including reviews from the National Academy of Sciences; and engages diverse stakeholders in a meaningful way to inform and influence Hanford decisions.

Pacific Northwest National Laboratory's In Situ Redox Manipulation technology (a passive cleanup system for stabilizing or detoxifying contaminants before they reach the Columbia River) is proving safe to implement and will require minimal long-term maintenance. This technology is becoming a recognized model for advanced cleanup technologies. In Situ Redox

Manipulation is now being applied full-scale at the Hanford Site to treat underground plumes of chromate and prevent their migration to the Columbia River.

In the future, our environmental challenges will focus even further on quality of life issues and resource sustainability. We will continue to provide solid science and technology policy to achieve our national goals for environmental quality, products, and services. These policies will support a science mission that works toward preventing pollution, minimizing waste, minimizing risks to human health, and reducing costsin close alignment with operations that are consistent with DOE's emphasis on environmental quality.

\section{Major Research and Development Thrusts}

We are carrying out three major technical efforts to expand our role in the DOE environmental quality research portfolio.

\section{Process Science and Technology for Complex and Special Wastes}

Pacific Northwest National Laboratory will continue to provide strong process science and technology capabilities to address DOE needs, with special emphasis on complex and special wastes. The nature of complex wastes, such as those present in the Hanford high-level tanks, adds technical uncertainty, significantly increasing the costs and risks to retrieval, treatment, and disposal efforts. We are addressing these issues by developing work-plan roadmaps and new technologies. We plan to provide a stronger science and technology role for the Office of River Protection. We are identifying knowledge gaps, where significant reductions in cost and uncertainty can be achieved.

Pacific Northwest National Laboratory continues to support the research on the effective retrieval and treatment of tank waste streams. Our research efforts on advanced analytical tools and robotic characterization systems are successful examples of areas 
where we have made significant contributions. Another example is our study of colloidal agglomerates in tank sludge and their impact on waste processing. Our scientists are conducting experiments to understand and identify the chemical conditions that control the formation and agglomeration of colloidal particles in waste. In this way, the effect that agglomerate structures have on the rheology and sedimentation properties of the waste can be quantified, and methods for manipulating agglomerate structures to optimize tank waste transfer and processing conditions can be developed. This new knowledge and data also will benefit the cleanup of $\mathrm{K}$ Basin liquids in the Hanford 100 Area, as well as the problems of tank wastes at the Oak Ridge and Savannah River sites.

\section{Systems and Risk Analysis}

Pacific Northwest National Laboratory is recognized for its expertise in risk assessment. We will continue to improve our understanding of the basic processes that influence the release, transport, human exposure, and health effects of environmental contaminants through studies in our health sciences projects and initiatives. These include the health-related projects that are part of the Environmental Management Science Program, our molecular biology program's low-dose initiative, and our biological sciences initiative.

Among current projects is an effort to study mechanisms that are involved in trichloroethylene-induced liver cancer and the linkages to environmental cleanup policy. This work involves the induction and progression of liver tumors using the advanced imaging capabilities for small animals in the Environmental Molecular Sciences Laboratory. In this study, Laboratory scientists are developing critical data for updating the human health and safety risk-based cleanup standards for trichloroethylene that were developed more than 20 years ago. These data could potentially allow changes in risk-based standards for trichloroethylene that could reduce complex-wide cleanup costs by several billion dollars while still protecting humans and the environment.

The Laboratory leads several site-wide risk assessments at Hanford in support of cleanup decision making. The Waste Disposal Integration Team supports DOE's Office of River Protection in an effort that links risk allocation schemes with project costs to obtain the best balance of risk and cost. We work with DOE's Center for Risk Excellence and with the Richland Operations Office on risk-based methods and data for measuring change in site risk profiles as cleanup proceeds. This effort helps DOE ascertain the scope and requirements of long-term management and stewardship of an area as the cleanup mission evolves and proceeds toward closure.

\section{Groundwater and Vadose Zone Characterization, Monitoring, Modeling, and Treatment}

We continue to strengthen our science base for defining cleanup requirements and for understanding the natural processes that take place in the subsurface. These 


\section{R\&D 100 Award Winner}

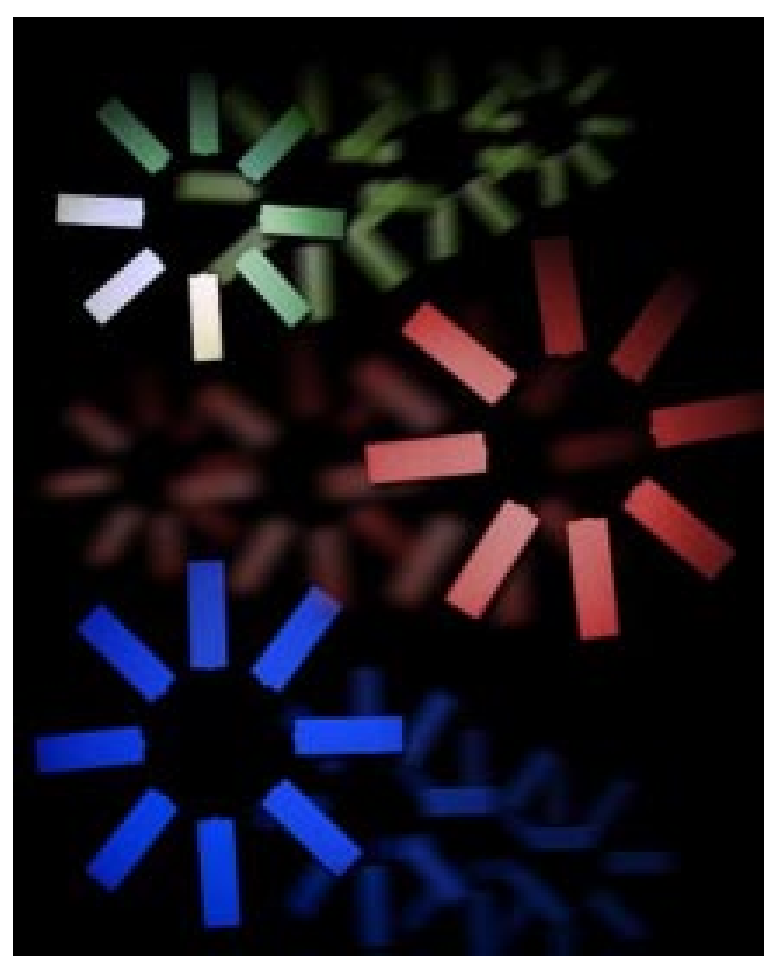

The Sunna Dosimeter ${ }^{T M}$ is a small, plastic wafer that is being marketed to accompany food products during irradiation (cold pasteurization). The dosimeter ensures that products receive doses within regulatory requirements. Shining blue light on the irradiated dosimeter induces it to emit red light (fluorescence). The intensity of the red provides the dose value that the food received, with a high degree of accuracy. Cold pasteurization destroys pathogens like E. coli and Listeria. Cold-pasteurized hamburger and chicken, as well as some produce, will be available in a limited number of supermarkets soon, and are expected to be readily available to consumers in the next few years. capabilities are enhanced by work such as the Natural and Accelerated Bioremediation Research project and through selected Laboratory Directed Research and Development investments in computational science and reactive transport.

Current projects in support of subsurface contaminant characterization, monitoring, modeling, and treatment include a study of mineral surface processes that are responsible for the decreased retardation (or enhanced mobilization) of cesium-137 from high-level tank waste discharges. Laboratory researchers are investigating the geochemistry of cesium-ion adsorption under conditions that resemble high-level waste tank releases. High sodium concentrations in tank waste are thought to suppress all but the most selective cesium sorption sites on the frayed edges of micaceous particles. The hydroxide and aluminate compounds in high-level waste may alter these sites chemically and may lead to faster transport through the soil. Our studies of these processes are enabled by the new capabilities provided by atomic-force and high-resolution electron-beam microscopes in the Environmental Molecular Sciences Laboratory-capabilities that were not previously available for visualizing and characterizing these processes.

The Office of Science and Technology is supporting our efforts to develop and deploy new technologies for in situ stabilization and containment using permeable barrier concepts and reactive treatment wells. This important characterization and modeling work provides a technical basis for exploring questions about the long-term management of some waste sites as part of the stewardship role that remains after cleanup.

\section{Capability Development: Role of Laboratory Initiatives}

Laboratory initiatives strengthen the science and technology capabilities that we need to carry out the above activities.

- The biological sciences initiative will provide a better understanding of the relationships between exposure and response-particularly at the cellular level. Research in this area will support our effort to strengthen cleanup policy and will provide stronger risk-based approaches.

- The Computational Sciences and Engineering initiative will develop the sciencebased capability to optimize new-generation contaminant cleanup technologies and to predict chemical and microbial processes in the subsurface. We are building the technical capabilities and tools that we need to better predict the fate and transport of contaminants through the subsurface. 


\section{Environmental Quality Program Roles}

DOE Office
Pacific Northwest National Laboratory Role

\section{Environmental Restoration and Waste Management}

DOE-EM (30) Office of Waste Management

DOE-EM (40) Richland Operations Office

DOE-EM (50) Office

of Science and

Technology

DOE-EM (60) Office of Nuclear Energy, Science and Technology

Office of Fissile Materials Disposition

\section{Environment, Safety and Health}

- Office of Oversight - Office of Environment -Office of Worker Health \& Safety - Office of Health Studies
Pacific Northwest National Laboratory provides support to DOE's Office of Environmental Management on numerous waste management activities on the Hanford Site that include special nuclear material stabilization and disposition and broad technical and special analytical support. Our support to the River Protection Project includes waste tank retrieval and review of key deliverables to DOE by the privatization contractor. We also provide the Site radiation services and manage the cleanup and Site closure of legacy waste. Pacific Northwest National Laboratory also provides support to cleanup of the West Valley Site in New York.

Pacific Northwest National Laboratory provides support on surface environmental surveillance, Hanford Site planning and integration, waste management operations, and Hanford environmental oversight activities. Additionally, Pacific Northwest National Laboratory provides management and technical support to ongoing environmental restoration activities. These include groundwater monitoring and the cultural resources programs on the Hanford Site. We also lead the science and technology effort for the Hanford Groundwater/Vadose Zone Integration project, and we provide project support to numerous activities at Hanford. A key facility in support of activities for the Richland Operations Office is the Radiochemical Processing Laboratory, where research is conducted on radioactive and hazardous material. Pacific Northwest National Laboratory provides technical support to the Office of Nuclear Material and Facility Stabilization in the spent fuel removal, treatment, and safe storage activities identifying cost-effective solutions for $\mathrm{K}$ Basin sludge.

Pacific Northwest National Laboratory plays a critical role in support of the Office of Science and Technology in the strategic planning and development of their five-year research agenda and their multiyear research and development program roadmaps. Through our management of the National Tanks Focus Area, we support development of the science and technology roadmaps and new technologies for tank waste cleanup efforts across the DOE complex. We also are leading and collaborating on new and innovative research projects through the Environmental Management Science Program and moving that knowledge into the national focus areas and site cleanup projects. Other activities include developing and deploying new technologies for in situ stabilization and containment using permeable barrier concepts and reactive treatment wells.

Pacific Northwest National Laboratory supports nuclear energy research and development planning by participating in subcommittees of the Nuclear Energy Research Advisory Committee. In support of the isotope production and distribution mission, we develop radiochemical processing and separations techniques for medical isotopes (such as yttrium-90 from strontium-90, and bismuth-213 from actinium-225). Although the yttrium-90 production activity was successfully privatized in fiscal year 1999, we have retained the backup capability to produce yttrium-90 if needed by DOE in the future.

Pacific Northwest National Laboratory provided a roadmap for developing accelerator transmutation of waste technology, which DOE submitted to Congress in November 1999. We prepared the Fast Flux Test Facility Scoping Plan at the request of the Secretary of Energy. Based on this report, the Nuclear Energy Research Advisory Committee recommended that work proceed toward a Record of Decision on the Fast Flux Test Facility, and the Secretary adopted this recommendation. Pacific Northwest National Laboratory also won four of the 46 awards under the Nuclear Energy Research Initiative, and is a collaborator on two additional awards to university-led teams.

Pacific Northwest National Laboratory supports DOE-MD through programs that use our plutonium expertise and hot cell facilities to support pit conversion and vitrification of plutonium.

Pacific Northwest National Laboratory supports the Office of Environment, Safety and Health in its mission to ensure that DOE's activities conform to the applicable laws and requirements governing environmental protection, safety, and health of workers and the public. This programmatic support includes technical assistance in the areas of policy analysis, independent oversight, programmatic assessments, worker protection, and health studies. 


\section{Energy Resources}

Our country faces the continuing challenges of diminishing natural energy resources and increasing demands on our energy supplies. Pacific Northwest National Laboratory is engaged in essential research that will significantly benefit DOE's energy mission by providing technical competencies in four areas where we can deliver added value: clean and efficient vehicles, efficient and affordable buildings, clean and affordable power, and clean and productive industries.

\section{Strategic Intent}

We will focus the resources of the Laboratory-from basic research to engineering development-to create valuable solutions that resolve critical gaps in the ability of industry to respond to the Department of Energy's mission objectives. The Laboratory will seek to accomplish these outcomes through effective collaboration with industry and other national laboratories and by building on our long history of industrial research.

Pacific Northwest National Laboratory's capabilities in materials science, fuel cell technology, sensors and controls, systems engineering, computational engineering, and manufacturing process innovation will be used to demonstrate technical outcomes important to DOE's strategic energy goals. We will maintain our technical strengths in building codes and standards, and will greatly increase the scientific and technical content of our energy programs in power and transportation systems, industrial efficiency, and climate-change issues.

Supporting our strategy for innovation, we are investing internal resources in technical thrust areas of efficient and lightweight vehicle structures, fuel cell systems technology, clean fuels and vehicle emissions-reduction technology, and engineering simulation and modeling. Through these investments, the Laboratory will provide leadership and accomplishment to DOE's energy

Relevant Technical Capabilities

- Compulational Sciences and Engineering

- Computer Science and Information Technology

- Design and Manufacturing Engineering

- Eneroy Technology and Management

- Material Science and Engineering

- Policy and Manogement Sciences

- Sensors and Controls

- Separations and Comversion

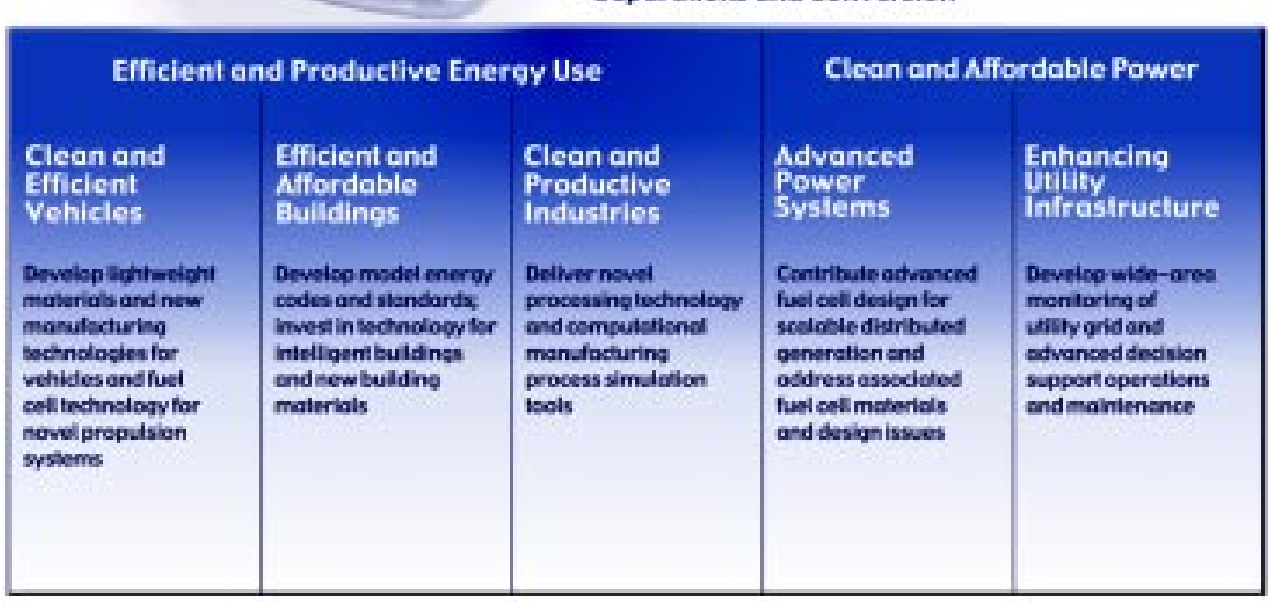

Energy resources mission strategy. resources agenda.

In addition, we will support energy resources in developing robust strategies that address the technological implications and market impacts of carbon management. This will be accomplished by focused investments in bio-derived fuels and feedstock products. Each element of our energy resource strategy is integrated into a crosscutting carbon management agenda. We are providing a balanced perspective to the technological, ecological, and economic dimensions associated with stabilizing and reducing atmospheric carbon levels. 


\section{Our Role in the Energy Resources Research and Development Portfolio}

Pacific Northwest National Laboratory will advance DOE's mission to provide efficient and productive energy use and clean and affordable power by making significant contributions to five high-level objectives defined in the energy resources research and development portfolio. We will strive to develop new technologies in each of the major focus areas of the portfolio: reliable and diverse energy supply, clean and affordable power, and efficient and productive energy use. Specifically, research in energy science and technology at the Laboratory will focus on cleaner and more efficient vehicles, efficient and more affordable buildings and building-support technologies, and new technologies for helping industry to reduce costs and to increase the reliability of distributed and hybrid advanced power systems.

\section{Efficient and Productive Energy Use}

Automobiles, buildings, and industries are major consumers of energy resources. Pacific Northwest National Laboratory is engaged in research to meet current and future energy consumption challenges.

\section{Clean and Efficient Vehicles}

We will continue to develop lightweight materials and new manufacturing technologies that support vehicle gas mileage reduction in light and heavy vehicles. We will develop new fuel cell technology for novel propulsion systems and auxiliary power sources for clean fuels and for advanced vehicle emission reduction technologies.

Our leadership in the Northwest Alliance for Transportation Technology initiative highlights our role in achieving clean and efficient vehicles. This initiative is a public-private partnership designed to meet the challenges of developing automobiles and trucks with reduced pollutant emissions and higher fuel efficiencies. The Northwest Alliance will position Pacific Northwest National Laboratory as a significant player in mission-critical areas for automotive and heavyvehicle manufacturing. The strategic foundation of the Alliance is to establish a systems management approach that links our technical competencies in system design, materials innovation, virtual system simulation, and manufacturing process innovation. This linkage will ensure that the Laboratory adds value to the missions, objectives, and critical outcome drivers of key initiatives of the Partnership for the Next Generation Vehicle and DOE's programs for energy-efficient heavy vehicles. Strategic alliances developed with the automotive and heavy-truck industries will ensure that industry needs are met, and that commercially viable technology and intellectual

\section{FLC Award Winner}

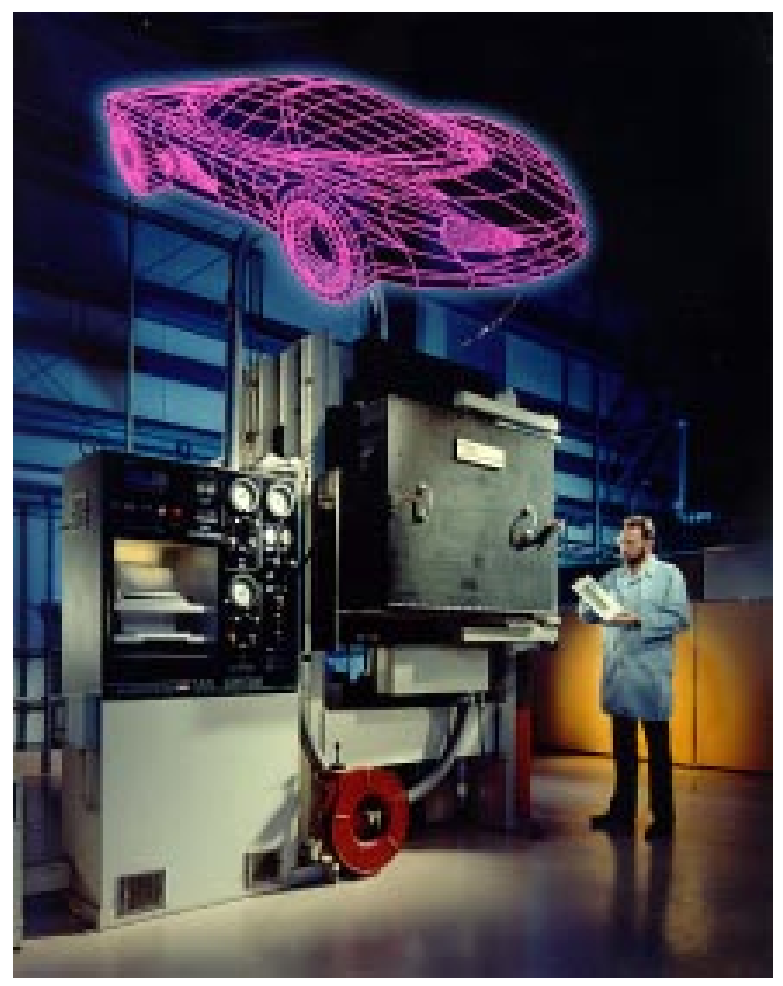

Researchers at Pacific Northwest National Laboratory are collaborating with U.S. automakers on superplastic forming of metals in support of U.S. "Clean Car" requirements for lighter, more energy-efficient cars. Superplastic forming of aluminum has the potential to reduce the weight and cost of structural components as well as improve automotive mileage. 
property is readily transferred and adopted by the auto and heavy-vehicle industries. This initiative is also developing new capabilities in vehicle emission reduction technologies and advanced lightweight materials.

The auto industry needs new engineering simulation and design tools if new materials and manufacturing processes are to be adopted. Building on Pacific Northwest National Laboratory's strengths in large-scale, high-speed scientific computing and simulations, we are aggressively pursuing new approaches to engineering simulation tools and approaches that use the capabilities of next-generation parallel computers with the auto industry and DOE. These engineering simulation efforts are integrated within the Laboratory's Computational Sciences and Engineering group.

\section{Efficient and Affordable Buildings}

We will develop new technology for "smart buildings," including new building materials, microscale heat pump devices, and automated diagnostics for operations and maintenance. In addition to providing a place to work and live for nearly all Americans, our buildings must provide a healthy and safe indoor environment.

Pacific Northwest National Laboratory focuses on multidisciplinary solutions to improve building energy efficiency. We also are looking closely at ways to improve the comfort and health of building occupants. We work closely with the building industry and with other partners to improve the energy efficiency of the buildings and to increase their use of renewable resources. The Laboratory supports the initiation of the Buildings of the $21^{\text {st }}$ Century program that will integrate modern building technologies. We played a critical role in developing and implementing model energy codes and standards. We

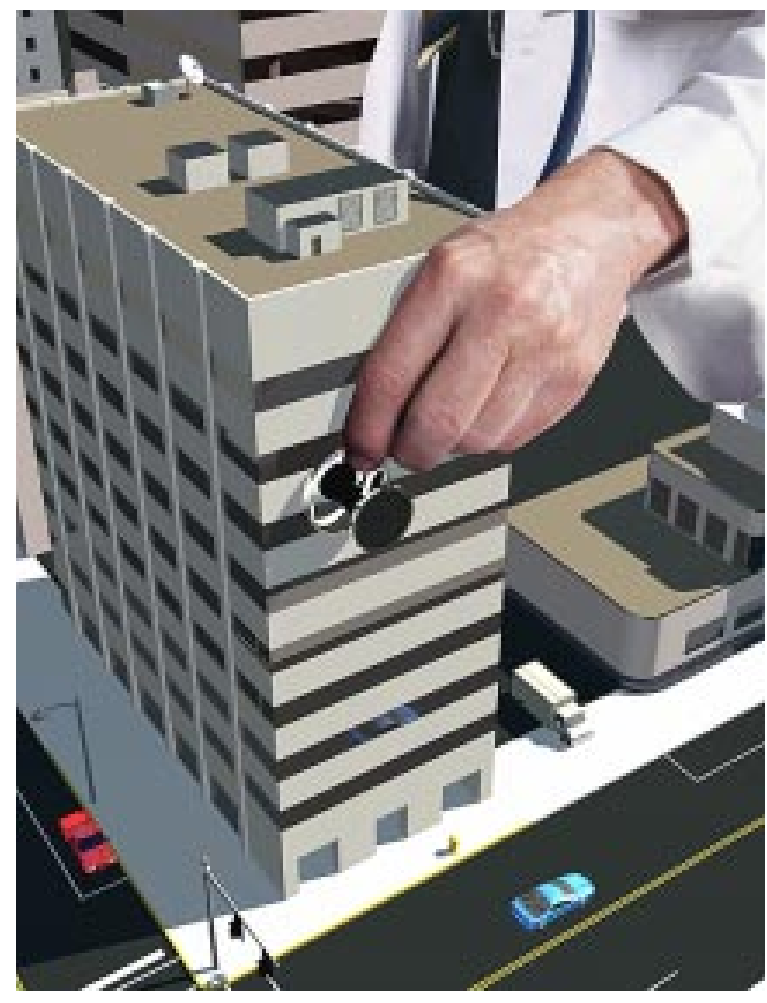

The Whole Building Diagnostician reveals hidden illnesses that plague most heating, ventilating, and air-conditioning systems. It monitors the performance of air-handling units to detect problems with outside air control and tracks overall building energy use. are an established leader in developing automated diagnostics for building applications. We currently work with industry to develop the intelligent building capabilities such as microscale heat pump concepts for building temperature control.

\section{Clean and Productive Industries}

Inefficient industrial processes waste vast amounts of energy. Pacific Northwest National Laboratory is developing new technologies and computational tools for simulating the manufacturing process to reduce industrial costs. We also are studying alternative bioderived fuels and bio-derived chemical feedstocks for the industrial chemical, forest products, aluminum, and glass industries. The Laboratory provides leadership for the Industries of the Future Laboratory Coordinating Council. This group facilitates access to the Laboratory capabilities that can help solve the major technology challenges.

Pacific Northwest National Laboratory's support to the clean and productive industries mission covers a broad range of activities, from program planning and technical evaluation to technology development and demonstration. Our process science and engineering competencies develop new methods for recovering energy from industrial wastes, identifying renewable routes for value-added chemical manufacture, and enhancing pulp and paper plant efficiencies with improved separation technologies. We are applying our capabilities in sensors and advanced manufacturing 
to glass fabrication through the use of non-contact stress measurement techniques and advanced process control methods. Other novel sensors will help the pulp and paper industry to measure pulp slurry characteristics and paper web properties. One of the key issues addressed by our collaborations with other national laboratories, industries, and universities is the characterization of multiphase fluid dynamic behavior in chemical plants with help from advanced computations and modeling.

\section{Clean and Affordable Power}

Fuel cells can provide abundant power without the emission of harmful contaminants. Pacific Northwest National Laboratory is committed to overcoming many of the immense technical obstacles that limit the broader application of fuel cells as a clean and affordable energy source.

\section{Advanced Power Systems}

Our efforts in solid-oxide fuel cell technology centers around a program jointly managed with the National Energy Technology Laboratory called the Solid-State Energy Conversion Alliance. This public-private alliance between federal agencies that fund advanced fuel cell research targets the transportation, mobile-military power, and stationary-power markets. The members of this alliance share a common commitment to commercializing cost-competitive, high-efficiency, fuel cell power.

If advanced, ultra-clean fuel cell technology can move from niche markets to widespread use in stationary-power and transportation applications, the high efficiency inherent in these technologies will result in significantly reduced carbon dioxide emissions and lower costs for power. The alliance approach coordinates federal research and development investments and encourages national program integration.

\section{Enhancing the Utility Infrastructure}

Inefficient energy grids waste electrical power and increase the costs to consumers. Pacific Northwest National Laboratory has extensive experience working with DOE and the utility industry to address the technology needs for reliable electricity supplies in the $21^{\text {st }}$ century. Laboratory staff conduct research to improve the operation and maintenance of power utility infrastructure and power-distribution control. We provide technology for reliable control of power plants, wide-area monitoring of utility grids, frameworks to facilitate deployment of distributed resources, and for infrastructure security. We have established partnerships with the utility industry on distributed resource systems and policy studies, grid reliability technology research, and new intelligent system control frameworks. The Laboratory will continue to collaborate with federal energy agencies on potential energy test beds and demonstrations.

Pacific Northwest National Laboratory has developed a real-time power system control called the Wide-Area Monitoring project, which aids in analyzing utility grid reliability. We conduct programs in energy resources management, environmental impact studies, and market transformation, which serve the power and energy services entities. We will be supporting the new initiatives in grid reliability and distributed resources. We will seek to deliver advanced operations and maintenance technologies to the power and transmission entities to aid in reducing regional power costs.

\section{Major Research and Development Thrusts}

To develop and expand our contributions to the energy resources research and development portfolio, Pacific Northwest National Laboratory is pursuing the following thrust areas:

- Smart Buildings Technology—Advanced sensor systems will help buildings operate more cost-effectively and with healthier interior environments for occupants. The Laboratory is working with other research institutions and with industry to develop 


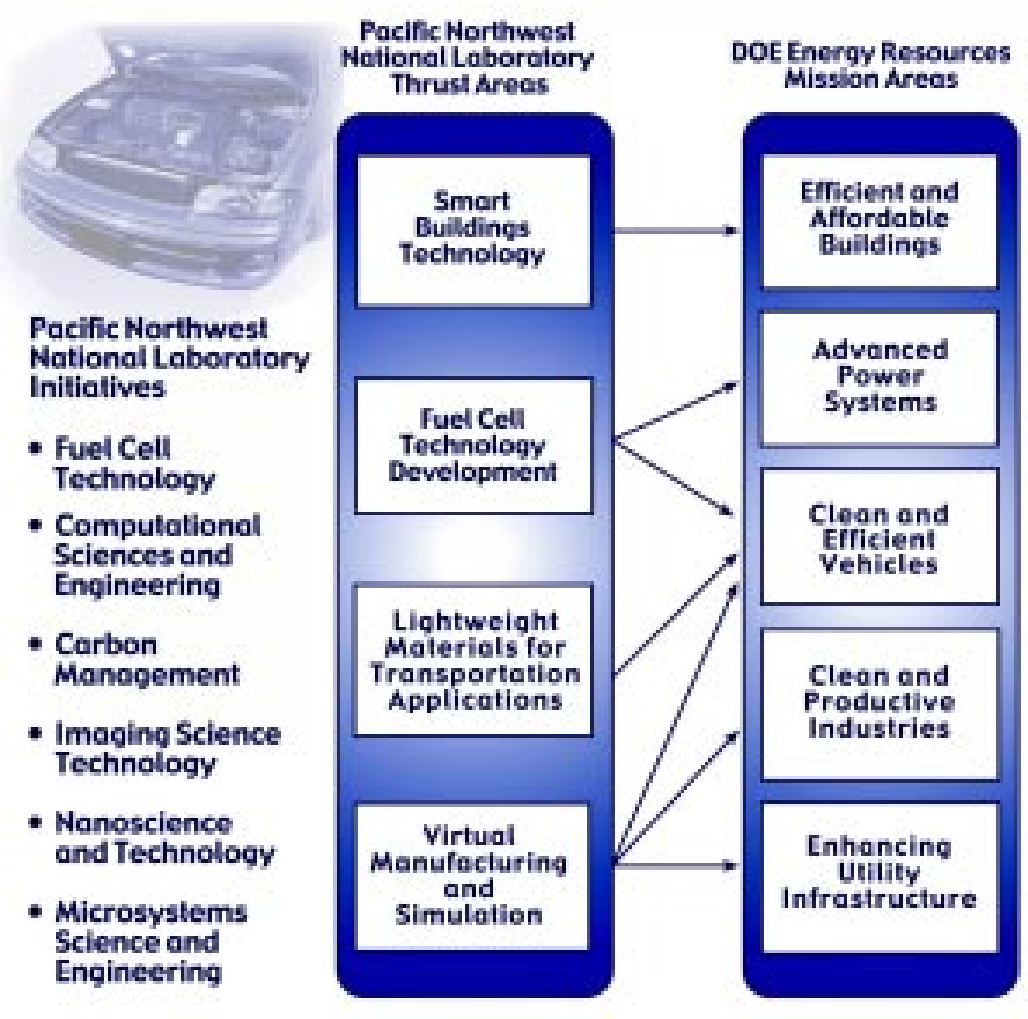

Major energy resources research and development thrusts. advanced system controls and diagnostics for improved and more reliable ventilation, heating, and air-conditioning.

- Fuel Cell Technology Development-This program will overcome barriers to mass customization of solid-oxide fuel cells. This research focuses on developing high-temperature materials, improved manufacturing, fuel reformation strategies, system performance models, intelligent diagnostics, and control systems.

- Lightweight Materials for Transportation ApplicationsThis program improves Laboratory competencies in system design, materials innovation, virtual system simulation, and manufacturing process innovation. Our goal is to produce improved light metal alloys and composites, and to deploy these new materials in automotive and heavy vehicle structures.

- Virtual Manufacturing and Simulation-Our high-performance scientific and engineering modeling uses advanced modeling software and creates a virtual prototyping for advanced manufacturing capability. Applications in this initiative include basic materials theory, prototyping analysis, and life-cycle assessment.

\section{Capability Development: Role of Laboratory Initiatives}

Our energy sciences and technology initiatives strengthen Laboratory capabilities that are needed to carry out the major DOE research and development objectives.

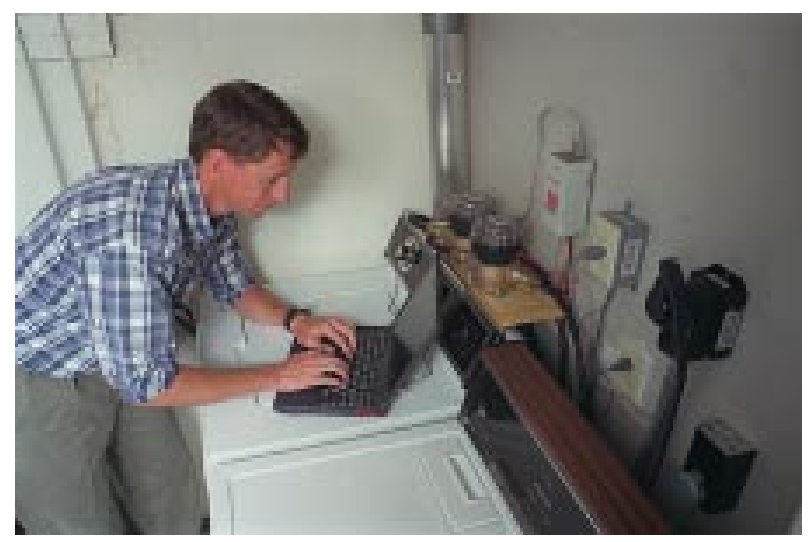

Pacific Northwest National Laboratory brought metering expertise to a study of water savings in two Oregon cities and also was responsible for evaluating study results. The study was sponsored by the U.S. Department of Energy.
- Pacific Northwest National Laboratory's Microsystems Science and Engineering initiative will build capabilities that will result in innovative heat pumps for man-portable, vehicle, and distributed heating and cooling applications. The chemical processing techniques for microtechnologies are providing new concepts for fuel reformation. This initiative was in transition from Laboratory Directed Research and Development to programmatic support in fiscal year 2000.

- Our Computational Sciences and Engineering initiative builds capabilities and tools for virtual manufacturing software applications, including material property studies, advanced engineering mechanics, problem-solving, and simulations.

- Our Carbon Management initiative builds on Laboratory expertise in climate research. This initiative will support DOE with technologies for limiting carbon releases to the atmosphere. 


\section{Energy Resources Program Roles}

\section{Office of Energy Efficiency and Renewable Energy}

Building Technology, State and Community Programs

Bonneville Power Administration

Federal Energy

Management Program

Office of Industrial Technologies

Office of Power

Technologies

Office of Transportation Technologies

Policy Office

\section{Fossil Energy}

Fuel Cell Programs and Solid-State Energy Conversion Alliance
The Building Standards Program plays a critical role in supporting the Office of Building Technology, State and Community Programs in developing and implementing model energy codes and standards. We also are key participants in the Rebuild America, Building Systems, Economic and Systems Analysis Program, Market Transformation, and commercial equipment standards programs that support the development of energy efficiency for buildings and their use of renewable resources.

We provide research and development to reduce Bonneville Power Administration operating costs and to increase the value of services offered by Bonneville Power. Pacific Northwest National Laboratory deploys its capabilities and products to serve Bonneville's transmission group in real-time power system control and operation via the Wide-Area Monitoring project, conducted in partnership with the Electric Power Research Institute and DOE. Pacific Northwest National Laboratory also contributes fisheries and ecosystem science support to Bonneville's mission to rejuvenate fisheries in the Northwest. Bonneville has established a regional leadership position in assessing the role that distributed energy resources can play in the Northwest. Pacific Northwest National Laboratory is working with Bonneville to frame the benefits and options of various distributed resources technologies in this new industry trend, which promises to have significant positive impact on Bonneville's future strategy.

Pacific Northwest National Laboratory is a key participant in the Federal Energy Management Program to increase the efficiency of federal energy use by facilitating implementation of energy and water conservation measures in federal facilities through policy action, coordination, and assistance with technology and financing tools.

The role of Pacific Northwest National Laboratory in supporting the Office of Industrial Technologies covers a broad range of activities, from program planning and technical evaluation to technology development and demonstration. Current technology development programs draw upon Pacific Northwest National Laboratory competencies in process science and engineering, sensors, and advanced manufacturing technologies. Specific projects address technology needs associated with resource efficiency in the chemicals, glass, and forest products industries. We also support the NICE3 Program and provide leadership to the Laboratory Coordinating Council.

Pacific Northwest National Laboratory provides technologies and capabilities to the Office of Power Technologies and the utility industry on distributed resource systems and policy studies, grid reliability technology research, intelligent system control frameworks, and technologies to ensure security and integrity in an unregulated utility industry.

Pacific Northwest National Laboratory plays a leadership role in the National Alliance for Transportation Technology, a public-private partnership designed to meet selected goals within the Partnership for a New Generation of Vehicles and for heavy vehicles. We also have a significant role in fuel cell technology, fuel reformation, and emission control. Pacific Northwest National Laboratory provides assistance to the Policy Office in economic and policy analysis. Our assistance has also resulted in improvements in understanding policy approaches to controlling greenhouse gas concentrations and in the development of the Second Generation Economic Model and in supporting international nonproliferation agreements.

Pacific Northwest National Laboratory provides leadership in the Fossil Energy Fuel Cell Program and technology developments in support of the evolving public-private partnerships and Fossil Energy's Vision-21 initiatives. 


\section{National Security}

The threats to United States' security in the $21^{\text {st }}$ century are real and diverse. Proliferation of weapons of mass destruction and their associated delivery systems remains a worldwide concern. Terrorism exists. Protecting our critical infrastructure is essential to our national security. The Department of Energy and its national laboratories have a critical role in addressing these national security issues-providing technical solutions in support of national policy.

\section{Strategic Intent}

Pacific Northwest National Laboratory's strategy is to support DOE's national security mission. DOE is charged by law to enhance U.S. national security through the military application of nuclear technology and to reduce the global danger from the proliferation of weapons of mass destruction. The Laboratory's objective is to employ its science and technology capabilities to meet specific goals identified in DOE's national security research and development portfolio. The national security portfolio highlights the following priorities: maintaining the nuclear deterrent, monitoring

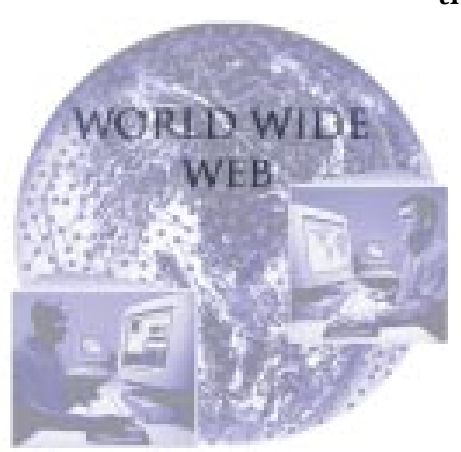
nuclear treaties and agreements, preventing proliferation, detecting
Relevant Technical Capabilitics

- Analyticel and Physical Chemistry

- Eorth Systems Science

- Materials Science and Technology

- Enerwy Technology and Manogement

- Nuclear Science and Enģineering

- Policy and Manogement Sciences

- Sensors and Electronics proliferation, countering weapons of mass destruction terrorism, and continued development of naval nuclear reactors. The Laboratory contributes strengths to each of these portfolio areas except the development of naval nuclear reactors, and expects to

- continue making significant contributions to nuclear treaty verification and nuclear nonproliferation, particularly in materials protection, control, and accountability; nuclear safety; nuclear component disposition; monitoring instrumentation; and technical policy

- expand our role in preventing and detecting the proliferation of chemical and biological weapons of mass destruction and in arms-control compliance

- develop significant capabilities to increase our role in counterterrorism, information security, and infrastructure protection

National security mission stragegy. 
- bring fundamentally new technologies and approaches to critical knowledge management problems posed by counterterrorism, nonproliferation and arms control, and intelligence analyses

- support maintaining the national stockpile of tritium and safe disposal of excess weapons-grade plutonium.

In addition to Pacific Northwest National Laboratory's programmatically supported national security work, science-based capabilities for national security applications are developed under our Laboratory Directed Research and Development program. The Infrared Sensing initiative provides capability development for DOE and its role in detecting the proliferation of nuclear, biological, and chemical weapons; in counterterrorism activities; and in related environmental research. The Cyber Security initiative builds capabilities that protect our critical information and network infrastructures from a variety of threats. The Imaging Science and Technology initiative will develop a new generation of image processing algorithms, analysis methods, and visualization (decision support) technologies to meet the challenges related to the generation and interpretation of large, multidimensional images at various scales in many fields. Other research efforts also address DOE's national security technology needs.

Pacific Northwest National Laboratory's national security work is conducted principally for DOE's National Nuclear Security Administration, Defense Nuclear Nonproliferation and Defense Programs, Office of Counterintelligence, Office of Intelligence, and Office of Security and Emergency Operations. DOE and the Laboratory also play an essential role in providing technical expertise to the Department of Defense, the State Department, the Department of Justice, and other government agencies through the Work for Others program. The National Nuclear Security Administration within DOE became effective on March 1, 2000. Consequently, the full impact of this reorganization on Pacific Northwest National Laboratory's national security work remains unknown; however, no significant impacts are anticipated for fiscal year 2001.

In the following sections, we describe our role in the DOE national security research and development portfolio and the technical thrusts that we are undertaking to strengthen our contributions and build capabilities to respond to future needs.

\section{Our Role in the National Security Research and Development Portfolio}

\section{Monitoring Nuclear Test Ban Treaties and Agreements}

For greater than half a century, Pacific Northwest National Laboratory scientists and their Hanford Site predecessors have been global leaders in monitoring man-made sources of radioactivity in the environment. Throughout the Cold War, the Laboratory operated sensitive systems for analyzing fallout and other samples from nuclear tests. In recent years, Laboratory staff have incorporated scientific and engineering expertise into fully automated, remotely programmable systems for monitoring atmospheric concentrations of radioactive particles and noble gases with exceptional sensitivity for near real-time measurements. These capabilities already have been employed in support of DOE's nuclear explosion monitoring program. In cooperation with DOE and other agencies, the Laboratory has identified additional radionuclide technology needs that must be satisfied for effective monitoring of foreign activities. When attempting to detect and characterize extremely weak signatures, as is necessary when using a few stations for monitoring the entire globe, it is quite easy to confuse signals and noise or other irrelevant phenomena. For this reason, statistical methods are designed carefully and applied to enhance the reliability of interpretations. The development and deployment of technologies to detect nuclear explosions benefits from decades of Laboratory experience applied throughout the Cold War for many of the same reasons currently proposed. Those detection technologies also will be valuable for potential nuclear test ban treaties. We project no end to this need. 
In support of the Department of Energy's national security strategic goal to continue leadership in technology development for international arms control and nonproliferation efforts, the Laboratory is committed to bringing technology and expertise to bear on the problems of monitoring nuclear treaties and agreements. The strategic goal for the program is to enhance the U.S. capability to monitor nuclear test activities of other nations. The following are strategies we use to approach this goal:

- Provide the U.S. government with the enhanced radionuclide collection and analysis capabilities needed to monitor other nations' compliance with the Comprehensive Test Ban Treaty and to satisfy its monitoring obligations as established in the Treaty. To do this, we develop, transfer, support, and enhance the necessary radionuclide technology.

- Provide the U.S. government with the experts for the negotiation of cost-effective Comprehensive Test Ban Treaty implementation measures. To do this, we send radionuclide experts to interagency meetings to advise on technical policy, and we provide radionuclide experts to staff the U.S. Treaty delegation.

- Provide the U.S. government with statistical tools and expertise needed for optimum processing and interpretation of nuclear test monitoring data. This is accomplished by cooperating with seismic experts at other institutions to optimize processing and interpretation of waveform data, and by developing new statistical tools to minimize the costs of operating monitoring capabilities.

\section{Nuclear Nonproliferation and Arms Reduction Monitoring}

DOE has a critical role in the Administration's interagency-wide effort to reduce the number of nuclear weapons and the amount of weapons grade material both in the U.S. and in the former Soviet Union. Technology must be developed, demonstrated, and deployed for confirming that an examined object is a nuclear weapon or a weapon component, without releasing any nuclear weapons design information or other information deemed sensitive by either the U.S. or Russia. Congress requires that material stored under the Mayak Transparency be proven to have come from actual nuclear weapons. Nuclear components must be tracked to long-term storage and the vault continuously monitored to ensure no material is returned to the stockpile.

Pacific Northwest National Laboratory is a key participant in DOE's efforts to develop technology that will verify the presence of nuclear material in a warhead, or that nuclear material was derived from a nuclear weapon, yet also have robust "information barriers" that prevent disclosure of classified or sensitive information. We also provide technical support to DOE and other policymakers regarding START III negotiation options.

\section{Preventing Proliferation}

Arms control treaties and agreements have resulted in significant quantities of weaponsusable fissile materials becoming excess to national defense needs in both the U.S. and Russia. Protection of these excess fissile materials from theft and unauthorized uses is of utmost importance. The Department of Energy's research and development portfolio for preventing proliferation addresses

- developing and implementing technologies that convert U.S. weapons-usable plutonium into forms that prevent its use for nuclear weapons

- assisting Russia in the demonstration of plutonium conversion technologies

- developing technologies to control and account for nuclear materials and physically protect these materials

- developing proliferation-resistant fuel for commercial reactors, to reduce and eventually eliminate the international traffic in highly enriched uranium for commercial purposes. 


\section{Fissile Materials Disposition}

Pacific Northwest National Laboratory staff are participants in DOE's efforts, together with other national laboratories in

- developing immobilization technologies for ultimate disposal of weapons-usable plutonium

- burning weapons plutonium in mixed-oxide fuel in existing domestic reactors

- demonstrating to the Russians that plutonium immobilization is a viable disposition option.

\section{Nuclear Materials Protection}

Effective material protection control and accounting measures will deter suppliers who seek long-term access to material for diversion. The development of real-time inventory and monitoring technologies will play an increasing role in future materials protection, control, and accounting activities. Laboratory staff will research, develop, and evaluate technologies for rapid inventory and remotely attended monitoring that use our capabilities in microsensors, information technology, and "collaboratory" technologies.

\section{Proliferation Resistant Fuel Cycle Technologies}

Pacific Northwest National Laboratory supports the development of chemical process technology for recovering and purifying molybdenum-99 for use in medical applications from targets specifically developed to use low enriched uranium fuels in the reactor.

\section{International Nuclear Safety and Cooperation}

Pacific Northwest National Laboratory will continue to provide primary support to DOE with international nuclear safety and security missions. We will provide lead project management, technical, and administrative support. This work reduces the risks of Soviet-designed reactors by working cooperatively with host countries to upgrade nuclear power plants to meet international standards and to build lasting safety cultures. We will lead bilateral efforts to stabilize the deteriorating "shelter" surrounding the destroyed Chornobyl reactor in Ukraine. We also will support the transition of this work to the European Bank for Reconstruction and Development, which has consolidated international funding and provides an integrated role. The Laboratory will provide increasing support to DOE in developing and implementing its nuclear security program to stop the production of weapons-grade plutonium.

This work supports several of Pacific Northwest National Laboratory's missions, such as

- meeting environmental, national security, energy, and human health needs by providing protection for Europe's public, economic, and environmental health and for U.S. personnel in Europe

- reducing the risk of destabilizing nuclear accidents in the emerging free-market democracies of the Newly Independent States

- working with other countries toward the shutdown of the least safe Soviet-designed nuclear power plants (those like the Chornobyl plant)

- supporting U.S. nuclear security goals by helping countries eliminate production of weapons-grade plutonium. 


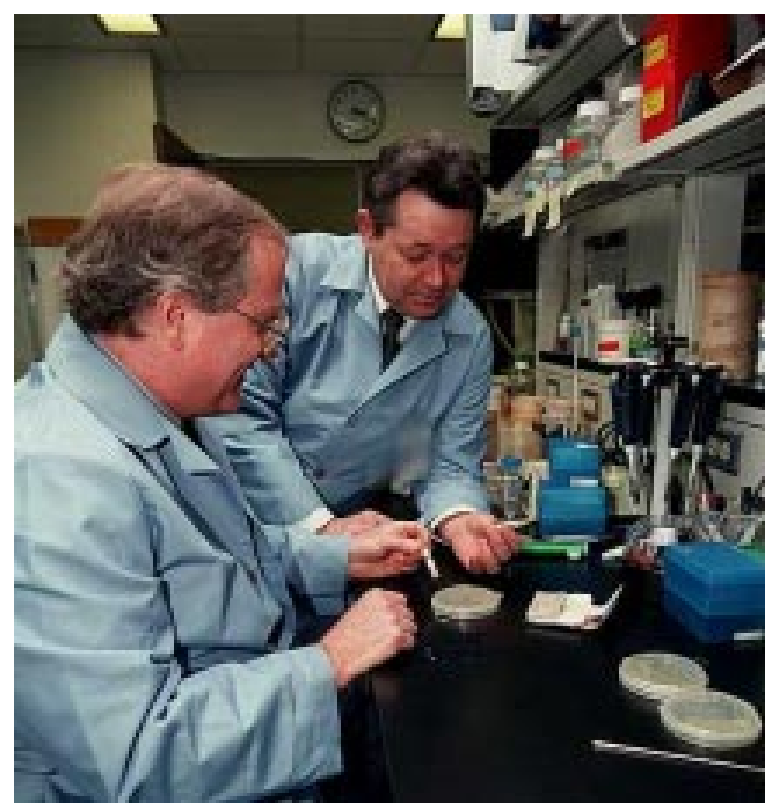

The Initiative for Proliferation Prevention is a collaborative program between the DOE's national laboratories, former weapons centers in the Newly Independent States and Russia, and U.S. industry to coordinate the transformation of biological, chemical, and nuclear weapons knowledge into peaceful, commercially successful products. In this photo, U.S. and Russian scientists discuss a method for detecting chemical signatures in living organisms.

\section{Initiative for Proliferation Prevention}

Pacific Northwest National Laboratory is a participant in the Initiative for Proliferation Prevention with the Newly Independent States of the former Soviet Union. The goals of this U.S. government program, executed jointly by the DOE and the Department of State, are to

- stabilize supporting technology, equipment, and facilities to enhance global nonproliferation

- develop advanced technology commercial opportunities and markets

- enhance U.S. science and engineering capabilities

- engage weapons scientists, engineers, and technicians in non-weapons-based activities.

The Laboratory coordinates the chemical and biological cooperative program under the Initiative for Proliferation Prevention.

\section{Detecting Proliferation}

Pacific Northwest National Laboratory's strategy is to develop solutions for a wide array of national security needs related to detection and identification of effluents and physical objects to reveal the proliferation or spread of weapons of mass destruction. Many of these effluent and physical detection technologies have direct civil applications in addition to addressing national security needs in detecting proliferation of weapons of mass destruction.

\section{Effluent Detection Technologies}

DOE's and the Laboratory's objectives in effluent detection include the development and demonstration of sensor systems for detection of chemical signatures indicative of proliferation of weapons of mass destruction. Among the national security needs that can be addressed are

- identifying chemical effluents from the production of nuclear, biological, and chemical weapons

- identifying and mapping chemical warfare agents on the battlefield

- wartime intelligence collection and targeting

- assessing battle and collateral damage from strikes against nuclear, biological, and chemical weapons and industrial targets

- supporting counterterrorism activities.

Civilian and research applications of chemical detection systems include

- counter-narcotics operations

- atmospheric chemistry and meteorology

- environmental monitoring and cleanup

- industrial and agricultural process control. 
Based on infrared technologies, most of Pacific Northwest National Laboratory's chemical sensing activity is focused on detecting the proliferation of nuclear, biological, and chemical weapons. Current efforts include generating infrared spectral data for effluent chemicals, advanced sensor science and component technology research, small-scale instrument system development, and limited development of data exploitation algorithms. An example of technology under development is a Dewar assembly for our portable Light Detection And Ranging (LIDAR) system. The Laboratory has profound strengths in a wide array of science, technology, and engineering fields related to infrared sensing, and these strengths provide the basis for a much broader program. The Infrared Sensing initiative strategy is, therefore, to develop a broader array of Laboratory capabilities and to expand participation in DOE's national security related remote chemical detection program and other DOE and Department of Defense programs.

The remote chemical detection program is in transition as major programs change focus, the Hyperspectral Infrared Imaging Spectrometer passive detection program undergoes a major transition, and as DOE contemplates funding for a hybrid Differential Absorption LIDAR (DIAL)/passive prototype. The hybrid prototype requires numerous optimization trade studies and major technique/technology developments, and is therefore an opportunity for growth in the Laboratory's sensor science and technology activities. The hybrid differential absorption infrared sensing program transition provides opportunity for Laboratory expertise in infrared signatures, algorithms for exploiting and interpreting the data from complex sensor systems, and field intelligence.

\section{Physical Detection Technologies}

Pacific Northwest National Laboratory will continue to grow its capabilities to provide quality analysis of physical objects using remote sensing data. Our goal is to become a leading innovator and developer of data analysis algorithms and techniques for exploitation of remote sensing data. A key future focus will be environmental treaty monitoring. Continued growth in these focus areas will allow the Laboratory to increase its support of DOE, the Department of Defense, and other government agencies.

Our current efforts emphasize a diverse set of innovative technologies to improve the state of the art in image analysis. These include

- automated feature extraction

- multi-sensor data fusion

- land-use classification and environmental degradation analysis

- a revolutionary approach to data registration and calibration

- visualization of spatial data. 
Pacific Northwest National Laboratory also conducts more applied remote physical detection analysis for a variety of other clients. Examples of applied research and development projects include automated land-use classification at Mount St. Helens, rangeland management, agricultural analysis, and applications in exploration for minerals, oil, and gas.

Future technologies being developed by Laboratory staff include enhancing the statistical analysis of data, automating data processing, improving data visualization, and creating links to other forms of information technology. These capabilities will enhance our ability to serve the evolving needs of national security clients and help us support new clients in environmental monitoring.

A new Laboratory-level initiative in imaging science will develop additional capabilities relevant to proliferation detection, treaty verification, and environmental forensicsbuilding on our current multidisciplinary science and technology base in remote sensing and analysis.

\section{Countering Weapons of Mass Destruction Terrorism}

\section{Nuclear Weapons}

Pacific Northwest National Laboratory will continue to expand its position as a national resource for technologies for countering nuclear terrorism. We anticipate that Laboratory research and technologies will have a significant impact on reducing the nuclear danger. Our research and development will draw heavily on the Hanford experience and core competencies that support the enduring mission of environmental science and technology. Our major emphasis will continue to be satisfying user needs while advancing the state of the art. We will continue to meet aggressive requirements for measurement sensitivity and selectivity, while minimizing cost.

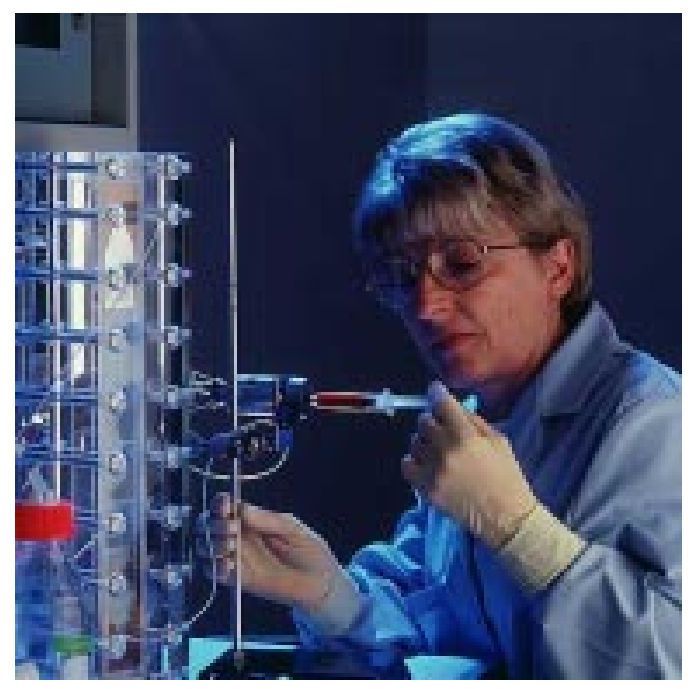

Pacific Northwest National Laboratory supports DOE's safeguards and security program by helping to protect sensitive operations across the DOE complex from the threat of use of chemical or biological agents in the hands of terrorists or adversaries. Laboratory scientists are helping to define the national priorities for protecting the U.S. civilian population against chemically or biologically armed terrorists.
Countering nuclear terrorism requires specific focus on detection systems, nuclear materials tracking and interception, nuclear materials forensics, and attribution assessment.

Pacific Northwest National Laboratory will research new technologies to exploit the intrinsic and stimulated radiation signatures of special nuclear materials and to evaluate their performance in various scenarios. Emphasis will be directed toward new gamma-ray sensors (such as CdZnTe, that operate at room temperature and offer adequate resolution for many applications), cryocoolers, advanced low-power electronics, highly enriched uranium detection, and cost-effective detector technologies.

Pacific Northwest National Laboratory will continue to research, develop, and evaluate nuclear materials tracking and tagging technologies that will improve law enforcement and the broader counterterrorism community's capability to respond to diversion of materials. These technologies will support real-time material tracking, material search, near-field pursuit, and infrastructure protection.

Forensic analysis and data interpretation will be developed to identify the sources and illicit routes of seized nuclear materials. The Laboratory will continue to develop rapid in-field forensic technologies and procedures for the attribution assessment of illicit nuclear materials. 


\section{Chemical and Biological Warfare Agents}

Pacific Northwest National Laboratory supports the DOE safeguards and security program by helping to protect sensitive operations across the DOE complex from the threat of use of chemical or biological agents in the hands of terrorists or adversaries. Laboratory scientists are helping to define the national priorities for protecting the U.S. civilian population against chemically or biologically armed terrorists. Our scientists are also asked to support related efforts by the Centers for Disease Control and Prevention and the National Institutes of Health. We are working with regional public health services to equip health providers with the ability to prepare for and respond to potential biological agent attacks.

Pacific Northwest National Laboratory is developing technologies to protect American soldiers against

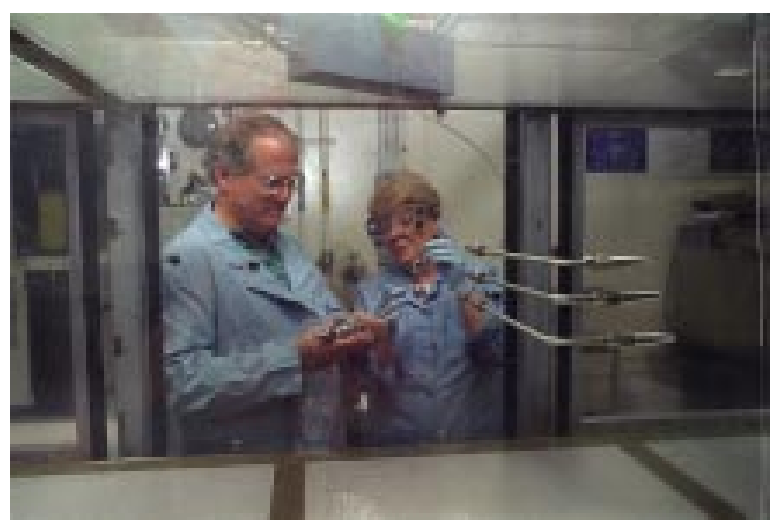

Scientists at Pacific Northwest National Laboratory use the Aerosol Research Facility, or the Environmental Wind Tunnel, to study occupational and environmental concerns.

chemical or biological agent attacks. We conduct basic research on technologies that detect the production of weapons of mass destruction. The DOE Chemical and Biological Nonproliferation Program supports research on biological signatures and use of the Aerosol Research Facility as a biological agent detector test bed. We also provide research, development, and analysis to the Department of Defense, the Federal Bureau of Investigation, the State Department, and the intelligence community. We expect to continue to provide an increased level of support in chemical and biological defense, with focus in the following areas:

- chemical and biological detection

- remote sensing, signatures analysis, aerosol hazard characterization and mitigation

- decontamination and demilitarization, including decommissioning demilitarization facilities.

For many years, Pacific Northwest National Laboratory has supported DOE and other government agencies in chemical detection and remote sensing as applied to chemical effluents from a variety of military and industrial processes. Laboratory scientists continue to receive recognition from the Department of Defense, the Federal Bureau of Investigation, and other agencies for the work on biological pathogen detection. The Laboratory's mission in environmental cleanup of former nuclear weapons production activities provides an outstanding base for addressing chemical and biological hazards and mitigation, such as clouds of chemical and biological agents. We will ensure that the Aerosol Research Facility, one of two environmental wind tunnels in the world ideally suited for complex experiments on agent fate, will be used to the greatest advantage in support of our defense against these types of weapons. As an environmental science laboratory, we can apply our nuclear materials detection experience directly to applications involving the decontamination and demilitarization of chemical and biological weapons agents and production facilities.

\section{Critical Infrastructure}

Pacific Northwest National Laboratory is taking a proactive role to ensure that the nation's critical physical resources are protected. The Laboratory has ongoing programs in materials security, physical security, information security, critical infrastructure protection, and transportation security. Although the common theme is counterterrorism, our collective work has a broader focus. Our goal is to lead in developing the technologies, processes, and capabilities that will protect society from internal and external threats. 
Pacific Northwest National Laboratory is involved with the protection of special nuclear materials and government property across the DOE complex. In conjunction with the Raytheon Company and the DOE Chicago Field Office, Pacific Northwest National Laboratory ensures that appropriate safeguards and security interests are protected and controlled at the Pit Disassembly and Conversion Facility, which will be located at the Savannah River Site. At the Hanford Site, the Laboratory supports the Hanford Safeguards and Security Program. Under the auspices of the DOE Office of Security and Emergency Operations, Pacific Northwest National Laboratory and the Army Special Forces perform vulnerability assessments and conduct force-on-force security exercises at various DOE sites.

In the areas of information security and critical infrastructure protection, the Laboratory has developed information visualization technologies (STARLIGHT and SPIRE) that present a visual representation of text and other data formats in formats that are natural for the human mind. Both are being used to analyze network transcripts and connection logs to help identify actual and potential cyber-intrusions at over 100 Defense computer sites around the world. A similar program supports DOE needs.

The Information Security Resource Center was established at the Laboratory by the Office of Safeguards and Security to provide technical assistance for DOE's security programs, requirements, and countermeasures. The Information Security Resource Center is networked into the resources of the national laboratories and other federal and industrial organizations to promote, develop, and support information assurance initiatives. The Center has continued to expand its resident subject matter expertise in information security, power grids, and the national information infrastructure to keep pace with related technology innovations and evolving cyber threats to the nation's critical infrastructures.

The DOE Office of Safeguards and Security established an information assurance outreach program to provide the nation's energy industries with access to skills and expertise developed for the protection of information assets. This effort is consistent with the findings and recommendations of the President's Commission on Critical Infrastructure Protection, and assists DOE with the discharge of its responsibilities mandated by Presidential Decision Directive 63.

Pacific Northwest National Laboratory established a Critical Infrastructure Protection and Analysis Laboratory for information assurance and operations, critical infrastructure protection, and related research. This laboratory contains a heterogeneous network for most major computational platforms so that computer and network systems can be connected for extensive vulnerability testing. The scope of this on-site research focuses on information and network technologies, vulnerability assessment and training, evaluation of hacking tools, and computer forensic activities.

Over the past several years, Pacific Northwest National Laboratory has pioneered the development of microwave and millimeter-wave holographic surveillance systems for transportation security. This development responded to a need by the Federal Aviation Administration, airports, commercial airlines, and the traveling public for a personnel surveillance system capable of detecting concealed weapons fabricated from plastic and ceramic and explosives made out of liquid and plastic.

\section{Maintaining the Nuclear Deterrent}

The Laboratory will continue to support the DOE Office of Defense Programs in areas where our technical capabilities best contribute to the Defense Programs mission strategy. Our capabilities will help maintain the nation's tritium stockpile and help safely dispose of excess weapons material.

Pacific Northwest National Laboratory will continue to support DOE plans to produce tritium for the weapons stockpile in commercial light-water reactors. This technology is based on designs and fabrication processes developed at our Laboratory. 
In support of the Secretary of Energy's selection of the commercial light-water reactor option as the preferred approach for meeting the nation's tritium stockpile requirements, the Laboratory will

- develop a reactor-specific design of the tritium-producing burnable absorber rods for the first tritium production mission

- provide technical support for competitive procurement of a commercial burnable absorber rod fabricator

- transfer the technology needed to design and fabricate burnable rods to the commercial fabricator

- develop tritium extraction processes

- continue to evaluate methods and materials for improving the effectiveness and reducing the costs of burnable rod components.

Other areas in which Pacific Northwest National Laboratory will support the weapons thrust area include

- assisting Defense Programs in interpreting safeguards and security policies and identifying cost-effective implementation procedures

- consulting to the DOE weapons laboratories

- providing technical expertise to support DOE environmental compliance on defense missions

- supporting DOE in the safe disposal of excess weapons-grade plutonium.

\section{Major Research and Development Thrusts}

To develop and expand our role in the national security mission area, Pacific Northwest National Laboratory will conduct research and development in four distinct comprehensive technology thrusts:

- detecting and analyzing weapons of mass destruction, by developing new methods and instruments for detecting, identifying, and characterizing nuclear, chemical, and biological agents

- providing policy support and analysis assistance for treaty negotiation and verification protocols, and integrating technical data from multiple resources to support national and international efforts against weapons of mass destruction and weapons security policy
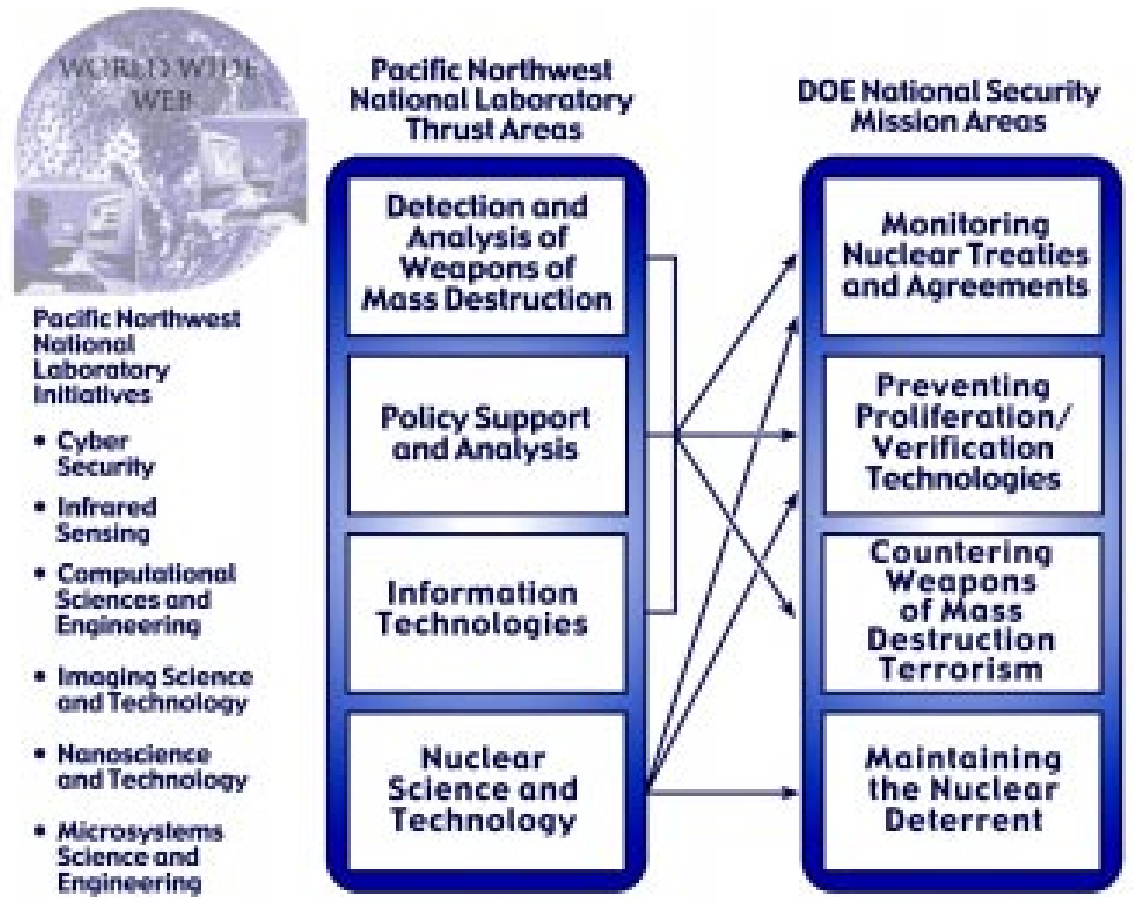

Major national security research and development thrusts. 
- applying innovative information analysis technologies and tools to strengthen data collection and analysis, data visualization, and support information assurance

- applying nuclear science and technology capabilities to new detection methods, nuclear forensics, tagging and tracking, materials security, and tritium generation.

\section{Capability Development: Role of Laboratory Initiatives}

Our Cyber Security, Infrared Sensing, and Imaging Science and Technology initiatives are central to building capabilities required for our national security mission. The Microsystems Science and Engineering initiative is creating energy-efficient, portable power generators and heat exchangers applicable to man-portable protection systems, remote instruments, and distributed power sources. Another Laboratory initiative, the Computational Sciences and Engineering initiative is developing advanced methods of analyzing data applicable to interpreting satellite information, forensics tools, and critical infrastructure protection.

These technology thrust areas and initiatives are related to DOE's national security research and development portfolio.

\section{National Security Program Roles}

DOE Office

Pacific Northwest National Laboratory Role

\section{National Nuclear Security Administration}

\section{Defense Nuclear Nonproliferation}

Office of Nonproliferation Research \&

Engineering (NN-20)

Office of International Nuclear Safety (NN-30)

Office of Arms Control and Nonproliferation (NN-40)

Office of International Material Protection and Emergency Cooperation (NN-50)
Pacific Northwest National Laboratory supports the Office of Nonproliferation Research and Engineering in nuclear, chemical, and biological nonproliferation research and development for treaty negotiation, development, and verification in the areas of on-site systems, regional monitoring, remote sensing, and advanced systems. Other key areas of support are chemical and physical detection systems for weapons of mass destruction proliferation detection and technology to counter weapons of mass destruction terrorism and to protect critical infrastructures.

Pacific Northwest National Laboratory serves as the overall integrating contractor for the Office of International Nuclear Safety and provides assistance in Soviet-designed reactor safety, Chornobyl bilateral assistance initiatives, action to cease production of plutonium in Russian production reactors (the Core Conversion Project), fuel technology transfer to Ukraine, and related nuclear safety and security activities in the former Soviet Union as well as Central and Eastern Europe.

Pacific Northwest National Laboratory supports the Office of Arms Control and Nonproliferation in several major areas, the core of which is in the area of nuclear weapons of mass destruction. Activities related to delivery system proliferation prevention and arms control, conventional weapons arms control, international treaty negotiations and implementation, and other regional security issues support this core area. Other key areas of support to NN-40 include international safeguards, treaty negotiations and implementation activities, Initiatives for Proliferation Prevention, Nuclear Cities Initiatives, export control, isotope separations and analysis, and humanitarian activities.

Pacific Northwest National Laboratory supports the Office of International Material Protection under the Materials Protection, Control \& Accountability Program. This program is responsible for assisting the Russian government and its nuclear facilities in the protection, control, and accounting of weapons-usable nuclear material. Activities are in the areas of physical protection and material control/accounting system upgrades as well as development of the Russian infrastructure (regulations, training) to provide long-term sustainability for such upgrades. 


\section{National Security Program Roles}

DOE Office

Office of Fissile Materials Disposition $(\mathrm{NN}-60)$

Defense Programs

Office of Counterintelligence

Office of Intelligence

Office of Security and Emergency Operations

\author{
Pacific Northwest National Laboratory Role
}

Pacific Northwest National Laboratory supports the Office of Fissile Materials Disposition in providing a strategy for disposition of weapons-usable plutonium including immobilizationand burning as mixed-oxide fuel in domestic commercial reactors, developing and characterizing an immobilization form for excess weaponsusable plutonium, and assisting the Federal Nuclear and Radiation Safety Authority of Russia (Gosatomnadzor of Russia) in developing plutonium disposition regulatory documents.

Pacific Northwest National Laboratory supports Defense Programs through safeguards and security activities; continuation of the Tritium Target Qualification Program, including additional target development, manufacturing, and privatization; consultations with DOE weapons laboratories; and providing technical expertise to support DOE efforts in environmental compliance, safety, and health issues on defense missions.

Pacific Northwest National Laboratory supports the DOE Office of Counterintelligence by enhancing counterintelligence capabilities through development of relevant technologies that will assist in ongoing local and national efforts to prevent, identify, and neutralize adversarial efforts targeted against Pacific Northwest National Laboratory, $\mathrm{DOE}$, and the entire Intelligence Community to gain unauthorized access to classified and sensitive information and technologies.

Pacific Northwest National Laboratory directly supports the DOE Office of Intelligence. We perform intelligence analysis and computational modeling that addresses national issues in nuclear weapons materials production, nonproliferation of weapons of mass destruction, nuclear energy resources, environmental security, and other tasks as appropriate. Additionally, in cooperation with Intelligence, we perform intelligence-related work for other government organizations on these and additional proliferation issues concerning weapons of mass destruction, including chemical and biological weapons, and means of delivery. The Laboratory also has grown its support to the DOE Office of Intelligence's Special Technologies Program by drawing on various areas of scientific and engineering expertise in Pacific Northwest National Laboratory to provide specialized technology products for DOE and its intelligence community customers.

Pacific Northwest National Laboratory supports the Office of Security and Emergency Operations through the development and deployment of technical tools to assist in the collection and assessment of incident and threat data. 


\section{6}

\section{Operations and Infrastructure Strategic Plan}

This section of the Institutional Plan describes the key elements of our supporting operations and infrastructure and how they support our overall strategy to enable highquality research. The most critical operational issues affecting each element also are described. Our principal objective is to operate and maintain the Laboratory in an effective, efficient, and safe manner, while protecting the physical Laboratory assets entrusted to us by the Department of Energy. The Human Resources section describes the importance we place on developing leadership, supporting our workforce, and recruiting new talent needed to conduct our programs. The Environment, Safety, and Health Management section describes our emphasis on providing an effectively managed, safe work environment. The Safeguards and Security section describes our continuing efforts to protect the Laboratory's physical and intellectual assets, including classified matter, nuclear material control and accountability, and computer and network systems security. Our plans for Site and Facilities management describe the buildings and laboratories that we occupy, consolidation efforts to vacate excess and aging facilities, revitalization of priority space, and the need for new facilities to accommodate future research activities. The Information Resources section describes our plan to modernize networked computer systems for effective support of key Laboratory missions. The Management Practices and Standards section describes our emphasis on integrated systems that provide the foundation for operational excellence. The last section, Communications and Trust, highlights the Laboratory's commitment to be a valued and trusted community and regional asset.

Pacific Northwest National Laboratory is one of five national laboratories managed by the DOE Office of Science, which is the Cognizant Secretarial Office for the Laboratory. The Director of the DOE Office of Science is the institutional steward for the Laboratory, and is responsible for all aspects of Laboratory performance, including policy, operations, facilities, infrastructure, security, environment, safety, and health. The Office of Science Director, acting through the Manager of the Richland Operations Office, employs the Assistant Manager for Science and Technology as the central point of contact for administering the Laboratory contract. In this role, the Assistant Manager is responsible for services and resources needed to support the Laboratory's science and technology mission. The Richland Operations Office applies a "partnership" philosophy in carrying out its performance-based management duties to plan for, manage, evaluate, and reward Laboratory performance. This partnership with the Laboratory improves the delivery of products and services, facilitates communications, encourages the achievement of excellence, and guides decision making. This strategic partnership helps DOE and the Laboratory to work closely together and to ensure the mutual success of all Laboratory missions.

\section{Human Resources}

Pacific Northwest National Laboratory's human resources strategy is designed to provide the Laboratory with the leaders and staff needed to ensure excellence in science and technology, operations, and community relations, as well as a work environment that optimizes staff satisfaction and individual contribution. Critical to our success is our focus on enhancing our core staff competencies, thus more effectively delivering highvalue products that serve the Laboratory's strategic plan, the DOE mission portfolio, and the major Laboratory initiatives. The human resources strategy consists of several key elements:

- developing Laboratory leadership and staff capabilities through enhanced knowledge and skill development opportunities 


\begin{tabular}{|c|c|c|c|c|c|c|c|c|c|c|c|c|c|c|c|c|}
\hline \multirow{3}{*}{$\begin{array}{l}\text { Occupational } \\
\text { Codes } \\
\text { Gender }\end{array}$} & \multicolumn{16}{|c|}{ Equal Employment Opportunity ${ }^{(a, b)}$} \\
\hline & \multicolumn{2}{|c|}{ Staff } & \multicolumn{2}{|c|}{ Minority } & \multicolumn{2}{|c|}{ White } & \multicolumn{2}{|c|}{ Black } & \multicolumn{2}{|c|}{ Hispanic } & \multicolumn{2}{|c|}{$\begin{array}{l}\text { Native } \\
\text { Americans }\end{array}$} & \multicolumn{2}{|c|}{$\begin{array}{l}\text { Asian/Pacific } \\
\text { Islanders }\end{array}$} & \multicolumn{2}{|c|}{$\begin{array}{l}\text { Staff with } \\
\text { Disabilities }\end{array}$} \\
\hline & $\mathbf{M}$ & $\mathbf{F}$ & $\mathbf{M}$ & $\mathbf{F}$ & $\mathbf{M}$ & $\mathbf{F}$ & M & $\mathbf{F}$ & $\mathbf{M}$ & $\mathbf{F}$ & $\mathbf{M}$ & $\mathbf{F}$ & M & $\mathbf{F}$ & M & $\mathbf{F}$ \\
\hline Manager & $\begin{array}{c}469 \\
(81.4)\end{array}$ & $\begin{array}{c}107 \\
(18.6)\end{array}$ & $\begin{array}{c}22 \\
(3.8)\end{array}$ & $\begin{array}{c}5 \\
(0.9)\end{array}$ & $\begin{array}{c}447 \\
(77.6)\end{array}$ & $\begin{array}{c}102 \\
(17.7)\end{array}$ & $\begin{array}{c}3 \\
(0.5)\end{array}$ & $\begin{array}{c}1 \\
(0.2)\end{array}$ & $\begin{array}{c}12 \\
(2.1)\end{array}$ & $\begin{array}{c}4 \\
(0.7)\end{array}$ & $\begin{array}{c}4 \\
(0.7)\end{array}$ & $\begin{array}{c}0 \\
(0.0)\end{array}$ & $\begin{array}{c}3 \\
(0.5)\end{array}$ & $\begin{array}{c}0 \\
(0.0)\end{array}$ & 27 & 1 \\
\hline \multicolumn{17}{|l|}{ Professional } \\
\hline Scientists & $\begin{array}{c}643 \\
(77.4)\end{array}$ & $\begin{array}{c}188 \\
(22.6)\end{array}$ & $\begin{array}{l}57 \\
(6.9)\end{array}$ & $\begin{array}{c}21 \\
(2.5)\end{array}$ & $\begin{array}{c}586 \\
(70.5)\end{array}$ & $\begin{array}{c}167 \\
(20.1)\end{array}$ & $\begin{array}{c}2 \\
(0.2)\end{array}$ & $\begin{array}{c}0 \\
(0.0)\end{array}$ & $\begin{array}{c}6 \\
(0.7)\end{array}$ & $\begin{array}{c}0 \\
(0.0)\end{array}$ & $\begin{array}{c}4 \\
(0.5)\end{array}$ & $\begin{array}{c}2 \\
(0.2)\end{array}$ & $\begin{array}{c}45 \\
(5.4)\end{array}$ & $\begin{array}{c}19 \\
(2.3)\end{array}$ & 23 & 4 \\
\hline Engineers & $\begin{array}{c}329 \\
(82.9)\end{array}$ & $\begin{array}{c}68 \\
(17.1)\end{array}$ & $\begin{array}{c}26 \\
(6.5)\end{array}$ & $\begin{array}{c}2 \\
(0.5)\end{array}$ & $\begin{array}{c}303 \\
(76.3)\end{array}$ & $\begin{array}{c}66 \\
(16.6)\end{array}$ & $\begin{array}{c}2 \\
(0.5)\end{array}$ & $\begin{array}{c}0 \\
(0.0)\end{array}$ & $\begin{array}{c}9 \\
(2.3)\end{array}$ & $\begin{array}{c}1 \\
(0.3)\end{array}$ & $\begin{array}{c}1 \\
(0.3)\end{array}$ & $\begin{array}{c}0 \\
(0.0)\end{array}$ & $\begin{array}{c}14 \\
(3.5)\end{array}$ & $\begin{array}{c}1 \\
(0.3)\end{array}$ & 11 & 3 \\
\hline $\begin{array}{l}\text { Management/ } \\
\text { Admin }\end{array}$ & $\begin{array}{c}394 \\
(50.9)\end{array}$ & $\begin{array}{c}380 \\
(49.1)\end{array}$ & $\begin{array}{c}31 \\
(4.0)\end{array}$ & $\begin{array}{c}32 \\
(4.1)\end{array}$ & $\begin{array}{c}363 \\
(46.9)\end{array}$ & $\begin{array}{c}348 \\
(45.0)\end{array}$ & $\begin{array}{c}6 \\
(0.8)\end{array}$ & $\begin{array}{c}2 \\
(0.3)\end{array}$ & $\begin{array}{c}14 \\
(1.8)\end{array}$ & $\begin{array}{c}13 \\
(1.7)\end{array}$ & $\begin{array}{c}5 \\
(0.6)\end{array}$ & $\begin{array}{c}3 \\
(0.4)\end{array}$ & $\begin{array}{c}6 \\
(0.8)\end{array}$ & $\begin{array}{c}14 \\
(1.8)\end{array}$ & 20 & 7 \\
\hline Technicians & $\begin{array}{c}100 \\
(60.6)\end{array}$ & $\begin{array}{c}65 \\
(39.4)\end{array}$ & $\begin{array}{c}11 \\
(6.7)\end{array}$ & $\begin{array}{c}4 \\
(2.4)\end{array}$ & $\begin{array}{c}89 \\
(53.9)\end{array}$ & $\begin{array}{c}61 \\
(37.0)\end{array}$ & $\begin{array}{c}2 \\
(1.2)\end{array}$ & $\begin{array}{c}1 \\
(0.6)\end{array}$ & $\begin{array}{c}5 \\
(3.0)\end{array}$ & $\begin{array}{c}2 \\
(1.2)\end{array}$ & $\begin{array}{c}3 \\
(1.8)\end{array}$ & $\begin{array}{c}0 \\
(0.0)\end{array}$ & $\begin{array}{c}1 \\
(0.6)\end{array}$ & $\begin{array}{c}1 \\
(0.6)\end{array}$ & 8 & 5 \\
\hline Clerical & $\begin{array}{l}20 \\
(3.7)\end{array}$ & $\begin{array}{c}516 \\
(96.3)\end{array}$ & $\begin{array}{c}1 \\
(0.2)\end{array}$ & $\begin{array}{c}62 \\
(11.6)\end{array}$ & $\begin{array}{c}19 \\
(3.5)\end{array}$ & $\begin{array}{c}454 \\
(84.7)\end{array}$ & $\begin{array}{c}0 \\
(0.0\end{array}$ & $\begin{array}{c}18 \\
(3.4)\end{array}$ & $\begin{array}{c}1 \\
(0.2)\end{array}$ & $\begin{array}{c}34 \\
(6.3)\end{array}$ & $\begin{array}{c}0 \\
(0.0)\end{array}$ & $\begin{array}{c}4 \\
(0.7)\end{array}$ & $\begin{array}{c}0 \\
(0.0)\end{array}$ & $\begin{array}{c}6 \\
(1.1)\end{array}$ & 1 & 19 \\
\hline $\begin{array}{l}\text { Craftsmen/ } \\
\text { Laborers }\end{array}$ & $\begin{array}{c}145 \\
(92.9)\end{array}$ & $\begin{array}{c}11 \\
(7.1)\end{array}$ & $\begin{array}{c}17 \\
(10.9)\end{array}$ & $\begin{array}{c}4 \\
(2.6)\end{array}$ & $\begin{array}{c}128 \\
(82.1)\end{array}$ & $\begin{array}{c}7 \\
(4.5)\end{array}$ & $\begin{array}{c}4 \\
(2.6)\end{array}$ & $\begin{array}{c}0 \\
(0.0)\end{array}$ & $\begin{array}{c}12 \\
(7.7)\end{array}$ & $\begin{array}{c}4 \\
(2.6)\end{array}$ & $\begin{array}{c}1 \\
(0.6)\end{array}$ & $\begin{array}{c}0 \\
(0.0)\end{array}$ & $\begin{array}{c}0 \\
(0.0)\end{array}$ & $\begin{array}{c}0 \\
(0.0)\end{array}$ & 8 & 2 \\
\hline $\begin{array}{l}\text { Service } \\
\text { Workers }\end{array}$ & $\begin{array}{c}24 \\
(48.0)\end{array}$ & $\begin{array}{c}26 \\
(52.0)\end{array}$ & $\begin{array}{c}2 \\
(4.0)\end{array}$ & $\begin{array}{c}1 \\
(2.0)\end{array}$ & $\begin{array}{c}22 \\
(44.0)\end{array}$ & $\begin{array}{c}25 \\
(50.0)\end{array}$ & $\begin{array}{c}1 \\
(2.0)\end{array}$ & $\begin{array}{c}0 \\
(0.0)\end{array}$ & $\begin{array}{c}0 \\
(0.0)\end{array}$ & $\begin{array}{c}1 \\
(2.0)\end{array}$ & $\begin{array}{c}1 \\
(2.0)\end{array}$ & $\begin{array}{c}0 \\
(0.0)\end{array}$ & $\begin{array}{c}0 \\
(0.0)\end{array}$ & $\begin{array}{c}0 \\
(0.0)\end{array}$ & 3 & 2 \\
\hline Totals & 2124 & 1361 & 167 & 131 & 1957 & 1230 & 20 & 22 & 59 & 59 & 19 & 9 & 69 & 41 & 101 & 43 \\
\hline $\begin{array}{l}\text { (a) Data } \\
\text { (b) Num }\end{array}$ & & 00. & & & & & & & & & & & & & & \\
\hline
\end{tabular}

- ensuring a diverse work environment that optimizes staff satisfaction, individual contribution, and organizational effectiveness through improvements in the quality of work life

- continually enhancing workforce planning for aggressive succession planning, hiring, and developing key staff capabilities.

Achievement of our goals is not possible without top-quality staff who find personal and professional fulfillment in the work they do. To ensure that all staff thrive in a work environment that supports innovation and the creative scientific process, Pacific Northwest National Laboratory is committed to continually enhancing the work environment. In response to regular quality of work life survey feedback, a management skills development program and enhanced succession planning program were introduced in 1999. These programs were designed to give leaders and managers the opportunities, tools, and skills needed to foster (lead and manage) exceptional research and development. As a result of survey feedback, a career development web site and an expanded scientific career ladder were introduced in 1999. Each of these programs was designed to preserve the vitality, quality, and diversity of our capabilities and to ensure we maintain the high retention rate that the Laboratory currently enjoys.

In addition to quality of work life efforts, Pacific Northwest National Laboratory established an external minority community advisory board in 1999 to help the Laboratory understand how it can broaden networks and contacts in the minority community. The advisory board was established in response to focus groups conducted with members of the minority community. The focus groups developed an initial action plan with goals to increase educational opportunities and enhance communication and recruitment at the Laboratory. Some noteworthy accomplishments in fiscal year 2000 included

- The Education Equipment Gift Program gave equipment to nonprofit organizations whose purpose it is to increase the interest and participation of underrepresented youth in math, science, and engineering academic areas. 


\begin{tabular}{|c|c|c|c|c|c|c|}
\hline \multicolumn{7}{|c|}{ Laboratory Staff Composition } \\
\hline $\begin{array}{l}\text { Full and Part- } \\
\text { Time } \\
\text { Employees }\end{array}$ & Total \# & $(\%)$ & PhD & $\begin{array}{l}\text { MSI } \\
\text { MA } \\
\end{array}$ & $\begin{array}{l}\text { BSI } \\
\text { BA } \\
\end{array}$ & Other \\
\hline Managers & 576 & (16.5) & 155 & 195 & 166 & 60 \\
\hline Scientists & 831 & (23.8) & 381 & 239 & 204 & 7 \\
\hline Engineers & 397 & (11.4) & 71 & 163 & 157 & 6 \\
\hline $\begin{array}{l}\text { Management and } \\
\text { Administrative }\end{array}$ & 774 & (22.2) & 12 & 118 & 343 & 301 \\
\hline Technicians & 165 & $(4.7)$ & 0 & 2 & 16 & 147 \\
\hline Clerical & 536 & $(15.4)$ & 0 & 1 & 44 & 491 \\
\hline Craftsmen/Laborers & 156 & $(4.5)$ & 0 & 0 & 5 & 151 \\
\hline Service Workers & 50 & (1.4) & 0 & 0 & 1 & 49 \\
\hline Total & 3485 & & 619 & 718 & 936 & 1212 \\
\hline
\end{tabular}

- The Laboratory's Diversity Program worked with African Americans for an Academic Society to develop the Society's website.

- The Laboratory worked with the Hispanic Academic Achievement Program and board members from the African Americans for an Academic Society to jointly plan the 2001 award banquets.

- The Cooperative Office Education Program increased minority participation from 18 percent in fiscal year 1999 to 47 percent in 2000.

- The Laboratory actively participated in the first ever Fiesta de la Familia event and sponsored a business event called Mucho Dinero. The purpose of the Mucho Dinero was to help Hispanic and non-Hispanic business owners reach each others' markets.

- Laboratory communications staff worked with Columbia Basin College on an upcoming event called Race Unity Day, Bridges of Friendship. The goal of this event is to showcase and celebrate cultures from all over the world.

Affirmative action programs, both internal and external, continue to expand. A recruiting referral program was introduced and has resulted in the identification and selection of a significant number of women or minority candidates. Of the 37 hires over the two-year period since its inception, 92 percent were female and 22 percent were minority. The newly formed women and minority scientist and engineer rotation program also will provide an excellent introduction into the Laboratory for diverse, high-potential graduates. Results from these enhancements will be demonstrated in fiscal year 2001 Equal Employment Opportunity data. As a result of some of our past programs, Pacific Northwest National Laboratory was awarded an Exemplary Voluntary Efforts Award in 1999 by the U.S. Department of Labor, Office of Federal Contract Compliance Programs. We will continue to ensure diversity success in the future by concentrating our programmatic resources on specific diversity and minority recruitment events at the national level.

Our overall strategic recruitment efforts focus on finding the most qualified and capable individuals who can meet the requirements of current clients and missions. We have effectively positioned our recruiters for success by placing dedicated, human resources teams directly with division leaders to identify strategies for success. Because retaining and attracting valuable talent and expertise is paramount to our future, we have addressed issues related to our geographical location and non-urban environment. We target our recruiting efforts among the southwestern states where we have experienced the greatest acceptance and retention results. 
We instituted a spousal employment assistance program in 1999 to help attract and retain staff relocating to the Tri-Cities area by addressing dual career family needs. In fiscal year 2000, we assisted 12 spouses in their job search. The intent of the assistance is to provide the spouse with the necessary tools to facilitate their job search. We have been successful opening doors, making introductions, setting up appointments, circulating resumes, and providing information such as local web sites, lists of employers, area maps, and brochures.

To appropriately compete for professional talent in the research and development market, Pacific Northwest National Laboratory must offer competitive salaries, additional cash reward and recognition programs, and an adequate level of benefits. We will need to further enhance our total remuneration programs to maintain our ability to attract stellar scientific talent in the future by offering incentives (additional vacation, incentive payments, and hiring bonuses) comparable to our competitors in the job market.

Although our competition for staff talent may enjoy certain advantages in geographic location, urban environments, and related community amenities, we believe that our strategies for offering the less tangible advantages to staff, such as a challenging work environment, autonomy, purpose, and leadership, will distinguish Pacific Northwest National Laboratory as the research laboratory employer of choice.

\section{Environment, Safety, and Health Management}

Environment, Safety and Health at Pacific Northwest National Laboratory is responsible for environmental management services, facility safety, integrated environment, safety and health, radiological control, training and qualification, and worker safety and health management systems. Our goal is to provide the highest-quality and most costeffective services in support of the Laboratory's missions. Our integrated environment, safety, and health management system highlights the linkages with other supporting management systems and their contributions in the context of our overall environment, safety, and health program.

Much of the Environment, Safety and Health organization is funded directly by the projects that require our support services. We provide project and line managers with control over their support costs while ensuring that operations are carried out in a safe manner.

\section{Overall Vision, Goals, and Objectives}

Our vision for Pacific Northwest National Laboratory is to be the benchmark standard for a research and development laboratory in environment, safety, and health management. We provide innovative services and systems that enable work to be conducted in a safe, efficient, and environmentally sound manner to achieve compliance with federal, state, and local regulations.

Our strategic objectives guide future planning and help us achieve excellence in safe operations. These objectives are to

- fully develop and deploy effective management systems

- optimize staff involvement in, ownership of, and development of environment, safety, and health practices

- optimize customer satisfaction with our services

- achieve excellence in managing Pacific Northwest National Laboratory's environment, safety, and health resources. 


\section{Current Laboratory Conditions and the Status of Integrated Safety Management}

We have integrated environment, safety, and health requirements into our management systems as required by our operating contract with the Department of Energy. ${ }^{(a)}$ Major initiatives conducted over the past several years have established a firm operating basis for environment, safety, and health and conduct of operations. This capability was confirmed by the phase I and II validation of our integrated environment, safety, and health program that we received from the Richland Operations Office in 1998. Pacific Northwest National Laboratory is now focused on process maturity and continuous improvement to ensure that we sustain long-term operational excellence.

\section{Long-Range Plans to Ensure Compliance with Applicable Requirements}

The following strategies define how we manage continuous improvement in environment, safety, and health management system activities.

- The integrated environment, safety, and health management system identifies, tracks, and addresses weaknesses in the program. The highest priority areas for improvement are chemical management, requirements flowdown to subcontactors, off-site safety, and hazards assessment.

- The integrated environment, safety, and health management system is working with management system owners to create measures of maturity in development and deployment of supporting management systems. We will continue to incorporate more rigorous performance-based measures into our operating contract.

- We will continue the rollout of the integrated operations concept and tools to additional facilities. The integrated operations tools include hazard identification and communication, identification and tracking of training requirements, hazard mitigation through self-assessment, detailed work practices, and user access authorization and control.

- Integrated environment, safety, and health management, together with the requirements management system, provide the tool to identify an appropriate set of contract requirements that are current, accurate, and relevant. The requirements integration and tailoring process was applied during fiscal year 2000, and will continue on an "as needed" basis while work scope and requirements evolve. Both management systems are working for the removal of archived and nonapplicable directives from the contract and their replacement with a current, appropriate requirements set.

- Our management is committed at all levels to the Voluntary Protection Program, established by DOE to recognize superior performance in health and safety. This program is a partnership between labor, management, and the government to promote worker safety through employee involvement. It involves work site analysis, hazard prevention and control, safety and health training, management leadership, and employee involvement. Pacific Northwest National Laboratory's application for "STAR" status was signed by the Laboratory Director and transmitted online to DOE for review in October.

- Several areas of concern regarding nuclear safety rule compliance have been identified and are being tracked, both in the DOE noncompliance tracking system, and in the Pacific Northwest National Laboratory assessment tracking system. Corrective action plans are in place for the following areas:

- $\quad$ recurring work planning and control issues

(a) DE-AC06-76RL01830 Modification M255, Clause I-64, entitled Integration of Environment, Safety, and Health Into Work Planning and Execution (June 1997). 
- $\quad$ subcontract requirements flowdown

- willful procedural nonadherence.

\section{Stewardship of Our Environment}

Our pollution prevention program's "green lab" approach to environmental stewardship incorporates environmental practices into the design, development, marketing, deployment, and use of Pacific Northwest National Laboratory's services and technologies.

Our objective is to fully integrate pollution prevention into all Laboratory activities while promoting development and commercialization of intellectual property and technology that are economically viable, and that also provide environmental and social benefit. Our goals are to reduce waste, increase business, and to enable the Laboratory to become the acknowledged premier environmental laboratory within the DOE complex.

Pacific Northwest National Laboratory continually assesses the potential environmental impacts of our services and technologies, and we take appropriate and reasonable action to protect the environment in performance of our core business. We communicate our commitment to environmental stewardship, and we maintain an open dialogue with the public and other stakeholders about the ways in which we improve the environmental performance of our products, services, and technologies.

In fiscal year 2001, the Laboratory will begin its pursuit of implementation of ISO 14001 (International Standards Organization) in earnest. The ISO 14001 criteria provides a tool to evaluate the existing Integrated Safety Management systems for environmental management system content that goes beyond regulatory compliance to pollution prevention. The use of ISO 14001 to evaluate and drive changes in existing Integrated Safety Management systems will enable the Laboratory to: 1) embrace pollution prevention in their business systems and meet the requirements in Executive Order $13148,2)$ rigorously evaluate other key components of their management system (records management, corrective action management) from a slightly different perspective, and 3) establish environmental improvement goals and demonstrate continuous improvement as required by the Department of Energy Acquisition Regulations Clause 970.5204-2 "Integration of Environment, Safety and Health into Work Planning and Execution," as noted in Pacific Northwest National Laboratory's operating contract.

\section{Operations Compatible with Environment, Safety, and Health Performance}

Pacific Northwest National Laboratory demonstrated continued excellence in environment, safety, and health conduct of operations, as confirmed by the Outstanding rating by DOE's Richland Operations Office for the operational excellence critical outcome in fiscal year 1999. The environment, safety, and health review of fiscal year 2000 performance indicates another Outstanding rating for conduct of operations; confirmation is pending the DOE's Richland Operations Office evaluation.

An enhanced network-based hazard analysis tool will assist work planning by ensuring that hazards are adequately controlled and that requirements are fully identified. This tool will capture hazard analysis information from existing work processes, provide common definitions, and communicate that information to staff and project management.

\section{Non-Research Activities at Pacific Northwest National Laboratory Funded by the DOE-Office of Environmental Management}

The Office of Environmental Management supports our waste operations and management (current generation) activities by funding the infrastructure (assay, analysis, acceptance, handling, storage, packaging, and shipment) needed to dispose of newly generated wastes. This program also supports effluent monitoring for radiological air emissions sampling and facility emission points. 


\section{Potential Issues, Actions, or Funding Problems that Could Adversely Affect Other Missions}

\section{Strategic Issue}

The Laboratory's environmental management services are re-engineering the Laboratory's waste operations. We receive about $\$ 7$ million from the Office of Environmental Management to fund waste operations and environmental compliance technical support services. In fiscal year 2001, a transfer of $\$ 1.2$ million from the Office of Environmental Management will be made to the Office of Science to fund Office of Science waste management activities. In fiscal year 2001, the Office of Environmental Management will continue to directly fund the remaining \$5.8 million, because most of the waste generated at Pacific Northwest National Laboratory is from Office of Environmental Management projects. A similar approach is expected for funding in future years, which follows a funding practice used at other Office of Science national laboratories.

\section{Emerging Issues}

Pacific Northwest National Laboratory's waste management organization is working with the research and development divisions and with the Facilities and Operations staff to identify waste generation, management, and disposal options. Waste forecasting, planning, and costing tools will allow a more detailed costing of waste management activities, as well as life-cycle cost estimates and waste minimization activities. In addition, the Laboratory initiated a five percent pollution prevention fee in fiscal year 2000. The funds collected from this fee, based on waste disposal costs, are used to complete pollution prevention initiatives within the Laboratory. We are studying options for treating waste on-site to reduce or eliminate future costs and liabilities. Waste generators must ensure that a waste disposal pathway exists prior to generating waste.

DOE's new Radioactive Waste Management Order (435.1) was issued in fiscal year 1999. The Laboratory issued an implementation plan, coordinated with other contractors at the Hanford Site, which changes our management systems and operating procedures.

Worker exposure to beryllium and its associated health risks was identified by DOE (10 CFR Part 850) as a major health issue that required proactive measures to minimize further exposures at DOE facilities. This standard establishes a DOE precedence that has the potential to impact future industrial hygiene monitoring practices, health hazard control strategies, and medical surveillance for chemical exposures.

\section{Safeguards and Security}

Pacific Northwest National Laboratory puts science and technology to work to solve problems for its primary customer, the Department of Energy, as well as for other government agencies and private industrial customers. The Laboratory deploys an effective, ongoing safeguards and security program to support the Laboratory's research. This program facilitates an open and supportive research environment while ensuring appropriate levels of protection for information, assets and property, personnel, and nuclear materials. The Laboratory's safeguards and security program consists of the following broad areas:

- safeguards and security program management

- physical security and protection operations

- information security

- nuclear material control and accountability

- personnel security (including foreign visits and assignments)

- cyber security. 
These program elements work together in conjunction with a counterintelligence program and an export control program to ensure appropriate protection and control of Laboratory assets while ensuring that Pacific Northwest National Laboratory remains appropriately accessible to visitors for technical collaboration.

Pacific Northwest National Laboratory is a multiprogram Laboratory rated by DOE as a Class A facility. This designation denotes the relative importance of a facility in relationship to other DOE facilities and to the security and common defense of the United States. Class A facilities may engage in administrative activities considered essential to the direction and continuity of the overall DOE nuclear weapons program, and are authorized to possess Top Secret matter, or possess Category I quantities of special nuclear materials. Pacific Northwest National Laboratory does not possess Category I quantities of special nuclear materials but does possess lower category quantities and Top Secret matter. As such, commitments for the protection of special nuclear materials and classified matter are priorities for the safeguards and security program. Protecting information, intellectual property, and physical property is a vital commitment in the Laboratory's institutional and operational philosophy.

Most requirements involving nonproliferation and counterintelligence have minimal impact on the Laboratory's research mission. Through the National Security Division, the Laboratory provides support to DOE's national security mission (including monitoring nuclear treaties and agreements, preventing and detecting proliferation, promoting international nuclear safety, countering weapons of mass destruction terrorism, and contributing to maintaining the U.S. nuclear deterrent).

Pacific Northwest National Laboratory has established an Integrated Safeguards and Security Management Program with a short-term goal to fully implement in the near future. Similar to what has been successfully implemented for integrated safety management, this program will integrate safeguards and security requirements into the processes of planning and conducting work at the Laboratory and assist management in addressing identified threats and associated risks. This program ensures that all safeguards and security elements work together effectively to provide a strong, protective umbrella for long-term business strategies.

We are aware that threats to scientific and technological information and programs continue to exist. Pacific Northwest National Laboratory has a very proactive safeguards and security program to ensure that appropriate measures are employed to discourage or defeat attempts to collect information or disrupt operations. Defense against loss, theft, sabotage, and espionage is an essential consideration for DOE program activities, cooperative research and development activities, and work for others, and is consistent with the following current and long-term safeguards and security program priorities:

- physical protection, control, and accountability for nuclear and special nuclear materials

- protection of classified matter

- protection of physical and intellectual property (which includes operating facilities, sensitive information, sensitive property, and equipment)

- assurance that the safeguards and security performance objectives and supporting milestones agreed upon by Pacific Northwest National Laboratory and DOE are conducted in a cost-effective manner.

\section{Safeguards and Security Program Management}

The total security environment is regularly reviewed by program management as well as line management to ensure that protective measures are properly deployed and remain effective. Protection program planning considerations are examined and weighed in conjunction with levels of management support, staff awareness, status of physical and administrative control systems, financial support and constraints, number and 


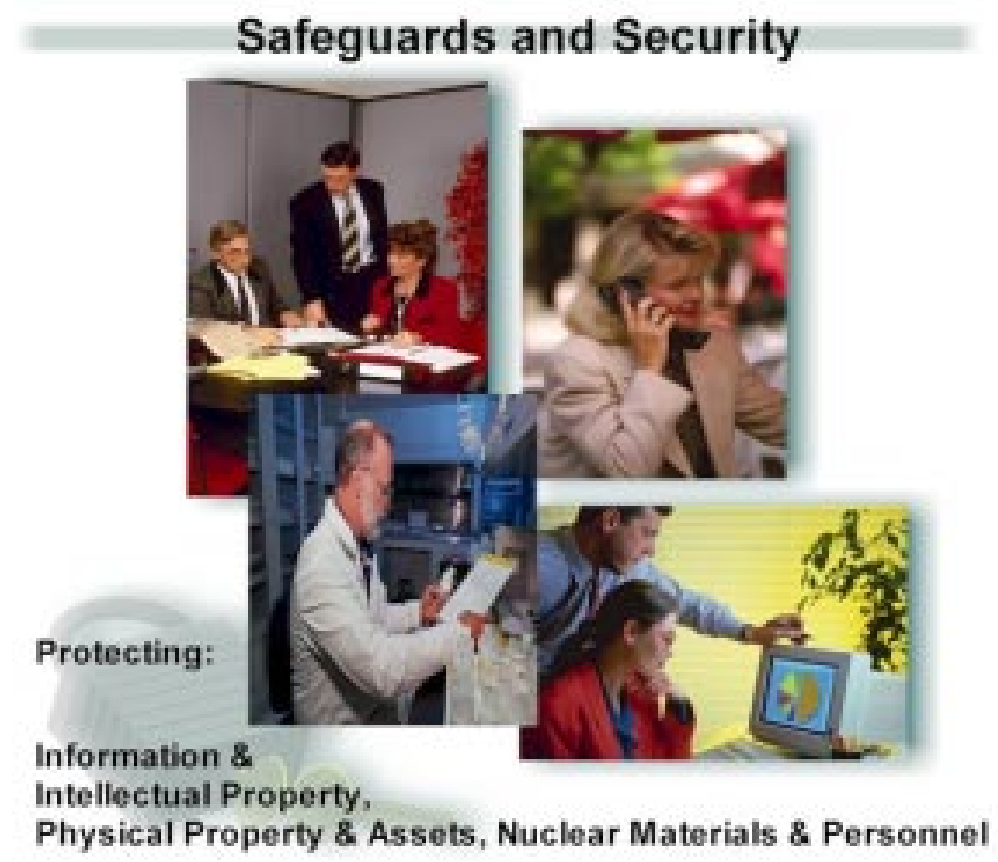

proficiency of resources and facilities, and operational requirements. Laboratory operations, including classified and sensitive work, or work involving special nuclear materials, are reviewed to determine whether options exist for reducing vulnerabilities and for economizing facility and security system costs.

\section{Physical Security and Protection Operations}

Physical security measures are designed to provide increasing levels of protection to facilities and property inward from the facility or area perimeter, as required by the nature of the property and the work involved. Physical security measures are applied in a graded manner, depending on the value of the asset and the consequences of its loss or misuse. Asset protection agreements are developed to document the identification of the security interest activities and associated protection measures by facility location. They take into account the nature of the security interest, protection requirements, threat potentials, and countermeasures, and assign a defense or safeguards priority position based on a composite evaluation of these factors.

\section{Information Security}

Information security measures are designed to address the protection and control of classified and sensitive information. Information security also ensures that individuals effectively protect the information to which they have access or custody.

The information security program includes

- operations security

- classified matter protection and control, including security of foreign intelligence information, sensitive compartmented information, and special access programs

- communications security and technical surveillance countermeasures

- protection of unclassified controlled nuclear information, official use only, naval nuclear propulsion information, and other sensitive information.

The information security program establishes a protection and control system that requires higher degrees of protection for each higher classification level (Confidential, Secret, Top Secret). A rigorous operations security program helps management identify threats and mitigation measures. The operations security activities at Pacific Northwest National Laboratory directly relate to and support counterintelligence program initiatives.

The Laboratory's counterintelligence program deters and neutralizes foreign, industrial, or other intelligence activities directed at or involving DOE programs, facilities, technology, personnel, unclassified sensitive information, and classified matter. This activity is an integral part of the overall protection program and is a pivotal information-gathering process for identifying actual and potential threats to the Laboratory's activities and information. 


\section{Nuclear Material Control and Accountability}

A safeguards program is in place to ensure the physical protection and accountability of nuclear materials. Safeguards ensure the effectiveness of the measurement systems and the ability to obtain precise and accurate values. Our nuclear materials accounting process maintains accurate records of the Laboratory's nuclear material inventories. We develop, administer, document, and maintain program plans and procedures (including emergency plans and response) involving the protection and control of nuclear materials. To support programmatic requirements and to provide for cost-effective operations, nuclear materials management ensures planning for future nuclear material needs.

\section{Personnel Security}

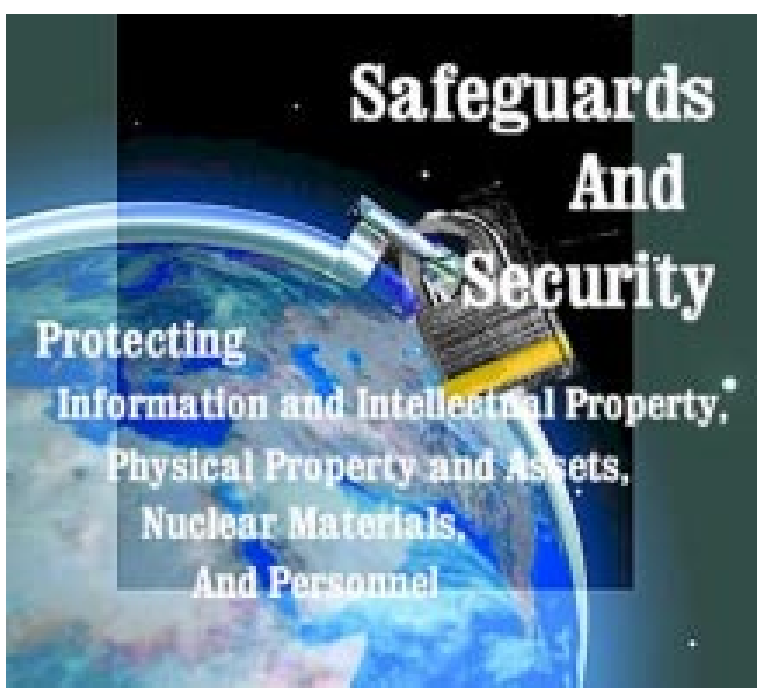

Among almost 3500 staff at Pacific Northwest National Laboratory are 900 with security clearances. Our personnel security program ensures that individuals are processed for, granted, and retain a DOE access authorization (clearance) only when their official duties require such access. The program also ensures that individuals are allowed access to DOE classified matter and special nuclear materials only when such access will not endanger the common defense and security and is consistent with the national interest. The program maintains the minimum levels and numbers of clearances necessary to ensure the operational efficiency of DOE programs and operations.

We provide visitor control by maintaining procedures for processing visits to and from Pacific Northwest National Laboratory so that only officially authorized visitors are permitted access to classified or sensitive information, materials, or areas. Incoming visits of U.S. citizens and foreign national visits and assignments, as well as outgoing visits of staff to other locations, are coordinated, processed, and tracked.

Our review process ensures foreign national visit and assignment activities (including hiring) are coordinated and reviewed from an integrated perspective to determine the overall need and associated benefit. Operations security, counterintelligence, export control liaison, and the Laboratory approval authority receive information regarding all foreign national visits, assignments, and hire requests.

During fiscal year 1999, there were over 9600 visitors to the Laboratory. Over 350 of these visits involved classified interactions and over 1190 were for foreign national visitors and assignees.

\section{Cyber Security}

The cyber security program at Pacific Northwest National Laboratory ensures the protection of information that is stored, processed, or viewed by electronic means. Cyber security includes all personnel, operating, equipment, and maintenance activities associated with unclassified (both sensitive and nonsensitive) and classified information and information systems, and cyber infrastructure.

- The unclassified computer security program is responsible for the policy, guidance, and strategies for the protection of all unclassified information and information systems that generate, receive, transmit, use, store, reproduce, or destroy information in electronic form. The protection level for information and systems is commensurate with the threat, risk, and potential harm that could result from the loss, misuse, disclosure, or unauthorized modification of information processed, stored, or transmitted by electronic methods. Protection includes all security-related activities associated with network management, Internet access, training and education, intrusion detection, system recovery, and cyber security architecture. 
- The classified computer security program is the classified version of our unclassified computer security program. Our key objective is to protect classified information that is created, stored, processed, viewed, or prepared for transmission by electronic means.

- The communications security program protects information that must be transmitted by electronic means over telecommunications facilities both internal and external to the perimeter protection boundary of the Laboratory. This includes methods for ensuring the authentication, integrity, and confidentiality of information sent and received between systems and users.

Cyber infrastructure includes all operating and maintenance for protecting computer and information systems critical to facility operations from traditional and information warfare threats (both internal and external adversaries). Computer and information systems critical to the maintenance of the infrastructure include automated process control systems; fire, criticality, and security alarm systems; telephone and network switching systems; electrical power distribution control systems; oil and gas distribution control systems; and other supervisory control and data acquisition systems.

\section{Export Control Program}

The export control program protects U.S. government-controlled information. The unauthorized release of such information has the potential to undermine the U.S. economy and national security. This program promotes awareness of the different dissemination methods and institutes proper review procedures to effectively minimize this risk.

The export control program is built around regulations regarding the transfer of unclassified equipment, materials, and information that could adversely affect nonproliferation objectives and national security.

\section{Program Changes}

In May 1999, DOE Secretary Bill Richardson announced his security reform package, which was the most sweeping reform of security programs in DOE's history. This comprehensive plan involved the creation of the Office of Security and Emergency Operations and the elevation and revitalization of the DOE Office of Independent Oversight and Performance Assurance. In order to ensure that adequate resources were devoted to safeguards and security and to correct the fragmentation of the program, DOE requested that the safeguards and security budget be direct funded from this office. In December, Pacific Northwest National Laboratory responded and provided field work proposals to DOE and estimates of the Laboratory's safeguards and security program costs.

The direct-funded estimates were provided in two phases. Phase I was a baseline that developed cost estimates using actual resources from fiscal year 1999 budgets $(\$ 17,154,000)$. Phase II added resources required to implement incremental costs for new order requirements (identified as "over target") that had been received subsequent to the Phase I submittal (an additional $\$ 10,925,000$ ). We continue to work with DOE to assess the costs of new safeguards and security requirements.

Our safeguards and security program is responsive to the new requirements and will ensure that the DOE assets at this Laboratory are protected. Our challenge is to balance programmatic needs with the need to achieve compliance with the Secretary's security reform measures. The Laboratory is proactive in addressing this challenge through a variety of activities. A current initiative being worked in cooperation with the line organizations is the consolidation of non-laboratory limited area islands into a single facility. Another activity is the integrated safeguards and security management program that the Laboratory is using to ensure appropriate assimilation of current, proposed, and new requirements. 


\section{Site and Facilities Management}

Pacific Northwest National Laboratory faces a challenging and changing work environment as it enters the $21^{\text {st }}$ century. Modern science in the $21^{\text {st }}$ century requires highly specialized laboratories and research equipment. Our responsibility is to ensure that our scientists and engineers conduct first-rate scientific research in modern and efficient facilities with state-of-the-art instruments. The current mix of facilities at the Laboratory includes both aging and modern research laboratories. Although we have worked hard to improve our physical plant to its present condition, we recognize that 1) a substantial portion of our laboratory facilities require renovation, and 2) the current Laboratory infrastructure does not have the necessary facility capabilities for conducting modern science or for meeting the anticipated growth during the next decade. In addition, as a multiprogram research laboratory serving a diverse customer base-including DOE, other federal agencies, and commercial sector clients-we must ensure that our facilities serve a broad spectrum of purposes. This rapidly changing environment underscores the need for an insightful facility strategy that responds appropriately to DOE's missions in ways that are both flexible and scalable to the capabilities that we require to meet the needs of our customer. The following sections address how we intend to meet these requirements. In addition, this plan reflects the strategies detailed in the Strategic Facilities Plans for Achieving Laboratories of the $21^{\text {st }}$ Century that was developed in September 2000. That very important plan supported the Department of Energy and, specifically the Office of Science, in identifying the infrastructure and modernization requirements necessary to support the Laboratory mission now and into the future.

\section{Laboratory Site and Facilities}

The facilities that compose Pacific Northwest National Laboratory have evolved from Hanford legacy laboratories and the original set of buildings that Battelle began constructing in 1965 in Richland, Washington. These Laboratory holdings include facilities that are owned by DOE and buildings that are owned by Battelle or leased from others. Through a formal arrangement with DOE, this collection of DOE and privately owned facilities makes up the consolidated Laboratory, and is used by over 3400 scientists, engineers, and support staff to perform work for DOE, for other federal agencies, and for private industry.

The Laboratory has 196,000 square meters $(2,106,000$ square feet $)$ of facilities. As identified in the fiscal year 2000 Laboratory Space Distribution table, 53 percent of Pacific Northwest National Laboratory facility space is in DOE-owned buildings located in the south end of the 300 Area on the Hanford Site. However, DOE's Richland Operations is currently developing a proposal for restoring the Columbia River corridor by cleaning and closing the 300 Area by the year 2010. The 300 Area Accelerated Closure Plan calls for dismantling and removing current 300 Area buildings, with the exception of the buildings and laboratories that Pacific Northwest National Laboratory requires for future use, leaving vacant land and some limited utility infrastructure in place. The future and role of the Laboratory in the 300 Area Accelerated Closure Plan is one of the critical strategic decisions facing the Laboratory over the next several months.

The DOE-leased buildings are located just south of the 300 Area close to the Battelle privately owned and leased buildings. The remaining Battelle privately owned buildings are located at the Marine Sciences Laboratory in Sequim, in northwestern Washington State. This distribution of buildings and locations provides a diverse capability to meet a broad range of technical needs.

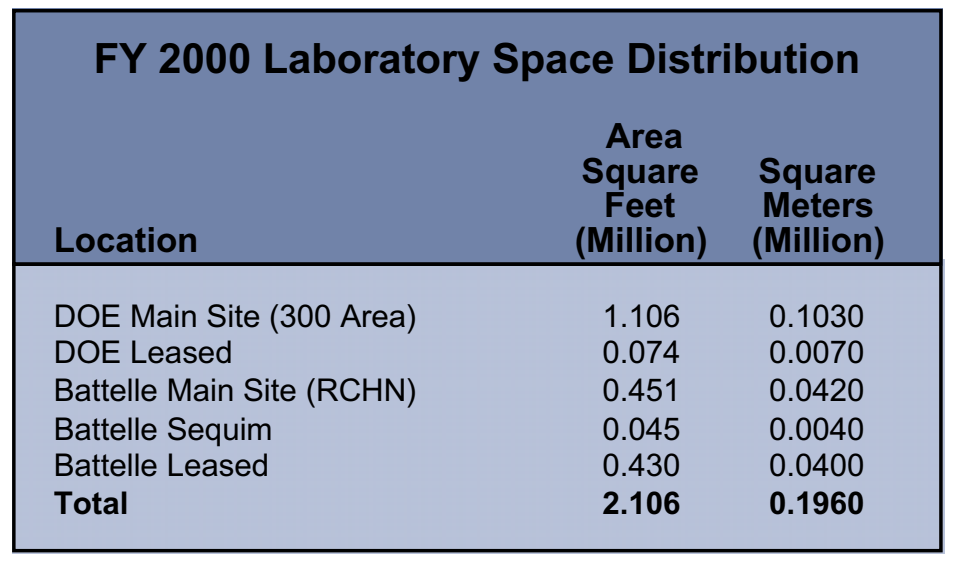


Each set of facilities uses different utility service providers to ensure continuous delivery of services. The Project Hanford Management Contractor and Johnson Controls, Inc., provide utility services to the DOE-owned facilities. Pacific Northwest National Laboratory continues to work with DOE-Richland Operations Office and the Hanford Site Integrated Group to ensure that the Laboratory's physical facilities requirements are supported beyond the end of the current environmental restoration era at the Hanford Site.

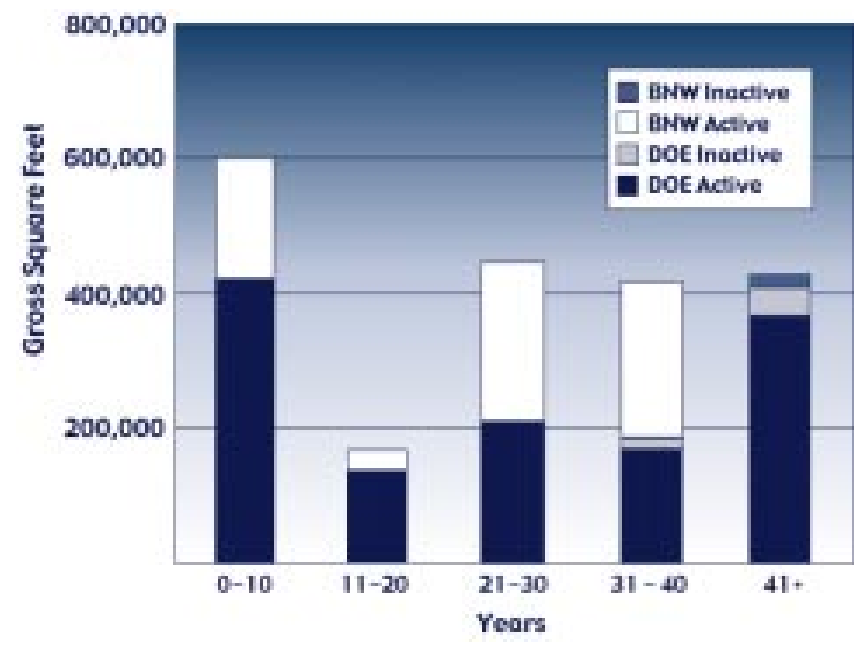

Age of laboratory buildings.

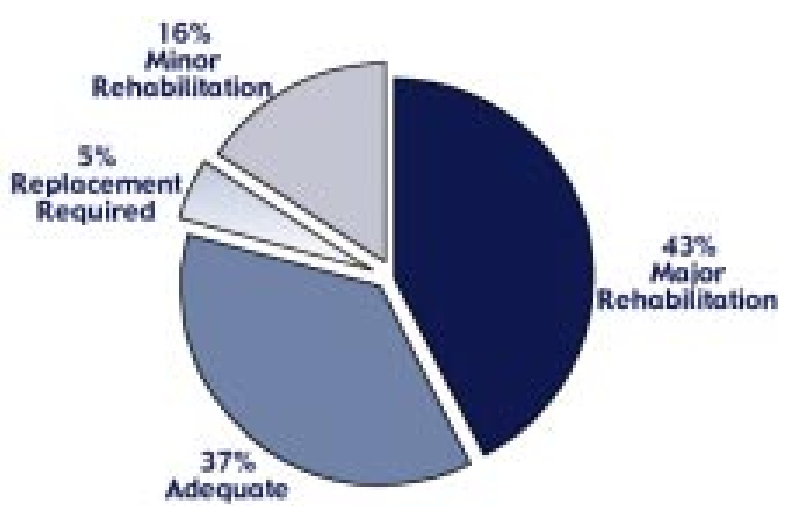

Condition of DOE laboratory space.

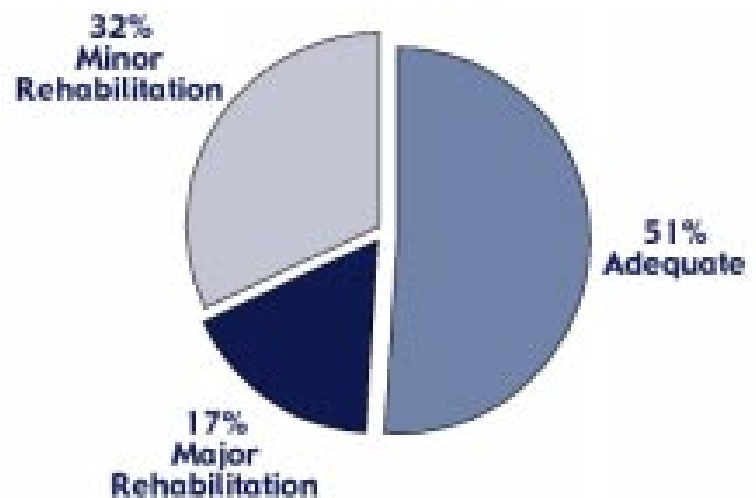

Condition of Battelle laboratory space.
The majority of the DOE-owned active buildings are 1950s vintage with an average age of 31 years (excluding the new William R. Wiley Environmental Molecular Sciences Laboratory, see the figure). These buildings require considerable investments to maintain and upgrade their capabilities to support world-class research (see Condition of DOE Space figures). The Battelle privately owned buildings are reaching ages of 20 to 25 years (average 21 years). These aging facilities require major capital investments to continue to meet DOE missions at the Laboratory (Conditions of Battelle Space figures). Capital investments for the Battelle-owned buildings are provided by Battelle Memorial Institute. The age and gradual deterioration of this collection of privately owned facilities requires an aggressive rehabilitation program, with balanced investments by each landlord, to meet the growing DOE mission requirements.

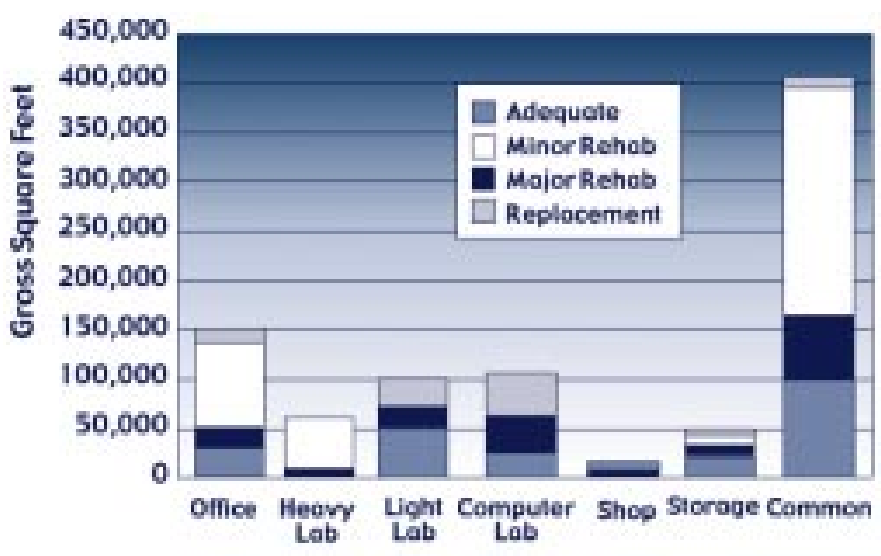

Use and condition of active DOE laboratory space.

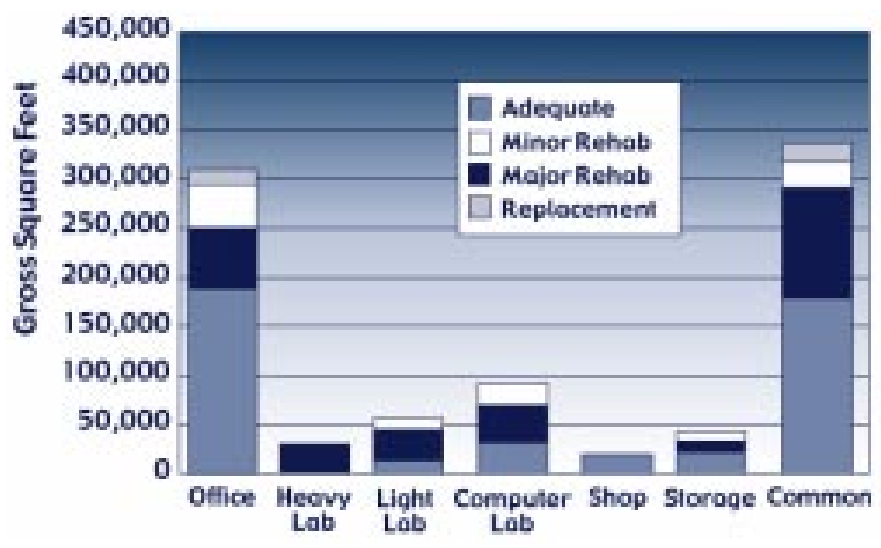

Use and condition of active Battelle laboratory space. 
Pacific Northwest National Laboratory has developed Building Life-Cycle Plans for each building it uses. The Building Life-Cycle Plans are updated as new information is made available, including a revision as building walkthroughs are conducted every three years. The Building Life-Cycle Plans drive the replacement and rehabilitation investments required for each building.

The Facility Replacement Value table summarizes Pacific Northwest National Laboratory's active buildings. The DOE replacement value for fiscal year 2000 is $\$ 360$ million, an amount that was derived from the Richland Property System. The Battelle-owned replacement value is $\$ 72$ million, an amount that is developed by a private company (FM Global, Johnston, Rhode Island).

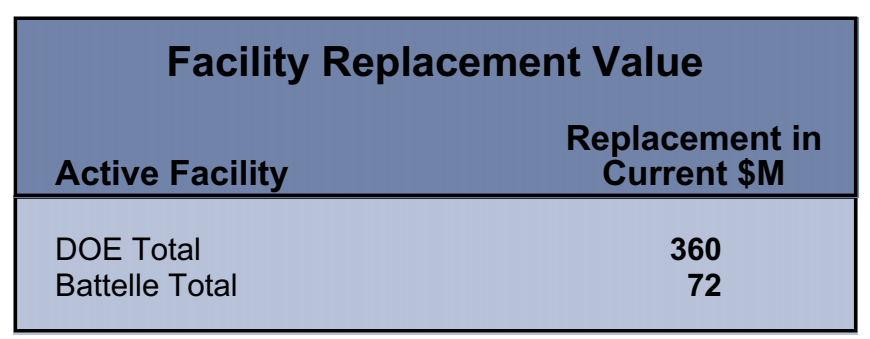

\section{Site and Facility Trends}

Pacific Northwest National Laboratory continues an aggressive facility consolidation effort that began in 1995. Our consolidation objective is to vacate and remove excess facilities from our portfolio, to improve the use of space, and to reduce the cost of operation. The proposed 300 Area Accelerated Closure Plan requires the Laboratory to examine carefully each building and identify those that can and should be removed from the facility inventory, as well as those that should remain to retain essential capabilities. Once the plan is approved and funding is secured, Pacific Northwest National Laboratory will move toward closures and consolidations under the provisions of the plan.

The DOE-Richland Operations Office has asked Pacific Northwest National Laboratory to play a leading role in developing the economic future of the Hanford Site following cleanup and restoration. The Laboratory will enhance its comprehensive site planning and form strategic partnerships with state and local municipalities, universities, and the private sector to facilitate this effort. The comprehensive Site Plan will account for land use restrictions identified in the recently released Hanford Environmental Impact Statement. Another important part of the Laboratory's future strategy involves increasing DOE support through the Office of Science Stewardship Initiative and incorporating principles of facility sustainability, using Laboratory expertise in energy-efficient building design, efficiency technologies, and pollution prevention as applied to facility design. Given the current gap between our needs to expand capabilities to produce desired outcomes and the limited resources historically available to DOE, it will be essential for the Laboratory to partner with other agencies, institutions, and private firms to enhance and develop the needed facility infrastructure.

\section{Facility Modernization and Revitalization Plans and Options}

\section{Modernization}

We believe that facility resources will need to expand and change to meet growth and capability requirements to support the DOE science and technology mission areas. Pacific Northwest National Laboratory is working hard to keep up with the rapid pace and changing nature of research and development to ensure that Laboratory capabilities maintain pace with the expectations and needs of DOE science missions. As a DOE multiprogram national laboratory, our roles and responsibilities are aligned with the priorities identified in DOE's Strategic Plan and in DOE's research and development portfolio for science, environmental quality, energy resources, and national security.

Whenever possible, the Laboratory will support these mission areas with high-quality workplaces for research by upgrading existing outdated facilities and infrastructure. For example, in fiscal year 2000, Pacific Northwest National Laboratory upgraded its existing computer network to include an OC-3 grade fiber optics system capability. The OC-3 system will greatly enhance the transfer of computer data, visualization data, 
desktop videoconferencing, and other applications where high-speed transmission is essential. In the near future, the Laboratory's internal network will be upgraded to OC- 12 capability standards.

Emerging sciences, such as proteomics and nanotechnology, fuel cell technology, chemical processing, and information management, will require new and larger facility configurations, highly specialized instruments, and advanced computer systems beyond that which we currently have in place. The table summarizes the investments that will be needed to support Laboratory missions. These investments, whether through modernization or revitalization, will

- provide the quality of working environments that attract and retain high-quality staff

- provide secure computing and laboratory space for classified and national security projects

- address elements of environment, safety, and health that are required to make the Laboratory a safe place for its staff, visitors, and the community in which we operate.

\section{Summary of Investments Needed to Support Laboratory Missions}

Investment Area

Advanced Computing Science Facilities

\section{Biological Science Laboratories}

\section{Engineering Research} Laboratories

\section{Mission Support}

Laboratory scientists conduct ever-increasing computations and simulations as an alternative to bench-level experimentation due to economy of scale and flexibility. Existing supercomputer resources have not kept pace with either the demand for high-performance computing or the current state of technology. We currently require substantial upgrades in parallel-architecture speed, and in mass storage. High network bandwidth is needed between graphics and visualization laboratories, workstations, and computing resources. These facilities require specialized engineering of utilities, heating/ventilation/air conditioning, and networked access, and need to be located close to other data-intensive laboratories.

New facilities are needed for proteomics research (the study of protein expression and function) that we believe will lead to increased understanding of the human genome; technologies for understanding the health consequences of environmental pollutants, new drugs, and diagnostic discoveries; and other scientific knowledge. The Laboratory will build on its base in molecular science and radiation biology to further study the mechanisms and effects of contaminants on living systems. We anticipate an increased level of research for the National Institutes of Health, which will require advanced capabilities and instruments. In support of rapidly expanding proteomics research in the post-genomic era, we have identified immediate needs for new laboratory space to accommodate mass spectrometers, cell culture facilities, wet chemistry laboratories, and designated space for genomic arrays, antibody production, tagging and labeling, and data analysis and visualization instrumentation. In addition to proteomics, advanced biological sciences laboratories are needed to conduct detailed observations on the response of living cells to various insults. This "cellular observatory" research will require integrated laboratory facilities for cell culturing, cell characterization, microscopy, data analysis, and nuclear magnetic resonance spectroscopy. Virtual biology computing facilities are needed to conduct cyber experiments, modeling simulations, and analysis of experimental data.

Expanded mission responsibilities are anticipated for DOE programs in fuel cell materials and technology, microtechnology, lightweight materials research for energy-efficient automobiles and trucks, advanced passive and active electronic sensors, advanced electronic systems, and bio-based processing. New facilities are needed for prototype testing and technology demonstration, materials synthesis, fabrication, storage, and computations. We anticipate the need for segregated work areas to accommodate the special confidentiality requirements of industrial partners. 


\section{Summary of Investments Needed to Support Laboratory Missions}

Investment Area

National Security

Complex

Process Science and

Engineering Complex

Visitor Support

Complex

\section{Mission Support}

We develop innovative solutions to critical national and international problems by applying and deploying the full science and technology capabilities of the Laboratory to our safety and security programs. The national security missions of the Laboratory will continue to expand and will require new laboratories for research, offices for staff members, and upgraded computational resources for classified computing and information management.

Replacement laboratories, offices, and special-purpose facilities (such as hot cells for radioactive material characterization and separations science), high-bay space, fuel assembly test areas, wet chemistry laboratories, and clean areas for analytical instruments are needed as legacy 300 Area laboratories are decommissioned and dismantled. Replacement facilities will reduce health and safety problems associated with legacy hazards, such as residual radioactive contamination, beryllium, and asbestos. In addition to replacement facilities, our Radiochemical Processing Laboratory will require major upgrades and renovations to support ongoing environmental management and Hanford Site restoration activities and programs.

Housing, meeting rooms, and cafeteria facilities are needed to support the increasing number of scientific users at the Laboratory.

The figure identifies the roadmap and the approximate time frame for adding new facilities to the Pacific Northwest National Laboratory campus.

Taken as a whole, our facility plans are designed to encourage and enable Pacific Northwest National Laboratory to be among the world's truly premier scientific laboratories for solving the most critical scientific and technological problems.

\section{Revitalization}

An important issue to address in the revitalization program over the next several years is the age and condition of the

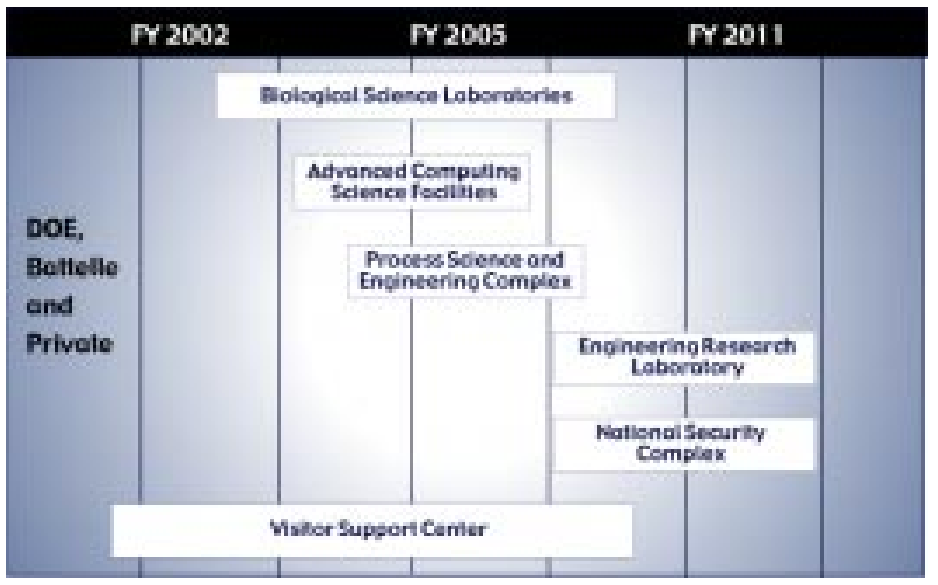

Future facility modernization roadmap. Laboratory's space. Researchers and their ability to conduct work are greatly impacted by deteriorating space. "Work arounds," if even possible, are necessary for staff to continue their research. Today's research equipment and needs for work process flow require substantially different laboratory configurations and services than laboratories of 30 and 50 years ago. Revitalization at Pacific Northwest National Laboratory began over a decade ago, and substantial progress has been made. Past investments have focused on rehabilitating the physical plant and reducing occupational safety and environmental risks. These past investments total $\$ 111$ million and have placed the Laboratory in a positive position to be the model for DOE. However, more must be done to complete the vision to modernize the existing facilities to meet the science of the $21^{\text {st }}$ century. This vision encompasses the entire portfolio relating to work for the Office of Science, Environmental Management, and others. The project descriptions and funding profiles (described in detail in the next section) strike a balance between high-priority environmental, safety, health, and infrastructure projects, and our science and technology needs. A portfolio management approach is used to maintain a balance between all aspects of the projects.

The rapid pace and changing nature of research and development has had a considerable impact on the adequacy of research equipment. Technology advances quickly render equipment obsolete. We are concerned that our research capabilities will be compromised 
without an adequate replacement and upgrade plan to ensure that Laboratory capabilities maintain pace with the expectations and needs of DOE's science missions.

\section{Facility Modernization and Revitalization Resource Requirements}

\section{Modernization}

For Pacific Northwest National Laboratory to deliver excellence in science, environmental quality, energy resources, and national security, the changing national and DOE needs

\begin{tabular}{|c|c|c|}
\hline \multicolumn{3}{|c|}{ Modernization Is Driven by Mission Need } \\
\hline & $\begin{array}{l}\text { Estimated } \\
\text { Size (thousand } \\
\text { square } \\
\text { feet) }\end{array}$ & $\begin{array}{l}\text { Estimated } \\
\text { Construction } \\
\text { Costs }(\$ M)\end{array}$ \\
\hline Advanced Computing Science Facilities & $175-225$ & $35-45$ \\
\hline Biological Science Laboratories & $250-375$ & $103-137$ \\
\hline Engineering Research Laboratories & $150-280$ & $62-123$ \\
\hline National Security Complex & $75-130$ & $31-42$ \\
\hline Process Science \& Engineering Complex & $40-80$ & $17-34$ \\
\hline Visitor Support Complex & $60-80$ & $15-19$ \\
\hline
\end{tabular}

must be addressed.

Our Laboratory vision requires facilities to support advanced science and technology missions, new high-performance computers, specialized laboratory space for molecular and cellular biology, protected areas for national security missions, and process and engineering pilot-scale test research. The current shortage of office space and housing for visitors and Laboratory users complicates the need to rapidly move forward at creating this long-term vision. The sizing of new facilities and estimated costs are shown as ranges to reflect the current level of facility definition.

\section{Revitalization}

The Laboratory capital facility revitalization projects directed to the Multiprogram Energy Laboratory-Facility Support Program and our two DOE Landlord offices are summarized in the Major Revitalization Construction Projects table. The priority system for capital facility requirements is risk-based to ensure that facilities and infrastructure are operated safely to protect our staff, the public, and the environment while addressing science and technology rehabilitation and infrastructure needs. The Building Life-Cycle Plans and Condition Assessments are essential for identifying needs and for establishing facility priorities.

Since 1995, Pacific Northwest National Laboratory has been implementing a facility consolidation program. A key outcome of that has enabled the Laboratory to invest the limited DOE resources it receives more directly toward its long-term strategic and mission-critical facilities. General Plant Project funding has been critical to continuing the rehabilitation process, but limited resources have forced the Laboratory to pursue other funding mechanisms, such as Energy Saving Performance Contracts, to assist in reducing the backlog.

The facility revitalization plan assumes that the 300 Area Accelerated Closure Plan is authorized and funded separately. The facilities scheduled for closure under the plan include the 305B, 306W, 323, 332, 3718A, 3718P, 3718S, 3720, 3730, 3745, and 3760 buildings. The Process Science and Engineering Complex will replace and modernize the capability lost by the closure of these aging facilities. Funding for the replacement facility is addressed in the 300 Area Accelerated Closure Plan. Other key Laboratory facilities (320, 325, 326, 329, 337, 331, among others) will remain, but will be supported by a modernized and consolidated utility infrastructure service.

If the 300 Area Accelerated Closure Plan is not authorized, many of the affected buildings listed above will continue to be occupied, but will require major infrastructure rehabilitation. For example, most of the buildings scheduled for closure will require 


\section{Major Revitalization Construction Projects \\ (Budget Authorization Dollar Amount in Millions)}

Total Est.

Const. Cost

$\begin{array}{lll} & \text { Fiscal Year } \\ 199920002001 \quad 2002\end{array}$

200320042005

FUNDED CONSTRUCTION

General Plant Projects

General Plant Projects (KP) ${ }^{(a)}$

General Plant Projects EM 60 (EW)

General Plant Projects EM

Multiprogram Energy Laboratories-

Facility Support Program Projects (KG)

Total Funded Construction

$\begin{array}{lll}3.4 & 4.6 \quad 3.5\end{array}$

PROPOSED CONSTRUCTION

General Plant Projects

General Plant Projects (KP)

General Plant Projects EM 60 (EW)

18.9

14.1

Multiprogram Energy Laboratories-

Facilities Support Program Project (KG)

Laboratory Systems Upgrades - FY 2002 New Start

320 Building Infrastructure - FY 2002 New Start

Laboratory FY 2003 Systems and Rehabilitation

Upgrades New Start

Total Proposed Construction

Total Construction

$3.1 \quad 3.7$

$0.3 \quad 0.9$

3.5

9

$\begin{array}{llllllll}9.0 & & & & & & & \\ 7.4 & & & & 0.9 & 4.8 & 3.3 & \\ 9.7 & & & & 4.2 & 3.2 & & \\ & & & & & 3.8 & 5.9 & \\ 59.1 & & & & & & & \\ 67.1 & 3.4 & 4.6 & 3.5 & 11.3 & 23.8 & 15.3 & 5.2 \\ & & & & & & & \\ & & & & & & & \end{array}$

(a) Budget codes are identified in parentheses.

roof replacement, piping, and upgrades to heating, ventilation, and air-conditioning systems. We have identified $\$ 14$ million of facility upgrades that would be required to continue to occupy the facilities scheduled for closure.

Energy Saving Performance Contracts provide resources for utility infrastructure improvements from the savings achieved by improved energy performance. However, the projects with the most immediate payback have been identified and completed, thus reducing the potential projects that can be accomplished using this method in the future. We recognize that Congress is under increasing pressure to reduce capital investments in DOE facilities. However, Pacific Northwest National Laboratory will continue to look at ways for creative investment strategies to ensure good stewardship of DOE and Battelle capital resources to meet the most important DOE mission needs.

\section{Required Multi-Program Energy Laboratory-Facility Support Investments}

In fiscal years 1999 and 2000, we analyzed our critical Office of Science facilities to estimate the funding that would be needed to improve and refurbish those facilities. As a result, we believe that $\$ 26.1$ million is needed for three line item projects starting in fiscal year 2002 and ending in 2004. The growing need for capital funding and limited availability during the past five years complicates this aggressive schedule.

\section{FY 2002 Line Item - 320 Building Infrastructure Rehabilitation}

The 320 Building is recognized as one of our core DOE facilities. The 320 Building was originally constructed in 1964. Due to heavy use, the 320 Building is deteriorating. We requested funding from the Office of Science in 1999 to rehabilitate the 320 Building to decrease operating and maintenance costs and to provide a safer and more productive work environment. Project D-485 will upgrade this strategic laboratory and its facility systems to extend its useful lifetime. Existing facility system, including the heating, 
ventilation, and air-conditioning systems, will be modernized with highly efficient equipment and controls to reduce energy and operational costs. Existing conditions in the facility result in a waste of 5 percent to 10 percent of research staff hours annually (or $\$ 300,000$ to $\$ 600,000$ ). These system modifications will eliminate excessive vibration caused by heating, ventilation, and air-conditioning equipment that interferes with performance of sensitive microscopes and spectrometers.

\section{FY 2002 Line Item - Laboratory Systems Upgrades}

If the Accelerated 300 Area Closure Plan moves forward, line item upgrades will be reviewed to ensure that upgrades are planned only for the buildings that will remain in place. This Line Item will upgrade the less-efficient building systems with retrofitted technology that increases the life span of the building while decreasing energy consumption and maintenance service costs. These systems include heating, ventilation, and air-conditioning components (replacement of supply and exhaust fans with both equipped with variable frequency drive systems). We will replace chemical exhaust fume hoods that cannot be retrofitted with variable air volume fans with controllable damper systems and modular controls for the vane dampening controls within the system. Heating and cooling systems in three buildings (329, 336, and 338) will be equipped with digital controls for existing supply and exhaust fans, inlet vanes, and isolation dampers.

Old, energy-inefficient chemical fume hoods will be replaced in two buildings (331 and 326). Ninety-seven hoods will be retrofitted or replaced to add variable air volume capability. This type of fume hood allows sashes to be closed when not in use. These controls will decrease operator service (manipulation time) and will allow control by computer-based systems. A natural-gas-powered electrical generator will be installed to decrease the cost of backup power at the 331 Building. Energy savings will be obtained by replacing failed glazing (cracked and broken single-pane glazing and double-glazing where the seals have failed) in the 326 and 337 buildings.

\section{FY 2003 Line Item - Laboratory Systems and Rehabilitation Upgrade}

This project is part of the continued revitalization efforts ongoing at the Laboratory over the last 10 years. The revitalizations efforts over the past decade have focused on the physical plant in the strategic facilities in the 300 Area. This project supports the continuing revitalization plan and initiates the next decade of revitalization focused at laboratory and administrative space upgrades. The Laboratory Systems and Facilities Rehabilitation project finalizes the revitalization of the physical plant initiated with the FY 2002 Line Item project, Laboratory Systems Upgrades, and upgrades laboratory and administration space in strategic facilities. This project will reduce operation, maintenance, and utility costs by replacing or upgrading hoods with variable air volume controls and converting the 337 and 350 Buildings to gas heat. Additionally, this project will rehabilitate the remaining section of laboratory and office space in the 329 Building. The north end of the building was rehabilitated during the FY 1991 Line Item. The remaining portion of the building requires laboratories to be upgraded to meet the science challenges of the $21^{\text {st }}$ century that cannot be met with the exiting configuration and equipment.

\section{General Plant Equipment}

Pacific Northwest National Laboratory understands the need for general plant equipment and has developed an equipment plan to support the Laboratory mission over the next five years. This plan requires an annual investment of $\$ 2$ million.

\section{Assets Management and Inactive Surplus Facilities Plan}

Pacific Northwest National Laboratory reviewed its facility holdings and determined that approximately one-half of the facilities were candidates to be vacated over the next five years. Subsequent to this review, we began consolidating operations for full use of the strategic facilities and closing nonstrategic, uneconomical, or underused facilities. 
From a total of 204 facilities, 102 were removed from active inventory. Of the 102 that were removed, 72 facilities were physically removed or were transferred to another operator, 29 are in standby (surveillance and maintenance) condition, and one remains to be placed in standby.

We expect that all of the currently excess facilities will be transferred to the Office of Environmental Management, starting no later than 2002 (per the Memorandum of Understanding approved by the Office of Environmental Management, Office of Defense Programs, and Office of Science). The cost of final disposition of these facilities is included in the Hanford Site's Office of Environmental Management cleanup baseline. Most of the radioactive contamination in these facilities resulted from defense activities (fuel processing and production) prior to 1971. The current annual surveillance and maintenance budget for the surplus facilities is approximately $\$ 60,000$ (funded by the Office of Environmental Management).

\section{Space Management}

Pacific Northwest National Laboratory manages active facility space by dividing all space into one of six categories: common (areas of a building that are shared equally by all occupants), storage, office, dry laboratory, wet laboratory, and filtered laboratory. On a fiscal year basis, the Laboratory develops billing rates for each space type. Space holdings by each of the organizations at the Laboratory are reconciled quarterly and are directly billed to each organization. The result of this "user pays" philosophy has been a major reduction in active space holdings. Over the past five years, 102 facilities have been vacated (a 20 percent reduction in space holdings).

\section{Energy Management}

Pacific Northwest National Laboratory is reducing energy and utility costs. As downsizing and environmental cleanup of nuclear facilities progresses, significant cost savings are feasible through right-sizing and modernizing the utility infrastructure. Alternative financing through Energy Savings Performance Contracts has provided the capital to modernize the utility infrastructure of the Hanford 300 Area and the Battelle campus in North Richland. The largest project provided distributed steam systems to the Hanford 300 Area facilities and eliminated the aged Hanford 300 Area central steam system plant. This project resulted in an 80 percent reduction in fuel, operation, and maintenance costs and a 99 percent reduction in emissions. To date, these projects have achieved \$11 million in capital and \$3.5 million in annual savings compared to the peak cost year (1994). Every year, the Energy Savings Performance Contracts service contractor has exceeded the annual guaranteed contract savings.

Additional fuel, operation, and maintenance cost savings are possible by converting from steam to hot-water heating. A pilot conversion project in one 300 Area building was initiated in fiscal year 2000 using the Energy Savings Performance Contract.

To reduce utility costs further in the Hanford 300 Area, the compressed air and standby power requirements were surveyed in fiscal year 2000. We believe that distributed systems for the facilities requiring these services would save over $\$ 200,000$ per year compared to the current central plants, provided that the capital funds can be found to make the changes.

Several energy and utility management projects are planned for start in fiscal year 2001. The major projects are

- right-sizing the Columbia River pumps to meet current programmatic requirements (90 percent related electrical energy reduction)

- initiating a second phase of the Battelle Energy Savings Performance Contracts (more than $\$ 100,000$ per year additional savings) 
- additional phases of the Hanford Site Energy Savings Performance Contracts for Site water systems, Site electrical systems, and individual building modifications

- increased use of automated energy control and monitoring systems.

The Laboratory's energy management program also targets other goals and activities, including

- minimizing energy and water use and costs by reducing water and sewer use, improving energy-related operations and maintenance, and seeking better energy prices and services

- supporting Pacific Northwest National Laboratory research efforts in nuclear safety, fire protection, codes, digital controls, project development, federal and state energy partnerships, and Energy Savings Performance Contracts

- serving the community as a strategic partner in the DOE/Tri-Cities Rebuild America partnership, which seeks to make the Tri-Cities more efficient and competitive.

\section{Information Resources}

The efficiency and effectiveness of Pacific Northwest National Laboratory's information management processes, tools, services, and resources enable our scientists and engineers to be more productive and innovative. The successful execution of Laboratory missions is enabled by convenient, reliable, fast, and cost-effective access to digital information. Information management encompasses information technology infrastructure and the scientific and technical information program. Our strategy is to provide our staff, collaborators, business partners, and customers with secure and timely access to information to enhance business decision-making and individual and team productivity.

\section{Information Technology Infrastructure}

The information technology infrastructure provides the essential networked computer systems and support for all of the research missions at the Laboratory. These resources include computers and computational facilities, systems and databases for scientific and administrative information, network and telecommunications, and user-oriented information services. Components are specifically adapted to support key missions in environmental science, energy science, and national security. Information technology services are focused on four strategic computing environments: 1) scientific and technical computing, 2) productivity and knowledge management, 3) business information systems, and 4) information technology infrastructure. These information environments are enhanced by a web-based computing connectivity that features a common network infrastructure.

\section{Current Capabilities}

Pacific Northwest National Laboratory's network infrastructure features a mixed 10/ 100BaseTX Ethernet that migrates to a 100BaseTX at the edges, with a mixed Fast Ethernet/Gigabit Ethernet backbone that migrates to a Gigabit Ethernet. The Environmental Molecular Sciences Laboratory is served by an ATM backbone over a fiber optic local-area-network-switched Ethernet. Our digital PBX telephone system will be replaced with a new switch capable of supporting voice and data convergence.

External connections to the Laboratory are provided by a T3 ESnet link and a backup T1 link to NorthWestNet, a regional internet service provider. The T3 link is shared with the National Science Foundation-funded Laser Interferometer Gravitational-Wave Observatory at the Hanford Site. This T3 link will be upgraded to OC-3.

Business computing for the Laboratory is provided by a networked array of Sun SPARC distributed computing systems that we refer to as our Information Resource Management 
environment. This array uses Oracle and Sybase data management software. This intranet computing environment supports the Laboratory's data warehouse, decision support applications, and tracking and reporting systems. We use commercial software to the maximum extent practical for our core applications, which include cost accounting, procurement, human resources, payroll, and travel management. Interfaces to these systems are based on a web-centric, browser-accessible model for enhanced user access and productivity.

Desktop computing by our scientists, engineers, and support staff is mainly dependent on standardized Windows operating systems running on Intel platforms. Macintosh systems also are supported at the desktop level, and UNIX platforms are supported for special-purpose and scientific applications. Our computing platforms are acquired through a managed hardware program that features standard hardware and software configurations, pre-configured security settings, on-line ordering, accelerated delivery, and reduced acquisition, installation, and maintenance costs. Application software standards adopted as part of this program include Microsoft Office, Exchange/Outlook, Quick View Plus, Netscape, Norton Anti-virus, and Schedule+. Each of these software packages is acquired under a site license from the vendor.

Supercomputing is available on a high-performance IBM RS/6000 SPJ with 512 processors, an IBM SP with 96 processors, and a 192 processor Dell-Giganet cluster using $500 \mathrm{MHz}$ Pentium 3 processors. In addition, a high-performance visualization and graphics laboratory equipped with advanced Silicon Graphics, Sun, and IBM cluster machines, as well as over 400 high-performance UNIX-based workstations, is available at Pacific Northwest National Laboratory to support the advanced computing needs of our scientific staff.

The Pacific Northwest National Laboratory network is protected by a fully configured firewall. External access to this network is enabled for travelers, partners, and collaborators using a combination of protective access measures, including smart-card token access, Virtual Private Network capability, and Secure Sockets Layer authentication and proxy access. A public key infrastructure pilot for authentication and encryption was moved to pre-production status.

Pacific Northwest National Laboratory successfully completed the Year 2000 (Y2K) transition, including the February 29 leap year event, without incident.

\section{Strategies}

Our technical strategies for advanced computing are executed in accordance with the strategic vision described in our Five-Year Information Technology Strategic Plan. The Information Sciences \& Engineering organization is responsible for developing the plan with the advice and consent of the Management Information Systems Council (which oversees business information systems) and the Scientific Information Systems Council (which guides planning for scientific and engineering systems) at the Laboratory.

High-priority activities underway at Pacific Northwest National Laboratory include 1) completing the upgrade of the ESnet connection to OC-3,2) increasing desktop access to $100 \mathrm{Mb} / \mathrm{sec}$ networking across the Laboratory, and 3) further strengthening our network and system security.

Our developmental strategy for the internal network strategies is to complete the ongoing transition to switched 10/100 BaseTX for all local area network segments while upgrading performance to 100BaseTX. We are also extending the Fast Ethernet/ Gigabit Ethernet backbone to all major network segments. Concurrently, we are reducing the number of routers on the network backbone by consolidating their work on larger devices.

Network security is being enhanced in several areas. The prototype public key infrastructure initiated in fiscal year 1998 is being expanded. We plan to achieve full expansion to all staff in fiscal year 2001. The virtual private network capability was 
moved to production status and is being used to support direct subscriber line services. This capability will support a pilot work-from-home project to assess the effectiveness of alternative work locations. We have also initiated an activity over the next three years to redesign the network and to implement security enclaves. This activity will support network enclaves with varying security requirements while maintaining staff access to essential enterprise applications. An intrusion detection system was installed at the perimeter of the Pacific Northwest National Laboratory network in support of an ongoing counterintelligence incident monitoring activity.

External network strategies are focused on increasing the speed and functionality of existing ESnet connections. Pacific Northwest National Laboratory will complete the upgrade of the ESnet link to OC-3 and we will participate in the Internet 2 Gigapop operated by the University of Washington. In future years, we anticipate the need to further increase external network speed and functionality to support our strategic vision for advanced computing, modeling, and simulations.

Our last remaining mainframe system will be converted to a client-server environment in fiscal year 2001 to permit the release of the Hanford Site mainframe enterprise server.

\section{Resources and Initiatives}

Business information systems and most infrastructure investments are funded from general purpose and overhead accounts. Enterprise applications (such as payroll and human resources) and baseline infrastructure capabilities (such as those that are available to all staff) are funded as core services. Budgets for both classes of service are reviewed and approved by senior management as part of the annual budget planning and allocation process.

\section{Scientific and Technical Information Program}

Pacific Northwest National Laboratory's Scientific and Technical Information program provides guidance, products, and services to support proposal development, intellectual property development, and research. The program supports the technical organizations as they seek information important to their research projects and to meet contractual requirements for publication and dissemination of scientific and technical information. This program supports the life cycle of scientific and technical information, from creation through product development, dissemination, retention, and reuse.

\section{Current Capabilities}

In the information-rich work environment, desktop access to information and tools is critical. Examples include desktop delivery of technical journals and other library resources, and the Electronic Records and Information Capture Architecture (ERICA) system.

The Hanford Technical Library is the steward of much of the Laboratory's information assets. The library is located in the Consolidated Information Center, together, with the Washington State University Tri-Cities Library and the DOE Public Reading Room. The Technical Library also has a Legal Library branch located in the Federal Building. The Technical Library collection focuses on energy, engineering, environmental sciences, chemistry, and other basic sciences. The DOE Public Reading Room contains reports related to current and historical operations at the Hanford Site. The Legal Library houses legal and regulatory material. The library continues to aggressively add resources to the desktop via the intranet. To date, Pacific Northwest National Laboratory staff can access the Library's catalog, 680 full-text journals, and a variety of scientific and bibliographic databases, such as Web of Science and Inspec, from their desktops. The Library's web pages also contain subject area resource guides that include links to relevant web sites and electronic documents. The DOE Public Reading Room's catalog is available on the web as well. 
ERICA enables the Laboratory to keep pace with current federal and client records requirements, streamline work processes, position the Laboratory to comply with DOE's plan to deliver published scientific and technical information electronically, and help strengthen the Laboratory's business decision-making processes. When fully implemented, ERICA will integrate and link critical scientific and technical information with records, databases, and repositories that exist at the workstation level in organizations throughout the Laboratory. ERICA will allow organizations to have more control over the disposition of their records and documents. ERICA can reduce redundant data entry in the field and, in some cases, eliminate work in information review and release, transmit documents, prepare Records Inventory Disposition forms, and prepare Records Transfer and Data Input forms.

\section{Strategies and Initiatives}

The ever-increasing demand to publish documents electronically on the web for many clients requires ERICA to support the storage and web publishing of large multiple-file reports. Pacific Northwest National Laboratory must identify new and more detailed publication standards for this type of document (such as relative addressing within the publication) to ensure long-term availability and storage via the Internet and in the electronic records repository. Training staff to publish these large documents must be supported with additional hardware (computer, storage web server) and software (additional tools) to enable smooth publication inside the firewall and outside the firewall. This enhancement will eliminate the requirement of single file uploads for electronic publishing via ERICA and increase the number of electronic products that can be made publicly available on the Laboratory's external home page.

Improving the acceptance rate of Pacific Northwest National Laboratory proposals by improving proposal development is essential to the Laboratory's business growth. Effective tools, resources, and information must be made available to prepare winning proposals. In fiscal year 2000, a proposals business line was established to prepare an integrated set of services and resources.

\section{Management Practices and Standards}

Pacific Northwest National Laboratory is committed to achieving the highest standards of scientific and operational excellence. Our goal is to be recognized as the benchmark standard for laboratory operations. We operate the Laboratory using management systems; examples include Environment, Safety and Health, Project Management, Human Resources, Integrated Planning, and Integrated Assessment. The collective set of management system defines the Laboratory's management standards, and delivers associated processes and tools to our staff. These management systems have improved over the last four years, and these improvements have resulted in more effective Laboratory operations. Our challenge is to continue to find ways to improve management systems so that we can be even more efficient in delivering products to our customers.

\section{Second-Generation Management Systems}

When initially developed in 1996, management systems documented the Laboratory's management practices that were in place at that time. With the implementation of our customer service model (internal organization and processes that focus the Laboratory's resources on our valued customers) and further development of our management systems, the Laboratory has decided that it is now time to re-examine existing management systems and to initiate the development of second-generation management systems. The resulting fully integrated management systems will more clearly define the roles and responsibilities of all staff in implementing the customer service model. The new management systems will result in more efficient and systematic approaches to Laboratory operations with a greater focus on the tools, processes, and information that our scientists need to deliver products of greatest value to our customers. The 
development and implementation of second-generation management systems will help maintain our Laboratory as the benchmark standard for laboratory operations.

In parallel to the development of second-generation management systems, the Laboratory will develop a risk methodology for analyzing the impacts of making, or not making, specific improvements to management systems. This methodology will serve as an improved basis for making near-and long-term investments in management systems.

To ensure that we are collecting consistent information on the performance of all management systems, a self-assessment framework is being developed. This framework will define a common approach and tools that will be used by management systems to collect and analyze information on performance. Through the use of the framework to yield comparable performance information for all management systems, the Laboratory will be able to more efficiently judge where to fund improvements in specific management systems, and define the Laboratory's performance based on the integrated performance results for all management systems.

\section{Integrated Assessment and Planning}

The Laboratory will continue to integrate the assessment and planning processes. Our assessment management system provides four major processes: self-assessment, independent oversight, internal auditing, and peer review. These processes help us to identify strengths and weaknesses in our performance, and areas for improvement. The planning management system helps the Laboratory develop its performance goals and the strategies for achieving these goals. When management systems were first defined in 1996, the processes of the assessment and planning system were not developed in parallel. Parallel development would have ensured that inputs and outputs of the two systems were complementary. However, the results of the Laboratory's assessment processes must provide a major impact on its long-term strategy to improve Laboratory performance, and therefore these processes must be better integrated. Integration efforts initially will focus on mapping the processes of both systems and on developing a joint strategy that will lead to enhancements of the two systems-and ultimately a determination of whether the systems should be combined into one system. Regardless of the outcome, this effort will result in more robust and integrated planning and assessment processes.

\section{Continuous Improvement and Cost-Effectiveness}

Several major improvement programs were initiated in 1994, including the Operations Improvement Program, Management Systems Redesign, and Achieving the Competitive Edge. These programs are examples of our commitment to enhance performance and have resulted in reduced cost

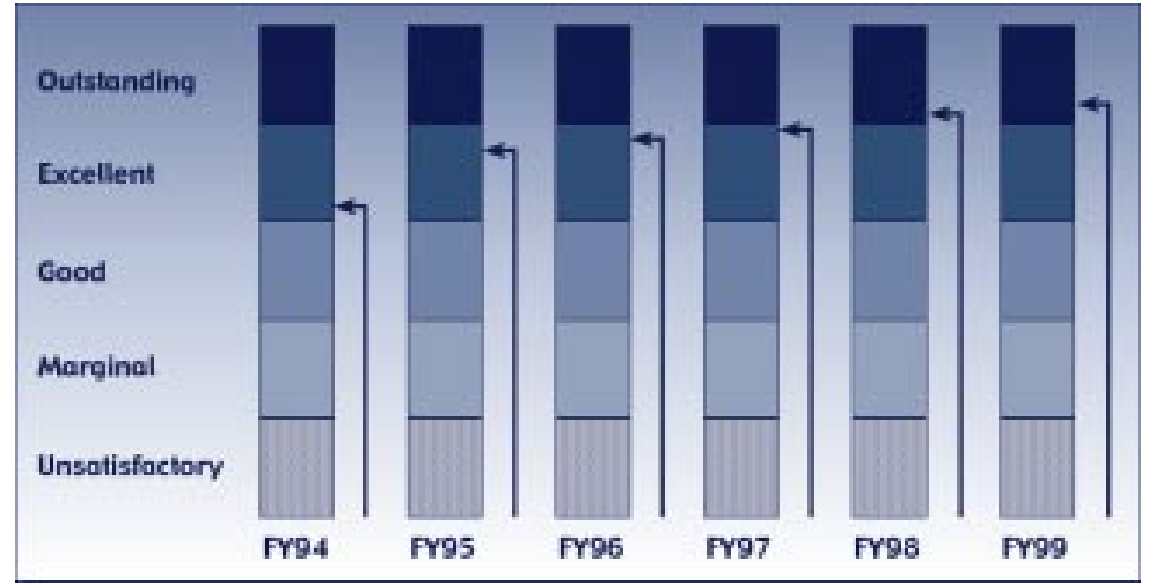

Summary of Pacific Northwest National Laboratory Annual Ratings received from DOE's Richland Operations Office. and risk of operating and managing the Laboratory. More importantly, they have laid the foundation for future improvement initiatives. The results of these improvement efforts, played a major role in the Laboratory receiving an overall rating of "Outstanding" in 1999 for its management and operation.

Despite this success, we still see many opportunities for future improvement. To that end, we will advance the development of operational tools and work practices that 
integrate safety into work activities while enhancing the innovation and creativity of our scientific staff. The next generation of our electronic standards-based management system will incorporate the principles of integrated safety management. A similar approach will be developed for integrated safeguards and security work at the Laboratory. New tools will be developed so that staff will be able to construct customized views of information relevant to their projects, assignments, and activities. Through these and related operational improvement efforts, and by building on the experience of the past five years, we believe that we can better enable our primary focus on scientific research, while providing stewardship for DOE assets and ensuring the health and safety of our staff, the public, and the environment.

Future operations also will require increased use of information technology, electronic commerce, videoconferencing, and application of "collaboratory" software tools for technical interactions. Our commitment to a solid foundation for our computing infrastructure will see the installation of the OC-3 fiber optics line and a further upgrade to the OC-12 within the next two years. Infrastructure stewardship will require us to continue working toward early completion of facility cleanup and to continue our practice of using innovative third-party financing mechanisms for new research facilities.

The Laboratory will also maintain its current focus on cost reduction. We will do so through continual focused review of costs, indirect resource expenditure consistent with strategic objectives, continual pursuit of cost reduction or avoidance opportunities, and documentation of benchmarks and baselines for results-based management.

We believe that significant advantage will be gained by more extensive sharing of experience, tools, and development efforts across the national laboratory system. Pacific Northwest National Laboratory will collaborate with other national laboratories to share best management practices and reduce overall costs to DOE. We have exported the electronic standards-based management system to Brookhaven National Laboratory, and plan to continue sharing these management systems with the National Renewable Energy Laboratory and with Oak Ridge National Laboratory.

We are developing a long-term, strategically driven budget for updated management systems, based on information from Baldridge award-winning companies, other national laboratories, and from our own managers and technical staff. We plan to document and communicate our efforts in cost management, including the use of metrics that can be benchmarked with other national laboratories and other comparable organizations. These efforts should help us maintain our cost-reduction momentum during the next five years.

\section{Communications and Trust}

Pacific Northwest National Laboratory's goal is to support the Department of Energy in creating community awareness and building trust with various audiences through timely communications, community involvement, and public awareness. We are committed to meeting the needs of DOE and the public through effective internal and external communications. We will continue to provide open and timely communications 
with local, regional, and national audiences to build awareness of Pacific Northwest National Laboratory as a premier science and technology research laboratory.

We aim to be a valued and trusted community and regional asset. Our goal is to make significant contributions to local and regional economic development, to science education, and to other major community interests. We unite with various constituencies in the community and Northwest region to build a strong and diverse economy, with particular emphasis on science technology development and deployment. Our community relations strategy uses a five-pronged approach:

- expand existing businesses

- start new businesses

- attract outside business to the region

- create a supportive business climate

- enhance quality of life.

\section{Programmatic Activities}

Our current communications and community development activities form a strong foundation for our efforts in the next five years. We will build on past good relations. For the past three decades, Pacific Northwest National Laboratory has been involved in and has invested heavily in our community. Our contributions have ranged from innovative science education programs that expand student and teacher knowledge to donations that support a wide range of health and human services. On average, we invest about $\$ 2.5$ million per year in the community through communications, economic development, community relations, and education.

- Communications. By providing open and timely communications, our communication programs enable the Laboratory to create awareness and build trust with various audiences in the region. We place articles in numerous national, regional, and local media that enhance the Laboratory's scientific and technical reputation. We also have developed several electronic tools that provide our customers and the general public with easy access to Laboratory news and information.

In the future, we will continue to provide leadership in support of DOE's objective to create awareness and build trust with our neighbors. We will continue to expand information resources at the desktop, enhance web-based market resources, and strategically contribute meaningful science and technology articles in the mass media to meet this goal.

- Economic Development. Through our Economic Development Office, we assisted more than 350 businesses since 1995 and helped create 52 companies in the last 4 years. In the future, we plan to

- generate new, technology-based companies by creating a virtual incubator network

- bundle together intellectual property from the Laboratory and partner universities to improve commercialization opportunities for local businesses

- promote the growth of innovation-driven companies statewide through collaborations between the Applied Processing Engineering Laboratory in Richland, and the Seattle-based Washington Technology Center

- encourage new industry to move into the region by pursuing tax incentive zones.

- Community Relations. Many of our community relations efforts are donated from private Battelle funds to support a wide array of programs that enhance both Battelle's and Pacific Northwest National Laboratory's image in the region. One of our most impressive programs is Team Battelle, a program designed to recognize and support 
staff members who volunteer in the community. In 2000, Team Battelle volunteers logged more than 17,770 hours in 47 community projects that ranged from participating in the Wishing Star Foundation bowl-a-thon to teaching senior citizens to navigate the Internet. Another successful community relations program is our Speakers Bureau, which relies on staff volunteers to make presentations about science and technology to local and regional organizations.

In addition to Team Battelle and Speakers Bureau, we operate a Corporate Contributions program that supports projects providing lasting benefits to the community. Among the recipients of the more than $\$ 720,000$ we donated last year are the Tri-Cities Cancer Center, United Way, Columbia Basin Dive and Rescue, and ten school districts for a myriad of science and mathematics programs.

In an effort to form stronger links to our community's minority populations, Pacific Northwest National Laboratory formed a minority community relations advisory group. This group, composed of leaders from the Hispanic, Native American, and African American communities, gives us ideas on how we can not only recruit more minorities, but also on how we might better support the health, human, and educational services needed by these groups.

In the future, we will continue to enhance community development by expanding the Speakers Bureau, by building on the success of Team Battelle, and by implementing the suggestions brought forth by the minority community relations advisory group. We also will continue to work with community leaders to develop broad-impact projects that improve the quality of life in the Tri-Cities and the region.

- Science Education. Key to enhancing the Laboratory's value to the region is opening the Laboratory's doors to the region's students and teachers so that they can experience first-hand the excitement of science and technology. We also establish partnerships with local and regional education institutions to enhance collaborations on joint research projects. The statistics from our science education programs in 1999 indicate that we are continuing on a successful path. Last year we

- hosted more than 2000 students from local high schools, Columbia Basin College, and Washington State University; and 80 science, mathematics, and technology teachers participated in Laboratory-sponsored projects

- supported science education reform through the Washington State Leadership and the Assistance for Science Education Reform project

- partnered with Washington State University, the University of Washington, Heritage College, Columbia Basin College, the Mid-Columbia Education Alliance, and other educational institutions on various activities including fellowships, adjunct appointments, joint research, and classroom teaching.

In the future we will take bold steps to enhance Pacific Northwest National Laboratory as a major science and technology asset and resource. We will work toward increasing regional visibility, advocacy, and collaboration with neighboring institutes of higher education. We will continue building research alliances with the University of Washington and Washington State University, and other research institutions. These alliances may involve creating joint institutes. These relationships complement and expand our ongoing collaborations between Laboratory staff, students, and faculty. Many Laboratory scientists serve as adjunct or affiliate faculty members of universities and colleges. Several important activities are showing results, including

- an agreement with the University of Washington to form a new Joint Institute for Nonproliferation and International Security Studies, which will expand the collaboration between the two institutions in the area of arms control and nonproliferation 
- a collaboration with the University of Washington's Human Interface Technology Laboratory to develop software for team collaborative analysis of large information spaces (we also are actively investigating how to best use the talents and resources of both organizations to strengthen our position in selected markets)

- strong support for the new Science and Education Center at the Washington State University campus in Richland

- an informal arrangement with Washington State University to provide adjunct faculty for a nuclear pharmacy program that has been proposed for the 20012002 academic year at the University's branch campus in Richland.

Pacific Northwest National Laboratory will continue to support our region's economy by helping to nurture an "inviting" business climate that encourages businesses to grow and thrive in our community. We plan to support this growth by strengthening our research and development base with new initiatives in environmental health, biosensors, and fuel cells.

The Laboratory's role will expand significantly in the $21^{\text {st }}$ century as we commit to helping shape and energize the region's economy and advancing our quality of life. The Laboratory's future and that of the region are intertwined. With a strong and diverse community, current businesses will prosper, new businesses will move into the area, and a stable population will be sustained. As a result, Pacific Northwest National Laboratory will be in a strong position to attract and retain the best and the brightest people to the Laboratory. These efforts will protect and enhance the value of our infrastructure, will foster an environment for growth and diversity, and will continue to generate the goodwill that we are best known for in our community. 


\section{7 \\ Resource Projections}

The resource requirements of research and development for Hanford Site support are included in the resource projections of the various funding programs. Research and development for other U.S. Department of Energy sites at other DOE facilities, however, are shown as a separate program. The resource projections for fiscal years 1999 and 2000 are actual values.

\begin{tabular}{|c|c|c|c|c|c|c|c|}
\hline \multicolumn{8}{|c|}{$\begin{array}{l}\text { Laboratory Funding Summary } \\
\text { (Budget Authorization Dollar Amount in Millions) }\end{array}$} \\
\hline & 1999 & 2000 & 2001 & $\begin{array}{c}\text { Fiscal Year } \\
2002\end{array}$ & 2003 & 2004 & 2005 \\
\hline DOE Effort & 394.6 & 372.7 & 393.4 & 408.7 & 418.6 & 432.1 & 445.2 \\
\hline DOE Site Transfers and Cash Work & $(84.7)$ & $(60.7)$ & $(72.7)$ & $(72.7)$ & (72.7) & $(72.7)$ & $(72.7)$ \\
\hline Work for Others & 44.7 & 33.8 & 48.7 & 51.7 & 54.7 & 56.0 & 58.1 \\
\hline Total Operating & 354.6 & 345.8 & 369.4 & 387.7 & 400.6 & 415.4 & 430.6 \\
\hline Capital Equipment & 8.9 & 6.7 & 19.4 & 18.5 & 18.5 & 18.5 & 18.6 \\
\hline General Purpose Equipment-GPE & 0.0 & 1.0 & 1.0 & 1.0 & 1.0 & 1.0 & 1.0 \\
\hline General Plant Projects-GPP & 3.7 & 4.3 & 4.6 & 4.6 & 4.6 & 4.6 & 4.6 \\
\hline Construction Line Items & 0.0 & 0.0 & 0.0 & 0.0 & 5.1 & 5.2 & 0.0 \\
\hline Total Laboratory Funding & 367.2 & 357.8 & 394.4 & 411.8 & 429.8 & 444.7 & 454.8 \\
\hline
\end{tabular}

\begin{tabular}{|c|c|c|c|c|c|c|c|}
\hline \multicolumn{8}{|c|}{$\begin{array}{c}\text { Laboratory Personnel Summary } \\
\text { (Full-Time Equivalents [FTEs]) }\end{array}$} \\
\hline & 1999 & 2000 & 2001 & $\begin{array}{l}\text { Fiscal Year } \\
2002\end{array}$ & 2003 & 2004 & 2005 \\
\hline DOE Effort & 1135 & 1178 & 1191 & 1177 & 1154 & 1168 & 1185 \\
\hline Work for Others & 188 & 151 & 177 & 176 & 178 & 178 & 182 \\
\hline Total Operating & 1323 & 1329 & 1368 & 1353 & 1332 & 1346 & 1367 \\
\hline Capital Equipment & 2 & 4 & 8 & 8 & 8 & 8 & 8 \\
\hline General Plant Projects-GPP & 5 & 5 & 5 & 5 & 5 & 5 & 5 \\
\hline Construction Line Items & 0 & 0 & 0 & 0 & 6 & 6 & 0 \\
\hline Total Direct & 1330 & 1338 & 1381 & 1366 & 1351 & 1365 & 1380 \\
\hline Indirect & 1494 & 1483 & 1461 & 1472 & 1481 & 1493 & 1505 \\
\hline Total Laboratory Personnel (FTEs) & 2824 & 2821 & 2842 & 2838 & 2832 & 2858 & 2885 \\
\hline
\end{tabular}




\begin{tabular}{|c|c|c|c|c|c|c|c|}
\hline \multicolumn{8}{|c|}{$\begin{array}{c}\text { Funding by Secretarial Officer } \\
\text { (Budget Authorization Dollar Amount in Millions) }\end{array}$} \\
\hline & \multicolumn{6}{|c|}{ Fiscal Year } & 2005 \\
\hline \multicolumn{8}{|l|}{ Office of Science } \\
\hline Operating & 60.8 & 58.0 & 52.7 & 53.3 & 53.9 & 54.5 & 55.1 \\
\hline EMSL Operations - Expense & 27.4 & 27.4 & 31.0 & 31.3 & 31.6 & 31.9 & 32.3 \\
\hline Capital Equipment & 5.6 & 1.6 & 4.9 & 4.1 & 4.1 & 4.1 & 4.1 \\
\hline EMSL Operations Capital Equipment & 2.2 & 2.0 & 12.0 & 12.0 & 12.0 & 12.0 & 12.0 \\
\hline General Purpose Equipment-GPE & 0.0 & 1.0 & 1.0 & 1.0 & 1.0 & 1.0 & 1.0 \\
\hline General Plant Projects-GPP & 3.4 & 3.4 & 3.5 & 3.5 & 3.5 & 3.5 & 3.5 \\
\hline Construction Line Items & 0.0 & 0.0 & 0.0 & 0.0 & 5.1 & 5.2 & 0.0 \\
\hline Total & 99.4 & 93.4 & 105.1 & 105.2 & 111.2 & 112.2 & 108.0 \\
\hline \multicolumn{8}{|l|}{ Office of Environmental Management } \\
\hline Operating & 98.4 & 100.3 & 100.3 & 103.9 & 106.9 & 109.9 & 112.9 \\
\hline Capital Equipment & 0.2 & 0.8 & 0.1 & 0.1 & 0.1 & 0.1 & 0.1 \\
\hline General Plant Projects-GPP & 0.3 & 0.9 & 1.1 & 1.1 & 1.1 & 1.1 & 1.1 \\
\hline Total & 98.9 & 102.0 & 101.5 & 105.1 & 108.1 & 111.1 & 114.1 \\
\hline \multicolumn{8}{|l|}{$\begin{array}{l}\text { Assistant Secretary for Energy } \\
\text { Efficiency and Renewable Energy }\end{array}$} \\
\hline Operating & 24.0 & 25.2 & 24.5 & 26.2 & 27.5 & 30.2 & 33.4 \\
\hline Capital Equipment & 0.1 & 0.1 & 0.2 & 0.2 & 0.2 & 0.2 & 0.2 \\
\hline Total & 24.1 & 25.3 & 24.7 & 26.4 & 27.7 & 30.4 & 33.6 \\
\hline \multicolumn{8}{|l|}{ Assistant Secretary for } \\
\hline \multicolumn{8}{|l|}{ Environment, Safety and Health } \\
\hline Total Operating & 3.2 & 1.9 & 2.0 & 2.5 & 3.0 & 4.0 & 4.0 \\
\hline \multicolumn{8}{|l|}{$\begin{array}{l}\text { Assistant Secretary for } \\
\text { Defense Programs }\end{array}$} \\
\hline Operating & 23.6 & 25.7 & 24.2 & 25.0 & 19.0 & 17.0 & 15.0 \\
\hline Capital Equipment & 0.2 & 0.3 & 0.3 & 0.0 & 0.0 & 0.0 & 0.1 \\
\hline Total & 23.8 & 26.0 & 24.5 & 25.0 & 19.0 & 17.0 & 15.1 \\
\hline \multicolumn{8}{|l|}{$\begin{array}{l}\text { Office of Defense Nuclear } \\
\text { Nonproliferation }\end{array}$} \\
\hline Operating & 125.3 & 91.6 & 103.0 & 106.7 & 112.3 & 117.9 & 123.7 \\
\hline Capital Equipment & 0.6 & 1.0 & 1.5 & 1.6 & 1.6 & 1.6 & 1.6 \\
\hline Total & 125.9 & 92.6 & 104.5 & 108.3 & 113.9 & 119.5 & 125.3 \\
\hline \multicolumn{8}{|l|}{ Office of Intelligence } \\
\hline Total Operating & 6.4 & 6.2 & 6.0 & 6.5 & 7.2 & 7.5 & 7.9 \\
\hline \multicolumn{8}{|l|}{ Office of Counterintelligence } \\
\hline Operating & 4.9 & 13.4 & 16.5 & 17.1 & 17.6 & 17.1 & 17.6 \\
\hline Capital Equipment & 0.0 & 0.6 & 0.0 & 0.0 & 0.0 & 0.0 & 0.0 \\
\hline Total & 4.9 & 14.0 & 16.5 & 17.1 & 17.6 & 17.1 & 17.6 \\
\hline \multicolumn{8}{|l|}{$\begin{array}{l}\text { Assistant Secretary for } \\
\text { Nuclear Energy }\end{array}$} \\
\hline Total Operating & 1.9 & 0.5 & 1.9 & 3.5 & 5.0 & 5.4 & 5.4 \\
\hline \multicolumn{8}{|l|}{$\begin{array}{l}\text { Office of Security and Emergency } \\
\text { Operations }\end{array}$} \\
\hline Total Operating & 3.5 & 6.4 & 16.8 & 16.9 & 17.1 & 17.4 & 15.8 \\
\hline
\end{tabular}




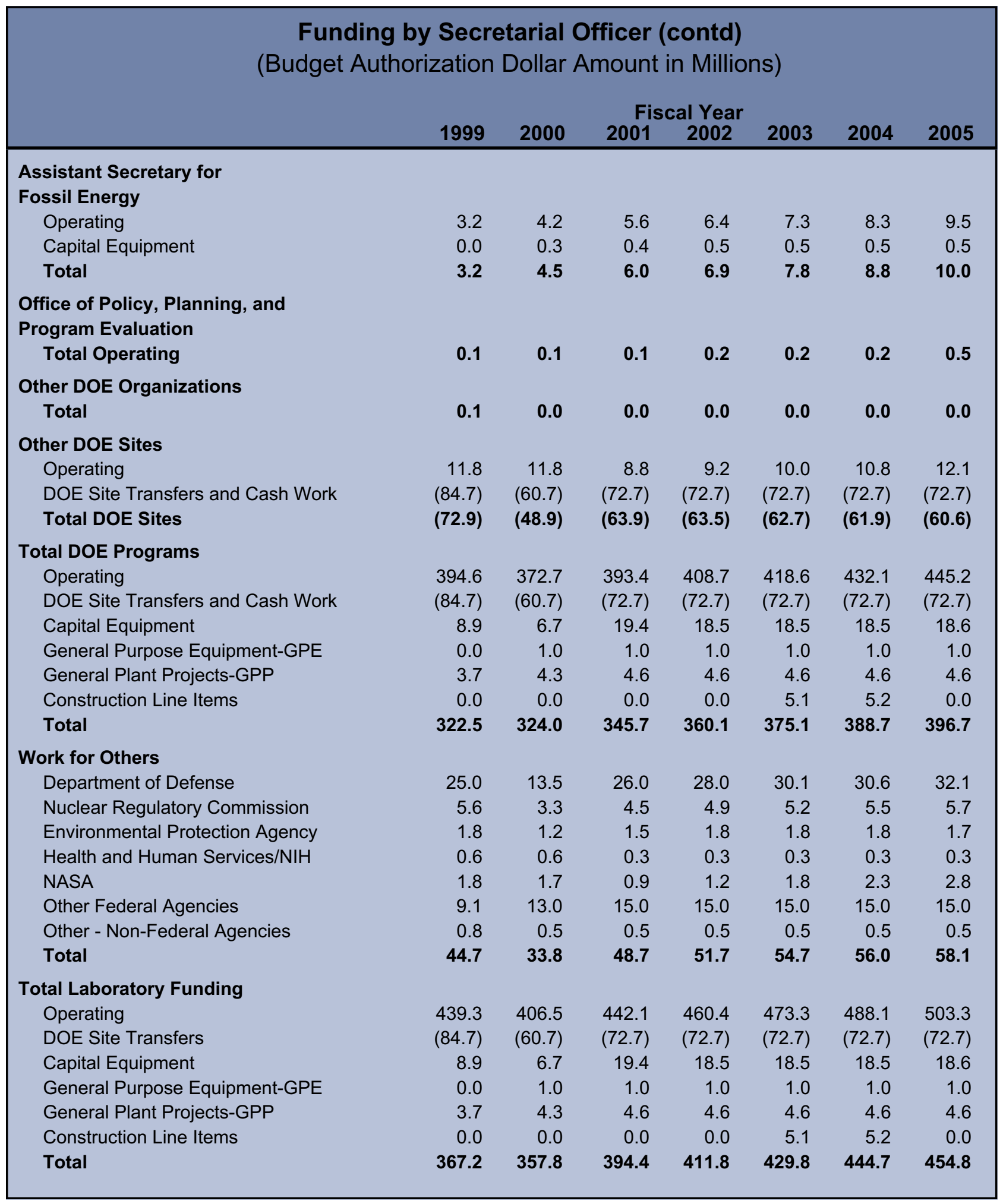




\begin{tabular}{|c|c|c|c|c|c|c|c|}
\hline \multicolumn{8}{|c|}{$\begin{array}{c}\text { Direct Personnel by Secretarial Officer } \\
\text { (Full-Time Equivalents) }\end{array}$} \\
\hline & 1999 & 2000 & $\begin{array}{r}\mathrm{Fi} \\
2001\end{array}$ & $\begin{array}{l}\text { al Year } \\
2002\end{array}$ & 2003 & 2004 & 2005 \\
\hline $\begin{array}{l}\text { Office of Science } \\
\text { Operating }\end{array}$ & 316 & 318 & 304 & 287 & 278 & 274 & 274 \\
\hline $\begin{array}{l}\text { Office of Environmental } \\
\text { Management }\end{array}$ & & & & & & & \\
\hline Operating & 320 & 348 & 339 & 336 & 334 & 339 & 344 \\
\hline $\begin{array}{l}\text { Assistant Secretary for Energy } \\
\text { Efficiency and Renewable Energy }\end{array}$ & & & & & & & \\
\hline Operating & 86 & 94 & 89 & 89 & 89 & 96 & 105 \\
\hline $\begin{array}{l}\text { Assistant Secretary for } \\
\text { Environment, Safety and Health }\end{array}$ & & & & & & & \\
\hline Operating & 12 & 7 & 7 & 9 & 10 & 13 & 13 \\
\hline $\begin{array}{l}\text { Assistant Secretary for Defense } \\
\text { Programs }\end{array}$ & & & & & & & \\
\hline Operating & 85 & 96 & 88 & 85 & 62 & 54 & 47 \\
\hline $\begin{array}{l}\text { Office of Defense Nuclear } \\
\text { Nonproliferation }\end{array}$ & & & & & & & \\
\hline Operating & 201 & 155 & 162 & 168 & 170 & 179 & 188 \\
\hline Office of Intelligence & & & & & & & \\
\hline Operating & 23 & 23 & 22 & 22 & 23 & 24 & 25 \\
\hline $\begin{array}{l}\text { Office of Counterintelligence } \\
\text { Operating }\end{array}$ & 18 & 50 & 60 & 58 & 57 & 54 & 55 \\
\hline $\begin{array}{l}\text { Assistant Secretary for } \\
\text { Nuclear Energy }\end{array}$ & & & & & & & \\
\hline Operating & 7 & 2 & 7 & 13 & 18 & 19 & 17 \\
\hline $\begin{array}{l}\text { Office of Security and } \\
\text { Emergency Operations }\end{array}$ & & & & & & & \\
\hline Operating & 13 & 24 & 60 & 57 & 55 & 55 & 49 \\
\hline $\begin{array}{l}\text { Assistant Secretary for } \\
\text { Fossil Energy }\end{array}$ & & & & & & & \\
\hline Operating & 12 & 16 & 20 & 22 & 24 & 26 & 30 \\
\hline $\begin{array}{l}\text { Office of Policy, Planning, } \\
\text { and Program Evaluation }\end{array}$ & & & & & & & \\
\hline Operating & 0 & 0 & 0 & 1 & 1 & 1 & 2 \\
\hline Other DOE Sites & & & & & & & \\
\hline Operating & 43 & 44 & 32 & 31 & 33 & 34 & 38 \\
\hline Total DOE Programs & 1136 & 1177 & 1190 & 1177 & 1153 & 1167 & 1185 \\
\hline Work for Others & & & & & & & \\
\hline Department of Defense & 117 & 75 & 95 & 95 & 98 & 97 & 101 \\
\hline Nuclear Regulatory Commission & 20 & 12 & 16 & 17 & 17 & 18 & 18 \\
\hline Environmental Protection Agency & 7 & 5 & 6 & 6 & 6 & 6 & 5 \\
\hline Health and Human Services/NIH & 2 & 2 & 1 & 1 & 1 & 1 & 1 \\
\hline NASA & 7 & 6 & 3 & 4 & 6 & 7 & 9 \\
\hline Other Federal Agencies & 33 & 49 & 55 & 51 & 49 & 48 & 47 \\
\hline Other - Non-Federal Agencies & 3 & 2 & 2 & 2 & 2 & 2 & 2 \\
\hline Total & 189 & 151 & 178 & 176 & 179 & 179 & 183 \\
\hline
\end{tabular}




\begin{tabular}{|c|c|c|c|c|c|c|c|}
\hline \multicolumn{8}{|c|}{$\begin{array}{l}\text { Direct Personnel by Secretarial Officer (contd) } \\
\text { (Full-Time Equivalents) }\end{array}$} \\
\hline & \multicolumn{6}{|c|}{ Fiscal Year } & 2005 \\
\hline \multicolumn{8}{|l|}{ Laboratory Direct } \\
\hline Operating & 1323 & 1329 & 1368 & 1353 & 1332 & 1346 & 1367 \\
\hline Capital Equipment & 2 & 4 & 8 & 8 & 8 & 8 & 8 \\
\hline General Plant Projects-GPP & 5 & 5 & 5 & 5 & 5 & 5 & 5 \\
\hline Construction Line Items & 0 & 0 & 0 & 0 & 6 & 6 & 0 \\
\hline Total Laboratory Direct & 1330 & 1338 & 1381 & 1366 & 1351 & 1365 & 1380 \\
\hline Total Laboratory Indirect & 1494 & 1483 & 1461 & 1472 & 1481 & 1493 & 1505 \\
\hline Total Laboratory Personnel (FTEs) & 2824 & 2821 & 2842 & 2838 & 2832 & 2858 & 2885 \\
\hline
\end{tabular}




\begin{tabular}{|c|c|c|c|c|c|c|c|}
\hline \multicolumn{8}{|c|}{$\begin{array}{l}\text { Resources by Major DOE Areas } \\
\text { (Budget Authorization Dollar Amount in Millions) }\end{array}$} \\
\hline & \multicolumn{6}{|c|}{ Fiscal Year } & 2005 \\
\hline \multicolumn{8}{|l|}{ Office of Science } \\
\hline Magnetic Fusion (AT) & 1.3 & 1.3 & 1.3 & 1.3 & 1.3 & 1.3 & 1.3 \\
\hline Basic Energy Sciences $(\mathrm{KC})$ & 11.9 & 11.9 & 11.9 & 12.0 & 12.1 & 12.2 & 12.3 \\
\hline SC Laboratory Tech. Research (KJ) & 4.3 & 2.9 & 4.7 & 4.8 & 4.9 & 5.0 & 5.1 \\
\hline Energy Research Analysis (KD) & 0.3 & 0.4 & 0.4 & 0.4 & 0.4 & 0.4 & 0.4 \\
\hline Biological and Environmental Research (KP) & 42.4 & 41.2 & 34.4 & 34.8 & 35.2 & 35.6 & 36.0 \\
\hline EMSL Operations - Expense (KP-BER) & 27.4 & 27.4 & 31.0 & 31.3 & 31.6 & 31.9 & 32.3 \\
\hline Office of Science Pro. Dir. (KX, Univ Sci Ed) & 0.6 & 0.3 & 0.0 & 0.0 & 0.0 & 0.0 & 0.0 \\
\hline Total Operating & 88.2 & 85.4 & 83.7 & 84.6 & 85.5 & 86.4 & 87.4 \\
\hline Capital Equipment (AT) & 0.1 & 0.1 & 0.1 & 0.1 & 0.1 & 0.1 & 0.1 \\
\hline Capital Equipment (KC) & 1.0 & 0.9 & 1.1 & 0.9 & 0.9 & 0.9 & 1.0 \\
\hline Capital Equipment (KP) & 4.5 & 0.6 & 3.7 & 3.1 & 3.1 & 3.1 & 3.1 \\
\hline EMSL Operations Capital (KP-BER) & 2.2 & 2.0 & 12.0 & 12.0 & 12.0 & 12.0 & 12.0 \\
\hline Capital Equipment & 7.8 & 3.6 & 16.9 & 16.1 & 16.1 & 16.1 & 16.1 \\
\hline General Purpose Equipment-GPE (KP) & 0.0 & 1.0 & 1.0 & 1.0 & 1.0 & 1.0 & 1.0 \\
\hline General Plant Projects-GPP (KP) & 3.4 & 3.4 & 3.5 & 3.5 & 3.5 & 3.5 & 3.5 \\
\hline Construction Line items & 0.0 & 0.0 & 0.0 & 0.0 & 5.1 & 5.2 & 0.0 \\
\hline Total Funding & 99.4 & 93.4 & 105.1 & 105.2 & 111.2 & 112.2 & 108.0 \\
\hline \multicolumn{8}{|l|}{ Direct Personnel } \\
\hline Operating & 316 & 318 & 304 & 287 & 278 & 274 & 274 \\
\hline Capital & 2 & 1 & 5 & 4 & 4 & 4 & 4 \\
\hline General Plant Projects-GPP & 4 & 4 & 4 & 4 & 4 & 4 & 4 \\
\hline Construction Line Items & 0 & 0 & 0 & 0 & 6 & 6 & 0 \\
\hline Total Direct Personnel & 322 & 323 & 313 & 295 & 292 & 288 & 282 \\
\hline \multicolumn{8}{|l|}{ Office of Environmental Management } \\
\hline Technology Development (EW) & 17.5 & 15.5 & 18.0 & 17.0 & 17.0 & 17.0 & 17.0 \\
\hline Waste Management (EW) & 65.5 & 66.2 & 67.9 & 72.5 & 75.5 & 78.5 & 81.5 \\
\hline Waste Management (EX) & 0.7 & 0.0 & 0.0 & 0.0 & 0.0 & 0.0 & 0.0 \\
\hline Environmental Restoration (EW) & 14.7 & 18.6 & 14.4 & 14.4 & 14.4 & 14.4 & 14.4 \\
\hline Total Operating & 98.4 & 100.3 & 100.3 & 103.9 & 106.9 & 109.9 & 112.9 \\
\hline Capital Equipment (EW/EX) & 0.2 & 0.8 & 0.1 & 0.1 & 0.1 & 0.1 & 0.1 \\
\hline General Plant Projects-GPP & 0.3 & 0.9 & 1.1 & 1.1 & 1.1 & 1.1 & 1.1 \\
\hline Total Funding & 98.9 & 102.0 & 101.5 & 105.1 & 108.1 & 111.1 & 114.1 \\
\hline \multicolumn{8}{|l|}{ Direct Personnel } \\
\hline Operating & 320 & 348 & 339 & 336 & 334 & 339 & 344 \\
\hline General Plant Projects-GPP & 0 & 1 & 1 & 1 & 1 & 1 & 1 \\
\hline Total Direct Personnel & 320 & 349 & 340 & 337 & 335 & 340 & 345 \\
\hline
\end{tabular}




\begin{tabular}{|c|c|c|c|c|c|c|c|}
\hline \multicolumn{8}{|c|}{$\begin{array}{l}\text { Resources by Major DOE Areas (contd) } \\
\text { (Budget Authorization Dollar Amount in Millions) }\end{array}$} \\
\hline & \multicolumn{6}{|c|}{ Fiscal Year } & 2005 \\
\hline \multicolumn{8}{|l|}{$\begin{array}{l}\text { Assistant Secretary for Energy } \\
\text { Efficiency and Renewable Energy }\end{array}$} \\
\hline Solar Energy (EB) & 0.6 & 1.1 & 1.2 & 1.3 & 1.5 & 1.7 & 2.0 \\
\hline Buildings Sector (EC) & 8.3 & 9.7 & 8.6 & 8.6 & 7.9 & 8.2 & 8.6 \\
\hline Industrial Energy Conservation (ED) & 4.4 & 2.5 & 3.4 & 3.7 & 4.0 & 4.5 & 5.0 \\
\hline Transportation Sector (EE) & 7.0 & 8.0 & 8.0 & 9.3 & 10.8 & 12.5 & 14.5 \\
\hline Policy and Management (EH) & 0.2 & 0.1 & 0.1 & 0.1 & 0.1 & 0.1 & 0.1 \\
\hline Federal Emergency Mgmt. (EL) & 3.5 & 3.8 & 3.2 & 3.2 & 3.2 & 3.2 & 3.2 \\
\hline Operating & 24.0 & 25.2 & 24.5 & 26.2 & 27.5 & 30.2 & 33.4 \\
\hline $\begin{array}{l}\text { Capital Equipment } \\
\text { Total Funding }\end{array}$ & $\begin{array}{r}0.1 \\
24.1\end{array}$ & $\begin{array}{r}0.1 \\
25.3\end{array}$ & $\begin{array}{r}0.2 \\
24.7\end{array}$ & $\begin{array}{r}0.2 \\
26.4\end{array}$ & $\begin{array}{r}0.2 \\
27.7\end{array}$ & $\begin{array}{r}0.2 \\
30.4\end{array}$ & $\begin{array}{r}0.2 \\
33.6\end{array}$ \\
\hline Direct Operating Personnel & 86 & 94 & 89 & 89 & 89 & 96 & 105 \\
\hline \multicolumn{8}{|l|}{$\begin{array}{l}\text { Assistant Secretary for Environment, } \\
\text { Safety and Health }\end{array}$} \\
\hline Environment, Safety and Health-Non Def. (HC) & 1.8 & 0.6 & 1.0 & 1.3 & 1.5 & 2.0 & 2.0 \\
\hline Environment, Safety and Health-Defense (HD) & 1.4 & 0.9 & 0.8 & 1.0 & 1.3 & 1.8 & 1.8 \\
\hline Security Oversight \& Performance Assurance & 0.0 & 0.4 & 0.2 & 0.2 & 0.2 & 0.2 & 0.2 \\
\hline Total Funding & 3.2 & 1.9 & 2.0 & 2.5 & 3.0 & 4.0 & 4.0 \\
\hline Direct Operating Personnel & 12 & 7 & 7 & 9 & 10 & 13 & 13 \\
\hline \multicolumn{8}{|l|}{ Assistant Secretary for Defense Programs } \\
\hline Materials Production (GE/DP) & 23.6 & 25.7 & 24.2 & 25.0 & 19.0 & 17.0 & 15.0 \\
\hline Operating & 23.6 & 25.7 & 24.2 & 25.0 & 19.0 & 17.0 & 15.0 \\
\hline Capital Equipment & 0.2 & 0.3 & 0.3 & 0.0 & 0.0 & 0.0 & 0.1 \\
\hline Total Funding & 23.8 & 26.0 & 24.5 & 25.0 & 19.0 & 17.0 & 15.1 \\
\hline Direct Operating Personnel & 85 & 96 & 88 & 85 & 62 & 54 & 47 \\
\hline \multicolumn{8}{|l|}{ Office of Defense Nuclear Nonproliferation } \\
\hline Verification \& Control Technology (GC) & 16.6 & 17.5 & 19.1 & 20.5 & 22.0 & 23.5 & 25.0 \\
\hline Export Control, Nonprolif. \& Safeguards (GJ) & 26.5 & 20.0 & 21.1 & 25.9 & 28.7 & 31.4 & 34.3 \\
\hline International Nuclear Safety Program (NN-30) & 79.9 & 51.3 & 58.0 & 55.0 & 56.0 & 57.0 & 58.0 \\
\hline Fissile Materials Disposition (GA) & 2.3 & 2.8 & 4.8 & 5.3 & 5.6 & 6.0 & 6.4 \\
\hline Operating & 125.3 & 91.6 & 103.0 & 106.7 & 112.3 & 117.9 & 123.7 \\
\hline Capital Equipment (GC) & 0.6 & 0.4 & 0.9 & 1.0 & 1.0 & 1.0 & 1.0 \\
\hline Capital Equipment (GJ) & 0.0 & 0.6 & 0.6 & 0.6 & 0.6 & 0.6 & 0.6 \\
\hline Total Funding & 125.9 & 92.6 & 104.5 & 108.3 & 113.9 & 119.5 & 125.3 \\
\hline \multicolumn{8}{|l|}{ Direct Personnel } \\
\hline Operating & 201 & 155 & 162 & 168 & 170 & 179 & 188 \\
\hline Capital Equipment & 0 & 2 & 2 & 2 & 2 & 2 & 2 \\
\hline Total Direct Personnel & 201 & 157 & 164 & 170 & 172 & 181 & 190 \\
\hline \multicolumn{8}{|l|}{ Office of Intelligence (IN) } \\
\hline Total Funding & 6.4 & 6.2 & 6.0 & 6.5 & 7.2 & 7.5 & 7.9 \\
\hline Direct Operating Personnel & 23 & 23 & 22 & 22 & 23 & 24 & 25 \\
\hline
\end{tabular}




\begin{tabular}{|c|c|c|c|c|c|c|c|}
\hline $\begin{array}{l}\text { Resour } \\
\text { (Budget A }\end{array}$ & $\begin{array}{l}\text { by } \mathbf{M a} \\
\text { ization }\end{array}$ & $\begin{array}{l}\text { or DOI } \\
\text { Dollar }\end{array}$ & $\begin{array}{l}\text { Areas } \\
\text { mount }\end{array}$ & $\begin{array}{l}\text { (contd) } \\
\text { n Millio }\end{array}$ & ר) & & \\
\hline & & & & sal Year & & & \\
\hline & 1999 & 2000 & 2001 & 2002 & 2003 & 2004 & 2005 \\
\hline Office of Counterintelligence (CN) & & & & & & & \\
\hline Operating & 4.9 & 13.4 & 16.5 & 17.1 & 17.6 & 17.1 & 17.6 \\
\hline Capital Equipment & 0.0 & 0.6 & 0.0 & 0.0 & 0.0 & 0.0 & 0.0 \\
\hline Total Funding & 4.9 & 14.0 & 16.5 & 17.1 & 17.6 & 17.1 & 17.6 \\
\hline Direct Operating Personnel & 18 & 50 & 60 & 58 & 57 & 54 & 55 \\
\hline Assistant Secretary for Nuclear Energy & & & & & & & \\
\hline Nuclear Energy R\&D (AF) & 0.6 & 0.2 & 1.9 & 3.5 & 5.0 & 5.4 & 5.4 \\
\hline Isotope Production (ST) & 1.3 & 0.3 & 0.0 & 0.0 & 0.0 & 0.0 & 0.0 \\
\hline Total Funding & 1.9 & 0.5 & 1.9 & 3.5 & 5.0 & 5.4 & 5.4 \\
\hline Direct Operating Personnel & 7 & 2 & 7 & 13 & 18 & 19 & 17 \\
\hline Office of Security and & & & & & & & \\
\hline Nuclear Safeguards and Security (GD) & 3.2 & 6.3 & 16.4 & 16.5 & 16.7 & 17.0 & 15.4 \\
\hline Emergency Management (ND) & 0.3 & 0.1 & 0.2 & 0.2 & 0.2 & 0.2 & 0.2 \\
\hline Total Funding & 3.5 & 6.4 & 16.6 & 16.7 & 16.9 & 17.2 & 15.6 \\
\hline Direct Operating Personnel & 13 & 24 & 60 & 57 & 55 & 55 & 49 \\
\hline Assistant Secretary for Fossil Energy & & & & & & & \\
\hline Coal (AA) & 1.1 & 0.9 & 1.0 & 1.1 & 1.3 & 1.5 & 1.7 \\
\hline Gas (AB) & 1.6 & 3.3 & 4.6 & 5.3 & 6.0 & 6.8 & 7.8 \\
\hline Petroleum (AC) & 0.5 & 0.0 & 0.0 & 0.0 & 0.0 & 0.0 & 0.0 \\
\hline Operating & 3.2 & 4.2 & 5.6 & 6.4 & 7.3 & 8.3 & 9.5 \\
\hline Capital Equipment & 0.0 & 0.3 & 0.4 & 0.5 & 0.5 & 0.5 & 0.5 \\
\hline Total Funding & 3.2 & 4.5 & 6.0 & 6.9 & 7.8 & 8.8 & 10.0 \\
\hline Direct Operating Personnel & 12 & 16 & 20 & 22 & 24 & 26 & 30 \\
\hline Capital Equipment Personnel & 0 & 1 & 2 & 2 & 2 & 2 & 2 \\
\hline $\begin{array}{l}\text { Office of Policy, Planning, } \\
\text { and Program Evaluation }\end{array}$ & & & & & & & \\
\hline Policy, Planning, and Analysis (PE) & 0.1 & 0.1 & 0.1 & 0.2 & 0.2 & 0.2 & 0.5 \\
\hline Total Funding & 0.1 & 0.1 & 0.1 & 0.2 & 0.2 & 0.2 & 0.5 \\
\hline Direct Operating Personnel & 0 & 0 & 0 & 1 & 1 & 1 & 2 \\
\hline Other DOE Organizations & & & & & & & \\
\hline Total Funding & 0.1 & 0.0 & 0.0 & 0.0 & 0.0 & 0.0 & 0.0 \\
\hline Other DOE Sites & & & & & & & \\
\hline Operating & 11.8 & 11.8 & 8.8 & 9.2 & 10.0 & 10.8 & 12.1 \\
\hline Site Transfers & (84.7) & $(60.7)$ & $(72.7)$ & (72.7) & $(72.7)$ & $(72.7)$ & (72.7) \\
\hline Total Net Funding & (72.9) & (48.9) & (63.9) & (63.5) & (62.7) & (61.9) & (60.6) \\
\hline Direct Personnel & 43 & 44 & 32 & 31 & 33 & 34 & 38 \\
\hline Total DOE Programs & & & & & & & \\
\hline Operating & 394.6 & 372.7 & 393.2 & 408.5 & 418.4 & 431.9 & 445.0 \\
\hline DOE Site Transfers & $(84.7)$ & $(60.7)$ & $(72.7)$ & (72.7) & $(72.7)$ & (72.7) & (72.7) \\
\hline Capital Equipment & 8.9 & 6.7 & 19.4 & 18.5 & 18.5 & 18.5 & 18.6 \\
\hline General Purpose Equipment-GPE & 0.0 & 1.0 & 1.0 & 1.0 & 1.0 & 1.0 & 1.0 \\
\hline General Plant Projects-GPP & 3.7 & 4.3 & 4.6 & 4.6 & 4.6 & 4.6 & 4.6 \\
\hline Construction Line Items & 0.0 & 0.0 & 0.0 & 0.0 & 5.1 & 5.2 & 0.0 \\
\hline Total Funding & 322.5 & 324.0 & 345.5 & 359.9 & 374.9 & 388.5 & 396.5 \\
\hline
\end{tabular}




\begin{tabular}{|c|c|c|c|c|c|c|c|}
\hline $\begin{array}{r}\text { Reso } \\
\text { (Budget }\end{array}$ & $\begin{array}{l}\text { by } \mathbf{M a} \\
\text { ization }\end{array}$ & $\begin{array}{l}\text { or DO } \\
\text { Dollar }\end{array}$ & $\begin{array}{l}\text { Areas } \\
\text { moun }\end{array}$ & $\begin{array}{l}\text { (contc } \\
\text { in Milli }\end{array}$ & & & \\
\hline & & & & cal Yea & & & \\
\hline Direct Personnel & & & & & & & \\
\hline Operating & 1135 & 1178 & 1191 & 1177 & 1154 & 1168 & 1185 \\
\hline Capital & 2 & 4 & 8 & 8 & 8 & 8 & 8 \\
\hline General Plant Projects (GPP) & 5 & 5 & 5 & 5 & 5 & 5 & 5 \\
\hline Construction Line Items & 0 & 0 & 0 & 0 & 6 & 6 & 0 \\
\hline Total Direct Personnel & 1142 & 1187 & 1204 & 1190 & 1173 & 1187 & 1198 \\
\hline Work for Others & & & & & & & \\
\hline Department of Defense & & & & & & & \\
\hline Operating & 25.0 & 13.5 & 26.0 & 28.0 & 30.1 & 30.6 & 32.1 \\
\hline Direct Personnel & 117 & 75 & 95 & 95 & 98 & 97 & 101 \\
\hline Nuclear Regulatory Commission & & & & & & & \\
\hline Operating & 5.6 & 3.3 & 4.5 & 4.9 & 5.2 & 5.5 & 5.7 \\
\hline Direct Personnel & 20 & 12 & 16 & 17 & 17 & 18 & 18 \\
\hline Environmental Protection Agency & & & & & & & \\
\hline Operating & 1.8 & 1.2 & 1.5 & 1.8 & 1.8 & 1.8 & 1.7 \\
\hline Direct Personnel & 7 & 5 & 6 & 6 & 6 & 6 & 5 \\
\hline Health and Human Services/NIH & & & & & & & \\
\hline Operating & 0.6 & 0.6 & 0.3 & 0.3 & 0.3 & 0.3 & 0.3 \\
\hline Direct Personnel & 2 & 2 & 1 & 1 & 1 & 1 & 1 \\
\hline NASA & & & & & & & \\
\hline Operating & 1.8 & 1.7 & 0.9 & 1.2 & 1.8 & 2.3 & 2.8 \\
\hline Direct Personnel & 7 & 6 & 3 & 4 & 6 & 7 & 9 \\
\hline Other Federal Agencies & & & & & & & \\
\hline Operating & 9.1 & 13.0 & 15.0 & 15.0 & 15.0 & 15.0 & 15.0 \\
\hline Direct Personnel & 33 & 49 & 55 & 51 & 49 & 48 & 47 \\
\hline Other - Non-Federal Agencies & & & & & & & \\
\hline Operating & 0.8 & 0.5 & 0.5 & 0.5 & 0.5 & 0.5 & 0.5 \\
\hline Direct Personnel & 3 & 2 & 2 & 2 & 2 & 2 & 2 \\
\hline Total Work for Others & & & & & & & \\
\hline Operating & 44.7 & 33.8 & 48.7 & 51.7 & 54.7 & 56.0 & 58.1 \\
\hline Direct Personnel & 189 & 151 & 178 & 176 & 179 & 179 & 183 \\
\hline Total Laboratory Funding & & & & & & & \\
\hline Operating & 439.3 & 406.5 & 442.1 & 460.4 & 473.3 & 488.1 & 503.3 \\
\hline Direct Personnel & 1323 & 1329 & 1368 & 1353 & 1332 & 1346 & 1367 \\
\hline DOE Site Transfers & $(84.7)$ & $(60.7)$ & (72.7) & (72.7) & $(72.7)$ & (72.7) & (72.7) \\
\hline Capital & 8.9 & 6.7 & 19.4 & 18.5 & 18.5 & 18.5 & 18.6 \\
\hline Direct Personnel & 2 & 4 & 8 & 8 & 8 & 8 & 8 \\
\hline General Purpose Equipment-GPE & 0.0 & 1.0 & 1.0 & 1.0 & 1.0 & 1.0 & 1.0 \\
\hline General Plant Projects-GPP & 3.7 & 4.3 & 4.6 & 4.6 & 4.6 & 4.6 & 4.6 \\
\hline Direct Personnel & 5 & 5 & 5 & 5 & 5 & 5 & 5 \\
\hline Construction Line Items & 0.0 & 0.0 & 0.0 & 0.0 & 5.1 & 5.2 & 0.0 \\
\hline Direct Personnel & 0 & 0 & 0 & 0 & 6 & 6 & 0 \\
\hline Indirect Personnel & 1494 & 1483 & 1461 & 1472 & 1481 & 1493 & 1505 \\
\hline Total Funding & 367.2 & 357.8 & 394.4 & 411.8 & 429.8 & 444.7 & 454.8 \\
\hline Total Personnel & 2824 & 2821 & 2842 & 2838 & 2832 & 2858 & 2885 \\
\hline
\end{tabular}




\section{Subcontracting and Procurement}

Pacific Northwest National Laboratory is dependent on external resources (universities and industry) for support in achieving timely and successful completion of assigned programs and projects. This support is secured by staff in the Contracts organization who use the procurement acquisition process for acquiring needed equipment, materials, supplies, and services. The table below reflects actual subcontracted amounts for fiscal years 1999 and 2000 and projections for fiscal years 2001 through 2005.

\begin{tabular}{|c|c|c|c|c|c|c|c|}
\hline \multicolumn{8}{|c|}{$\begin{array}{l}\text { Subcontracting and Procurement } \\
\text { (Dollar Amount in Millions) }\end{array}$} \\
\hline & 1999 & 2000 & 2001 & $\begin{array}{l}\text { Fiscal Year } \\
2002 \\
\end{array}$ & 2003 & 2004 & 2005 \\
\hline Obligated & 194.2 & 258.0 & 233.6 & 245.3 & 257.6 & 270.6 & 285.2 \\
\hline Universities & 16.4 & 21.8 & 19.7 & 20.7 & 21.8 & 22.9 & 24.1 \\
\hline All Others & 154.6 & 204.0 & 184.7 & 194.0 & 203.7 & 213.9 & 225.5 \\
\hline Other DOE & 24.2 & 32.2 & 29.1 & 30.6 & 32.1 & 33.8 & 35.6 \\
\hline $\begin{array}{l}\text { Total External Subcontracts } \\
\text { and Procurements }\end{array}$ & 195.2 & 258.0 & 233.5 & 245.3 & 257.6 & 270.6 & 285.2 \\
\hline
\end{tabular}

\section{Small and Disadvantaged Business Procurement}

Pacific Northwest National Laboratory is committed to support the socioeconomic objectives of DOE and has established procedures and programs that support meeting those objectives.

\begin{tabular}{|c|c|c|c|c|c|c|c|}
\hline \multicolumn{8}{|c|}{$\begin{array}{l}\text { Small and Disadvantaged Business Procurements } \\
\text { (Dollar Amount in Millions) }\end{array}$} \\
\hline & 1999 & 2000 & 2001 & $\begin{array}{l}\text { Fiscal Year } \\
2002 \\
\end{array}$ & 2003 & 2004 & 2005 \\
\hline Procurements from Small Business & 46.9 & 44.8 & 40.6 & 42.6 & 44.7 & 47.0 & 49.5 \\
\hline $\begin{array}{l}\text { Procurements from Disadvantaged } \\
\text { Businesses }\end{array}$ & 10.3 & 12.7 & 11.5 & 12.1 & 12.7 & 13.3 & 14.0 \\
\hline
\end{tabular}




\section{8}

\section{Acknowledgments}

The Strategic Planning Directorate coordinated the preparation of this document with assistance from the Technical and Electronic Communications Department. Technical contributions were provided by staff of the Laboratory's research and operations-support organizations. We would like to acknowledge the following persons who, among others, contributed to the Institutional Plan: Mary Ace, Lila Andor, Al Ankrum, Donna Austin-Workman, Don Baer, Angus Bampton, Theresa Bergsman, Don Boyd, Kathleen Cartmell, Larry Chick, Sue Chin, Mitch Cunningham, Dave Dixon, Roby Enge, Darrell Fisher, Charlette Geffen, Cindi Gregg, Kathi Hanson, Greg Herman, Pam Hughes, Ken Humphreys, Kathryn Lang, Katie Larson, Eric Leber, Doug Lemon, Paula Linnen, Gene Luczynski, Bob Mahan, Wayne Meitzler, Dan Montgomery, Larry Morgan, Ellyn Murphy, Kathy Neiderhiser, Carolyn Novich, Erik Pearson, Kathy Poston, Lura Powell, Bill Rogers, Dan Rutherford, Joe Sapp, Steve Schlahta, Mike Schwenk, Sue Senner, John Shultz, Steve Slate, Fran Stanley, Jan Tarantino, Mike Thompson, Robert Wegeng, and Gene Whelan.

The Institutional Plan is posted on the World Wide Web at: http://www.pnl.gov/instplan/

Please direct all correspondence regarding this Institutional Plan to

Darrell R. Fisher

Strategic Planning

Pacific Northwest National Laboratory

P.O. Box 999, K1-50

Richland, WA 99352

(509) 372-6900, fax (509) 372-6901

dr.fisher@pnl.gov 


\section{9}

\section{Acronyms and Abbreviations}

CORE2000

CRADA

DARPA

DoD

DOE

EMSL

EPA

ER

ERICA

FLC

ISO

NASA

NMR

NRC

SciDAC
COllaborative Research Environment

Cooperative Research and Development Agreement

Defense Advanced Research Projects Agency

U.S. Department of Defense

U.S. Department of Energy

William R. Wiley Environmental Molecular Sciences Laboratory

U.S. Environmental Protection Agency

U.S. Department of Energy Office of Energy Research

Electronic Records and Information Capture Architecture

Federal Laboratory Consortium

International Standards Organization

National Aeronautics and Space Administration

nuclear magnetic resonance

U.S. Nuclear Regulatory Commission

Scientific Discovery through Advanced Computing 


\section{A}

\section{Work for Others}

\section{Department of Defense}

Pacific Northwest National Laboratory's work for the U.S. Department of Defense supports the Office of the Secretary of Defense, the Navy, the Marines, the Army, the Air Force, the Defense Threat Reduction Agency, and the Defense Advanced Research Projects Agency (DARPA). Our defense research and development programs address significant national security problems and issues. These programs use our capabilities in analytical and physical chemistry, computational science and engineering, computer science and information technology, design and manufacturing engineering, earth systems science, energy technology and management, human health and safety, information synthesis, management and organizational science, materials science and technology, microtechnology, nanotechnology, molecular and cellular biology, nuclear science and engineering, sensors and electronics, separations and conversions, and statistics. Laboratory staff are currently working in the following technical areas:

- environmental science and waste technology

- treaty verification and technology assessment

- information sciences, networking, architectures, and software development

- advanced materials and process development

- sensors, electronic and automated systems, and their applications

- systems analysis and technology evaluation

- pollution prevention and technology development, demonstration, and deployment

- analytical chemistry and radionuclide applications

- advanced graphic technologies, automated training systems, cognitive systems and controls, and advanced workstation technology.

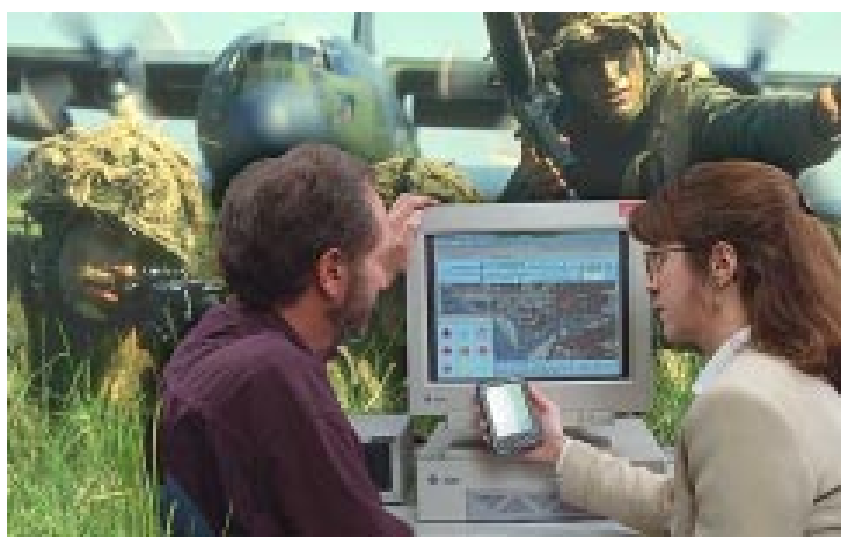

Specializing in design, rapid prototyping, testing, and evaluation of operator interfaces, Pacific Northwest National Laboratory applies user-centered design principles to promote effective human-machine systems for national security and defense applications. The Laboratory also has authored the human computer interface standards used by the Department of Defense for the Defense Information Systems Agency.

Treaty verification and technology assessment work is closely coordinated with DOE and is performed for a number of defense clients in support of national security needs.

Network architecture and distributed computing techniques have been developed by Pacific Northwest National Laboratory to meet the specific needs of the Army Chemical Biological Defense Command and other federal and state emergency organizations.

We will continue to support the Army in advanced materials and design testing. The kinetic energy projectile project supports the design, analysis, testing, and development of advanced munitions and manufacturing techniques for the Armament Research Development and Engineering Center. Related studies of composite and other materials are performed for other defense clients.

The Laboratory has developed special capabilities in very thin film and high-quality optical coatings. This leading-edge capability has historically met needs for large-scale laser mirrors and missile guidance filters for the Army and the Air Force strategic defense needs. We are now applying our 


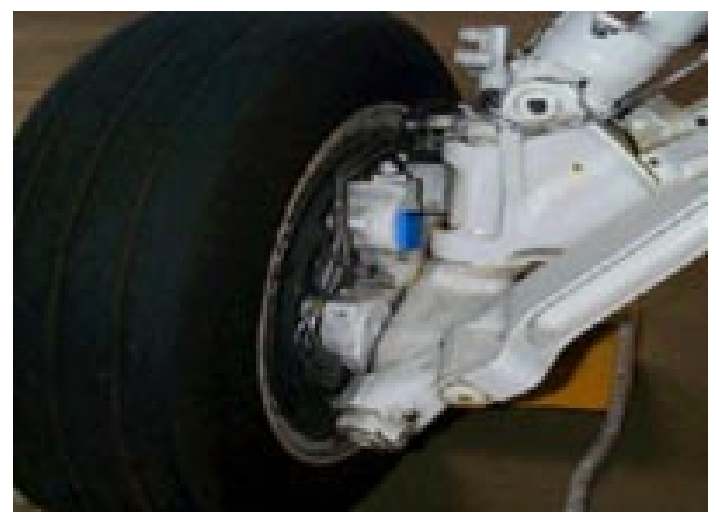

Our engineers have developed a sensor system that monitors brakes on Air Force F-16 fighters. The system includes a temperature sensor and a radio frequency tag.

thin-film technology base to applications such as highpower-density batteries, laser protection, low observable materials, and identification and paint filters for industrial applications.

Work will continue on sensors, electronics, and automated-systems development. We are developing sensors and integrated collection, detection, and evaluation technologies for chemical, environmental, and biological measurements. Radio frequency tags for remote monitoring of system condition are in development. New and innovative prognostics technologies have been developed and applied to the positive and growing problem of aging equipment and weapons, system health monitoring, and condition based monitoring.

Ultrasonic and electromagnetic imaging systems are being placed in the field to monitor and evaluate airframe, munitions, and undersea components. The Air Force and the Army continue to support our radar cross-section holographic imaging technology. A variety of singular robotics for safety testing and specialized repair and operations tasks has been developed for DARPA. Large and small mobile robots equipped with various sensors have been developed for the defense agencies. We developed a telerobotic system for disposal of explosive ordnance for the Navy. The Air Force has expressed interest in robotic systems for automated inspection of craft systems and components.

Pacific Northwest National Laboratory supports environmental program needs of the Army, the Navy, and the Air Force using our core capabilities in process technology, pollution prevention, water and land resources, risk management, environmental and regulatory compliance, marine science, and strategic environmental management. A wide range of integrated products and services are provided to our defense agency customers, including system engineering, decision analysis, life-cycle analysis, strategic planning, technology management, site assessments and characterization, remedial investigations, feasibility studies, National Environmental Policy Act support, environmental toxicology, pollution prevention, and technology development, adaptation, demonstration, and deployment. We emphasize demonstration and deployment of improved and innovative means to assess and clean up complex sites and reduce waste from existing and new systems.

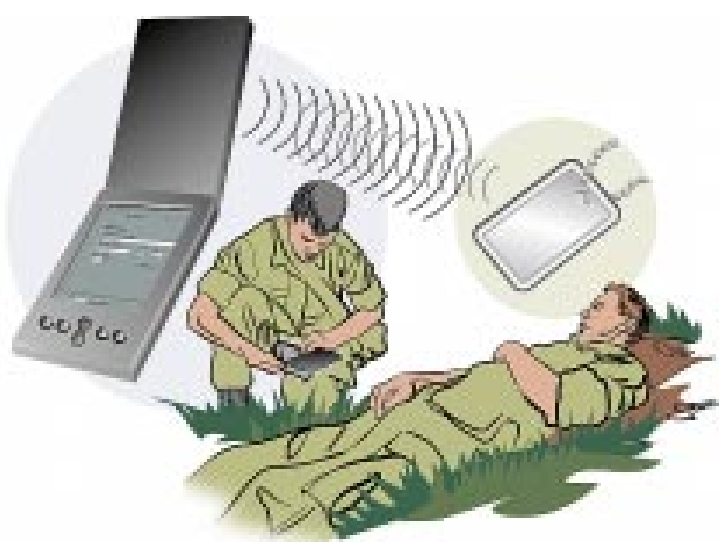

Navy medical staff could coordinate more efficient treatment, transport, and care of the wounded using a virtual medical system.

Staff at the Laboratory provide expert assistance to the defense agencies in systems analysis, technology evaluation, and statistics. This work includes technical support for modernization of major weapons production and logistics elements, evaluation of organization systems, procedures and methods, safety systems, and functioning of joint programs, and assessments of human factors impacts and training requirements. Industrial base modernization programs evaluate and apply computer-integrated manufacturing in Army production plants. We provide efficient automation technology options to meet specialized maintenance technology requirements of the Army, the Navy, and the Air Force.

Pacific Northwest National Laboratory developed ultrasound medical imaging systems and technologies that improve health care and battlefield treatment of the injured. We are continuing to work with both defense and DOE to expand this effort into a broad and integrated partnership that includes all the national laboratories, and the Army and Air Force medical centers. We are also working with DARPA and the Air Combat Command Surgeon General to develop a visual epidemiological tool to detect, analyze, and predict health and disease trends and patterns. 
Staff at Pacific Northwest National Laboratory develop microthermal and microchemical systems that are of particular interest to our defense clients. For DARPA, we are developing compact, microchannel chemical reactors. Our current efforts produced an integrated combustor-evaporator, which was designed to serve as a low-nitrous-oxides heat source to drive manportable soldier systems (such as a compact personal cooling unit, and a liquid-hydrocarbon fuel processor to support man-portable power generation in a lightweight fuel cell). We also are developing compact, microsystem-based heat pumps and hydrocarbon conversion units for the Army Land Warrior Program and for DOE. The Laboratory is also developing advanced information analysis and visualization technologies for DARPA.

Pacific Northwest National Laboratory continues to support the Defense Threat Reduction Agency. The emphasis of this support is on training foreign border enforcement personnel at the Hanford Hazardous Materials Management Emergency Response training facility near Richland, Washington.

Pacific Northwest National Laboratory continues to provide the Department of Defense with analytical chemistry support and radionuclide applications development. We have very sensitive and highprecision analytical techniques to meet measurement and testing requirements. Singular skills in analyzing radionuclides support specialized Department of Defense needs.

\section{Nuclear Regulatory Commission}

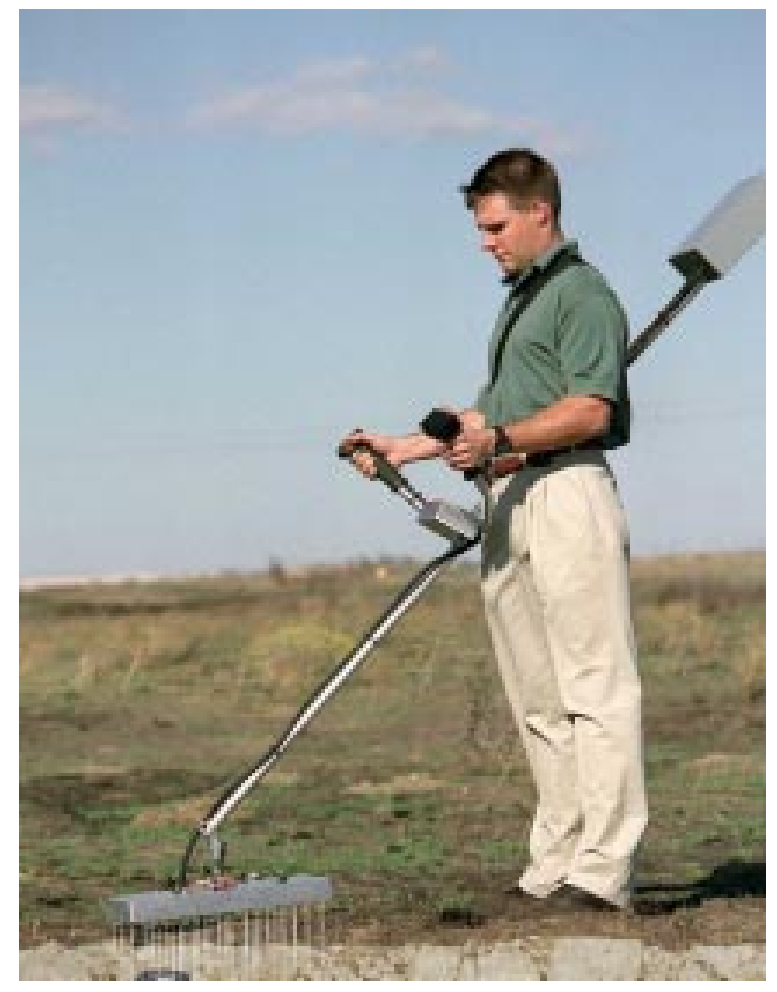

Pacific Northwest National Laboratory called upon its more than 40 years of experience in radiation detection and arms control treaty verification to develop an affordable, easy-to-use method to detect landmines. The prototype Timed Neutron Detector offers benefits not available from many of today's existing detection technologies: low price, rapid assessment, ease of use and, most importantly, the ability to detect landmines containing little or no metal.

Pacific Northwest National Laboratory's research and technical work supports all of the U.S. Nuclear Regulatory Commission (NRC) program offices and several regional offices. This work covers all aspects of nuclear safety regulation.

\section{Office of Nuclear Reactor Regulation}

Pacific Northwest National Laboratory supports the Office of Nuclear Reactor Regulation's Division of Licensing Project Management with technical assistance for improving work processes and for staff reviews of decommissioning-related activities. We also help to develop regulatory guidance and standard review plans for the nuclear facility decommissioning process. The Laboratory also provides the Division of Licensing Project Management with technical support by reviewing emergency action levels and by developing emergency preparedness training for NRC inspectors.

Pacific Northwest National Laboratory will continue to support the Division of System, Safety and Analysis in the area of commercial in-reactor fuel performance. This work includes technical reviews of vendor and utility submittals on fuel designs, fuel performance codes, and control rod assemblies. Our staff will continue to prepare an annual summary of in-reactor fuel performance based on information from the vendors and on open literature publications. This summary includes design trends, failure trends, and related topics on fuel performance. Laboratory staff also assists NRC with on-site audits and inspection of fuel vendors and utilities.

Pacific Northwest National Laboratory will continue to provide regulatory and licensing support to siting, operating license extension, and environmental protection areas, including the Environmental 
Standard Review Plan update and development effort. We will provide multidisciplinary managerial and technical expertise to assist the NRC with licensing reviews for operating reactors, for license extensions, and for regulatory guidance updating activities.

\section{Office of Nuclear Regulatory Research}

Pacific Northwest National Laboratory staff will continue to provide technical assistance to the Office of Nuclear Regulatory Research in decommissioning analysis and regulation. Technical analysis and cost estimates are provided for decommissioning licensed nuclear reactor power plants and licensed fuelcycle and other nuclear facilities. The support that we provide to the U.S. Nuclear Regulatory Commission on short-turnaround analyses and addenda to previous decommissioning analysis reports will continue on a task-order basis. Current and future work will include periodic updates of the document NUREG1307. These updates will reflect changes in the low-level waste burial site charge schedules. We will also reevaluate the earlier fuel-cycle and non-fuel-cycle facility reports to reflect current financial and regulatory conditions. We developed a new computer program for estimating decommissioning costs.

Nondestructive evaluation projects at the Laboratory provided the engineering databases that are needed to support NRC's position and policy on regulatory guides, statements, analysis codes, and regulations. The elements of these projects included 1) studying nondestructive evaluation reliability to determine the effectiveness of in-service inspections, 2) optimizing in-service inspection programs using nondestructive evaluation reliability data and parametric fracture mechanics analysis to control risks, 3) assessing new nondestructive evaluation techniques and transferring technology to the regional offices and to the utility industry, and 4) developing a technical database for fabrication flaws in U.S. reactor pressure vessels for use in remaining-life predictions. The nondestructive evaluation technologies under study at the Laboratory include ultrasonics (including the synthetic aperture focusing technique for ultrasonic testing), eddy currents, and acoustic emission. We anticipate that we will have similar research roles when the advanced light-water reactor designs are continued.

The Laboratory will continue to provide technical assistance to studies on low-level radioactive waste storage. This work will include classifying, characterizing, and assessing the characteristics of waste streams and activated metals, source terms for performance assessments, and chelating agents.

Pacific Northwest National Laboratory is one of the primary technical resources for NRC on commercial nuclear fuel. Issues related to high-burn-up fuel in nuclear power plants have high priority. Our staff will continue to develop and revise two fuel performance computer codes. This work is closely related to the fuel work being done for the Office of Nuclear Reactor Regulation.

\section{Office of Nuclear Material Safety and Safeguards}

Pacific Northwest National Laboratory staff will continue to support research on chemical safety, security and safeguards, structural engineering, and international physical protection. Our staff also supports the Spent Fuel Project Office in evaluating the performance of spent nuclear fuel casks. As the Department of Energy relinquishes additional fuel-cycle facilities to NRC for regulation, we anticipate new opportunities to assist in reviewing and inspecting those facilities.

\section{Other Nuclear Regulatory Commission Offices}

Pacific Northwest National Laboratory continues to support the NRC's Incident Response Office by refining analytical tools used by the emergency response organizations. New and improved models that address cloud-shine, modify wind fields, process meteorological forecasts, present results graphically, and that calculate dose rates will be added to the RASCAL computer program. After this computer program is revised, tested, and installed, Laboratory staff will train NRC staff on use of the program and code models. We are also assisting the Office of Administration, Division of Facilities and Security by revising operational security documents for conformance with revised federal regulations.

\section{Environmental Protection Agency}

Pacific Northwest National Laboratory conducts research for the U.S. Environmental Protection Agency (EPA) to assist the agency in its central role of developing, implementing, and enforcing environmental regulations. This research focuses on ways to protect human health and the environment from chemical 
and non-chemical agents. This work is directly related to and complements our environmental science research for the Department of Energy. We continue to conduct a variety of research and development activities to improve our understanding of exposure, impacts, and risk to human health and ecological systems from environmental pollutants. The primary areas of research that we conduct for EPA include the following:

- measuring and determining mass balance to assess sources and sinks of polychlorinated biphenyls in Lake Michigan

- measuring and analyzing the effects of toxic and hazardous chemicals on terrestrial and aquatic ecological systems, including the marine environment

- modeling and assessing the environmental impacts of increasing concentrations of trace contaminants, such as mercury and persistent organic pollutants (DDT, dieldrin), and associated air quality impacts

- modeling and analyzing hazardous waste transport and fate in soil, water (both fresh and marine), air, and biota

- modeling the formation, transport, and impacts of acid rain and evaluating strategies for control

- researching, evaluating, testing, developing, and demonstrating alternative or innovative hazardous waste treatment and radon mitigation technologies

- assessing the technologies and economic impacts of selected international strategies to reduce greenhouse gas emissions

- developing human health risk assessment information, methods, and guidance, as well as improving the science and practice of risk assessment

- developing innovative compliance information tools for industry

- developing innovative pollution prevention design, management tools, and methods.

Pacific Northwest National Laboratory has the capabilities in support of EPA risk-assessment priorities, including

- toxicology and dose-response relationships

- biological, ecological, and environmental field monitoring of toxic exposures and effects

- database and software development and quantitative modeling of exposure and risk

- exposure and risk interpretations and design of effective risk reduction strategies

- design and implementation of successful risk communication and outreach.

Pacific Northwest National Laboratory expects that the EPA will continue to support research in global climate research. We are involved in measuring and assessing the impacts of pollutants on ecosystems including the Arctic, Great Lakes, Everglades, and Northwest watersheds. Our researchers provide technical support to the environmental monitoring and assessment program by assisting in the design of studies to estimate on a regional basis the current status, extent, changes, and trends in indicators of the condition of the nation's ecological resources. We also provide technical support to the EPA's ocean disposal program by conducting bioassays of dredged material related to disposal area siting projects. The Laboratory also is developing and demonstrating methods and technologies for understanding and mitigating the risks associated with hazardous materials, such as the effects of contaminants on the reproductive health of humans and other mammals. The Laboratory supports a variety of EPA compliance and technical assistance programs. We are also involved in developing pollution prevention methods and tools, which go beyond compliance, for integrating environmental decision making into routine business practices, such as facility, product and process design, purchasing, and managerial accounting. 


\section{National Aeronautics and Space Administration}

Pacific Northwest National Laboratory conducts research for the National Aeronautics and Space Administration (NASA). This work applies Laboratory capabilities, developed in support of related DOE programs, to specific needs of the National Aeronautics and Space Administration. This work is largely focused in five areas

- climate processes - we conduct modeling studies of the effects of atmospheric aerosols on the global thermal radiation budget, and we conduct research, development, and testing of satellite-based measurements of cloud properties

- satellite operations-we develop intelligent systems to monitor spacecraft functions and to automate small-satellite mission operations centers

- Mars exploration—we develop microsystems for automated production of consumables on the Mars surface

- aircraft operations-we conduct statistical analysis of aircraft flight data and pilot reports for improving the safety and efficiency of commercial aircraft operations

- radiation dosimetry-we develop new radiation measuring systems for space flight applications.

Over the next several years, we will be expanding our research activities for the National Aeronautics and Space Administration in the above focus areas. The Laboratory user facilities (Environmental Molecular Sciences Laboratory and Atmospheric Radiation Measurement) will be of particular value to these studies. In addition, we will be working to build stronger collaborations between the DOE and the National Aeronautics and Space Administration climate research programs.

In the future, we will be looking for new opportunities to apply our capabilities in microtechnology and nanoscience to NASA needs. We plan to work with natural resource managers in the Northwest region to develop a Northwest collaboratory for natural resource management that will apply NASA remote sensing data to the solution of important resource management problems.

\section{Other Federal Agencies}

A number of other federal agencies fund research at Pacific Northwest National Laboratory. They include the Department of Transportation, Department of Justice, Federal Bureau of Investigation, and Department of Commerce. 


\section{B}

\section{University Partnerships and Collaborations}

Partnerships between the Department of Energy's national laboratories and universities strengthen our nation's economic competitiveness. Pacific Northwest National Laboratory is engaged in collaborative research with scientists at many universities, in the U.S. and worldwide. Collaborative interactions with scientists at universities generate enthusiasm and new ideas through the sharing of insights, resources, and information. These interactions range from participation in joint research institutes to support for teaching programs at regional colleges and universities. Although our primary focus is environmental research, we also conduct research in a diverse array of related scientific disciplines. These collaborations strengthen our capabilities, promote scientific discovery, provide educational opportunities, and bring together the best talent to work on DOE's most challenging problems.

This Attachment describes some of the important partnerships among more than 1000 formal and informal scientific collaborations between Laboratory scientists and their peers in academia. The Laboratory administers subcontracts, collaborative agreements, Cooperative Research and Development Agreements (CRADAs), and staff exchanges with many different institutions. We currently have 61 memorandums of understanding and 89 subcontracts in place with universities, including 26 CRADAs. Last year we hosted 400 graduate and undergraduate students, 235 postdoctoral appointments, and 72 visiting faculty members at the Laboratory representing more than 150 different institutions. These collaborations led to hundreds of jointly authored scientific reports and publications in the leading scientific and engineering journals.

The following are some of the important research collaborations with universities that support our Laboratory agenda, DOE missions, and other government agencies.

\section{Environmental Health Sciences}

Pacific Northwest National Laboratory and Oregon State University participate with the Oregon Health Sciences University's Superfund Basic Research Center to explore the effects on the nervous system of environmental pollutants that contaminate water supplies. The objective of this research is to improve assessment of exposure to populations adjacent to Superfund sites. This research involves cellular and molecular imaging, cell signaling, and chip arrays to investigate how toxic chemicals circulate in and enter the brain.

We collaborate with Washington State University on studies of DNA repair mechanisms, the role of nucleosomes in DNA repair, and damage recognition to better understand the role of protein function disorders. Our scientists are in the sixth year of collaboration with the Massachusetts Institute of Technology to develop and apply novel instruments and methods for magnetic resonance microscopy. A new collaboration with the Division of Bioengineering and Environmental Health involves cellsignaling research in the study of health and disease.

In the post-genomic era, our scientific focus is changing from complete DNA sequencing to characterizing gene products. We are developing new research collaborations with the University of Washington and the University of Utah. The rapidly evolving field of structural and functional proteomics at the Laboratory is supported by collaborations with the Institute for Systems Biology. This work in proteomics bridges the gap between the genome sequence and cellular behavior for a given disease state or for a specific set of environmental conditions. 
We collaborate with the University of California-San Diego and with the University of Arizona on single-molecule studies of ion-channel membrane receptors and other trans-membrane phenomena. We collaborate with Harvard University on studies of adaptive response and bystander effects for lowdose exposures to low linear energy transfer ionizing radiation. We also work with scientists at the University of Texas-Austin on the role of prostaglandins in oxidative stress after exposure to contaminants. We conduct studies with J ohns Hopkins University on the toxicology of particulate contaminants. We support the University of Washington and the Fred Hutchinson Cancer Research Center (Seattle) with medical internal dosimetry for two major, long-term clinical studies on advanced treatment of lymphoma and leukemia using high-dose radiolabeled monoclonal antibodies.

\section{Computational Sciences}

As a national scientific user facility, the capabilities of the William R. Wiley Environmental Molecular Sciences Laboratory are available to outside researchers. Active research collaborations in theory, modeling, and simulation involve scientists from about 80 colleges and universities in the U.S. and about 60 universities representing 30 countries. As another measure of collaboration, more than 250 sites use our Molecular Sciences Software Suite (MS3). Laboratory scientists work with computational scientists at the University of Washington on the development of methods to predict the behavior of waste storage glasses. Collaborations with the University of California-San Diego produced planewave electronic-structure codes for metals, and applications of molecular dynamics to the behavior of proteins and other biomolecules. A substantial collaboration with Washington State University has produced accurate quantum chemical methods, including new basis sets. We work with the University of Southern California on catalysis in zeolites, and on fluorine chemistry. Research with Columbia University produced new force field parameters for biomolecular and separation systems. We work with the University of Houston on studies of biomolecular interfaces, notably DNA-chip arrays, and on simulating the sedimentation of biomolecular assemblies. In collaboration with Ohio State University and Stevens Institute of Technology (Hoboken, New Jersey), we are using relativistic quantum chemical methods to predict the properties of actinide complexes. A long-term collaboration with the University of Minnesota has produced new theories of chemical reactions.

We work with the Massachusetts Institute of Technology and the University of Colorado on topics in applied mathematics and computational biology. An active collaboration with Oregon Health Sciences University involves computational chemical studies of biomarkers for neurotoxins. We have strong interactions with the Georgia Institute of Technology in studies of porous silicon. We collaborate on computational chemical methods with Texas A\&M, the University of Utah, the University of Utrecht, and the University of California-Berkeley. We collaborate in computational chemical applications with McMaster University, Hamilton, Ontario, on studies of inorganic complexes involving fluorine, and with the Autonomous University of Mexico-Iztapalapa on hydrogen bonding and new density functional theory approaches.

\section{Global Climate Change Studies}

The Atmospheric Radiation Measurement program is our highest priority global change research project, because it addresses some of the great uncertainties about greenhouse gases and their potential impact on global climate. We collaborate with the University of Washington on research to predict understanding of the impacts of climate change and variability on water resources in the western U.S. A joint project with the University of Arizona seeks to develop and apply regional climate and hydrologic models for semiarid regions, such as the southwestern U.S. We work with the University of California at Berkeley on coupled land-atmosphere models to account for land surface heterogeneity and its effects on the atmosphere. We collaborate with Oregon State University on a joint study on the impacts of climate change on vegetation, and with Washington State University to develop models for climate change impacts on crops. We work with the State University of New York at Albany on an inter-comparison of regional climate models over East Asia. We collaborate with the Georgia Institute of Technology to estimate radiative forcing of tropospheric aerosols. And, we are studying the climatic effects of El Niño and La Niña on agricultural production and water resources in the U.S. in joint research with the University of Florida.

The Laboratory collaborates with the University of Washington to assess the possible impact of global climate change over the next 50 years on climate, water resources, and salmon in Washington State 
using computer simulations. The Accelerated Climate Prediction initiative will acquire and place the computational resources needed for future worldwide simulations and will help DOE develop a rational, quantitative basis for energy policy decisions.

\section{Carbon Management}

Carbon management strategies require an in-depth understanding of atmospheric, ocean, terrestrial, technological, economic, and social systems in all parts of the globe. Collaborators with ongoing Laboratory studies on carbon management include Carnegie Mellon University, the Autonomous National University of Mexico, University of Alberta (Canada), University of Illinois, University of Lund (Sweden), University of Nebraska, and Victoria University (Canada).

We collaborate with Argonne and Oak Ridge national laboratories on carbon sequestration in terrestrial ecosystems as one component of a carbon management strategy. The universities that participate in this distributed research partnership include Cornell University, the University of Washington, North Carolina State University, Texas A\&M University, Ohio State University, Virginia Polytechnic Institute and State University, and Colorado State University. The goal of this effort is to discover and characterize links between critical pathways and mechanisms for creating larger, longer-lasting carbon pools in terrestrial ecosystems.

\section{Waste Characterization and Management}

Our Laboratory collaborates with several universities to solve one of the highest priorities at the Hanford Site- the safe disposal of more than 50 million gallons of highly radioactive waste. Laboratory staff collaborate with Washington State University and with Yale University to develop strategies for treating Hanford tank waste. Another project with Washington State University employs laser ablation and mass spectroscopy to analyze the material composition of tank waste. We work with the University of Idaho on waste sequestration and sonic methods for detecting plugs in waste-transfer pipelines. We collaborate with Texas Tech University on oxidation pathways in organic ion exchange media. We collaborate with the University of California-Santa Barbara on studies of molecular recognition and separation technologies using mesoporous materials.

We are developing models to predict flow behavior of radioactive particulate waste in collaboration with the University of Vermont. We contract with Washington State University and with the University of Delaware to study how radioactive waste from leaking underground storage tanks moves through the soil toward the Columbia River. We collaborate with Washington State University and Montana State University on the Natural and Accelerated Bioremediation Research program to stop the movement of toxic metals in groundwater. This project specifically targets lead and uranium, the two most common radioactive and metallic contaminants found in soil and groundwater at DOE facilities.

Our staff collaborate with scientists at the Oregon Health Sciences University and Oregon State University on pollutant toxicity associated with contaminated water supplies. This team is investigating ways to remove contamination, prevent toxic health disorders, and promote community and workplace health. We also collaborate with the University of Michigan on a study that has developed methods for immobilizing excess plutonium in gadolinium zirconate.

\section{Subsurface Contaminant Management}

We conduct a number of studies for the DOE Office of Science and Technology on the fate and transport of contaminants in the environment. We collaborate with several universities to develop predictive tools for environmental impact and risk assessment studies, exploring methods for site cleanup, and environmental management. Among these is an effort with New Mexico State University to develop improved sensors for contaminants in groundwater. A study with Oregon State University involves in situ ion exchange for immobilizing metals in sediments of the Hanford Site. A continuing research effort with the University of Texas uses tracer techniques to monitor dense, non-aqueous phase liquids such as trichloroethylene and carbon tetrachloride with down-hole detectors. Auburn University and the University of Arizona collaborate with Laboratory staff on the groundwater and vadose zone integration project to evaluate the risks of contaminant transport and measures to minimize the impacts of contaminants in the surrounding environment. 


\section{Environmental Molecular Sciences Institutes}

Three environmental molecular sciences institutes have been established at Columbia University, Northwestern University, and Princeton University, respectively, under an agreement with the National Science Foundation and the Department of Energy. Pacific Northwest National Laboratory is a principal research partner with each of these institutes. The Columbia University environmental institute focuses on chemical sources and sinks at liquid and solid interfaces, and involves developing new tools to predict and repair contamination by organic chemicals. This research will show how organic pollutants migrate and decompose in soils and groundwater. Investigators at Northwestern University's Institute for Environmental Catalysis study the catalytic oxidation of organic compounds to determine ways to reduce the formation of pollutants and enhance their removal from waste streams. Researchers at Princeton University study environmental bio-inorganic chemistry, and how metal-based enzymes affect marine ecosystems. These enzymes are important in global nitrogen and carbon cycles.

\section{Natural Resource and Ecosystem Management}

Pacific Northwest National Laboratory studies the impacts of land-use practices and the changes made by modern society on terrestrial and aquatic ecosystems. We collaborate with the University of Washington, Washington State University, and Oregon State University in studies of fish migration on the Columbia and Snake rivers as affected by hydroelectric power generation. A joint study with Washington State University and the University of Idaho seeks to understand the causes of declining native salmon within the Columbia River watershed. In collaboration with the Tri-Cities branch campus of Washington State University, we study the effects of grazing on terrestrial ecosystems for the Bureau of Land Management. In collaboration with Oregon State University, we study the effects of petroleum production and refinement on aquatic and terrestrial ecosystems using enzyme assays that indicate levels of exposure to hydrocarbons. A major collaboration with the University of Washington involves development and use of computer tools (PRISM) to describe and analyze the interactions of humans with the natural environment of the Puget Sound basin.

A recent effort involves the University of Idaho, Idaho State University, Oregon State University, and the University of Washington in a Pacific Northwest regional "collaboratory." This collaboratory will be a virtual environment to allow natural resources managers for private and tribal landowners to use NASA sensor technologies in decision making on complex water, fish, forest, agriculture, and urban-sprawl issues.

We participate in the Pacific Northwest Coastal Ecosystem Regional Study supported by the National Oceanic Atmospheric Administration. This coastal ecology research involves key collaborations with the University of Washington, the University of Oregon, and Oregon State University. The purpose of this study is to improve our understanding of natural variability and the human-caused stresses to natural systems.

\section{Bio-Based Processing}

The Laboratory is capitalizing on available biomass as a resource for renewable fuels, power, and chemicals. We partner with Michigan State University on catalyst formulation and organic separations, which complements our competencies in condensed phase catalysis and fermentation. We are also teaming with Florida State University and Portland State University to develop new extremophilic microorganisms for fermentation applications. Partnerships with Washington State University and the University of California at Davis have identified new sources of low-cost agricultural biomass and processes to recover biomass from complex waste streams cost-effectively.

\section{International Security and Nonproliferation}

Our Laboratory and the University of Washington established the Institute for International Security and Nonproliferation Studies to enhance weapons nonproliferation research. This research involves traditional subject areas as well as terrorism threats in the Pacific Rim and South Asia. We also collaborate with the University of Idaho to develop methods for detecting trace chemical vapors by infrared absorption spectroscopy. 
Princeton University and the University of California at Los Angeles contribute their expertise to our research on micro-electro-mechanical and nano-lithography technology, and to our development of micro-laser transmitter arrays for infrared chemical sensing.

\section{Computer and Network Infrastructure Security}

Pacific Northwest National Laboratory will collaborate with the University of Idaho on computer hardware, software, and network infrastructure security. Software, computer, and network security is a primary interest of collaboration with the University of Idaho and the Inland Northwest Research Alliance. The University of Idaho has efforts under way to develop secure and dependable software to detect and deter intruders, preserve information integrity, and improve the quality and security of electronically mediated interactions.

\section{Imaging Science and Technology}

Digital imaging plays an ever-increasing role in science and technology-from data formation and analysis to decision making. We collaborate with West Virginia University and Indiana State University on techniques for oil and gas exploration using remote sensing. We apply pattern theory, register images, and calibrate data from infrared spectrometry to identify geographic structure and lineaments that indicate new oil fields in ways that are less expensive than seismic tools.

In collaboration with NASA and the University of California at Santa Barbara, we develop new methods for analyzing crop stress based on hyper-spectral imagery. We work with Washington State University, Michigan State University, Lansing, and West Virginia University on projects that apply new imaging methods for assessing agricultural conditions, and for identifying features, such as roads, buildings, and forests from satellite images. We collaborate with the University of Washington on human-computer interaction technology aimed at developing the next generation of human-computer tools, beyond the customary mouse and two-dimensional display, to create a natural interface between users and information and collaboration among geographically dispersed users.

\section{Nanoscience and Nanotechnology}

The rapidly developing field of nanoscience and technology will require active collaborations with university researchers in materials science, chemistry, bioengineering, and computations. We are establishing a Northwest Institute for Nanoscience and Technology with the University of Washington for joint research on particles, films, and nanoclusters for a variety of applications, as well as chemically specific imaging at the nanoscale. Our strengths in synthesis, materials characterization, nanobiology, and computation will match well with the University of Wbshington's strengths in bioengineering and medical sciences. We are also collaborating on a proposal to the National Science Foundation's call for a Nanoscale Science and Engineering Center.

We are developing new projects in nanoscale mechanics involving electron beam and laser processing of materials with researchers at Washington State University. We collaborate with Portland State University in the developing area of chemical mechanic polish for semiconductor materials and microelectronics. We also are developing projects with the University of Idaho on synthesis of metal matrix composites with nanoscale mechanical features.

\section{Faculty Appointments and Teaching Support to Regional Colleges and Universities}

Pacific Northwest National Laboratory has a long history in effectively supporting educational programs throughout the region and nationally.

Among the scientists and engineers at the Laboratory are approximately 200 who hold adjunct or affiliate faculty appointments at 25 different colleges and universities in the Pacific Northwest region and across the U.S. Of these, 110 staff members hold appointments at the Washington State University, Tri-Cities branch campus (Richland) and at the main campus (Pullman). 


\section{Washington State University, Tri-Cities}

The local support by staff members is essential to the success of the Washington State University branch campus in Richland. Laboratory staff members teach regular undergraduate and graduate courses, mostly during evening off-hours, in biology, business administration, chemistry, civil engineering, communications, computer science, education, electrical engineering, engineering management, English, environmental sciences, environmental engineering, general science, liberal arts, management technology, materials science and engineering, mathematics, mechanical engineering, nuclear engineering, and statistics. Staff members also teach short courses in the Professional and Continuing Education program at Washington State University.

Staff members also support the teaching program at Washington State University by enrolling in courses and working toward advanced degrees.

The Consolidated Information Center is the main library facility at the branch campus in Richland. This Center includes the Hanford Technical Library (operated by Pacific Northwest National Laboratory) and the DOE Public Reading Room. The Laboratory and DOE provide substantial funding to support computing, library, telecommunications, and media services for the campus.

\section{Heritage College}

Heritage College is a small, liberal arts college in Toppenish, about 70 miles west of Richland. Heritage serves a nontraditional student population (predominantly women, Hispanics, and Native Americans) long known for its underrepresentation in higher education.

Several Laboratory scientists and managers actively support Heritage College in a variety of ways. The Laboratory and DOE have established a full-time loaned executive position to help establish curriculum and programs, and to teach courses at the college. The Laboratory provides adjunct faculty support to the teaching programs in environmental science and computer science. Students and faculty at Heritage benefit from internships and research appointments at the Laboratory.

\section{Regional Educational Centers}

The Laboratory supports the University of Idaho Research Park economic development initiative at Post Falls, Idaho, which involves high-technology engineering facilities and opportunities for both research and teaching. The University of Idaho offers engineering classes at both the Research

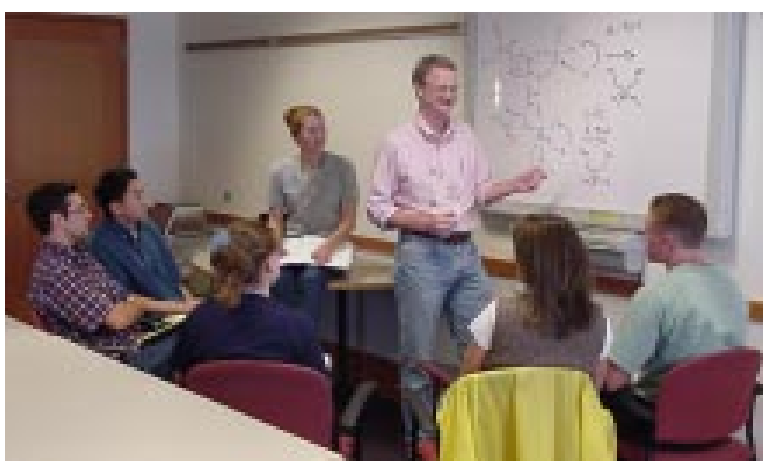

Dr. Sam Bryan, Environmental Technology Division, is one of 110 Laboratory staff members who serve as adjunct faculty at Washington State University, Tri-Cities.
Park and at the Northern Idaho College campus in Coeur d'Alene, Idaho, under a joint agreement with Washington State University, Gonzaga University, and Eastern Washington University.

In summary, Pacific Northwest National Laboratory maintains active collaborative relationships with approximately 500 colleges and universities. Laboratory-university partnerships direct complementary capabilities and resources toward common priorities for enhancing our quality of life and protecting and preserving our environment. These relationships promote shared interests in research, education, and professional and economic development, and bring new intellect, insights, and inspiration to our common focus on significant issues and opportunities. 


\section{Pacific Northwest National Laboratory}

Managed and Operated by Battelle for the U.S. Department of Energy

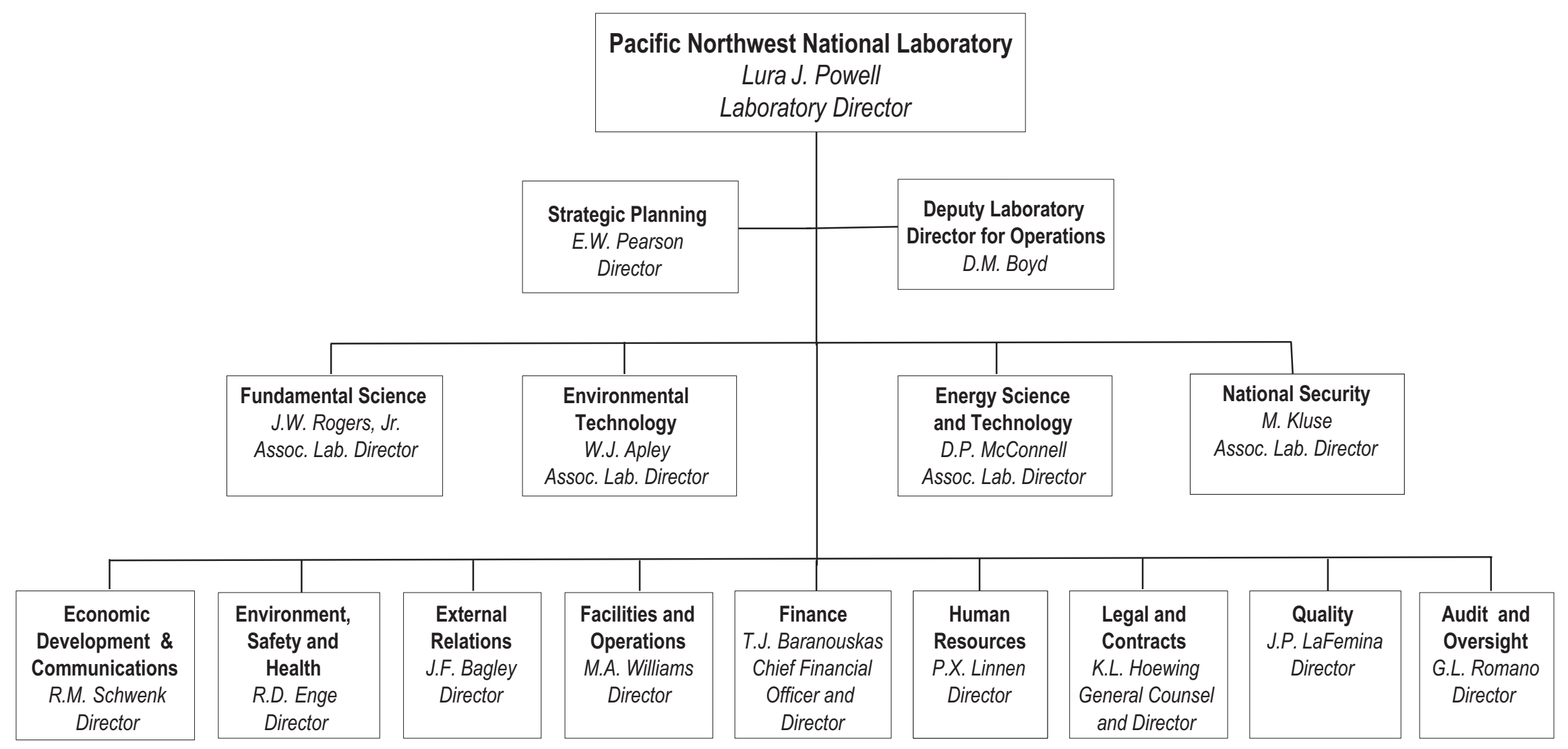

